\title{
Western Australian stygobiont amphipods (Crustacea: Paramelitidae) from the Mt Newman and Millstream regions
}

\author{
J. H. Bradbury \\ Department of Environmental Biology, University of Adelaide, \\ South Australia 5005, Australia \\ email: john.bradbury@adelaide.edu.au
}

\begin{abstract}
Sampling of underground waters in association with mining operations in the Pilbara region of Western Australia has revealed a considerable stygobiont fauna, which in waters of low salinity is dominated by crangonyctoid amphipoda. Two new crangonyctoid genera Chydaekata and Molina and sixteen new species are here described. Chydaekata includes 15 new species: C. acuminata, C. nudula, C. dolichodactyla, C. breviclava, C. transversa, C. diagonalis, C. carscutica, C. gyraspis, C. simulata, C. tetraspis, C. ovatosetosa, C. anophelma, C. scopula, C. scuticara and C. brachybasis. Molina is monospecific: $M$. pleobranchos.
\end{abstract}

\section{INTRODUCTION}

The prolific diversity of subterranean fauna, both terrestrial and aquatic, of Australia, and in particular north western Australia, has only recently been revealed (Bradbury and Williams, 1997); a diversity probably not exceeded in any comparable region (Humphreys, 1993a, b, c; Watts and Humphreys, 1999). This fauna is dominated by Amphipoda of the superfamily Crangonyctoidea, the most ubiquitous of Australian amphipods whose major distribution has hitherto, with few exceptions, been regarded as confined by the cool fresh waters of the south east and south west of the continent and Tasmania.

Amphipods are reported from several stygal sampling sites in the Pilbara craton, a tectonically stable region which has been emergent above the sea since the Precambrian. Here, calcrete deposits have developed extensively, and many ground waters have remained fresh (Humphreys, 1999); waters which are part of extensive palaeo channels - remnants of extinct river systems.

Widespread sampling using nets and traps has been conducted by the Western Australian Museum in aquifers in the vicinity of $\mathrm{Mt}$ Newman and Millstream, principally via bores constructed in the mining exploratory process. Water in the aquifers penetrated by these bores is generally fresh, and significant numbers of relict taxa, including amphipoda, are represented in the samplings (Humphreys, 1999).

Australian crangonyctoid (Williams and Barnard, 1988) Amphipoda are ancient animals, probably pre-dating the break up of Pangea (Barnard and Barnard, 1983). This group is bound to regions not inundated by the sea since the Cretaceous, and is restricted to permanent fresh waters (Bradbury, 1999). In the Pilbara region of arid northern Australia, where evaporation exceeds precipitation by about fifteen times (Mann and Horwitz, 1979), the Crangonyctoidea are confined to underground waters, presumably either as a result of being driven into refugia by climatic deterioration with the northward drift of the continent following the break-up of Gondwana, or as the remnant, stygal, survivors of a once more extensive epigean as well as hypogean fauna.

Increasingly, anthropogenic influences are impacting on the quality and quantity of ground waters in the Pilbara. These underground streams, and their associated faunas, which are subject to degradation and collapse when water extraction reaches critical levels (Humphreys, 1999), are most recently under threat from the activities of mining interests.

This work describes two new genera and sixteen species of crangonyctoid Amphipoda from subterranean waters of the Pilbara region, north western Australia. All species belong to the family Paramelitidae, the largest family of Australian inland amphipods, which is also represented in southern Africa. Affinities with other Australian amphipods of the family are as yet unclear.

\section{Amphipod stygofauna}

Typically, cosmopolitan characteristics of stygobiont amphipods, adaptations to a stygic environment, can include loss or reduction of eyes, loss of pigmentation, and attenuation and/or lengthening of the body and appendages, reduction of the coxal plates, and reduction of the pleopodal rami (Holsinger, 1994; Camachoo, 1992). Among the 
stygobiont crangonyctoid amphipods described here, loss of eyes and pigmentation is universal, attenuation or elongation of the body is not marked in all taxa, reduction of the coxal plates is present but not extreme, and the pleopods are not reduced in any species, although pereopods 5-7 are attenuated and lengthened in every case.

\section{Scope of the investigation and material examined}

Bore holes within the study area were tested for aquatic species by netting and trapping, yielding several hundred specimens, although many were immature or not of condition suitable for meaningful examination. Sixteen new stygobiont species representing two new genera are described. All taxa are small (7 mm max.), blind, pale coloured taxa, with somewhat reduced coxae, long posterior pereopods, few spines or setae on the body, the mature male first antenna bearing aesthetascs and the second well equipped with calceoli in one genus, although absent from the other. Both genera belong within the family Paramelitidae Bousfield.

\section{METHODS OF ANALYSIS AND DESCRIPTION}

A 'DELTA' database (Dallwitz, 1980, Dallwitz et al., 1993) was developed from which diagnoses and species descriptions were generated. Keys to both genera and to species of Chydaekata were produced from the 'DELTA' programme ' $K E Y^{\prime}$.

Terminology and abbreviations follow Bradbury and Williams $(1996,1999)$. All specimens are lodged in the Western Australian Museum (WAM). The notation $\mathbf{M}$, with an appended number, indicates the position of an object as a fraction of the distance from the base to the apex of an appendage. Abbreviations used in the figures are as follows: $A$, antenna; Abd, abdomen; acc, accessory; $C$, coxa; $d$, dorsal; dact, dactylus; E, epimeron; fl, flake; flag, flagellum; g, gill; G, gnathopod; Hd, head; $i$, inner; juv, juvenile; L, left; lac, lacinia mobilis; lat, lateral; LL, lower lip; MD, mandible; med, medial; mol, molar; MP, maxilliped; MX, maxilla; O, oostegite; opp, opposite; p, palp; P, pereopod; p1, plate; Pp, pleopod; $\mathbf{R}$, right; st, sternal gill; $T$, telson; $U$, uropod; UL, upper lip; UR, urosome; 1, 2, 3, 7, first, second, third ... seventh article, segment, somite or epimeron (as appropriate). Mandibular palp setae are described using the notation of Karaman (1969) and Barnard and Barnard (1983).

\section{Key to the stygobiont amphipods Chydaekata and} Molina (Paramelitidae)

1. Sternal gills present on sternites 6-7; dactyls of pereopods $3-7$ simple; gills present on coxae 2-6

2

Sternal gills present on sternites 2-7; dactyls of pereopods 3-7 multispinous; gills present on coxae 2-7 ................... Molina pleobranchos

2(1). Left first maxilla inner plate subtriangular, facially and medially setose (pubescent); first antenna accessory flagellum articles uniform .3

Left first maxilla inner plate ovate, facially, but not medially, setose (pubescent); first antenna accessory flagellum articles variable Chydaekata ovatosetosa

3(2). Third epimeron: posterior margin straight .... 4 Third epimeron: posterior margin sinuous ... 7 Third epimeron: posterior margin convex ..... 9 Third epimeron: posterior margin concave .....

4(3). Second antenna: peduncle length greater than flagellum

Second antenna: peduncle length subequal to flagellum 6

Second antenna: peduncle length less than flagellum ..................... Chydaekata brachybasis

5(4). First gnathopod dactyl not reaching to palmar corner; second gnathopod dactyl not reaching to palmar corner....

Chydaekata breviclava

First gnathopod dactyl reaching to palmar corner; second gnathopod dactyl reaching to palmar corner ................. Chydaekata simulata

First gnathopod dactyl reaching beyond palmar corner; second gnathopod dactyl reaching beyond palmar corner

Chydaekata dolichodactyla

6(4). First gnathopod palmar angle weakly oblique; left mandible molar without pappose seta; maxilliped palp third article naked laterally Chydaekata transversa

First gnathopod palmar angle oblique; left mandible molar bearing pappose seta; maxilliped palp third article sparsely setose laterally Chydaekata diagonalis

7(3). Third uropod longer than U1-2 in intact specimen; maxilliped inner plate bearing a row of submarginal pappose setae only, palp third article sparsely setose laterally ....

Third uropod not extending beyond U1-2 in intact specimen; maxilliped inner plate bearing a row of submarginal to subapical pappose setae, palp third article naked laterally .............................. Chydaekata nudula

8(7). Second antenna peduncle length greater than flagellum; second gnathopod large; second epimeron posteroventral corner acuminate . Chydaekata acuminato 
Second antenna peduncle length less than flagellum; second gnathopod moderate size; second epimeron posteroventral corner rounded Chydaekata gyraspis

Second antenna peduncle length subequal to flagellum; second gnathopod small; second epimeron posteroventral corner subquadrate ................... Chydaekata tetraspis

9(3). Maxilliped inner plate with a row of submarginal pappose setae; left mandible molar bearing pappose seta, and bearing penicillate hooked brushy basal setae.

Chydaekata scopula

Maxilliped inner plate with a row of submarginal to subapical pappose setae; left mandible molar without pappose seta and without penicillate hooked brushy basal setae Chydaekata anophelma

10(3). Left mandible molar bearing pappose seta; second antenna article 4 shorter than article 5; right mandible without penicillate hooked brushy basal setae Chydaekata scuticara

Left mandible molar without pappose seta; second antenna article 4 subequal with article 5; right mandible bearing penicillate hooked brushy basal setae:

Chydaekata carscutica

\section{Paramelitidae Bousfield}

\section{Remarks}

The family Paramelitidae has been comprehensively reviewed and re-diagnosed by Williams and Barnard (1988). Diagnostic characteristics of the family are that the antennal sinus may be well developed or weak; mandibular molar well developed and triturative; outer plate of the second maxilla bears only one type of seta apico-laterally, and the outer plate of the maxilla is not large; rugosities are absent from the maxillipedal palp and gnathopods; gnathopods are of medium size, the first not dominant, the carpi of medium length and not markedly lobate, the propodi attached to the carpi normally (ie. not cantilevered), and setae of the palms are not bifid; domination of the posterior lobes of coxae 5-7 is variable; oostegites broad; sternal gills simple or absent; urosomites not fused.

\section{Chydaekata gen. nov.}

\section{Type Species}

Chydaekata acuminata sp. nov.

\section{Diagnosis}

Body: cuticle smooth; pereon and pleon sparsely setose dorsally; urosomite 3 without dorsolateral robust setae. Head: rostrum vestigial; eyes absent, antennal sinus moderate. First antenna: article 3 shortest; flagellum much longer than peduncle; bearing aesthetascs; articles uniform; and sparsely setulate, accessory flagellum 4-6 articulate. Second antenna: setate. Upper lip: apical margin evenly rounded; connection to epistome symmetrical. Left mandible: palp article 2 with no small outer or medial margin setae, the second article bearing a distofacial oblique row of 3-6 robust rastellate setae, article 3 much shorter than article 2, bearing $D$ and E setae only, mandible with 4 setose accessory blades, molar fully triturating. Right mandible: palp article 2 with no small outer or medial marginal setae, article 3 much shorter than article 2; lacinia mobilis bifid and denticulate, with no denticles strongly extended; mandible bearing 2 setose accessory blades; molar bearing pappose seta, fully triturating. Left first maxilla: inner plate with 2 apicomedial plumose setae, the second article of the palp bearing a single robust articulated seta. Right first maxilla: palp asymmetrical with left, article 2 with 1 apicolateral robust seta and setae fused to the article forming broad tooth spines. Second maxilla: outer plate subrectangular, elongate, marginally setulose. Maxilliped: inner plate subrectangular, elongate; outer plate subovate; dactyl of palp third article bearing 2 accessory setae basal to the nail. First gnathopod: coxal plate ovate, with 1 posteroventral corner seta; merus with elongate scythe setae; carpus without posteroventral lobe or expansion; propodus posteroventral corner not lobate, bearing 1 lateral robust seta; palm convex; dactyl, with accessory setules at the junction of the nail. Second gnathopod: coxal plate ovate, with 1 posteroventral corner seta, and large ovate gill; merus (article 4) bearing posterior hump, with elongate scythe setae; carpus long, without posteroventral lobe or expansion, posterior margin with setae in transverse bands; propodus posteroventral corner rounded; not lobate; palm convex; dactyl with accessory setules at the junction of the nail. Pereopods: dactyls of pereopods 3-7 simple; merus of pereopod 3 weakly setose posteriorly; pereopods 5-7 similar; basis of pereopod 5 moderately expanded; coxa 6 bearing 1 seta on the posterior lobe; basis of pereopod 6 bearing short slender posterior setae; coxa 7 bearingnosetae on anterior lobe, moderately expanded, bearing short slender posterior setae. Gills: coxal gills present on coxae 26; gill of pereopod 6 not reduced. Sternal gills present on sternites 6-7; of simple, sausage form, attached to anterior of lateral edge of segments. Epimera 1: without anteroventral setae, without robust setae on anteroventral margin, without robust setae on posteroventral margin, without slender setae on ventral margin; posteroventral 
corner without spine or seta. Epimera 2: without anteroventral setae, without robust setae on posteroventral margin, without slender setae on ventral margin, with 1 slender seta on the posterior margin; posteroventral corner without spine or seta. Epimera 3: without anteroventral setae, without robust setae on posteroventral margin, with 1 slender seta on the posterior margin. Epimera 3: posteroventral corner without spine or seta. Pleon: pleonite 1 with 1 distolateral robust seta. Pleon: pleonite 2 with no distolateral robust setae. Pleopods: peduncle of first pleopod with no retinacula, but 2 additional setae. Peduncle of pleopods 2-3 with 2 retinacula and 2 additional setae disjunct from the retinacula. Urosomite 3: bearing 3 distolateral slender setae, and no distolateral robust setae. Uropods: first uropod peduncle with no apicodistal robust setae, no apicolateral robust setae, and 2 apicomedial robust setae, outer ramus shorter than inner; second uropod: with 1 apical robust seta, peduncle with 5 dorsolateral robust setae, outer ramus shorter than inner; third uropod short; peduncle with 2 dorsolateral robust setae, no dorsolateral slender setae, and no mediodistal slender setae; inner ramus shorter than outer ramus; one articulate; proximal article with 1 lateral transverse bands of small setae, no lateral transverse bands of mixed robust and small setae, no medial transverse bands of small setae, no medial small setae, no medial plumose setae, and no apicolateral long slender setae; distal article of outer ramus narrow, subrectangular, with 2 lateral robust setae, no lateral slender setae, no medial robust setae, no medial slender setae, no medial slender plumose setae, no apical plumose setae; inner ramus with no lateral robust setae, no lateral slender setae, no medial slender setae, no medial plumose setae, and no apical plumose setae. Telson: deeply cleft, lateral margins tapering, straight; dorsal setae absent, with paired lateral penicillate setae, and apical robust and penicillate setae.

\section{Relationships}

Chydaekata displays significant differences from other genera of the family Paramelitidae. The body is not vermiform, as in Giniphargus, nor robust as is Pilbarus; the antennal sinus does not terminate anteroventrally in a tooth as in Antipodeus; the first antenna is not long as in Protocrangonyx, and the accessory flagellum is of more than two articles thus differing from Protocrangonyx, Toulrabia, and Chillogoe; the second antenna is not pediform as is Uroctena, but bears calceoli in each species in contrast to other genera excepting Pilbarus and Totgammarus, in which calceoli are absent or variably present. The second article of the mandibular palp of Chydaekata bears a mediodistal row of strong scythe setae in contrast to other genera except Totgammarus, and the third article is without $A B C$ setae similar only to Hurleya, Protocrangonyx and Chillogoe, the latter also differing in the presence of inner lobes on the lower lip. The inner plate of the first maxilla of Chydaekata is without medial plumose setae, unlike Austrogammarus, Antipodeus, Giniphargus and Totgammarus, and bears two rather than one, three or five apicomedial setae as in Uroctena, Protocrangonyx or Totgammarus; the outer plate of the second maxilla is without an oblique row of setae as in Austrogammarus and Austrocrangonyx; neither simple nor scythe setae are present basal to the dactyl of the maxillipedal palp unlike Austrogammarus, nor is the dactyl long as it is in Giniphargus, and the apex of the third article of the palp bears short, fine setules, contrasting with long setules in Hurleya and the naked apex of Chillagoe. The coxae of pereopods 1-3 of Chydaekata do not bear posterior robust setae as in Austrogammarus, the fourth coxa is not enlarged like Totgammarus but strongly emarginate, contrasting with the absence of, or very little emargination in Uroctena, Giniphargus, Protocrangonyx, Toulrabia and Chillagoe; coxae 5-7 bear few marginal setae in contrast with Pilbarus, nor are they short as in Giniphargus; gnathopods are of moderate size, not small as in Giniphargus, Toulrabia, Chillagoe and Pilbarus, and of approximately equal relative size whereas in Uroctena and Totgammarus the second gnathopod is much larger than the first; carpi are not lobate as in Uroctena; propodi are subrectangular in form not trapezoidal as in Antipodeus nor ovate as in Hurleya; setae of the palms are sparse and simple, not dense as in Uroctena and Totgammarus, nor bifid like Hurleya and Protocrangonyx, neither is the male palm excavate as in Antipodeus; palmar angle is transverse, contrasting with oblique in Uroctena, Protocrangonyx, Toulrabia and Pilbarus and strongly oblique as in Hurleya; the palmar corners bear three robust setae, similar only to Antipodeus. Chydaekata bears gills on coxae 2-6, unlike Austrogammarus, Austrocrangonyx, Antipodeus and Totgammarus in which they occur on coxae 2-7. Sternal gills are found only on segments 6-7 similar to Hurleya, Giniphargus and Toulrabia, but unlike other genera. Pleopods bear 2 retinacula similar to Austrogammarus and Antipodeus and 1 or 2 accessory retinacula like Giniphargus only; inner rami of the pleopods bear bifid medial setae unlike the simple setae of Uroctena and Chillagoe, and the inner rami are not reduced as in Protocrangonyx. Chydaekata bears no basofacial seta on the peduncle of the first uropod as in Chillagoe, the rami of both first and second uropods bear two setal rows unlike Protocrangonyx which has only one row, and the second uropod does not bear an elongate seta as in Totgammarus. The third uropod of Chydaekata is not short as in Toulrabia and Chillagoe; the inner ramus is elongate in the male, as with Austrogammarus, 
although relatively longer, reaching almost to the end of the first article of the outer ramus, thus differing from most other genera in which the third uropod is parviramous or absent, excepting variramous in Pilbarus and magniramous in Totgammarus. Dorsal setation is absent from the telson of Chydaekata, which is thus unlike Austrogammarus, Austrocrangonyx, Pilbarus and Totgammarus; the few apical setae are robust not like Austrocrangonyx, and lateral margins are convex, but not tumid as in Austrogammarus, Austrocrangonyx, Hurleya and Chillagoe; posterior margins of pleonites are smooth, with sparse setae whereas those of Pilbarus are crenellate, with dense setae.

\section{Remarks}

Chydaekata displays a number of characters in common with Hurleya, Giniphargus, Pilbarus, and Uroctena. Although there are several significant similarities between Chydaekata and Hurleya particularly the presence of only DE setae on the mandibular palp and in the conformation of the inner plate of the first maxillae and disposition of the gills, the differences in size and form of the gnathopods, and the non parviramous third uropod of Chydaekata sufficiently distance the two taxa to warrant regarding them as individual genera. The most significant characters in common with Giniphargus are the presence of gills on coxae 2-6, their absence on coxa 7, and the presence of sternal gills on sternites 6-7 only; otherwise these taxa are not similar. Pilbarus, another Western Australian stygobiont amphipod from the Millstream, has similar gnathopods, pleopods, third uropod and the telson is similarly cleft. However, many differences clearly separate these two taxa, although they do share several characters and would appear to have more than distributional association. Despite some similarities, Toulrabia and Uroctena are distinctly different from Chydaekata in many ways, including the absence of calceoli on the second antenna, presence of $A B$ or $C$ setae on the third article of the mandibular palp, and absent or very weak emargination of the posterior edge of the fourth coxal plate. Chydaekata is thus regarded as a discrete genus, possibly associated with Hurleya, although the genus Hurleya is itself inadequately described and in need of review.

\section{Distribution}

The Pilbara region of north-western Western Australia.

\section{Etymology}

The generic name is derived from the Greek 'chydaios' (poured out in streams, abundant, overflowing), and the Greek 'kata' (down below).
Chydaekata therefore means 'numerous below'. The name is feminine.

Chydaekata acuminata sp. nov. Figures 1-4

\section{Material Examined}

Holotype

๙。, 'a' $5 \mathrm{~mm}$, Newman bore W152, Western Australia, Australia, $23^{\circ} 16^{\prime} \mathrm{S}, 119^{\circ} 53^{\prime} \mathrm{E}, 11$ November 1998, S. Eberhard, BES3518 (WAM C24650).

\section{Allotype}

Australia: Western Australia: $q$, ' b' $6 \mathrm{~mm}$, same data as holotype (WAM C24651).

\section{Paratypes}

Australia: Western Australia: $\delta$, 'c' $5.5 \mathrm{~mm}$, same data as holotype, more than 90 specimens, mainly juveniles, same data as holotype (WAM C24652).

\section{Diagnosis}

Second antenna: peduncle article 5 bearing 2 calceoli, flagellum 13 articulate, with calceoli on articles 1-6. Mandible: palp article 2 with a mediodistal row of 5 robust rastellate setae; article 3 with $9 \mathrm{D}$ and $3 \mathrm{E}$ setae apically. Left first maxilla: palp article 2 with 8 apical setae. Right first maxilla: palp apex with no articulated, and 4 fused broad based tooth setae. Maxilliped outer plate with a row of 7 slender naked, medial submarginal to disto-facial setae; a medial row of 8 submarginal to subapical robust, naked, tooth setae; 3 apicolateral setae. First gnathopod propodus: dactyl reaching to palmar corner, with a single recumbent inner tooth spine. Second gnathopod carpus: with posterior setae ranked in 5 transverse bands. Telson: cleft $90 \%$, bearing 2 subapical robust setae.

\section{Description}

Holotype (male, ' $a$ ' $5 \mathrm{~mm}$ )

Body (Figure 1): urosomite 1 and 2 without dorsolateral robust setae. First antenna (Figure 1): length $0.5 \times$ body, $1.6 \times$ second antenna; peduncle article 1 longest, with moderate setation; primary flagellum of 27 articles; accessory flagellum of 4 articles, reaching to article 6 of primary flagellum. Second antenna (Figure 1): length $0.3 \times$ body; peduncle length greater than flagellum, article 5 bearing 2 calceoli, article 4 subequal with article 5 , articles 3-5 with moderate ventral setation; flagellum 13 articulate, with moderate setation, bearing calceoli on articles 1-6. Left mandible (Figure 1): palp article 2 with a medio-distal row of 5 robust rastellate setae, article 3 with $9 \mathrm{D}$ setae and 3 E setae, facially strongly setulose 
(pubescent); incisor with 5 teeth, lacinia mobilis with 4 teeth, with 3 plumose interraker setae; molar without pappose seta, with 2 penicillate hooked brushy basal setae, and no penicillate setules. Right mandible (Figure 1): palp article 2 with a medio-distal row of 5 robust rastellate setae, article 3 with $9 \mathrm{D}$ setae and $3 \mathrm{E}$ setae; incisor with 5 teeth and 2 plumose interraker setae; molar without penicillate hooked brushy basal setae. Left first maxilla (Figure 1): palp article 2 with 4 apical and 1 subapical facial strong slender setae, with no apicomedial, 1 submarginal apicomedial, and 2 ventrofacial apicomedial strong slender setae; outer plate with 10 robust setae -9 denticulate, 1 naked; inner plate subtriangular, facially and medially setulose (pubescent). Right first maxilla (Figure 1): palp apex with no articulated, 4 fused broad based tooth setae, and no subterminal apicolateral facial setae. Second maxilla: outer plate length $3 \times$ width, bearing distal long, curved rastellate or naked setae; apicomedial corner of inner plate with 2 weakly submarginal thick plumose/pappose setae. Maxilliped (Figure 1): inner plate length $3.5 \times$ width, extending to M0. 9 of the outer plate, bearing small setules on the lateral margin and medioproximal face, 1 facial pappose setae at M0. 6 of its length, with a row of 6 submarginal pappose setae, extending to a row of 4 similar subapical and 2 apical setae, with 1 apicomedial, 2 mediodistal, and no apical naked tooth setae; outer plate long, length $2 \times$ width, distally naked, with a row of 7 slender naked, medial submarginal to distal facial setae, a medial row of 8 submarginal to subapical robust, naked, tooth setae, and 3 apicolateral setae. -1 naked, and 2 pappose; palp, second article strongly setose medially; third article sparsely setose laterally, strongly setose medially, with 3 facial, and 3 ventrofacial long strong setae basal to the dactyl, the apex moderately produced, setulate, with 3 long slender naked setae and 3 dorsal accessory setae on the dactyl. First gnathopod (Figure 2): coxal plate with 3 anteroventral setae, and no ventral setae; merus without posterior hump; carpus of moderate length, $1.2 \times$ width, subtriangular, posterior margin strongly setose, with setae ranked in 4 transverse bands; propodus subrectangular, moderate size, length $1.8 \mathrm{x}$ width, posteroventral corner rounded, with 2 medial robust setae, and 4 additional lateral elongate robust setae, palmar angle weakly oblique, smooth, dactyl reaching to palmar corner, with a single recumbent inner tooth spine. Second gnathopod (Figure 2): slightly larger than first; coxal plate with 3 anteroventral setae, and no ventral setae; carpus length $2 \times$ width, subtriangular, with setae ranked in 5 transverse bands; propodus subrectangular, large, length $2 x$ width, with 2 lateral robust setae, 1 medial robust seta, and 3 additional lateral elongate robust setae; palmar angle weakly oblique, smooth; dactyl reaching to palmar corner, with no recumbent inner tooth spine. Pereopods (Figure 2): pereopod 3 longer than the second gnathopod; coxa with no anterior setae, no long ventral setae, 3 short ventral setae, 1 seta at the posteroventral corner; carpus weakly setose posteriorly. Pereopod 4: subequal in length with pereopod 3 ; coxa anteroventral margin with 3 setae, posteroventral margin with 4 setae, ventral margin with no setae, posterior margin moderately emarginate; carpus moderately setose posteriorly. Pereopods 5-7: coxa 5 bearing 1 seta on anterior lobe, and 1 seta on the posterior lobe; basis of periopod 5 with slender posterior setae, bearing short robust anterior setae, weakly lobate posteriorly; pereopod 6 coxa bearing no setae on anterior lobe; basis scarcely expanded, bearing short robust anterior setae, weakly lobate posteriorly; pereopod 7 coxa with 1 seta on the posterior lobe; basis bearing short robust anterior setae, moderately lobate posteroventrally; bases of periopods expanded unequally, basis of periopod 7 most expanded, basis of periopod 6 least expanded. Epimera: first epimeron without slender setae on posterior margin; posterior margin straight, posteroventral corner acuminate; second epimeron, with 2 robust setae on the anteroventral margin; posterior margin straight, posteroventral corner acuminate; third epimeron with 4 robust setae on the anteroventral margin, without slender setae on ventral margin; posterior margin sinuous, posteroventral corner acuminate, without spine or seta. Pleon: dorsolateral margin of pleonite 1 with 2 feeble setae; of pleonite 2 with 4 feeble setae; of pleonite 3 with 2 feeble setae, and no distolateral robust setae. Pleopods (Figure 4): first and second pleopods with 1 accessory retinacula, and third pleopod with no accessory retinacula. Urosome: first urosomite bearing 2 distolateral slender setae, and no distolateral robust setae; urosomite 2: with 2 distolateral slender setae, and 1 distolateral robust seta. Uropods (Figure 4): first uropod peduncle length $1.2 \times$ the length of the inner ramus; with a strong row of 3 dorsolateral robust setae, and 3 dorsomedial robust setae; outer ramus with 1 dorsolateral robust seta, and 2 dorsomedial robust setae; inner ramus with 1 dorsolateral robust seta, 3 dorsomedial robust setae, and 5 apical robust setae; second uropod $0.6 \times$ length of uropod 1, peduncle about $1 \times$ length of inner ramus; with 1 apicolateral, 1 dorsomedial, and 1 apicomedial robust setae; inner ramus with 1 dorsolateral, 1 dorsomedial, and 5 apical robust setae; outer ramus with 1 dorsolateral, 2 dorsomedial, and 5 apical robust setae; third uropod extending beyond uropods 1 and 2 in intact specimen, $0.7 \times$ length of uropod 1 ; peduncle length $0.4 \times$ outer ramus, subequal in length to urosomite 3 , with 1 apicolateral robust seta, and 


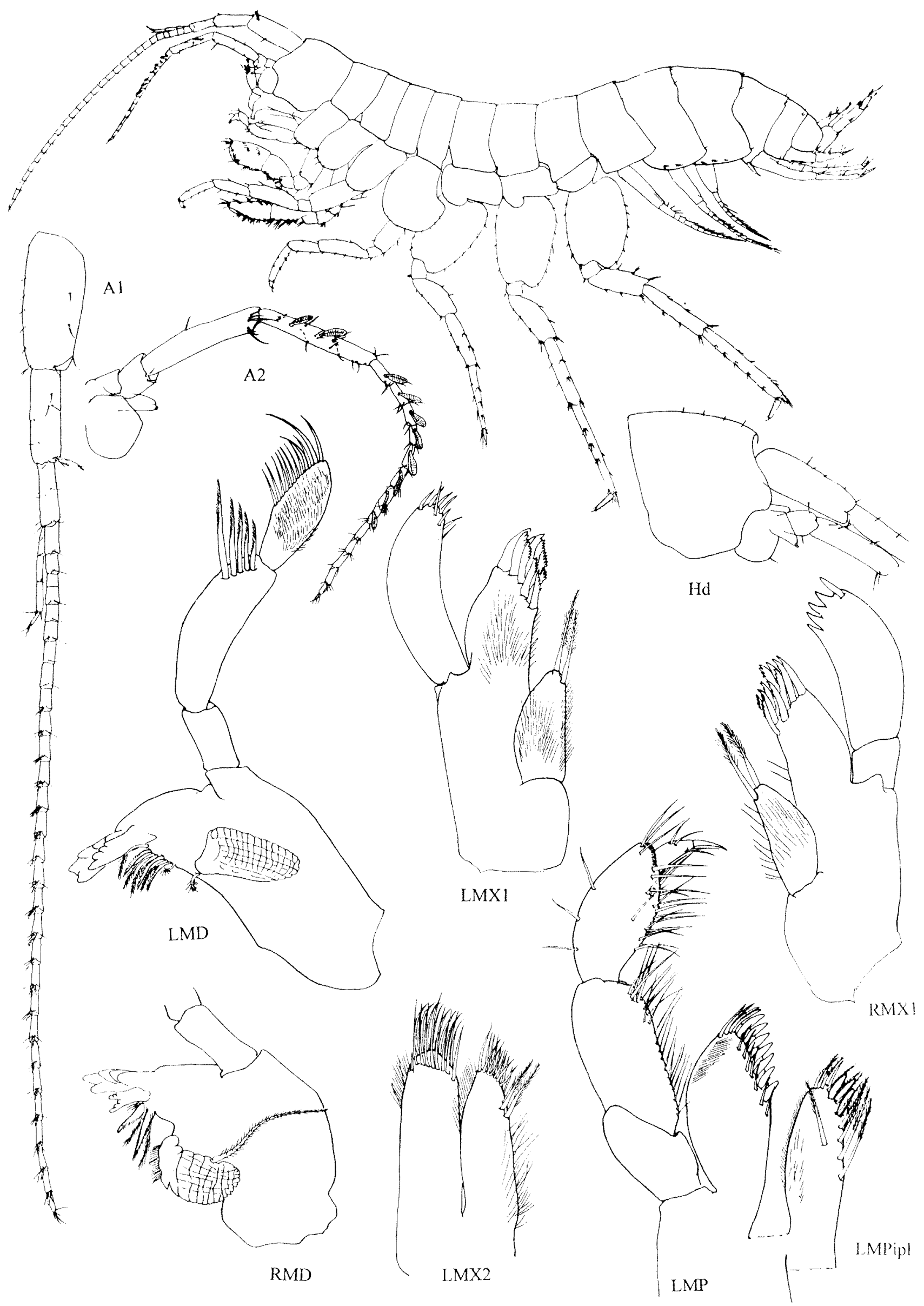

Figure 1 Chydaekata acuminata sp. nov. holotype, male 'a' $5 \mathrm{~mm}$. Whole animal, head, antennae and mouthparts. 


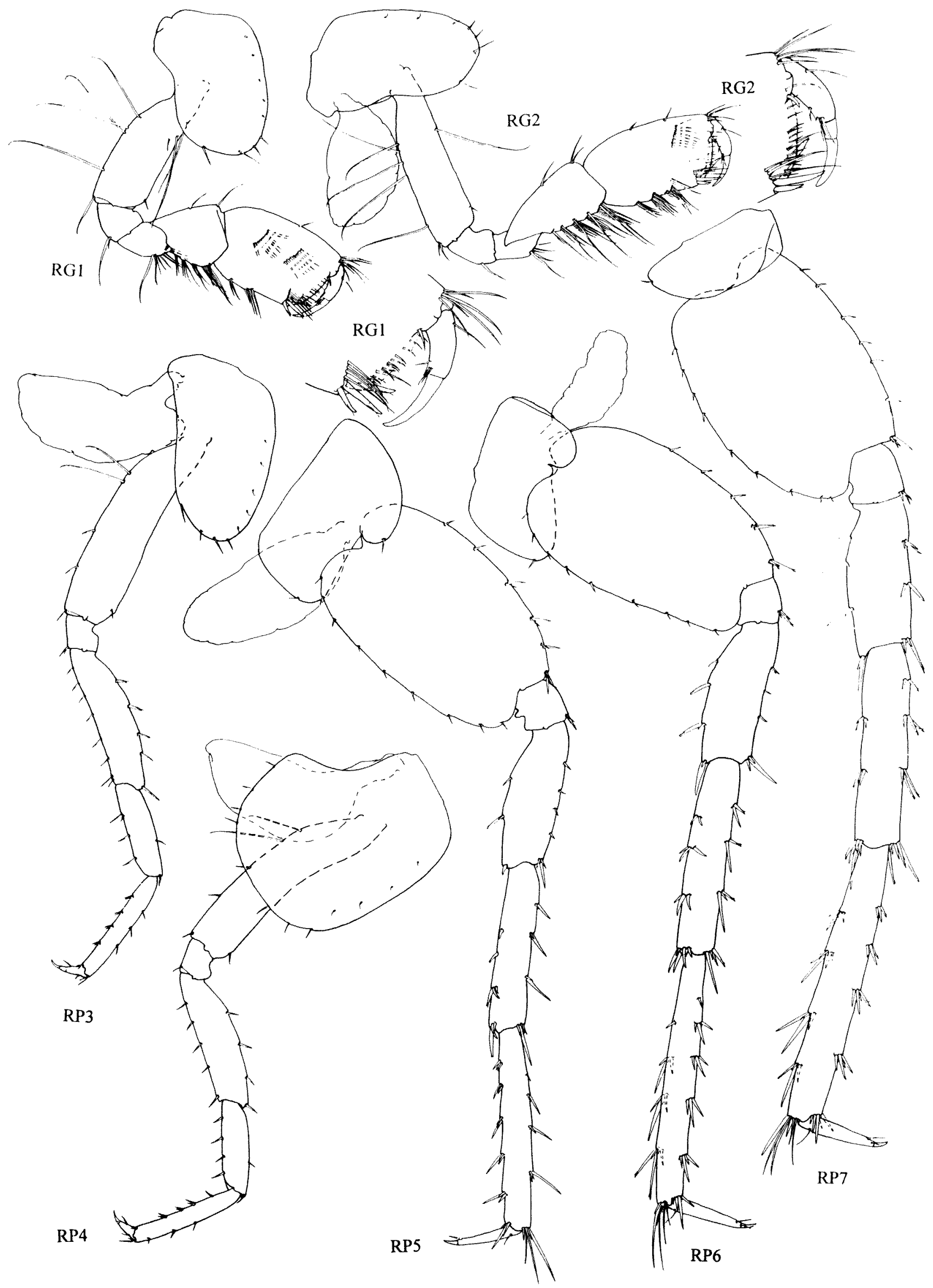

Figure 2 Chydaekata acuminata sp. nov. holotype, male 'a' $5 \mathrm{~mm}$. Gnathopods and pereopods. 


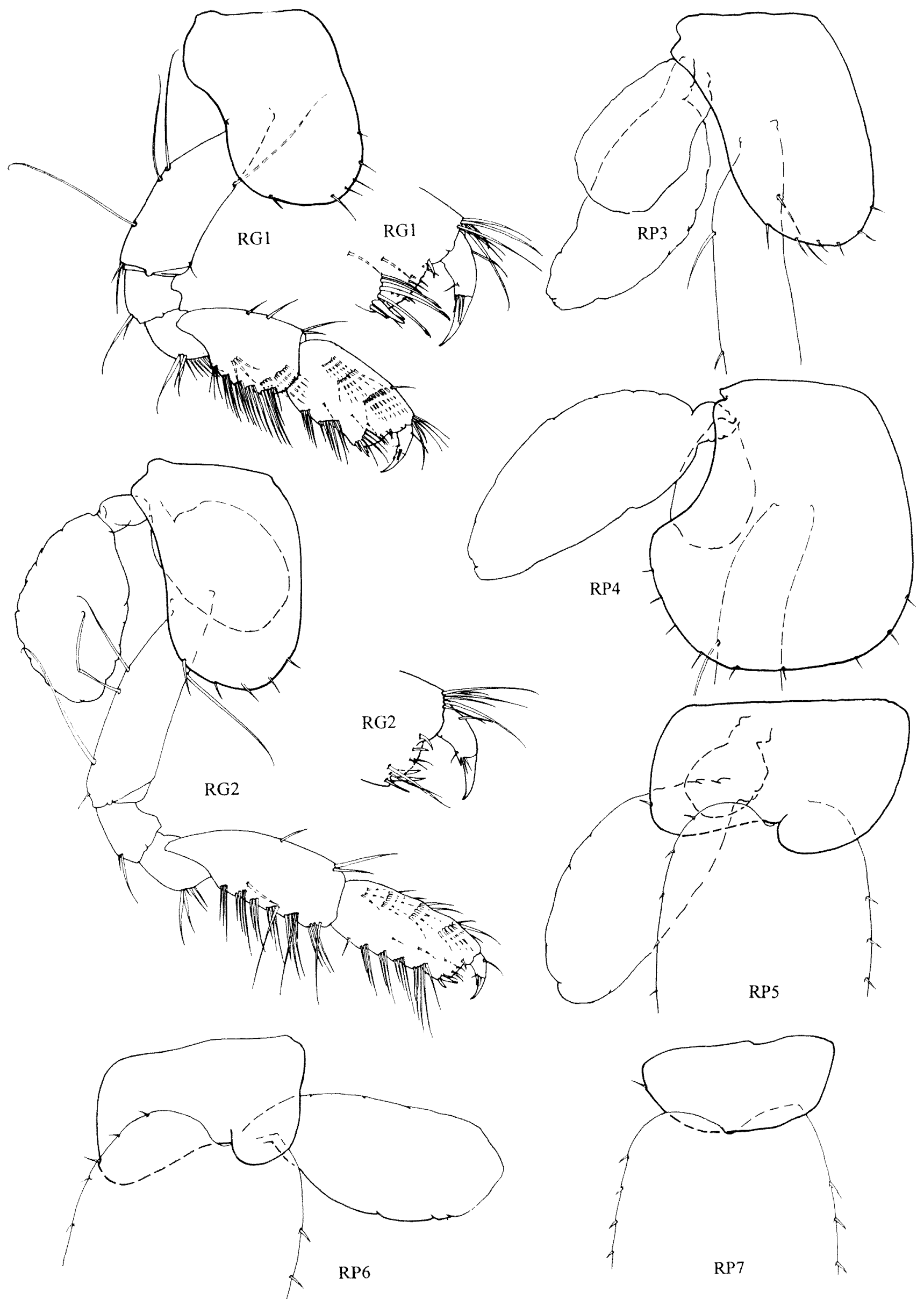

Figure 3 Chydaekata acuminata sp. nov. allotype, female ' $b$ ' $6 \mathrm{~mm}$. Gnathopods and pereopods. 


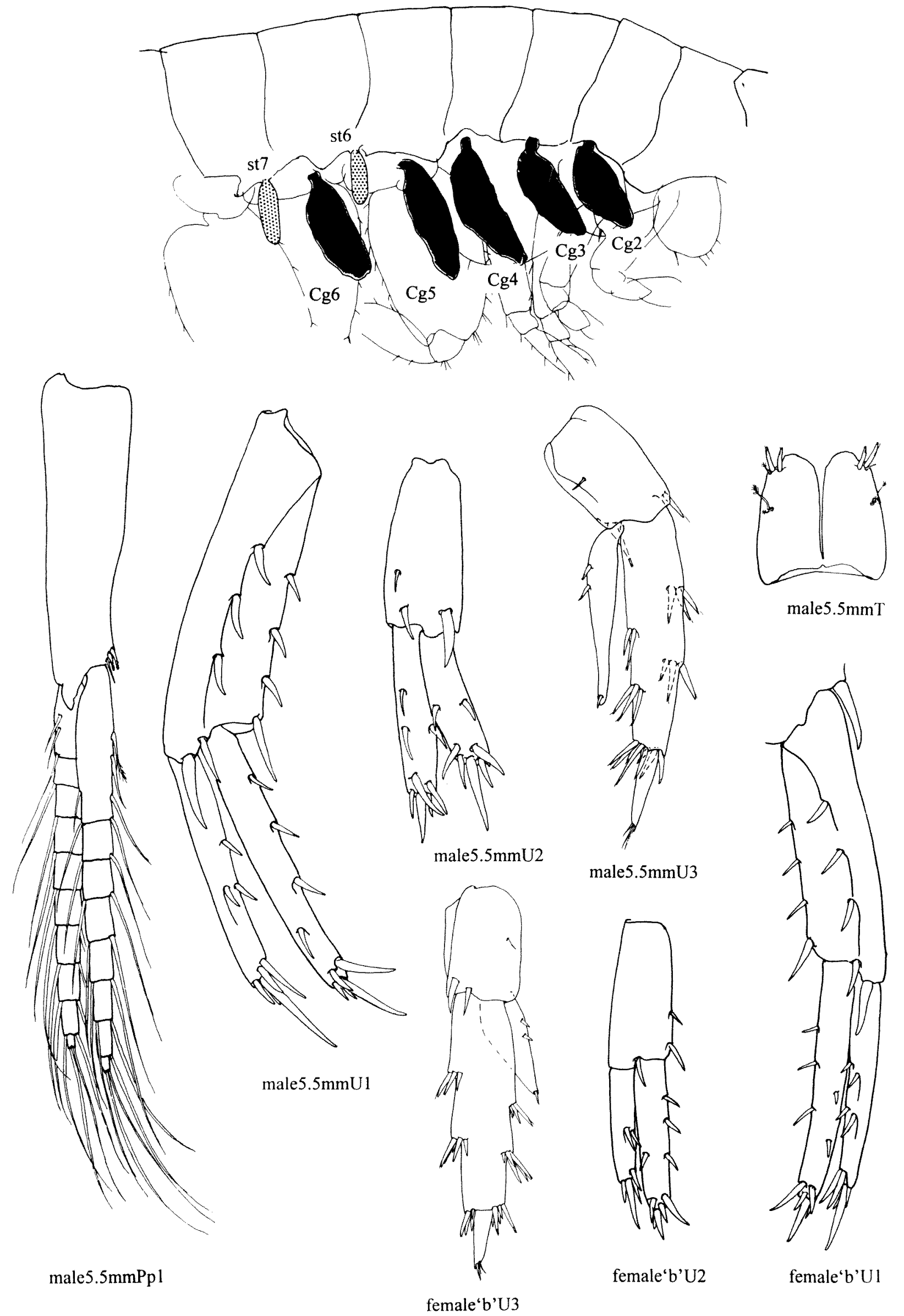

Figure 4 Chydaekata acuminata sp. nov. holotype, male 'a' $5 \mathrm{~mm}$. gills. Male $5.5 \mathrm{~mm}$, pleopod 1, uropods 1-3, telson. Allotype female ' $b$ ' $6 \mathrm{~mm}$, uropods $1-3$. 
no apicolateral slender setae, with 1 dorsomedial robust seta, and 1 dorsomedial slender seta, with 1 apicomedial robust seta, and no apicomedial slender setae, and with no mediodistal robust setae; inner ramus length $0.6 \times$ outer ramus; outer ramus proximal article setae arranged laterally and medially in transverse bands, with 2 lateral transverse bands of robust setae, with 2 medial transverse bands of robust setae, 3 apicolateral robust setae, no apicolateral small setae, 4 apicomedial robust setae, no apicomedial small setae, 1 apicomedial long slender seta; distal article long, with no apical robust setae, and 3 apical slender setae; inner ramus with 2 medial robust setae, 1 apical robust seta, and no apical slender setae. Telson (Figure 4): subequal in length to urosomite 3; cleft $90 \%$; as long as broad; apices rounded and laterally notched; 2 subapical robust setae, and no subapical slender setae; with 1 apical penicillate seta; and paired lateral penicillate setae at M0. 6 from the telson base.

\section{Allotype (female, ' $b$ ' $6 \mathrm{~mm}$ )}

Similar to the holotype except in the following. Body: length $6 \mathrm{~mm}$. First antenna: without aesthetascs or caceoli. Second antenna; without calceoli. First gnathopod (Figure 3): carpus longer than the holotype, length $1.7 x$ width, bearing 5 posterior transverse setal bands, 3 medio-facial setal bands, the propodus smaller and less robust than the male holotype the length $1.7 x$ width, bearing 3 mediofacial setal bands and an additional accessory slender seta adjacent the 2 lateral palmar corner setae. Second gnathopod (Figure 3): coxa bearing an additional ventral seta; carpus elongate (length $2.6 \mathrm{x}$ width), subrectangular, bearing 6 posterior transverse setal bands; propodus narrower than the holotype, (length $2.2 \times$ width) bearing 4 posterior transverse bands of setae, 4 mediofacial setal bands and 2 lateral setae accessory to the 2 robust lateral corner palmar setae. Pereopods (Figure 3): pereopod 5 coxa without a ventral seta on the anterior lobe. Oostegites: present on coxae 2-5, of length about $0.5 \times$ coxal plate, except oostegite of coxa 5 which is reduced. Uropods (Figure 4): first uropod rami each with an additional dorso-lateral seta; second uropod inner ramus bearing an additional dorsomedial seta: third uropod inner ramus short, extending to M0.5 of the first article of the outer ramus.

\section{Paratype (male, 'c' $5.5 \mathrm{~mm}$ )}

Similar to the holotype male 'a' $5 \mathrm{~mm}$.

\section{Etymology}

Derived from the Latin 'acuminatus' (pointed, sharpened), referring to the acuminate posteroventral comer of the second epimeron.
Chydaekata nudula sp. nov. Figures 5-8

\section{Material Examined}

\section{Holotype}

ठ. 'a' $6 \mathrm{~mm}$, Newman bore field, WB 23/4, Western Australia, Australia, 2319S', 117 $51^{\prime} \mathrm{E}$, taken with haul net, 23 July 1997, W.F. Humphreys and S.M. Eberhard, BES4827 (WAM C24653).

\section{Allotype}

Australia: Western Australia: $q$, 'b' $6.5 \mathrm{~mm}$, same data as holotype (WAM C24654).

\section{Paratypes}

Australia: Western Australia: 22 specimens, same data as holotype (WAM C24655).

\section{Diagnosis}

Second antenna: peduncle article 5 bearing 4 calceoli, flagellum 17 articulate, with calceoli on articles 1-13. Mandible: palp article 2 with a mediodistal row of 6 robust rastellate setae; article 3 with $13 \mathrm{D}$ and $4 \mathrm{E}$ setae apically. Left first maxilla: palp article 2 with 7 apical setae. Right first maxilla: palp apex with no articulated, and 5 fused broad based tooth setae. Maxilliped: outer plate with a row of 3 slender naked, medial submarginal to disto-facial setae; a medial row of 9 submarginal to subapical robust, naked, tooth setae; 2 apicolateral setae. First gnathopod: propodus dactyl reaching to palmar corner, with a single recumbent inner tooth spine. Second gnathopod: carpus with posterior setae ranked in 9 transverse bands. Telson: cleft $71 \%$, bearing 3 subapical robust setae.

\section{Description}

\section{Holotype (male, 'a' $6 \mathrm{~mm}$ )}

Body (Figure 5): urosomites 1 and 2 without dorsolateral robust setae. First antenna (Figure 1): length $0.9 \times$ body, $1.9 \times$ second antenna; peduncle article 1 longest, with sparse setae; primary flagellum of 42 articles; accessory flagellum of 5 articles, reaching to article 8 of primary flagellum. Second antenna (Figure 5): length $0.5 \times$ body; peduncle length greater than flagellum, article 5 bearing 4 calceoli, article 4 subequal with article 5 , articles 3-5 with sparse setation; flagellum 17 articulate, with sparse setation, bearing calceoli on articles 1 to 13. Left mandible (Figure 5): palp article 2 with a medio-distal row of 6 robust rastellate setae, article 3 with $13 \mathrm{D}$ and $4 \mathrm{E}$ setae, facially strongly setulose (pubescent); incisor with 6 teeth, lacinia mobilis with 5 teeth and 4 plumose interraker setae; molar bearing pappose seta, with 2 penicillate hooked brushy basal setae, and no penicillate setules. Right mandible (Figure 5): palp 
article 2 with a medio-distal row of 6 robust rastellate setae, article 3 with $12 \mathrm{D}$ and $4 \mathrm{E}$ setae; incisor with 6 teeth and 2 plumose interraker setae; molar without penicillate hooked brushy basal setae, and few penicillate setules. Left first maxilla (Figure 5): palp article 2 with 4 apical and 1 subapical facial strong slender seta, with 1 apicomedial and 1 ventrofacial apicomedial strong slender setae; outer plate with 10 robust setae -10 denticulate, none naked; inner plate subtriangular, facially and medially setulose (pubescent). Right first maxilla (Figure 5): palp apex with no articulated, and 5 fused broad based tooth setae, and 1 subterminal apicolateral facial seta. Second maxilla (Figure 5): outer plate length $3 \times$ width, bearing distal long, curved naked setae; apicomedial corner of inner plate with 2 weakly submarginal thick plumose/pappose setae. Maxilliped (Figure 5): inner plate length $3 \times$ width, extending to M0. 9 of the outer plate, bearing small setules on the lateral margin and medioproximal face, no facial pappose setae, no medial pappose setae, with a row of 4 submarginal to subapical pappose setae, extending to a row of 5 similar subapical and 2 apical setae, and 3 apical naked tooth setae; outer plate broad, length $1.8 \times$ width, distally naked, with a row of 3 slender naked, medial submarginal to distal facial setae, a medial row of 9 submarginal to subapical robust, naked, tooth setae, and 2 apicolateral setae -1 naked, and 1 pappose; third article naked laterally, moderately setose medially, with 3 facial, and 2 ventrofacial long strong setae basal to the dactyl, the apex weakly produced, setulate, with 3 long slender naked setae, and 1 dorsal accessory seta. First gnathopod (Figure 6): coxal plate bearing 1 ventral seta; merus bearing posterior hump; carpus of moderate length, $1.5 \times$ width, subtriangular, posterior margin strongly setose, with setae ranked in 7 transverse bands; propodus ovate, small, length $1.6 \times$ width, posteroventral corner rounded, with 3 lateral robust setae, 4 additional lateral elongate setae, palmar angle weakly oblique, smooth, dactyl reaching to palmar corner, with a single recumbent inner tooth spine. Second gnathopod (Figure 6): slightly larger than first; coxal plate with 4 anteroventral and 1 ventral setae; carpus length 2.4 $x$ width, subtriangular, with posterior setae ranked in 9 transverse bands; propodus subrectangular, small, length $0.8 \times$ width, with 3 lateral robust setae, 1 medial robust seta, and 3 additional lateral elongate setae, palmar angle weakly oblique, smooth, dactyl reaching beyond palmar corner, with a single recumbent inner tooth spine. Pereopods (Figures. 6-7): pereopod 3 longer than the second gnathopod, coxa with 4 anterior setae, 1 long ventral setae, and 1 seta at the posteroventral corner, carpus weakly setose posteriorly; pereopod 4: subequal in length with pereopod 3, coxa anteroventral margin with 3 setae, posteroventral margin with 4 setae, ventral margin with no setae, posterior margin strongly emarginate, carpus weakly setose posteriorly; coxa of pereopod 5 bearing 1 seta on anterior lobe, and 2 setae on the posterior lobe, basis of pereopod 5 with short slender posterior setae, bearing short robust anterior setae or bearing long robust anterior setae, weakly lobate posteriorly; pereopod 6 coxa bearing no setae on anterior lobe; basis moderately expanded, bearing short robust anterior setae or bearing long robust anterior setae, moderately lobate posteroventrally; pereopod 7 coxa with 1 seta on the posterior lobe, basis bearing short robust anterior setae or bearing long robust anterior setae, strongly lobate posteroventrally; bases of pereopods equally expanded. Epimera: first epimeron with 1 slender seta on the posterior margin, posterior margin convex, posteroventral corner rounded; epimeron 2 with 3 robust setae on the anteroventral margin, posterior margin straight, posteroventral corner rounded; epimeron 3 with 6 robust setae on the anteroventral margin, without slender setae on ventral margin, posterior margin sinuous, posteroventral corner rounded, without spine or seta. Pleon: dorsolateral margin of pleonites 1 and 2 with 6 feeble setae, of pleonite 3 with 2 feeble setae, and no distolateral robust setae. Pleopods (Figure 8): each bearing 1 accessory retinacula. Urosomites: first urosomite bearing 1 distolateral slender seta and 2 distolateral robust setae; urosomite 2: with no distolateral slender setae, and 3 distolateral robust setae. First uropod (Figure 8): peduncle length $1.4 \mathrm{x}$ the length of the inner ramus, with strong rows of 3 dorsolateral and 4 dorsomedial robust setae; outer ramus with 2 dorsolateral and 2 dorsomedial robust setae; inner ramus with 2 dorsolateral, 3 dorsomedial and 5 apical robust setae. Second uropod (Figure 8): $0.6 \times$ length of uropod 1; peduncle about $1.2 \times$ length of inner ramus with 1 apicolateral, 1 dorsomedial, and 1 apicomedial robust setae; inner ramus with 2 dorsolateral, 3 dorsomedial, and 5 apical robust setae; outer ramus with 1 dorsolateral, 1 dorsomedial, and 5 apical robust setae. Third uropod (Figure 8): not extending beyond uropods 1 and 2 in intact specimen, $0.6 x$ length of uropod 1 ; peduncle length $0.8 \times$ outer ramus, shorter than, $0.9 \times$ urosomite three, with 1 apicolateral robust seta, and no apicolateral slender setae, with no dorsomedial robust setae, and 1 dorsomedial slender seta, with 1 apicomedial robust setae, and no apicomedial slender setae, and with no mediodistal robust setae; inner ramus length 0.5 $x$ outer ramus; outer ramus proximal article setae arranged laterally and medially in transverse bands, with 3 lateral transverse bands of robust setae, 2 medial transverse bands of robust setae, with no medial transverse bands of mixed robust and small setae, 4 apicolateral robust setae, no apicolateral 


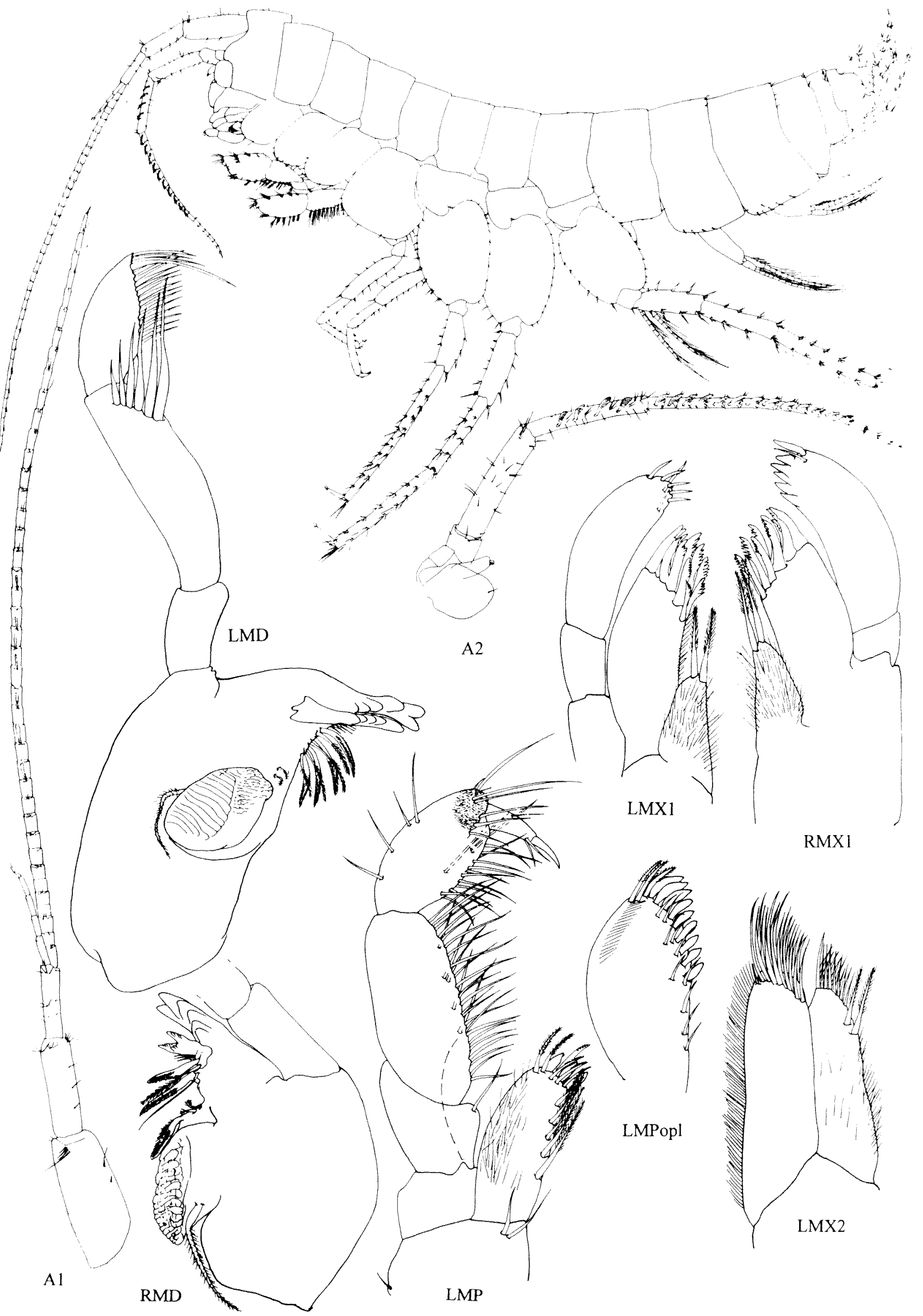

Figure 5 Chydaekata nudula sp. nov. holotype, male 'a' $6 \mathrm{~mm}$, whole animal, antennae and mouthparts. 


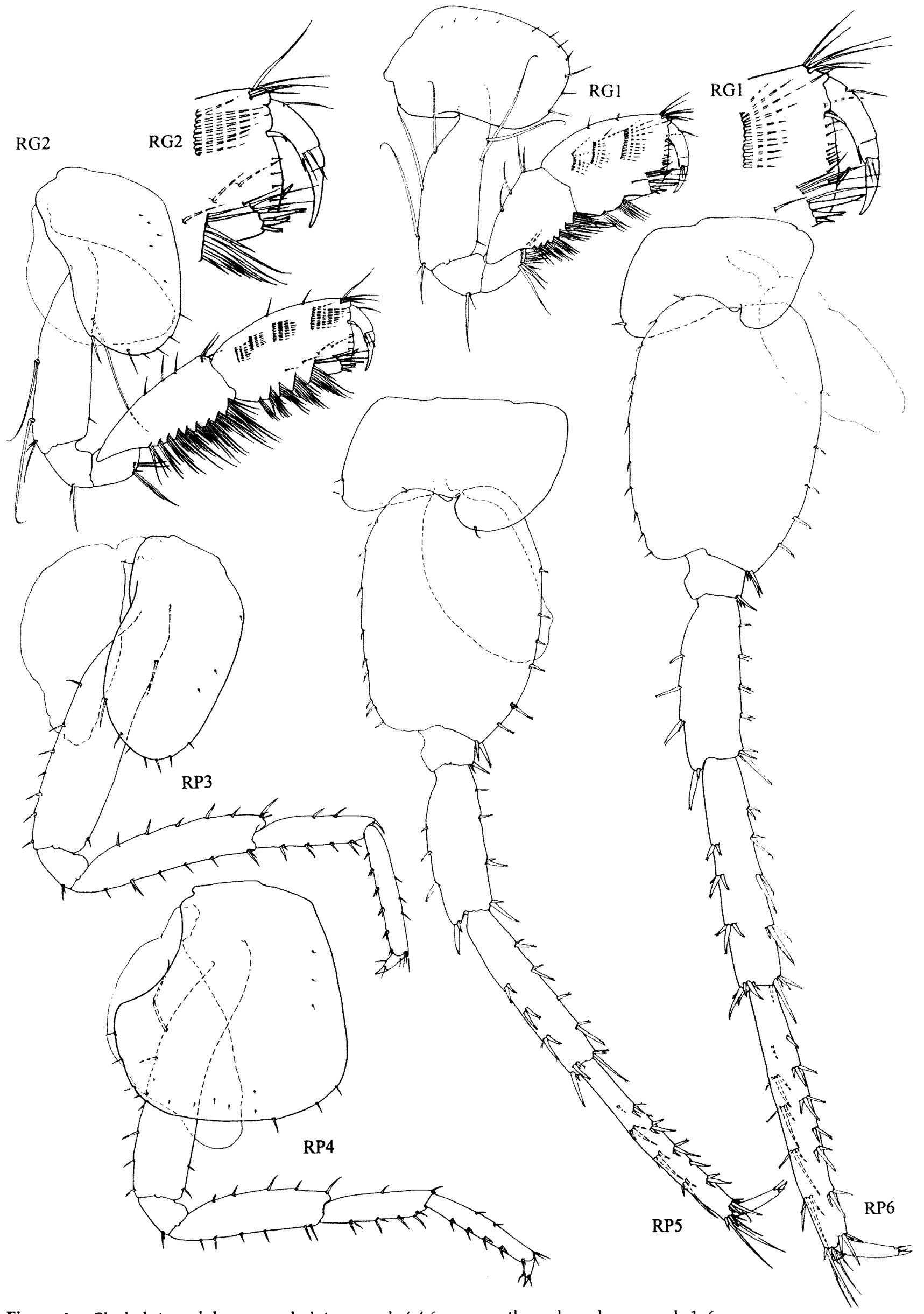

Figure 6 Chydaekata nudula sp. nov. holotype, male 'a' $6 \mathrm{~mm}$, gnathopods and pereopods 1-6. 


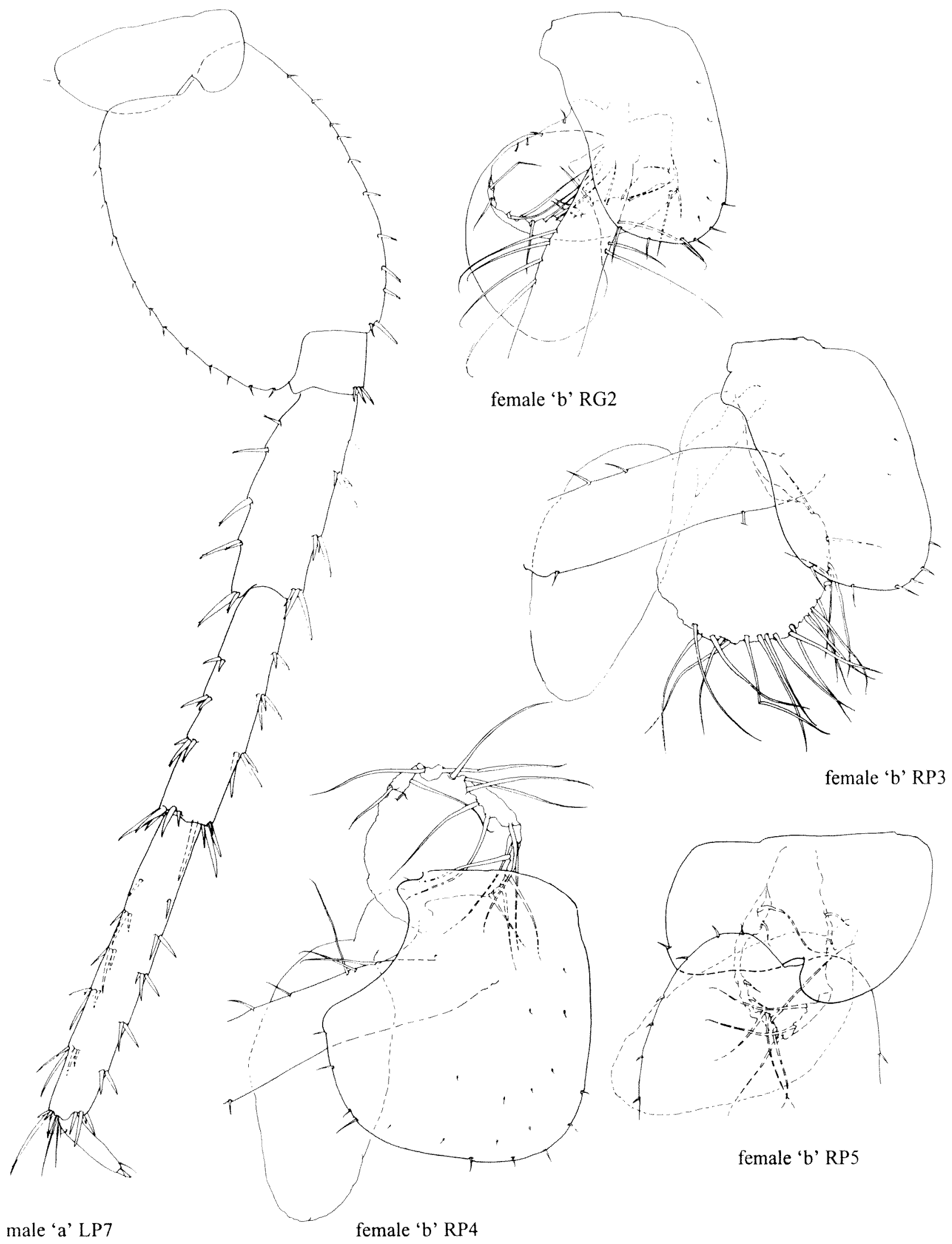

Figure 7 Chydackata nudula sp. nov. holotype, male 'a' $6 \mathrm{~mm}$, pereopod 7 . Allotype female ' $b$ ' $6.5 \mathrm{~mm}$, coxae of second gnathopod and of pereopods $3-5$. 

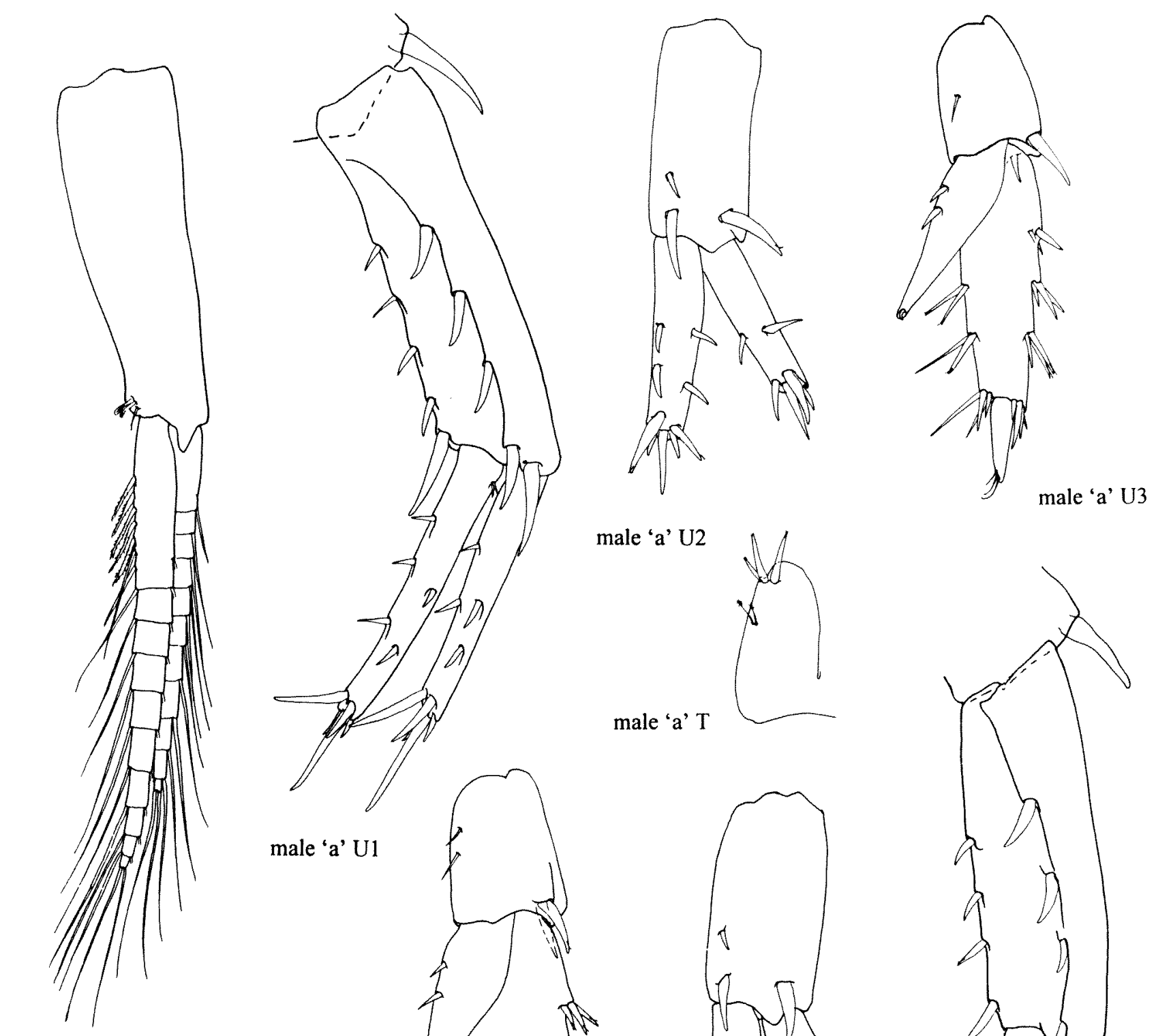

male 'a' Ppl

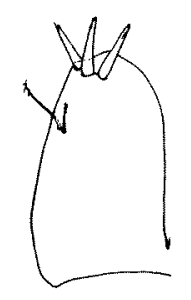

female ' $b$ ' $T$

male 'a' U1

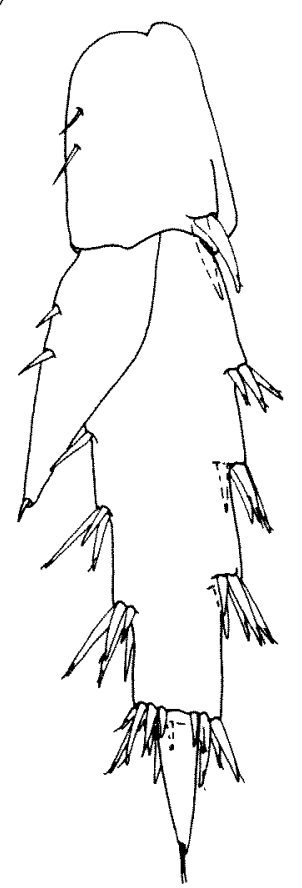

female 'b' U3

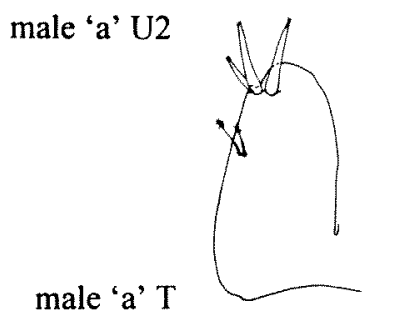

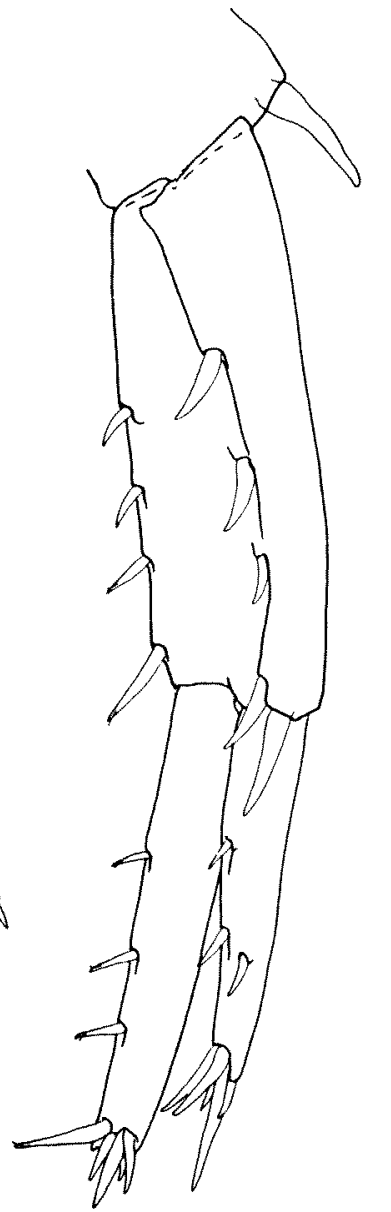

female 'b' Ul

Figure 8 Chydaekata nudula sp. nov. holotype, male 'a' $6 \mathrm{~mm}$, pleopod 1, uropods and telson. Allotype female 'b' 6.5 $\mathrm{mm}$, uropods and telson. 
small setae, 4 apicomedial robust setae, no apicomedial small setae, no apicomedial long slender setae; distal article short, with 3 apical robust setae, and no apical slender setae; inner ramus with 2 medial robust setae, no apical robust setae, and 1 apical slender setae. Telson (Figure 8): subequal in length to urosomite 3 ; cleft $71 \%$; longer than broad, length $1.1 \times$ breadth; apices rounded and laterally notched; 3 subapical robust setae, and no subapical slender setae; with 1 apical penicillate seta; and paired lateral penicillate setae at M0. 6 from the telson base.

\section{Allotype (female, 'b' $6.5 \mathrm{~mm}$ )}

Similar to the holotype except in the following. Body: length $6 \mathrm{~mm}$. First antenna: without aesthetascs or calceoli. Second antenna: without calceoli. Second gnathopod (Figure 7): coxa bearing large, ovate, marginally setose and involute oostegite, length about $0.7 x$ coxa. Pereopods (Figure 7). Third pereopod: coxa with fewer marginal setae, bearing large, paddle shaped marginally setose oostegite, about equal in size to the coxal plate. Fourth pereopod; coxa with more marginal setae than the holotype; bearing moderately sized round oostegite, apically inturned, and marginally setose apically and posteriorly. Fifth pereopod; coxa without anteroventral seta, and with 1 posterior seta (rather than 2 as in the holotype); bearing moderate to small paddle shaped, marginally setose and involute oostegite. Uropods (Figure 8). First uropod; peduncle bearing 3 medial robust setae; outer ramus with 1 lateral robust seta; inner ramus without lateral setae. Second uropod; outer ramus bearing 2 lateral and 2 medial robust setae, and 5 apical robust setae; inner ramus bearing 3 medial robust setae. Third uropod; peduncle bearing 2 small dorsomedial setae; outer ramus first article with 3 medial transverse rows of setae, apex of the second article with 2 slender setae. Telson (Figure $8)$ : similar to the male.

\section{Relationships}

Chydaekata nudula differs from others of the genus in that: first antenna accessory flagellum reaches to article 8 of primary flagellum; second antenna flagellum bears calceoli on 13 articles; maxilliped outer plate with a row of 3 slender naked medial submarginal to disto facial setae; first gnathopod coxal plate with no anteroventral setae, carpus with strong posterior rastellate setae ranked in 7 transverse bands; second gnathopod carpus with strong posterior rastellate setae ranked in 9 transverse bands, propodus length less than $0.8 \mathrm{x}$ width; pereopods - coxa 3 bearing 1 long ventral seta; coxa 5 bearing 2 setae on the posterior lobe; pleon - dorsolateral margin of pleonites 1 and 2 with 6 feeble setae; second uropod inner ramus with 3 dorsomedial robust setae; third uropod not extending beyond U1-2 in intact specimen, third uropod outer ramus distal article with 3 apical robust setae, third uropod outer ramus distal article with no apical slender setae.

\section{Etymology}

From the Latin 'nudus' (bare, naked), referring to the absence of lateral setae on the ultimate article of the maxillipedal palp.

\section{Chydaekata dolichodactyla sp. nov.}

Figures 9-12

\section{Material Examined}

\section{Holotype}

o', 'a' $4.5 \mathrm{~mm}$, Newman bore field, WB23/4, Western Australia, Australia, 23ำ $19^{\prime} \mathrm{S}, 117^{\circ} 51^{\prime} \mathrm{E}, 24$ July 1997, taken with trap, W.F. Humphreys and S.M. Eberhard, BES4841 (WAM C24656).

\begin{abstract}
Allotype
Australia: Western Australia: $q$, 'b' $6 \mathrm{~mm}$, same data as holotype (WAM C24657).

\section{Diagnosis}

Second antenna: peduncle article 5 bearing 1 calceolus, flagellum 9 articulate, with calceoli on articles 1-5. Mandible: palp article 2 with a mediodistal row of 3 robust rastellate setae; article 3 with $7 \mathrm{D}$ and $3 \mathrm{E}$ setae apically. Left first maxilla: palp article 2 with 6 apical setae. Right first maxilla: palp apex with no articulated, and 4 fused broad based tooth setae. Maxilliped outer plate with no medial submarginal to disto-facial setae; a medial row of 7 submarginal to subapical robust, naked, tooth setae; 2 apicolateral setae. First gnathopod propodus: dactyl reaching beyond the palmar corner, with a single recumbent inner tooth spine. Second gnathopod carpus: with posterior setae ranked in 4 transverse bands. Telson: cleft $68 \%$, bearing 2 subapical robust setae.
\end{abstract}

\section{Description}

Holotype (male, 'a' $4.5 \mathrm{~mm}$ )

Body (Figure 9): urosomite 1 bearing 1 dorsolateral robust seta, urosomite 2 bearing 2 dorsolateral robust setae. First antenna (Figure 9): length $0.6 \mathrm{x}$ body, $1.7 \times$ second antenna; peduncle article 1 longest, with sparse setae; primary flagellum of 26 articles; accessory flagellum of 4 articles, reaching to article 5 of primary flagellum. Second antenna (Figure 9): length $0.6 \times$ body; peduncle length greater than flagellum, article 5 bearing no calceoli, article 4 subequal with article 5, articles 3-5 with sparse setation; flagellum 11 articulate, with sparse setation, bearing calceoli on articles $2-4$. Left 
mandible (Figure 9): palp article 2 with a mediodistal row of 5 robust rastellate setae, article 3 with $9 \mathrm{D}$ and $3 \mathrm{E}$ setae, facially strongly setulose (pubescent); incisor with 5 teeth, lacinia mobilis with 5 teeth, and 2 plumose interraker setae; molar bearing pappose seta, with 1 penicillate hooked brushy basal seta. Right mandible (Figure 9): palp article 2 with a medio-distal row of 5 robust rastellate setae, article 3 with $9 \mathrm{D}$ and $3 \mathrm{E}$ setae; incisor with 5 teeth, and 2 plumose interraker setae; molar, with 2 penicillate hooked brushy basal setae, and, few penicillate setules. Left first maxilla (Figure 9): palp article 2 with 4 apical and 1 subapical-facial strong slender setae, and 1 apicomedial seta; outer plate with 10 robust setae - 10 denticulate, none naked; inner plate subtriangular, facially and medially setulose (pubescent). Right first maxilla (Figure 9): with no articulated and 4 fused broad based tooth setae, and 1 subterminal apicolateral facial seta. Second maxilla (Figure 9): outer plate length $3.4 \times$ width, bearing distal long, curved naked setae; apicomedial corner of inner plate with 2 weakly submarginal thick plumose/pappose setae. Maxilliped (Figure 9): inner plate length $2.8 \times$ width, extending to M0.7 of the outer plate, bearing small setules on the lateral margin, no facial or medial pappose setae, with a row of 2 submarginal pappose setae, extending to a row of 2 similar subapical, and 4 apical setae, with 1 apicomedial and 3 apical naked tooth setae; outer plate broad, length $1.8 \times$ width, distally setulose (pubescent), with a row of 10 , slender naked, medial submarginal to distal facial setae, a medial row of 6 submarginal to subapical robust, naked, tooth setae, and 3 apicolateral setae - none naked, 3 pappose; palp second article moderately setose medially, third article sparsely setose laterally, moderately setose medially, with 2 facial and 2 ventrofacial long strong setae basal to the dactyl, the apex not produced, setulate, with 2 long slender naked setae, and 1 dorsal accessory seta. First gnathopod (Figure 10): coxal plate with 3 anteroventral setae, and 1 ventral seta; merus bearing posterior hump; carpus of moderate length, $1.6 \mathrm{x}$ width, subtriangular, posterior margin, with setae ranked in 4 transverse bands; propodus subrectangular, small, length $1.5 \mathrm{x}$ width, posteroventral corner rounded, with 2 lateral and 1 medial robust setae, and 3 additional lateral elongate setae, palmar angle slightly oblique, bearing fine marginal teeth, dactyl reaching beyond palmar corner, with a single recumbent inner tooth spine. Second gnathopod (Figure 10): slightly larger than first; coxal plate with 2 anteroventral setae, and 1 ventral seta; carpus length $1.2 \times$ width, subtriangular, with setae ranked in 5 transverse bands; propodus subrectangular, moderate size, length $2 \times$ width, with 2 medial robust setae, 2 lateral robust setae, and 2 additional lateral elongate setae, palmar angle transverse, bearing fine marginal teeth, dactyl reaching beyond palmar corner, with a single recumbent inner tooth spine. Pereopods (Figure 10): pereopod 3 longer than the second gnathopod, coxa with 1 anterior seta, no long ventral setae, 1 short ventral seta, 1 seta at the posteroventral corner, carpus weakly setose posteriorly; pereopod 4 subequal in length with pereopod 3, coxa anteroventral margin with 2 setae, posteroventral margin with 2 setae, ventral margin with 1 seta, carpus moderately setose posteriorly; coxa 5 bearing 1 seta on anterior lobe, and 1 seta on the posterior lobe, basis of pereopod 5 with short slender posterior setae, bearing short robust anterior setae and long robust anterior setae, moderately lobate posteroventrally; pereopod 6 coxa bearing no setae on anterior lobe, basis moderately expanded, bearing short robust anterior setae or bearing long robust anterior setae, moderately lobate posteroventrally; pereopod 7 coxa with 1 seta on the posterior lobe, basis bearing short and long robust anterior setae, moderately lobate posteroventrally; bases of pereopods expanded unequally, basis of pereopod 7 most expanded, basis of pereopod 6 least expanded. Epimera: first epimeron with 1 slender seta on the posterior margin, posterior margin convex, posteroventral corner rounded; second epimeron without robust setae on anteroventral margin, posterior margin straight, posteroventral corner rounded; third epimeron with 2 robust setae on the anteroventral margin, without slender setae on ventral margin, posterior margin straight, posteroventral corner rounded, without spine or seta. Pleon: dorsolateral margin of pleonites 1 and 2 with 1 feeble seta, of pleonite 3 with 2 feeble setae, and no distolateral robust setae. Pleopods (Figure 12): first and second pleopods with 1 accessory retinacula, third pleopod with no accessory retinacula. Urosomites: first urosomite bearing no distolateral slender setae, and 2 distolateral robust setae; second urosomite with no distolateral slender setae, and 2 distolateral robust setae. First uropod (Figure 12): peduncle length $1.2 \times$ the length of the inner ramus, with a strong row of 3 dorsolateral and 3 dorsomedial robust setae; outer ramus with 1 dorsolateral and 2 dorsomedial robust setae; inner ramus with 1 dorsolateral and 2 dorsomedial robust setae, and 4 apical robust setae. Second uropod (Figure 12): $0.6 \times$ length of uropod 1, peduncle about $1 \times$ length of inner ramus, with 1 apicolateral, 1 dorsomedial, and 1 apicomedial robust setae; inner ramus with 1 dorsolateral, 2 dorsomedial, and 5 apical robust setae; outer ramus with 1 dorsolateral, 1 dorsomedial, and 5 apical robust setae. Third uropod (Figure 12): extending beyond uropods 1 and 2 in intact specimen, $0.6 \times$ length of uropod 1; peduncle length $0.4 \times$ outer ramus, subequal in length to urosomite 3 , with 1 apicolateral robust seta, and no apicolateral slender 


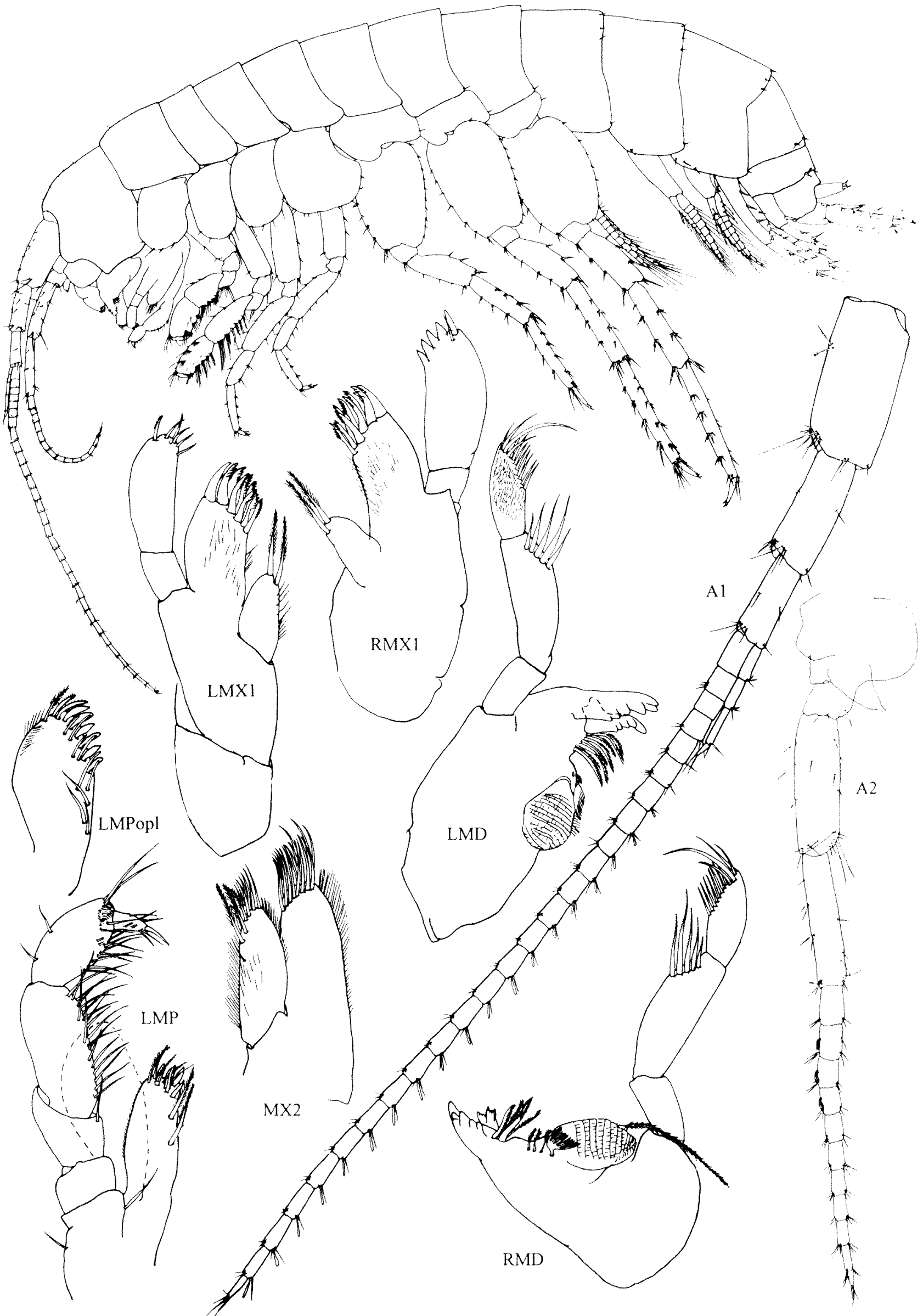

Figure 9 Chydaekata dolichodactyla sp. nov. holotype, male 'a' $4.5 \mathrm{~mm}$, whole animal, antennae and mouthparts. 


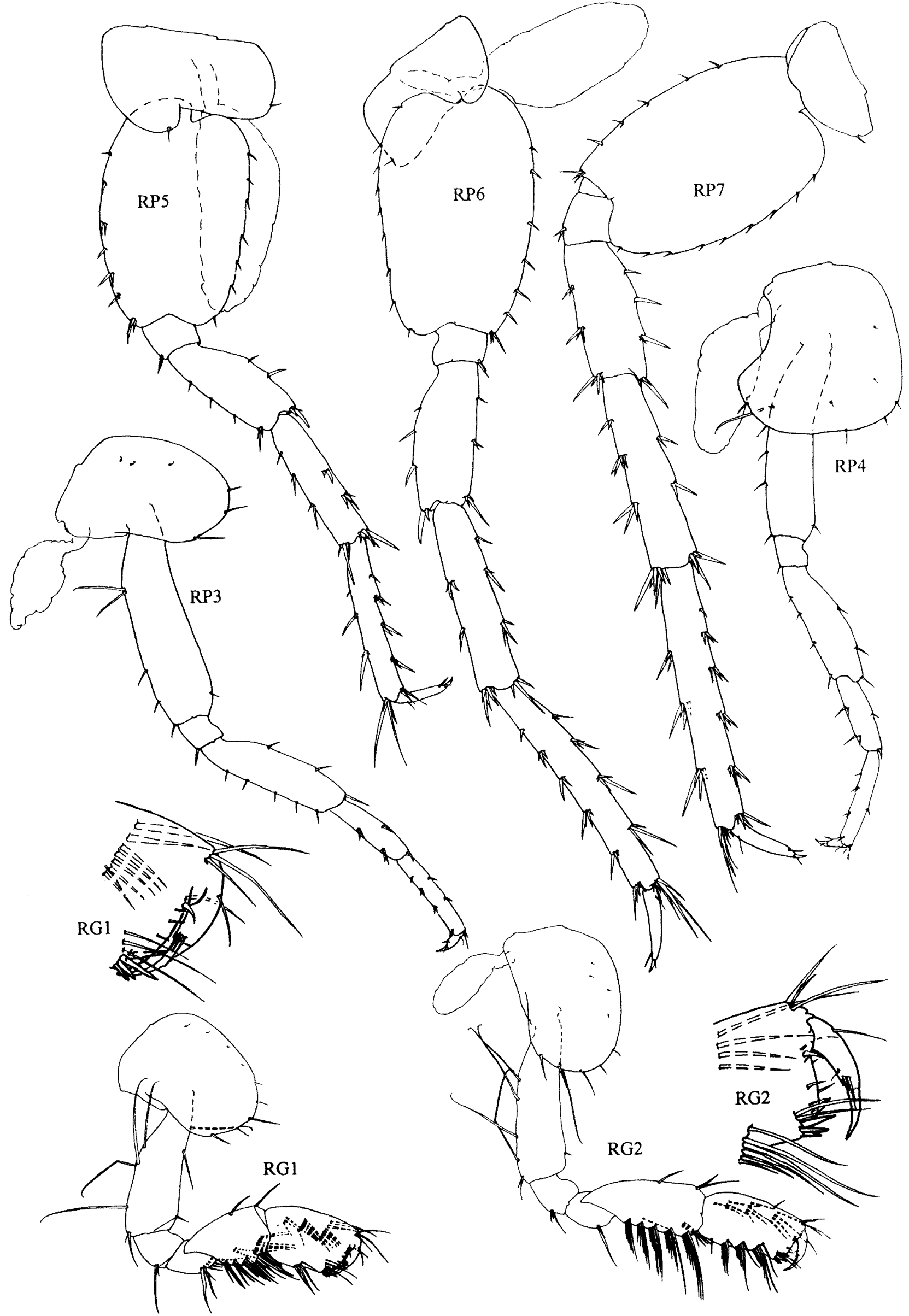

Figure 10 Chydaekata dolichodactyla sp. nov. holotype, male 'a' $4.5 \mathrm{~mm}$, gnathopods and pereopods. 


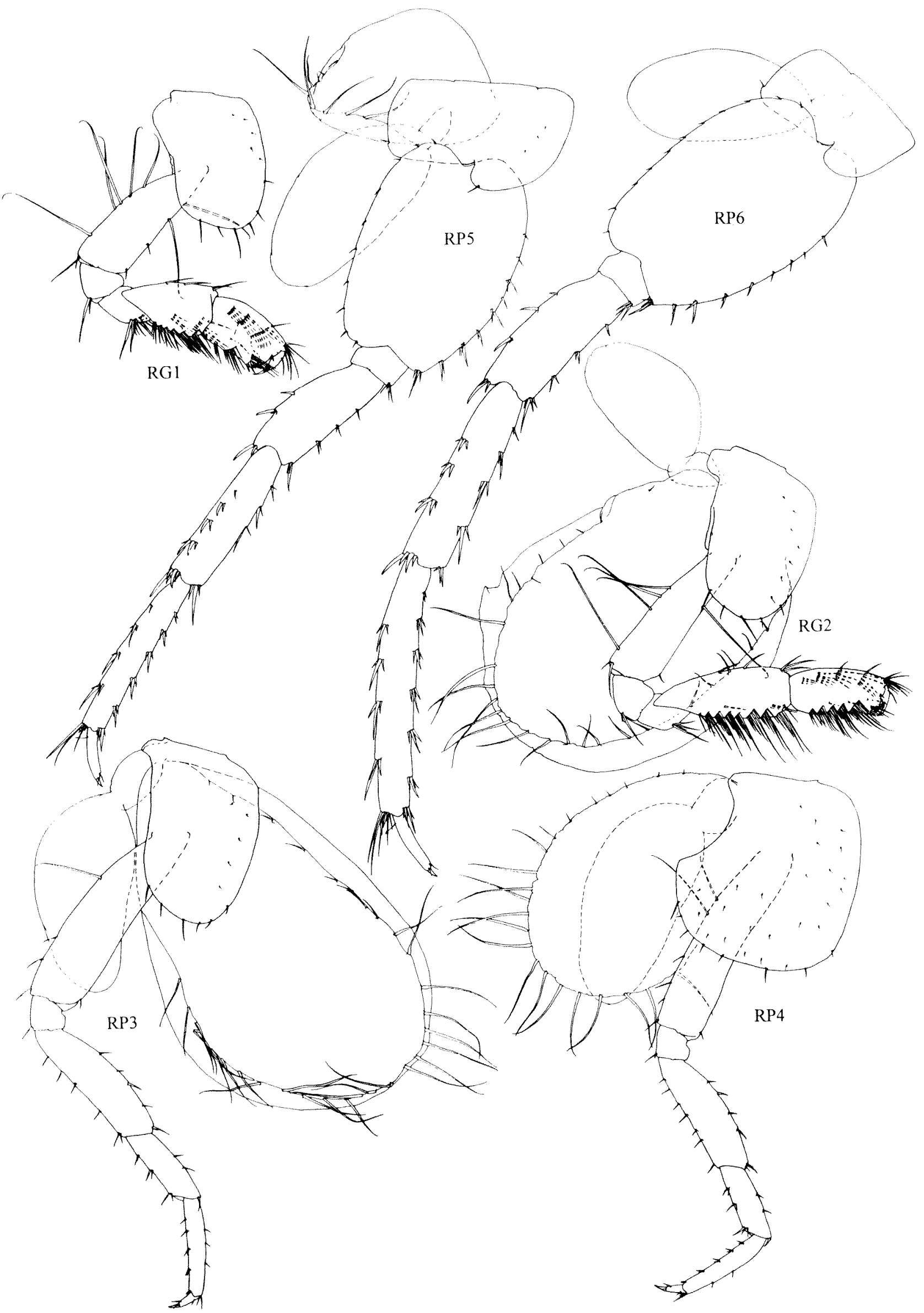

Figure 11 Chydaekata dolichodactyla sp. nov. allotype, female ' $b$ ' $6 \mathrm{~mm}$, gnathopods 1-2 and pereopods 3-6. 

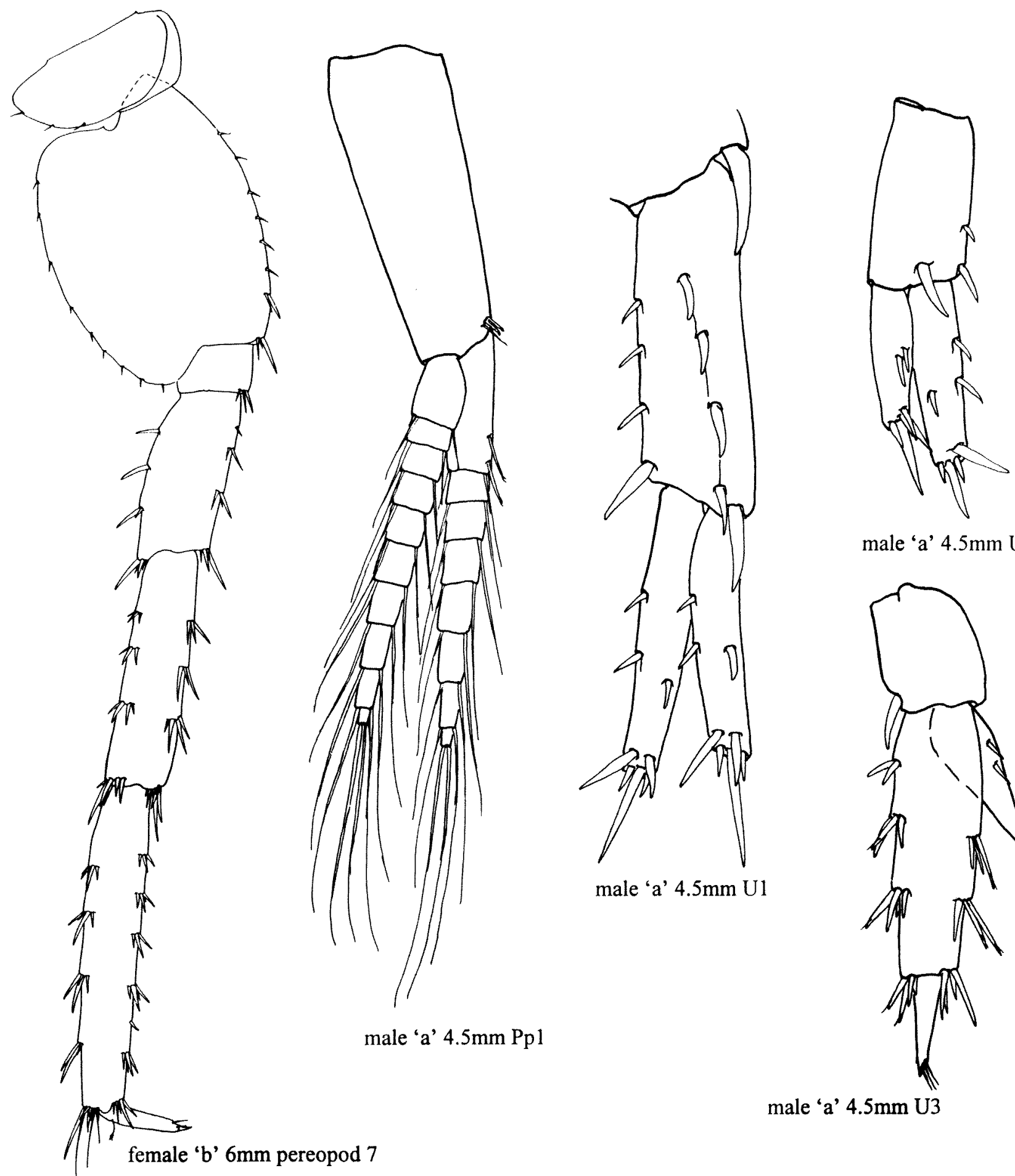

male ' $a$ ' $4.5 \mathrm{~mm} \mathrm{U} 2$

Figure 12 Chydaekata dolichodactyla sp. nov. holotype, male 'a' $4.5 \mathrm{~mm}$, pleopod 1, uropods 1-3. Allotype female 'b' 6 $\mathrm{mm}$, pereopod 7 .

setae, with no dorsomedial robust or slender setae, with no apicomedial robust or slender setae, and with 1 mediodistal robust seta; inner ramus length $0.5 \times$ outer ramus; outer ramus proximal article setae arranged laterally and medially in transverse bands, with 3 lateral and 2 medial transverse bands of robust setae, 4 apicolateral robust setae, no apicolateral small setae, 4 apicomedial robust setae, no apicomedial small setae, no apicomedial long slender setae; distal article long, with no apical robust setae, and 3 apical slender setae; inner ramus with 2 medial robust setae, no apical robust setae, and 1 apical slender seta. Telson: shorter than, $0.9 \mathrm{x}$, urosomite 3; cleft $74 \%$, shorter than broad, length $0.8 \times$ breadth; apices rounded and laterally notched, 2 subapical robust setae, with 1 apical penicillate seta; and paired lateral penicillate setae at M0.7 from the telson base. 
Allotype (female, ' $b$ ' $6 \mathrm{~mm}$ )

With the characteristics of the holotype except. Body: length $6 \mathrm{~mm}$. First antenna: flagellum of 30 articles, without aesthetascs or calceoli, accessory flagellum of 5 articles. Second antenna: flagellum of 14 articles, without calceoli. First gnathopod (Figure 11): coxa bearing 7 (versus 5) marginal setae; carpus bearing 6 (versus 4) posterior translateral setal bands; propodus less robust, narrower and longer than male, tapering apically, bearing 2 (versus 1) posterior translateral setal bands and additional mediofacial setae, palmar corner bearing 2 (versus 3) lateral robust setae. Second gnathopod (Figure 11): coxa smaller than in male, bearing a huge, ovate, marginally setose and involuted oostegite, length about 2.2x length of coxal plate; carpus longer and narrower than male with 8 (versus 5) posterior translateral setal bands but fewer mediofacial setae; propodus smaller, less robust than male, tapering apically, with 5 (versus 3 ) posterior translateral setal bands and additional mediofacial setae; palmar corner bearing 2 (versus 3) lateral robust setae. Pereopods (Figures. 11-12). Pereopod three: coxa bearing additional marginal setae (6 versus 3 ), and a huge, ovate/paddle shaped, marginally setose and involuted oostegite, length about $2.3 x$ coxal plate. Pereopod four: coxa with 8 (versus 5) marginal setae and many small facial setules, bearing large, marginally setose oostegite, length about $1.4 x$ coxal plate. Pereopod five: coxa bearing large, apically setose oostegite, length about equal to coxal plate, $0.4 x$ oostegite of coxa 3 . Pereopod six similar to holotype. Pereopod seven: coxa bearing 3 (versus 1) posterior setae.

\section{Relationships}

Chydaekata dolichodactyla differs from others of the genus in that: second antenna peduncle article 5 bearing no calceoli, flagellum without calceoli on article 1, bearing calceoli on 3 articles only; maxilliped inner plate with a row of 2 submarginal pappose setae, extending to a row of 2 similar subapical setae and 4 similar apical setae, outer plate bearing a medial row of 6 submarginal to subapical robust, naked, tooth setae; second gnathopod carpus length less than $1.2 \times$ width, propodus palmar angle oblique; first uropod inner ramus bearing 4 apical robust setae.

\section{Etymology}

From the Greek 'dolichos' (long), and 'dactylo' (finger), hence long finger, referring to extension of the dactyl of the second gnathopod propodus beyond the palmar corner.

\section{Chydaekata breviclava sp. nov.} Figures 13-16

\section{Material Examined}

Holotype

o', 'a' $5 \mathrm{~mm}$, Newman bore field, WB23/4, Western Australia, Australia, 2319'S, 117 $51^{\prime} \mathrm{E}$, taken with haul net, 24 July 1997, W.F. Humphreys and S.M. Eberhard, BES 4846 (WAM C24658).

\section{Allotype}

Australia: Western Australia: $q, b^{\prime} 6 \mathrm{~mm}$, same data as holotype (WAM C24659)

\section{Paratypes}

Australia: Western Australia: 17 specimens, same data as holotype (WAM C24660).

\section{Diagnosis}

Second antenna: peduncle article 5 bearing 4 calceoli, flagellum 15 articulate, with calceoli on articles 1-9. Mandible: palp article 2 with a mediodistal rows of 4 robust rastellate setae; article 3 with $12 \mathrm{D}$ and $4 \mathrm{E}$ setae apically. Left first maxilla: palp article 2 with 8 apical setae. Right first maxilla: palp apex with no articulated, and 5 fused broad based tooth setae. Maxilliped outer plate with a row of 9 slender naked, medial submarginal to disto-facial setae; a medial row of 8 submarginal to subapical robust, naked, tooth setae; 4 apicolateral setae. First gnathopod propodus: dactyl not reaching to palmar corner, with a single recumbent inner tooth spine. Second gnathopod carpus: with posterior setae ranked in 5 transverse bands. Telson: cleft $69 \%$, bearing 3 subapical robust setae.

\section{Description}

Holotype (male, 'a' $5 \mathrm{~mm}$ )

Body (Figure 13): urosomite 1 bearing 2 dorsolateral robust setae, urosomite 2 bearing 3 dorsolateral robust setae. First antenna (Figure 13): length $0.9 \mathrm{x}$ body, $1.7 \mathrm{x}$ second antenna; peduncle article 2 longest, with sparse setae; primary flagellum of 36 articles; accessory flagellum of 5 articles, reaching to article 6 of primary flagellum. Second antenna (Figure 13): length $0.5 \times$ body; peduncle length greater than flagellum, article 5 bearing 4 calceoli, article 4 longer than article 5 , articles 3-5 with sparse setation; flagellum 15 articulate, with sparse setation, bearing calceoli on articles 1 -9. Left mandible (Figure 13): palp article 2 with a medio-distal row of 4 robust rastellate setae, article 3 with $12 \mathrm{D}$ and $4 \mathrm{E}$ setae, facially strongly setulose (pubescent); incisor with 5 teeth, lacinia mobilis with 5 teeth, and 4 plumose interraker setae; molar without pappose seta, with 3 penicillate hooked brushy basal setae, and no penicillate setules. Right mandible (Figure 13): palp article 2 with a medio-distal row of 5 robust rastellate setae, article 3 with $12 \mathrm{D}$ and $4 \mathrm{E}$ setae; incisor with 6 
teeth, and 2 plumose interraker setae; molar with 1 penicillate hooked brushy basal seta, and no penicillate setules. Left first maxilla (Figure 13): palp article 2 with 5 apical and 2 subapical facial strong slender setae, with 1 apicomedial seta; outer plate with 10 robust setae -10 denticulate, none naked; inner plate subtriangular, facially and medially setulose (pubescent). Right first maxilla (Figure 13): palp apex with no articulated and 5 fused broad based tooth setae, and 1 subterminal apicolateral facial seta. Second maxilla (Figure 13): outer plate length $3.9 \times$ width, bearing distal long, curved naked setae; apicomedial corner of inner plate with 2 weakly submarginal thick plumose/pappose setae. Maxilliped (Figure 13): inner plate length $2.6 \times$ width, extending to M0.7 of the outer plate, bearing small setules on the lateral margin, no facial pappose setae, no medial pappose setae, with a row of 5, submarginal to subapical pappose setae, extending to a row of 5 similar subapical, but no apical setae, with 1 apicomedial, and 3 apical naked tooth setae; outer plate broad, length $1.7 \times$ width, distally naked, with a row of 9, slender naked, medial submarginal to distal facial setae, a medial row of 8 submarginal to subapical robust, naked, tooth setae, and 4 apicolateral setae -1 naked and 3 pappose; palp, second article moderately setose medially; third article sparsely setose laterally, moderately setose medially, with 3 facial, and 2 ventrofacial long strong setae basal to the dactyl, the apex moderately produced, setulate, with 3 long slender naked setae, and 1 dorsal accessory seta. First gnathopod (Figure 14): coxal plate with 4 anteroventral setae, and 1 ventral seta; merus without posterior hump; carpus of moderate length, $1.5 \mathrm{x}$ width, subtriangular, posterior margin, with setae ranked in 6 transverse bands; propodus subrectangular, small, length $1.6 \mathrm{x}$ width, posteroventral corner rounded, with 2 lateral and 1 medial robust setae, and 4 additional lateral elongate setae, palmar angle slightly oblique, smooth, dactyl not reaching to palmar corner, with a single recumbent inner tooth spine. Second gnathopod (Figure 14): slightly larger than first; coxal plate with 3 anteroventral setae, and 2 ventral setae; carpus length $2.4 \times$ width, trapezoidal, with posterior setae ranked in 5 transverse bands; propodus subrectangular, moderate size, length 1.8 $x$ width, with 2 lateral robust setae, 1 medial robust seta, and 3 additional lateral elongate setae, palmar angle weakly oblique, smooth, dactyl not reaching to palmar corner, with a single recumbent inner tooth spine. Pereopods (Figure 14, 16): pereopod 3 subequal in length to the second gnathopod; coxa with 4 anterior setae, no long ventral setae, 1 short ventral seta, 1 seta at the posteroventral corner; carpus moderately setose posteriorly; pereopod 4 subequal in length with pereopod 3, coxa anteroventral margin with 2 setae, posteroventral margin with 1 seta, ventral margin with 4 setae, posterior margin moderately emarginate, carpus moderately setose posteriorly; coxa 5 bearing 1 seta on anterior lobe, and 1 setae on the posterior lobe, basis with short slender posterior setae, bearing short and long robust anterior setae, moderately lobate posteroventrally; pereopod 6 coxa bearing no setae on anterior lobe; basis moderately expanded, bearing short and long robust anterior setae and short slender anterior setae, moderately lobate posteroventrally; pereopod 7 coxa with 1 seta on the posterior lobe; basis bearing short and long robust anterior setae and short slender anterior setae, moderately lobate posteroventrally; bases of pereopods equally expanded. Epimera: first epimeron with 1 slender seta on the posterior margin, posterior margin straight, posteroventral corner rounded; second epimeron with 2 robust setae on the anteroventral margin, posterior margin straight, posteroventral corner rounded; third epimeron with 3 robust setae on the anteroventral margin, without slender setae on ventral margin, posterior margin straight, posteroventral corner rounded, without spine or seta. Pleon: dorsolateral margin of pleonite 1 with 2 feeble setae, of pleonite 2 with 1 feeble seta, of pleonite 3 with 1 feeble seta and no distolateral robust setae. Pleopods (Figure 16): first, second and third pleopods with 1 accessory retinacula. Urosomites: first urosomite bearing 1 distolateral slender seta, and 2 distolateral robust setae; urosomite 2 with no distolateral slender setae, and 3 distolateral robust setae. First uropod (Figure 16): peduncle length $1.3 \times$ the length of the inner ramus, with a strong row of 4 dorsolateral robust setae, and 4 dorsomedial robust setae; outer ramus with 2 dorsolateral robust setae, and 3 dorsomedial robust setae; inner ramus with 2 dorsolateral robust setae, 3 dorsomedial robust setae, and 5 apical robust setae. Second uropod (Figure 16): $0.6 \times$ length of uropod 1, peduncle about $1.1 \times$ length of inner ramus, with 1 apicolateral, 1 dorsomedial, and 1 apicomedial robust setae; inner ramus with 2 dorsolateral, 2 dorsomedial, and 4 apical robust setae; outer ramus with 2 dorsolateral, 3 dorsomedial, and 5 apical robust setae. Third uropod (Figure 16): extending beyond uropods 1 and 2 in intact specimen, $0.7 x$ length of uropod 1; peduncle length $0.4 \times$ outer ramus, shorter than, $0.7 \mathrm{x}$, urosomite three, with 1 apicolateral robust seta, and no apicolateral slender setae, with no dorsomedial robust setae, and 2 dorsomedial slender setae, with no apicomedial robust setae, no apicomedial slender setae, and with 1 mediodistal robust setae; inner ramus length $0.5 \mathrm{x}$ outer ramus; outer ramus proximal article setae arranged laterally and medially in transverse bands, with 3 lateral and 3 medial transverse bands of robust setae, with no medial transverse bands of mixed robust and small setae, 5 apicolateral robust 


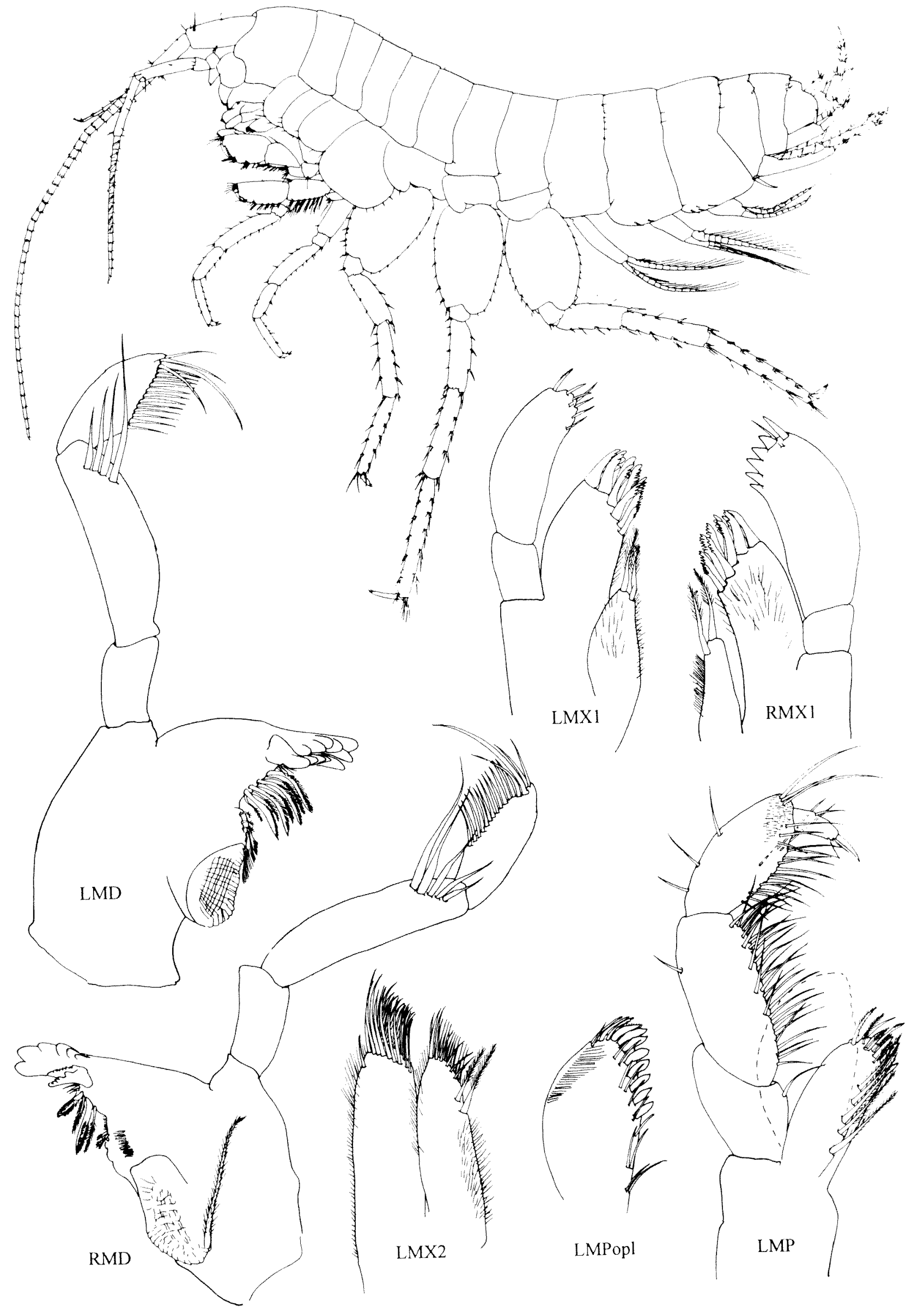

Figure 13 Chydaekata breviclava sp. nov. holotype, male 'a' $5 \mathrm{~mm}$, whole animal and mouthparts. 


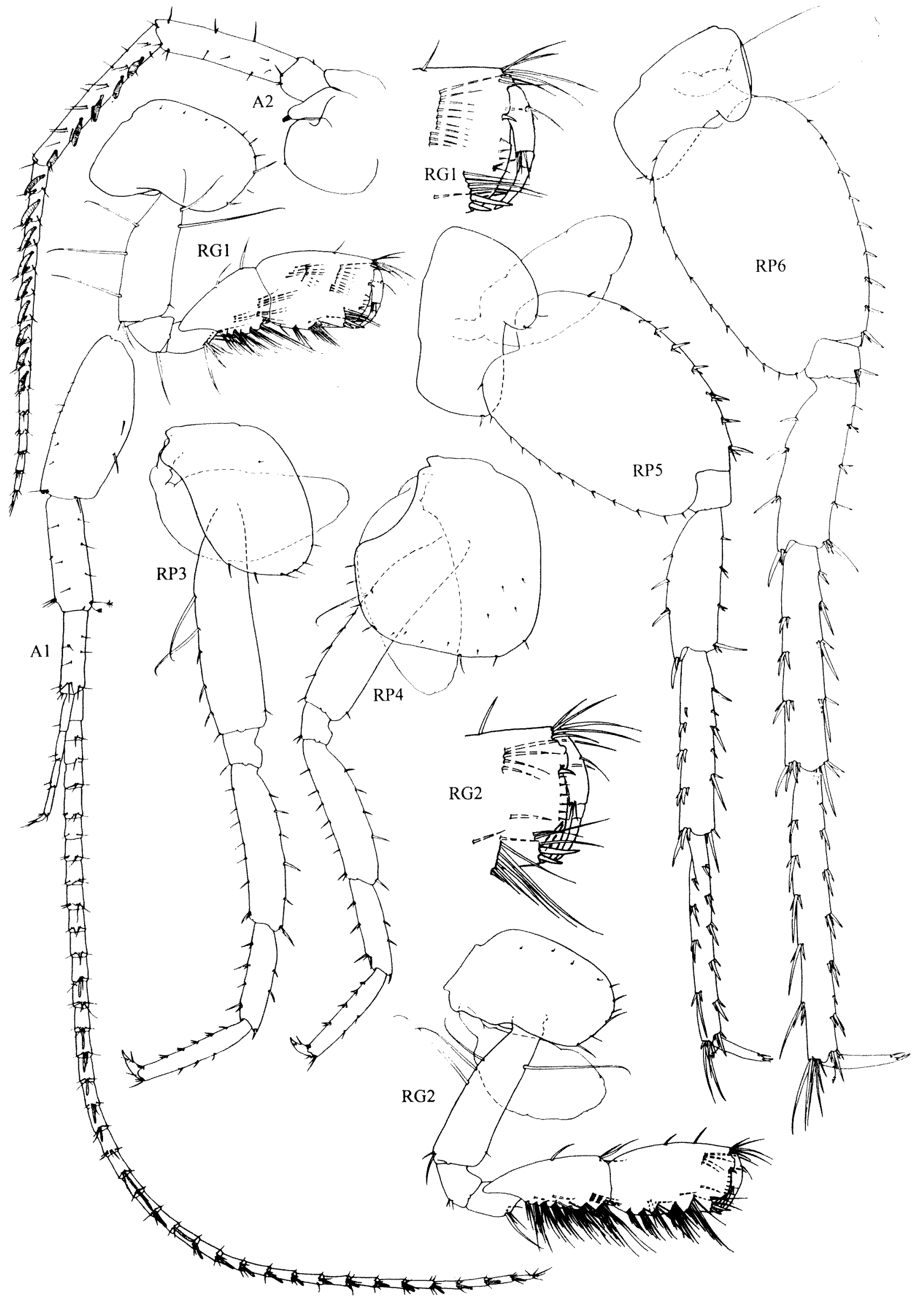

Figure 14 Chydaekata breviclava sp. nov. holotype, male 'a' $5 \mathrm{~mm}$, antennae, gnathopods 1-2, pereopods 3-6. 


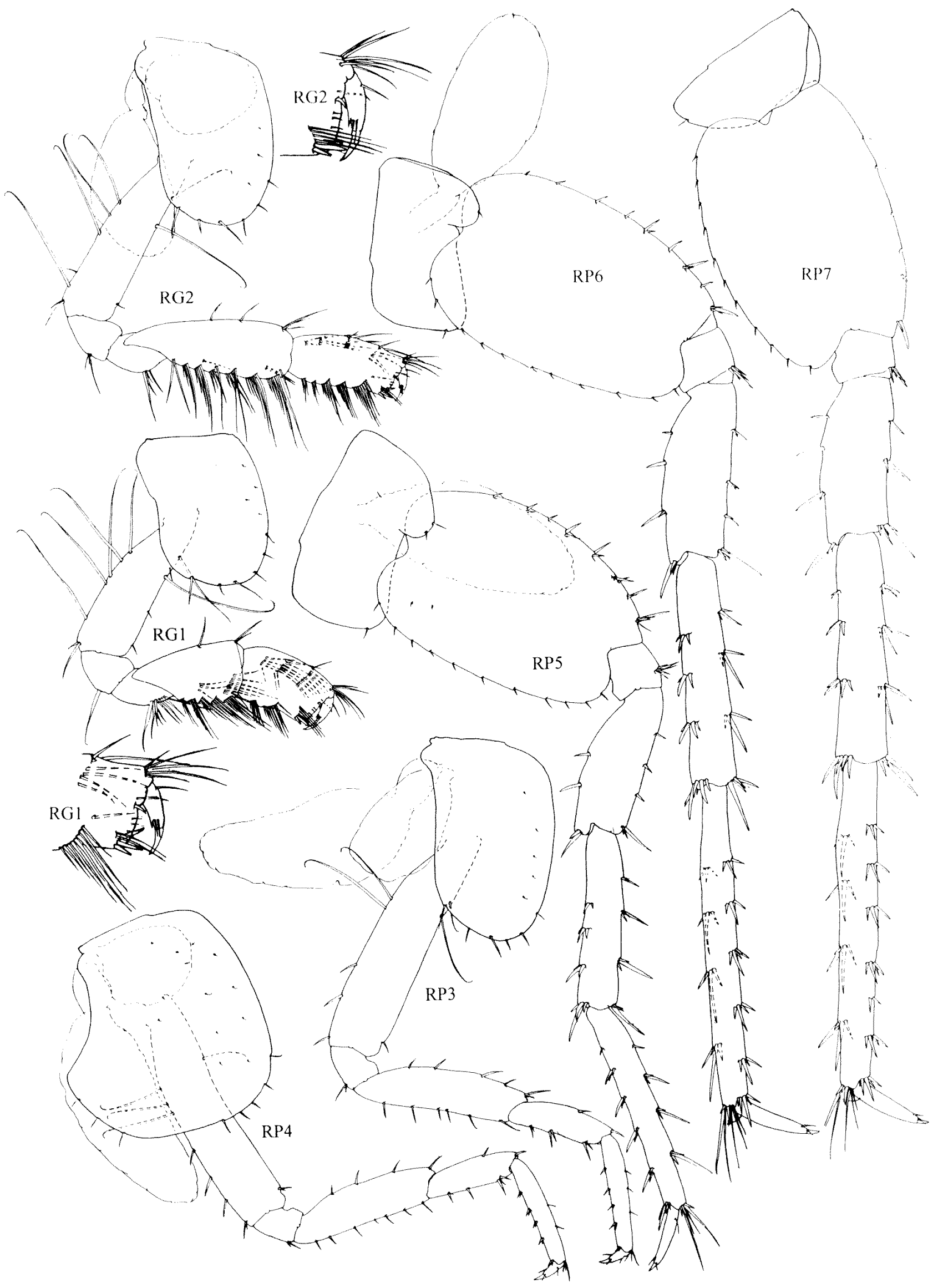

Figure 15 Chydackata breviclava sp. nov. allotype, female ' $b$ ' $6 \mathrm{~mm}$, gnathopods and pereopods. 

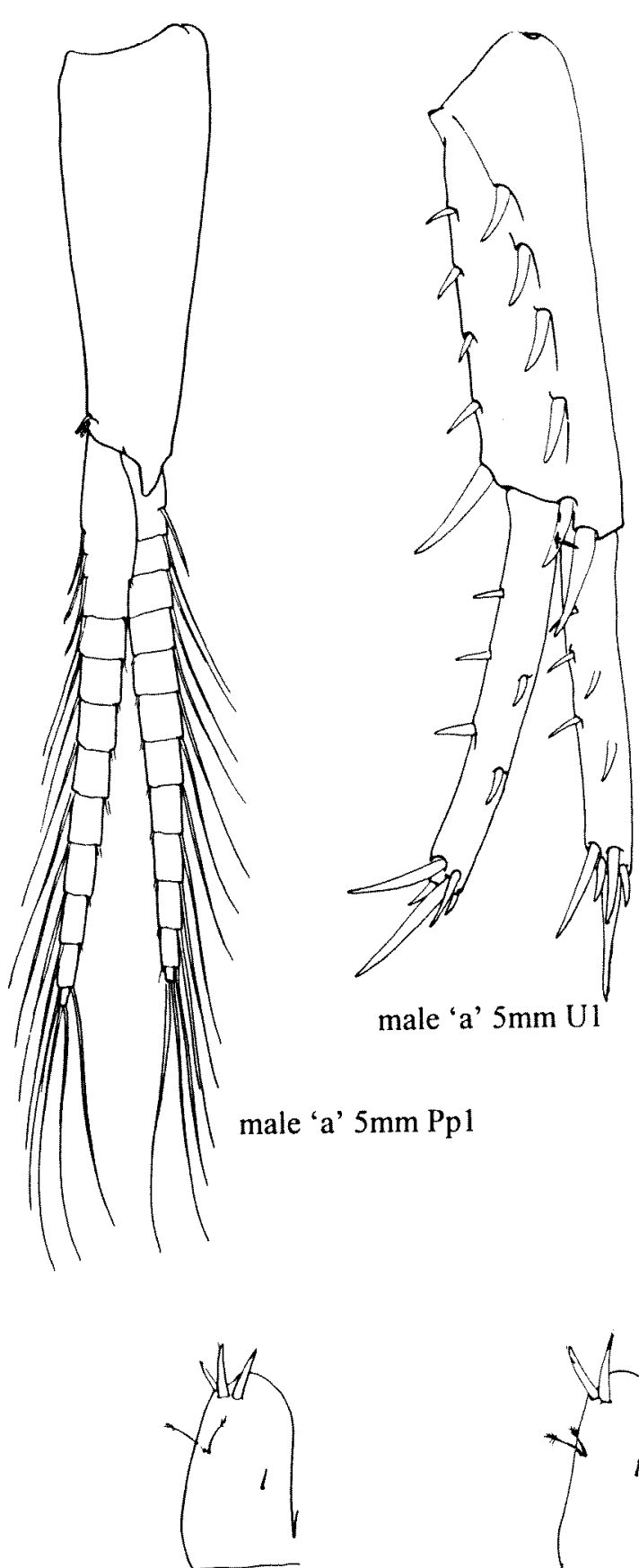

female ' $b$ ' $6 \mathrm{~mm} \mathrm{~T}$

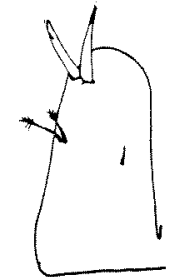

male 'a' $5 \mathrm{~mm}$ T

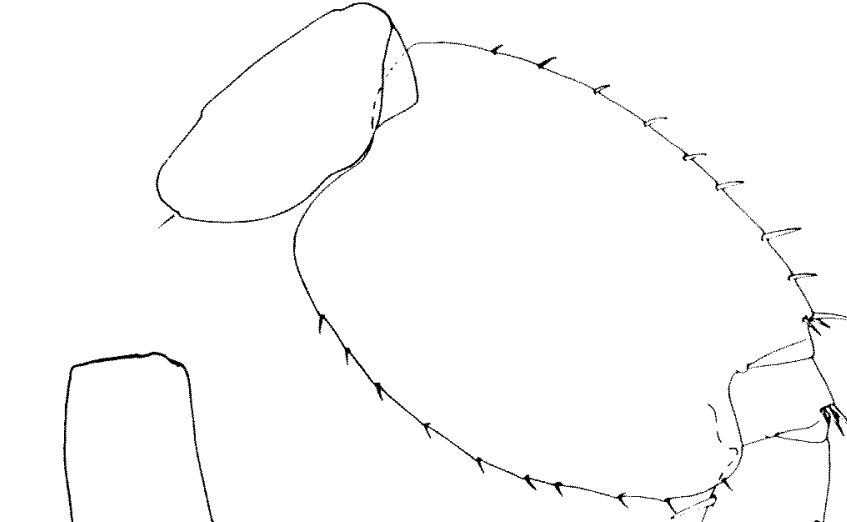

male 'a' $5 \mathrm{~mm}$ pereopod 7

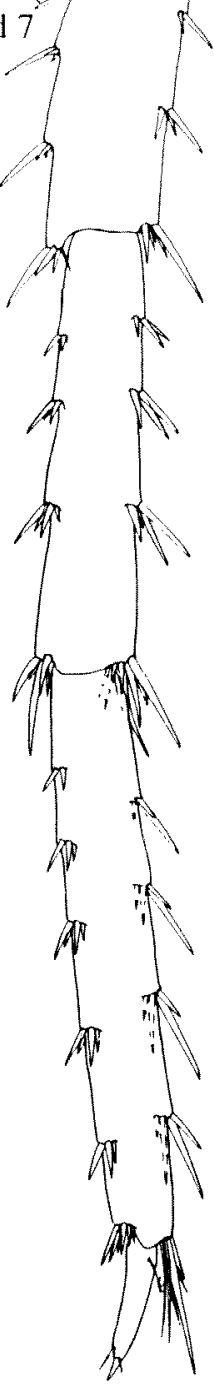

Figure 16 Chydaekata breviclava sp. nov. holotype, male 'a' $5 \mathrm{~mm}$. pleopod 1, uropods 1-3, telson, pereopod 7. Allotype female ' $b$ ' $6 \mathrm{~mm}$, telson.

setae, no apicolateral small setae, 6 apicomedial robust setae, no apicomedial small setae, no apicomedial long slender setae; distal article short, with no apical robust setae, and 3 apical slender setae; inner ramus with 2 medial robust setae, no apical robust setae, and 1 apical slender seta. Telson (Figure 16): shorter than, $0.9 \mathrm{x}$, urosomite 3; cleft $69 \%$, longer than broad, length $1.2 \times$ breadth; apices rounded and laterally notched, 3 subapical robust setae, apical penicillate setae absent; paired lateral penicillate setae at M0.5 from the telson base.

\section{Allotype (female, 'b' $6 \mathrm{~mm}$ )}

With the characteristics of the holotype except. Body: length $6 \mathrm{~mm}$. First antenna: without aesthetascs or calceoli. Second antenna: without calceoli. First gnathopod (Figure 15): coxa longer than male, similarly armed; carpus more elongate 
than male though similarly subtriangular, bearing 5 (versus 6) posterior translateral setal bands and 2 (versus 3 ) medio-facial bands; propodus narrower, less robust than male, tapering apically, with 2 (versus 3 ) posterior translateral setal bands, and similar to the male 3 mediofacial bands, but each with more setae, palm and dactyl similar. Second gnathopod (Figure 15): coxa longer than the male though similarly armed, bearing a moderately sized, round, naked oostegite, length about $0.5 x$ coxal plate; carpus longer and more slender than the male, bearing 7 (versus 8) posterior translateral setal bands and fewer medio-facial setae; propodus less robust than male, tapering apically, similarly armed posteriorly but 4 (versus 1) medio-facial setal bands, palm and dactyl similar to holotype. Pereopods (Figure 15). Pereopod three: coxa bearing a moderate size, paddle shaped, naked oostegite, length about $0.7 x$ coxal plate, otherwise similarly armed to holotype. Pereopod four: coxa bearing small, round, naked oostegite, 3 (versus 4) posterior ventral setae and 5 (versus 3 ) anterior ventral setae. Pereopod five: coxa lacking oostegite. Pereopod six: coxa anterior lobe bearing a single ventro-marginal seta (versus none), otherwise similar to the male. Pereopod seven: similar to the male. Telson (Figure 16): bearing 3 (versus 2) distolateral robust setae on either lobe.

\section{Relationships}

Chydaekata breviclava differs from other species of the genus in that: second antenna flagellum bearing calceoli on 9 articles; left first maxilla palp article 2 with 5 apical strong slender setae and 2 subapical facial strong slender setae; maxilliped outer plate with 4 apicolateral setae; second gnathopod dactyl not reaching to palmar corner; pereopods 4 coxa posteroventral margin with 1 seta, ventral margin with 4 setae; third uropod outer ramus proximal article with 5 apicolateral robust setae, and 6 apicomedial robust setae.

\section{Etymology}

From the Latin 'brevis' (short) and 'clavus' (nail), hence 'short nail', referring to the length of the dactyl of the propodus of the second gnathopod.

\section{Chydaekata transversa sp. nov.}

Figures 17-20

\section{Material Examined}

Holotype

o, 'a' $7 \mathrm{~mm}$, Newman bore field, WB23/4, Western Australia, Australia, 2319'S, 117 51'E, 22 July 1997, taken with haul net, W.F. Humphreys and S.M. Eberhard, BES 4817 (WAM C24661).
Allotype

Australia: Western Australia: $q$, ' b' $7.5 \mathrm{~mm}$, same data as holotype (WAM C24662).

\section{Paratypes}

Australia: Western Australia: $1 \sigma^{\circ}, c^{\prime} 6 \mathrm{~mm}, 1$, 'd' $7.5 \mathrm{~mm}$, and 10 other specimens, same data as holotype (WAM C24663).

\section{Diagnosis}

Second antenna: peduncle article 5 bearing 3 calceoli, flagellum 17 articulate, with calceoli on articles 1-11. Mandible: palp article 2 with a mediodistal row of 6 robust rastellate setae; article 3 with $12 \mathrm{D}$ and $4 \mathrm{E}$ setae apically. Left first maxilla: palp article 2 with 6 apical setae. Right first maxilla: palp apex with no articulated, and 4 fused broad based tooth setae. Maxilliped outer plate with a row of 6 slender naked, medial submarginal to disto-facial setae; a medial row of 7 submarginal to subapical robust, naked, tooth setae; 3 apicolateral setae. First gnathopod propodus: dactyl reaching to palmar corner, with a single recumbent inner tooth spine. Second gnathopod carpus: with posterior setae ranked in 7 transverse bands. Telson: cleft 79\%, bearing 3 subapical robust setae.

\section{Description}

\section{Holotype (male, ' $a$ ' $7 \mathrm{~mm}$ )}

Body (Figure 17): urosomites 1 and 2 without dorsolateral robust setae. First antenna (Figure 17): length $0.7 \times$ body, $1.8 \times$ second antenna; peduncle article 2 longest, with sparse setae; primary flagellum of 40 articles; accessory flagellum of 6 articles, reaching to article 6 of primary flagellum. Second antenna (Figure 17): length $0.4 \times$ body; peduncle length subequal to flagellum, article 5 bearing 3 calceoli, article 4 subequal with article 5 , articles 3-5 with sparse setation; flagellum 17 articulate, with sparse setation, bearing calceoli on articles 1 - 11. Left mandible (Figure 17): palp article 2 with a medio-distal row of 6 robust rastellate setae, article 3 with $12 \mathrm{D}$ and $4 \mathrm{E}$ setae, facially strongly setulose (pubescent); incisor with 6 teeth, lacinia mobilis with 5 teeth, and 1 plumose interraker seta; molar without pappose seta, with 4 penicillate hooked brushy basal setae, and no penicillate setules. Right mandible (Figure 17): palp article 2 with a medio-distal row of 6 robust rastellate setae, article 3 with $12 \mathrm{D}$ and $4 \mathrm{E}$ setae; incisor with 5 teeth, and 1 plumose interraker seta; molar without penicillate hooked brushy basal setae and few penicillate setules. Left first maxilla (Figure 17): palp article 2 with 4 apical and 1 subapical facial strong slender setae, with 1 apicomedial, no submarginal apicomedial and no ventrofacial apicomedial strong slender setae; outer plate with 10 robust setae -9 denticulate, 1 naked; inner plate 
subtriangular, facially and medially setulose (pubescent). Right first maxilla (Figure 17): palp apex with no articulated, 4 fused broad based tooth setae, and 1 subterminal apicolateral facial seta. Second maxilla (Figure 17): outer plate length $3.8 \times$ width, bearing distal long, curved rastellate setae or naked setae; apicomedial corner of inner plate with 2 weakly submarginal thick plumose/pappose setae. Maxilliped (Figure 17): inner plate length $2.3 \times$ width, extending to M0. 7 of the outer plate, bearing small setules on the lateral margin and lateroproximal face, 1 facial pappose seta at M0. 9 of its length, no medial pappose setae, with a row of 5 submarginal to subapical pappose setae, extending to a row of 5 similar subapical, and 2 apical setae, with no apicomedial, no mediodistal, and 3 apical naked tooth setae; outer plate long, length $2 \times$ width, distally setulose (pubescent), with a row of 6 slender naked, medial submarginal to distal facial setae, a medial row of 7 submarginal to subapical robust, naked, tooth setae and 3 apicolateral setae none naked, 3 pappose; palp second article strongly setose medially, third article naked laterally, moderately setose medially, with 3 facial, and 3 ventrofacial long strong setae basal to the dactyl, the apex moderately produced, setulate, with 2 long slender naked setae, and 1 dorsal accessory seta. First gnathopod (Figure 18): coxal plate with 5 anteroventral and 1 ventral setae; merus without posterior hump; carpus of moderate length, $1.6 \mathrm{x}$ width, subtriangular, posterior margin strongly setose, with setae ranked in 5 transverse bands; propodus subrectangular, small, length $1.7 \mathrm{x}$ width, posteroventral corner rounded, with 2 lateral and 1 medial robust setae, and 4 additional lateral elongate setae, palmar angle weakly oblique, smooth, dactyl reaching to palmar corner, with a single recumbent inner tooth spine. Second gnathopod (Figure 18): slightly larger than first; coxal plate with 3 anteroventral setae, and 1 ventral seta; carpus length $2.6 \times$ width, trapezoidal, with posterior setae ranked in 7 transverse bands; propodus subrectangular, small, length $2 \times$ width, with 2 lateral robust setae, 1 medial robust seta, and 2 additional lateral elongate setae, palmar angle transverse, smooth, dactyl reaching to palmar corner, with a single recumbent inner tooth spine. Pereopods (Figure 18): third pereopod longer than the second gnathopod, coxa with 2 anterior setae, no long ventral setae, 2 short ventral setae, 1 seta at the posteroventral corner, carpus weakly setose posteriorly; pereopod 4 subequal in length with pereopod 3, coxa anteroventral margin with 1 seta, posteroventral margin with 3 setae, ventral margin with 2 setae, posterior margin moderately emarginate; carpus weakly setose posteriorly; coxa 5 bearing 1 seta on anterior lobe and 1 seta on the posterior lobe; basis of pereopod 5 with short slender posterior setae, bearing short robust and short slender anterior setae, moderately lobate posteroventrally; pereopod 6 coxa bearing no setae on anterior lobe, basis moderately expanded, bearing short robust anterior setae, moderately lobate posteroventrally; bases of pereopods equally expanded. Epimera: first epimeron with 1 slender seta on the posterior margin; posterior margin straight, posteroventral corner rounded; second epimeron with 2 robust setae on the anteroventral margin, posterior margin straight, posteroventral corner rounded; third epimeron with 3 robust setae on the anteroventral margin, without slender setae on ventral margin, posterior margin straight, posteroventral corner rounded, without spine or seta. Pleon: dorsolateral margin of pleonite 1 with 3 feeble setae, of pleonite 2 with 2 feeble setae, of pleonite 3 with 2 feeble setae, and no distolateral robust setae. Pleopods (Figure 20): first pleopod and second pleopods with 1 accessory retinacula, and third pleopod with no accessory retinacula. Urosomites: first urosomite bearing no distolateral slender setae and 1 distolateral robust seta; second urosomite with no distolateral slender setae, and 3 distolateral robust setae. First uropod (Figure 20): peduncle length $1.3 \times$ the length of the inner ramus, with a strong row of 4 dorsolateral robust setae, and 4 dorsomedial robust setae; outer ramus with 3 dorsolateral and 3 dorsomedial robust setae; inner ramus with 2 dorsolateral, 4 dorsomedial and 5 apical robust setae. Second uropod (Figure 20): $0.6 \mathrm{x}$ length of uropod 1 , peduncle about $1.2 \times$ length of inner ramus, with 1 apicolateral, 1 dorsomedial, and 1 apicomedial robust setae; inner ramus with 1 dorsolateral, 2 dorsomedial, and 5 apical robust setae; outer ramus with 2 dorsolateral, 3 dorsomedial, and 5 apical robust setae. Third uropod (Figure 20): extending beyond uropods 1 and 2 in intact specimen, $0.8 \times$ length of uropod 1 ; peduncle length $0.3 \mathrm{x}$ outer ramus, shorter than, $0.9 \mathrm{x}$, urosomite three, with 1 apicolateral robust seta, and no apicolateral slender setae, no dorsomedial robust setae, and 2 dorsomedial slender setae, with no apicomedial robust setae, and no apicomedial slender setae, with 1 mediodistal robust seta; inner ramus length $0.4 \times$ outer ramus; outer ramus proximal article setae arranged laterally and medially in transverse bands or arranged medially singly with 3 lateral transverse bands of robust setae, 1 medial transverse band of robust setae, no medial transverse bands of mixed robust and small setae, 1 medial robust seta, 4 apicolateral robust setae, no apicolateral small setae, 4 apicomedial robust setae, no apicomedial small setae, and no apicomedial long slender setae; distal article short, with no apical robust setae and 3 apical slender setae; inner ramus with 2 medial robust setae, no apical robust setae, and 1 apical slender seta. Telson (Figure 20): shorter than, $0.9 \mathrm{x}$, urosomite 3; cleft $79 \%$; shorter than broad, length $0.9 \times$ breadth; apices 


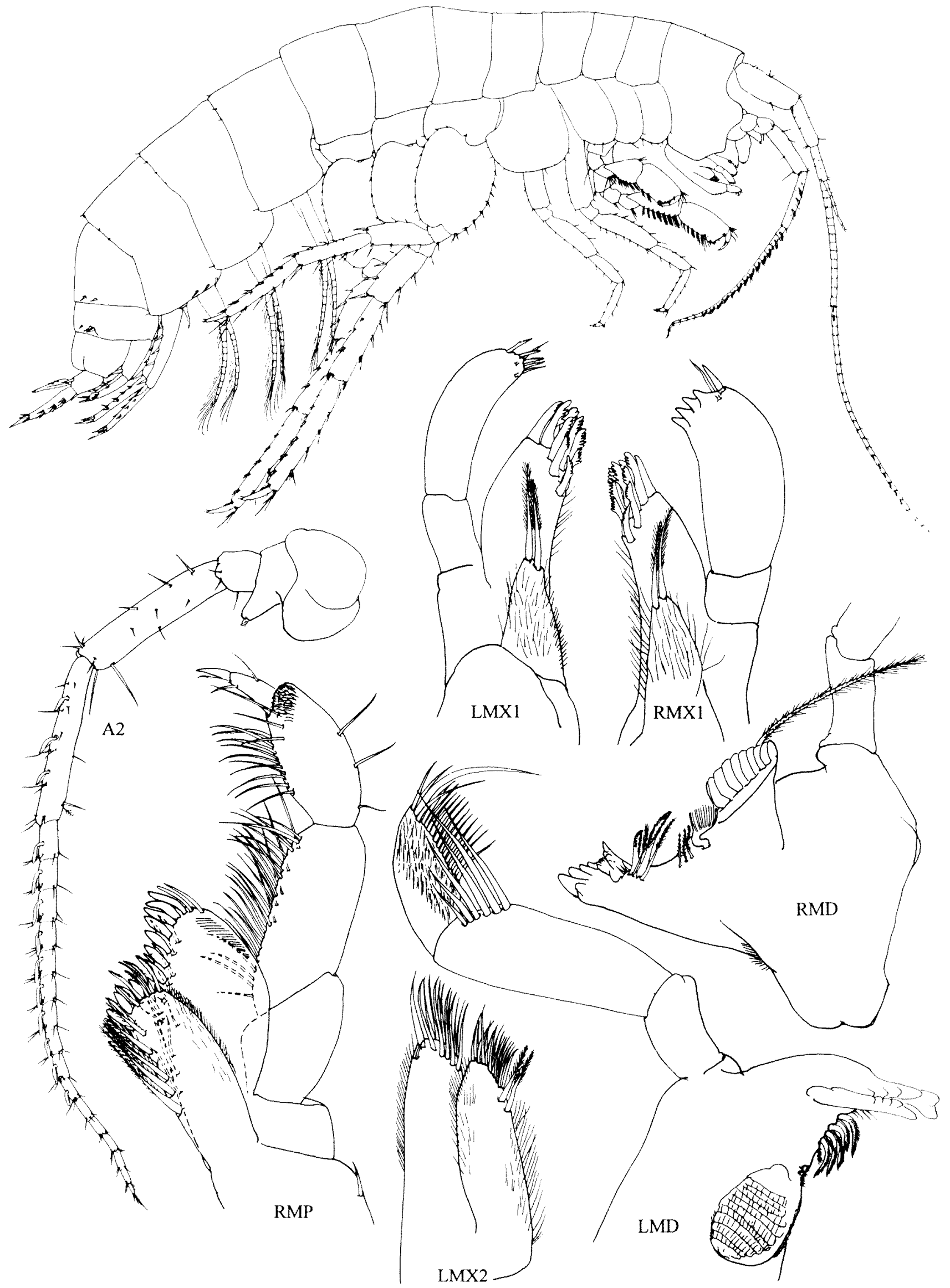

Figure 17 Chydaekata transversa sp. nov. holotype, male 'a' $7 \mathrm{~mm}$, whole animal, antenna 2 and mouthparts. 


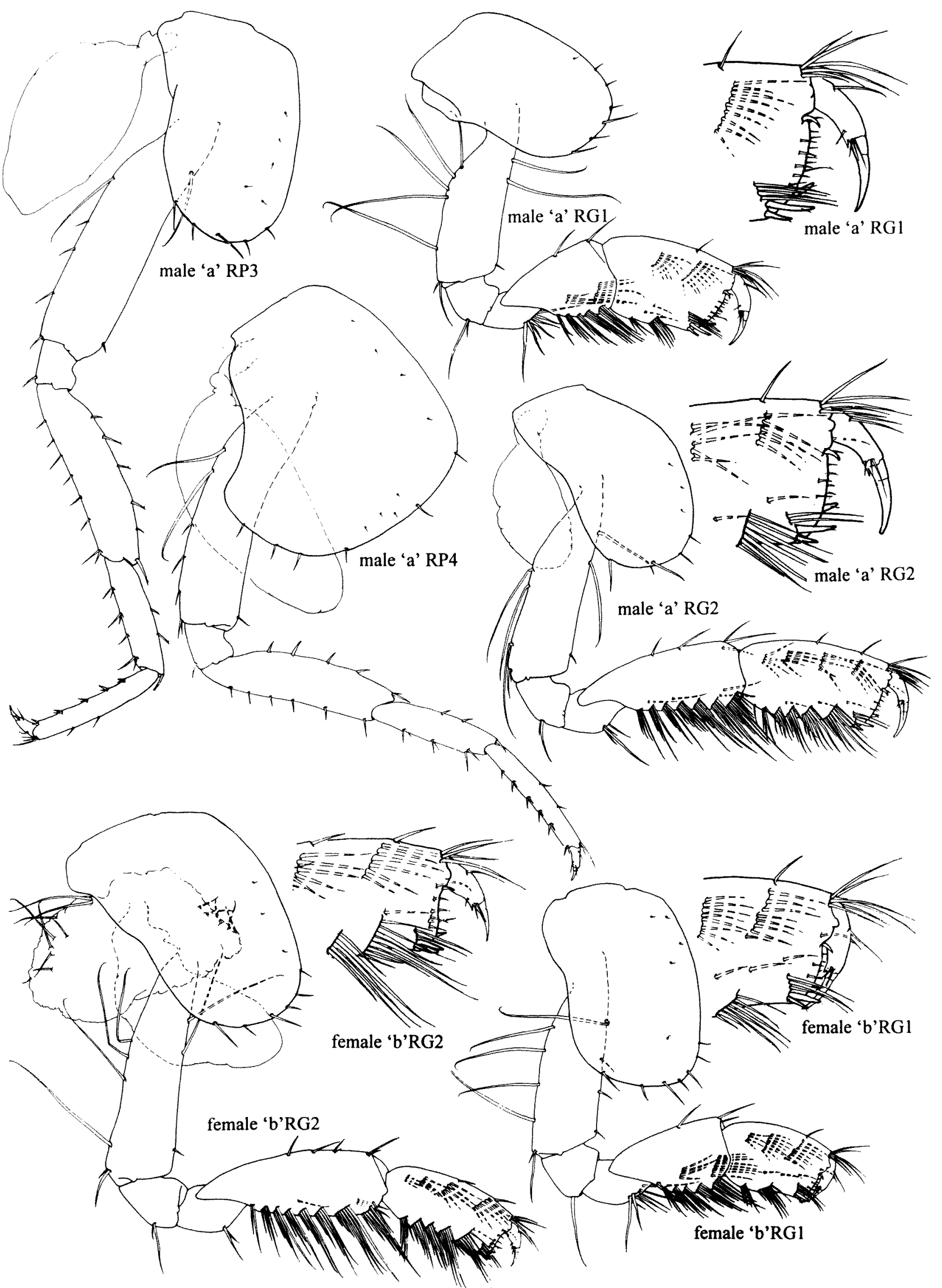

Figure 18 Chydaekata transversa sp. nov. holotype, male 'a' $7 \mathrm{~mm}$, gnathopods 1-2 and pereopods 3-4. Allotype female ' $\mathrm{b}$ ' $7.5 \mathrm{~mm}$, gnathopods $1-2$. 


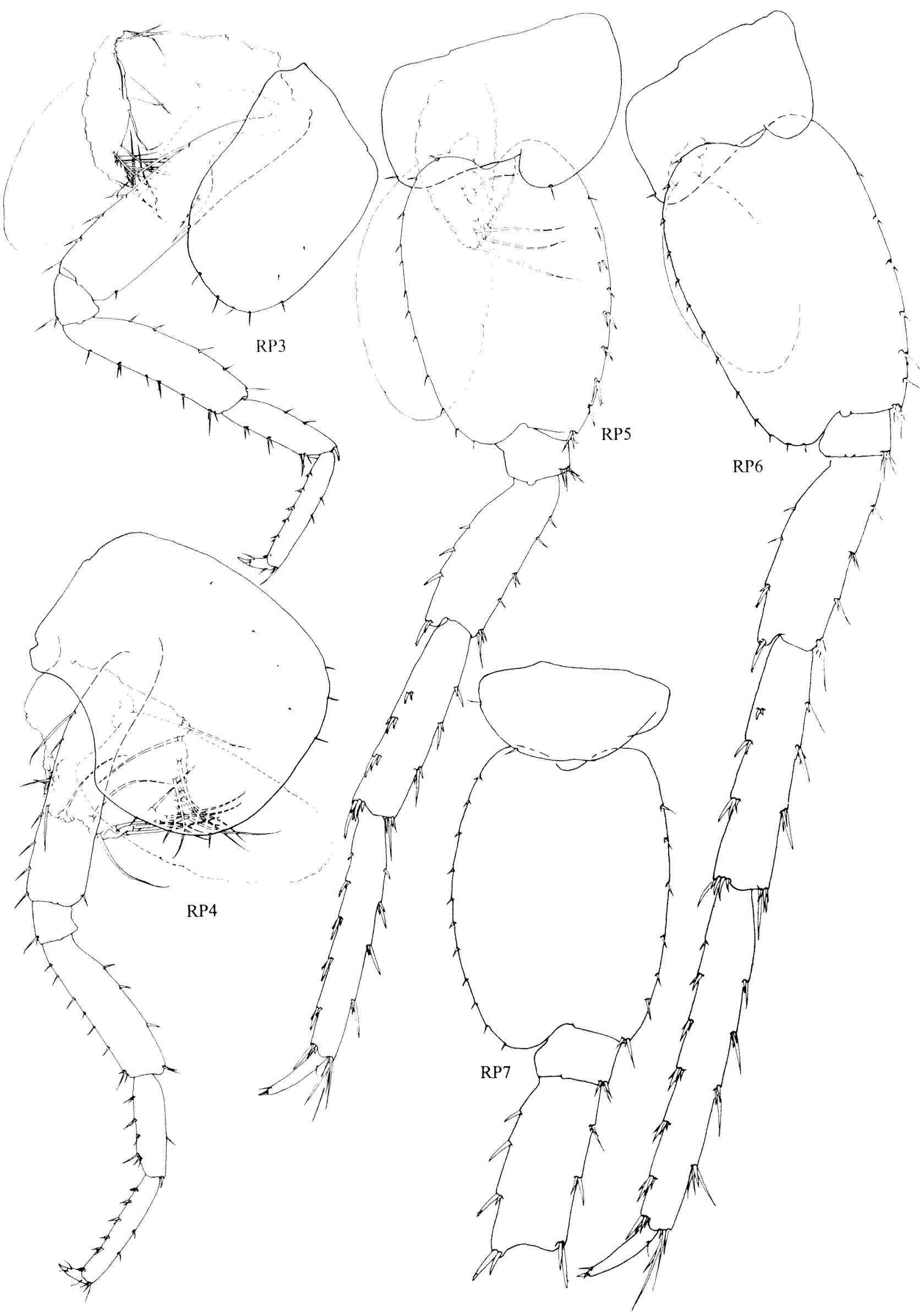

Figure 19 Chydaekata transversa sp. nov. allotype, female ' $\mathrm{b}$ ' $7.5 \mathrm{~mm}$, pereopods 3-7. 

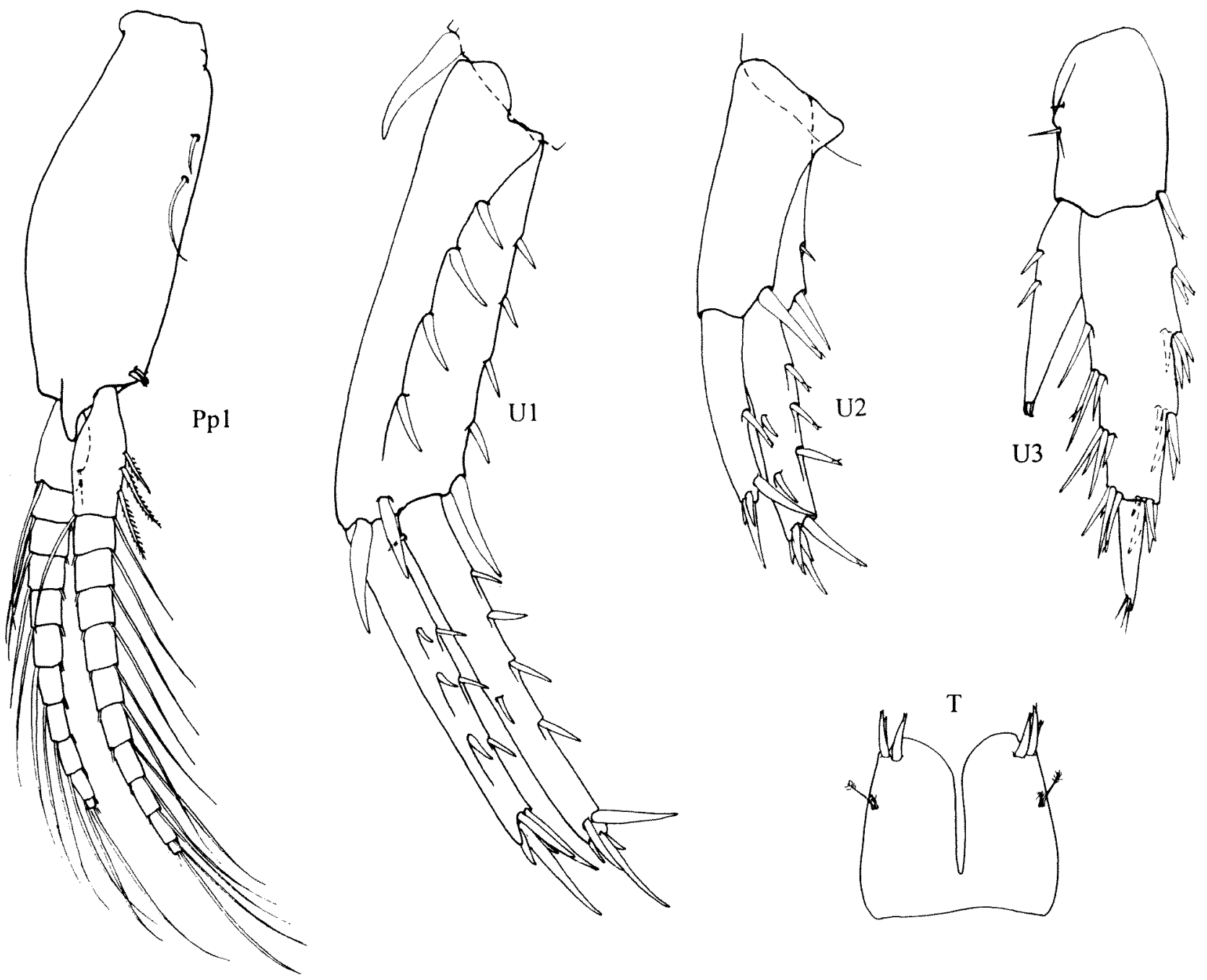

Figure 20 Chydaekata transversa sp. nov. holotype, male 'a' $7 \mathrm{~mm}$, pleopod 1, uropods 1-3, telson.

rounded and laterally notched, 3 subapical robust setae, and no subapical slender setae, with 1 apical penicillate seta, and paired lateral penicillate setae at M0.6 from the telson base.

\section{Allotype (female $7.5 \mathrm{~mm}$ )}

With the characteristics of the holotype except. Body: length $7.5 \mathrm{~mm}$. First gnathopod (Figure 17): less robust than male; coxa bearing 1 extra marginal seta; propodus narrower than in male, bearing 3 mediofacial setal bands. Second gnathopod (Figure 17): coxa bearing an additional ventral and anterior setae, with a large, irregular, marginally setose oostegite, length about $0.9 x$ coxal plate; carpus proportionally longer than the male, and bearing 8 posterior transverse setal bands; propodus with 5 posterior setal bands, but 4 medio-facial bands as in the male. Pereopods (Figure 18). Pereopod three: coxa bearing a large, ovate marginally setose and apically involute oostegite, length about equal to the length of the coxal plate; with an additional anterior marginal seta. Pereopod four: coxa bearing a large, irregular, marginally setose oostegite, length about
$0.8 x$ coxal plate. Pereopod five: coxa with an additional seta on the ventral margin of the anterior lobe; bearing a moderately long, irregularly ovate, apically setose oostegite, length about $0.7 x$ length of the coxal plate, about $0.9 x$ length of oostegite of coxa 3. Pereopod seven; coxa bearing an additional posterior ventral seta.

\section{Relationships}

Chydaekata transversa differs from others of the genus in: second antenna flagellum bearing calceoli on 1 article only; left mandible accessory blade with 1 plumose inter-raker seta; right mandible accessory blade with 1 plumose interraker seta; maxilliped inner plate bearing small setules on the lateral margin and latero-proximal face; first gnathopod coxal plate with 5 anteroventral setae; pereopod coxa 7 bearing no setae on the posterior lobe; first uropod outer ramus with 3 dorsolateral robust setae, inner ramus with 4 dorsomedial robust setae.

\section{Etymology}

From the Latin 'transversus' (crosswise), referring 
to the almost transverse palmar angle of the propodus of the first gnathopod.

\section{Chydaekata diagonalis sp. nov Figures 21-24}

\section{Material Examined}

Holotype

8, 'a' $6 \mathrm{~mm}$, Newman bore field, WB23/4,

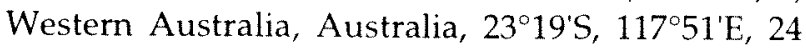
July 1997 taken with trap, W.F. Humphreys and S.M. Eberhard, BES 4839 (WAM C24664).

\section{Allotype}

Australia: Western Australia: $q$, ' b' $8 \mathrm{~mm}$, same data as holotype (WAM C24665).

\section{Paratypes}

Australia: Western Australia: 50 specimens, mainly juveniles, same data as holotype (WAM C24666).

\section{Diagnosis}

Second antenna: peduncle article 5 bearing 2 calceoli, flagellum 15 articulate, with calceoli on articles $1-8$. Mandible: palp article 2 with a mediodistal row of 7 robust rastellate setae; article 3 with $13 \mathrm{D}$ and $4 \mathrm{E}$ setae apically. Left first maxilla: palp article 2 with 7 apical setae. Right first maxilla: palp apex with 3 articulated, and 2 fused broad based tooth setae. Maxilliped outer plate with a row of 5 slender naked, medial submarginal to disto-facial setae; a medial row of 8 submarginal to subapical robust, naked, tooth setae; 2 apicolateral setae. First gnathopod propodus: dactyl reaching to palmar corner, with a single recumbent inner tooth spine. Second gnathopod carpus: with posterior setae ranked in 7 transverse bands. Telson: cleft $78 \%$, bearing 2 subapical robust setae.

\section{Description}

Holotype (male, 'a' $6 \mathrm{~mm}$ )

Body (Figure 21): urosomite 1 bearing 2 dorsolateral robust setae, urosomite 2 bearing 3 dorsolateral robust setae. First antenna (Figure 21): length $0.7 \times$ body, $1.9 \times$ second antenna; peduncle article 1 longest, with sparse setae; primary flagellum of 39 articles; accessory flagellum of 5 articles, reaching to article 7 of primary flagellum. Second antenna (Figure 21): length $0.4 \times$ body; peduncle length subequal to flagellum, article 5 bearing 2 calceoli, article 4 subequal with article 5 , articles 3-5 with sparse setation; flagellum 15 articulate, with sparse setation, bearing calceoli on articles 1-8. Left mandible (Figure 21): palp article 2 with a medio-distal row of 7 robust rastellate setae, article 3 with $13 \mathrm{D}$ and $4 \mathrm{E}$ setae, facially strongly setulose (pubescent); incisor with 5 teeth, lacinia mobilis with 4 teeth, and 4 plumose interraker setae; molar bearing pappose seta, with 2 penicillate hooked brushy basal setae. Right mandible (Figure 21): palp article 2 with a mediodistal row of 7 robust rastellate setae, article 3 with $11 \mathrm{D}$ and $4 \mathrm{E}$ setae; incisor with 5 teeth, and 2 plumose interraker setae; molar without penicillate hooked brushy basal setae, and few penicillate setules. Left first maxilla (Figure 21): palp article 2 with 4 apical and 1 subapical facial strong slender setae, with 1 apicomedial and 1 submarginal apicomedial setae; outer plate with 10 robust setae - 10 denticulate, none naked; inner plate subtriangular, facially and medially setulose (pubescent). Right first maxilla (Figure 21): palp apex with 3 articulated and 2 fused broad based tooth setae, and 1 subterminal apicolateral facial seta. Second maxilla (Figure 21): outer plate length $4 \mathrm{x}$ width, bearing distal long, curved naked setae; apicomedial corner of inner plate with 2 weakly submarginal thick plumose/pappose setae Maxilliped (Figure 21): inner plate length $2.5 \times$ width, extending to M0.6 of the outer plate, bearing small setules on the lateral margin and medioproximal face, no facial pappose setae, no medial pappose setae, with a row of 5 submarginal to subapical pappose setae, extending to a row of 4 similar subapical, and 1 apical setae, with 1 apicomedial and 3 apical naked tooth setae; outer plate long, length $2 \times$ width, distally setulose (pubescent), with a row of 5 , slender naked, medial submarginal to distal facial setae, a medial row of 8 submarginal to subapical robust, naked, tooth setae, and 2 apicolateral setae -1 naked, and 1 pappose; palp, second article strongly setose medially, third article sparsely setose laterally, moderately setose medially, with 3 facial, and 2 ventrofacial long strong setae basal to the dactyl, the apex moderately produced, setulate, with 2 long slender naked setae, and 1 dorsal accessory setae. First gnathopod (Figure 22): coxal plate with 3 anteroventral and 1 ventral setae; merus bearing posterior hump; carpus of moderate length, $1.6 \mathrm{x}$ width, subtriangular, posterior margin with setae ranked in 5 transverse bands; propodus subrectangular, moderate size, length equal to width, posteroventral corner rounded, with 2 lateral and 1 medial robust setae, and 4 additional lateral elongate setae, palmar angle slightly oblique, smooth, dactyl reaching to palmar corner, with a single recumbent inner tooth spine. Second gnathopod (Figure 22): subequal in size with first; coxal plate with 3 anteroventral and 1 ventral setae; carpus length $2.7 \times$ width, trapezoidal, with posterior setae ranked in 7 transverse bands; propodus subrectangular, large, length $2.3 \times$ width, with 2 lateral and 1 medial robust setae, and 3 additional lateral elongate setae, palmar 
angle weakly oblique, smooth, dactyl reaching beyond palmar corner, with a single recumbent inner tooth spine. Pereopods (Figures. 22-23): pereopod 3 longer than the second gnathopod; coxa with 3 anterior setae, no long ventral setae, 1 short ventral seta, 1 seta at the posteroventral corner; carpus weakly setose posteriorly; pereopod 4: shorter than P3; coxa anteroventral margin with 3 setae, posteroventral margin with 4 setae, ventral margin with 2 setae, posterior margin moderately emarginate; carpus weakly setose posteriorly; coxa 5 bearing 2 setae on anterior lobe, and 1 seta on the posterior lobe; basis of pereopod 5 with short slender posterior setae, bearing short robust anterior setae or bearing long robust anterior setae, moderately lobate posteroventrally; pereopod 6 coxa bearing 1 seta on anterior lobe; basis moderately expanded, bearing short robust anterior setae or bearing long robust anterior setae, moderately lobate posteroventrally; pereopod 7 coxa with 2 setae on the posterior lobe; basis bearing short robust anterior setae or bearing long robust anterior setae, moderately lobate posteroventrally; bases of pereopods expanded unequally, basis of pereopod 7 most expanded, basis of pereopod 6 least expanded. Epimera: first epimeron with 1 slender seta on the posterior margin; posterior margin sinuous, posteroventral corner rounded; second epimeron with 4 robust setae on the anteroventral margin, posterior margin straight, posteroventral corner rounded; third epimeron with 4 robust setae on the anteroventral margin, without slender setae on ventral margin, posterior margin straight, posteroventral corner rounded, without spine or seta. Pleon: dorsolateral margin of pleonite 1 with 2 feeble setae of pleonite 2 with 5 feeble setae, of pleonite 3 with 4 feeble setae, and no distolateral robust setae. Pleopods (Figure 24): first pleopod, second pleopod and third pleopods with 1 accessory retinacula. Urosomites: first urosomite bearing 1 distolateral slender seta and 2 distolateral robust setae; second urosomite with no distolateral slender setae, and 3 distolateral robust setae. First uropod (Figure 24): peduncle length 1.3 $x$ the length of the inner ramus, with a strong row of 3 dorsolateral robust setae, and 3 dorsomedial robust setae; outer ramus with 2 dorsolateral robust setae, and 2 dorsomedial robust setae; inner ramus with 2 dorsolateral robust setae, 3 dorsomedial robust setae, and 5 apical robust setae. Second uropod (Figure 24): $0.6 \times$ length of uropod 1, peduncle about equal to length of inner ramus, with 1 apicolateral, 1 dorsomedial, and 1 apicomedial robust setae; inner ramus with 1 dorsolateral, 1 dorsomedial, and 5 apical robust setae; outer ramus with 2 dorsolateral, 3 dorsomedial, and 5 apical robust setae. Third uropod (Figure 24): extending beyond uropods 1 and 2 in intact specimen, $0.7 \times$ length of uropod 1 ; peduncle length $0.4 \times$ outer ramus, shorter than, $0.8 \times$, urosomite three, with 1 apicolateral robust seta and no apicolateral slender setae, with no dorsomedial robust setae, no dorsomedial slender setae, no apicomedial robust setae, no apicomedial slender setae, and with 1 mediodistal robust seta; inner ramus length $0.5 \mathrm{x}$ outer ramus; outer ramus proximal article setae arranged laterally and medially in transverse bands or arranged medially singly with 2 lateral and 2 medial transverse bands of robust setae, 1 medial robust seta, 4 apicolateral robust setae, no apicolateral small setae, 5 apicomedial robust setae, no apicomedial small setae, and no apicomedial long slender setae; distal article short, with no apical robust setae, and 3 apical slender setae; inner ramus with 2 medial robust setae, no apical robust setae, and 1 apical slender seta. Telson (Figure 24): shorter than, $0.8 \mathrm{x}$, urosomite 3 , cleft $78 \%$, shorter than broad, length $0.9 \times$ breadth; apices rounded and laterally notched, 2 subapical robust setae and no subapical slender setae; apical penicillate setae absent; paired lateral penicillate setae at M0. 6 from the telson base.

\section{Allotype (female, ' $b$ ' $8 \mathrm{~mm}$ )}

With the characteristics of the holotype except. Body: length $8 \mathrm{~mm}$. First antenna: without aesthetascs or calceoli. Second antenna: without calceoli. First gnathopod (Figure 23): coxa bearing additional ventral and anterior setae; carpus with 6 (ie an additional) posterior transverse setal bands; propodus bearing 3 (ie. one additional) medio-facial setal bands, and 2 (versus 3) lateral robust setae at the palmar corner. Second gnathopod (Figure 23): coxa bearing 2 additional anterior setae, and a very large, ovate, marginally setate and involute oostegite, length about $1.4 x$ length of coxal plate; carpus bearing 7 (versus 6) posterior transverse setal bands and a medio-facial band; propodus bearing 4 (versus 3) medio-facial setal bands. Pereopods (Figures. 23-4). Pereopod three: coxa bearing additional ventral and anterior setae, and a very large, teardrop shaped, marginally setose and involute oostegite, length about $1.4 x$ length of the coxal plate. Pereopod four: coxa bearing 5 additional marginal setae and large, ovate, marginally setose oostegite, length about equal to the coxal plate. Pereopod five: coxa bearing an additional posterior seta, with a moderately large, irregularly ovate, marginally setose, apically involute oostegite, length about $0.7 x$ coxal plate, about $0.5 x$ length of the oostegite of coxa 3 . Pereopod six: coxa without a ventro-marginal seta on the anterior lobe. Urosomites. Urosomite four: bearing 2 robust dorsal setae (ie. 1 additional). Urosomite five: bearing 1 dorsal and 2 dorsolateral setae (versus no and 3). Uropods (Figure 24). Third 


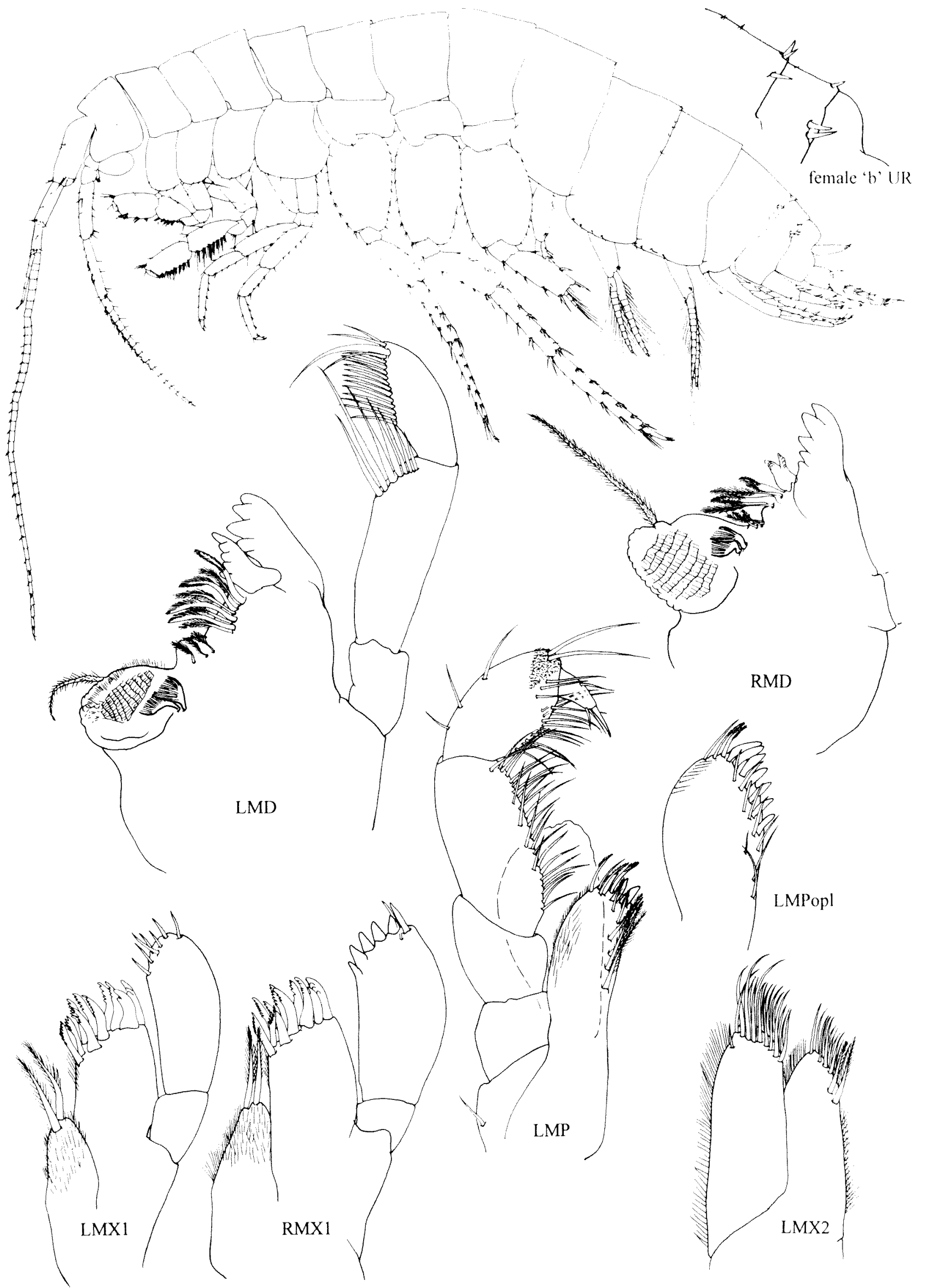

Figure 21 Chydaekata diagonalis sp. nov. holotype, male 'a' $6 \mathrm{~mm}$ whole animal and mouthparts. Allotype female 'b' 8 $\mathrm{mm}$, dorsal urosome. 


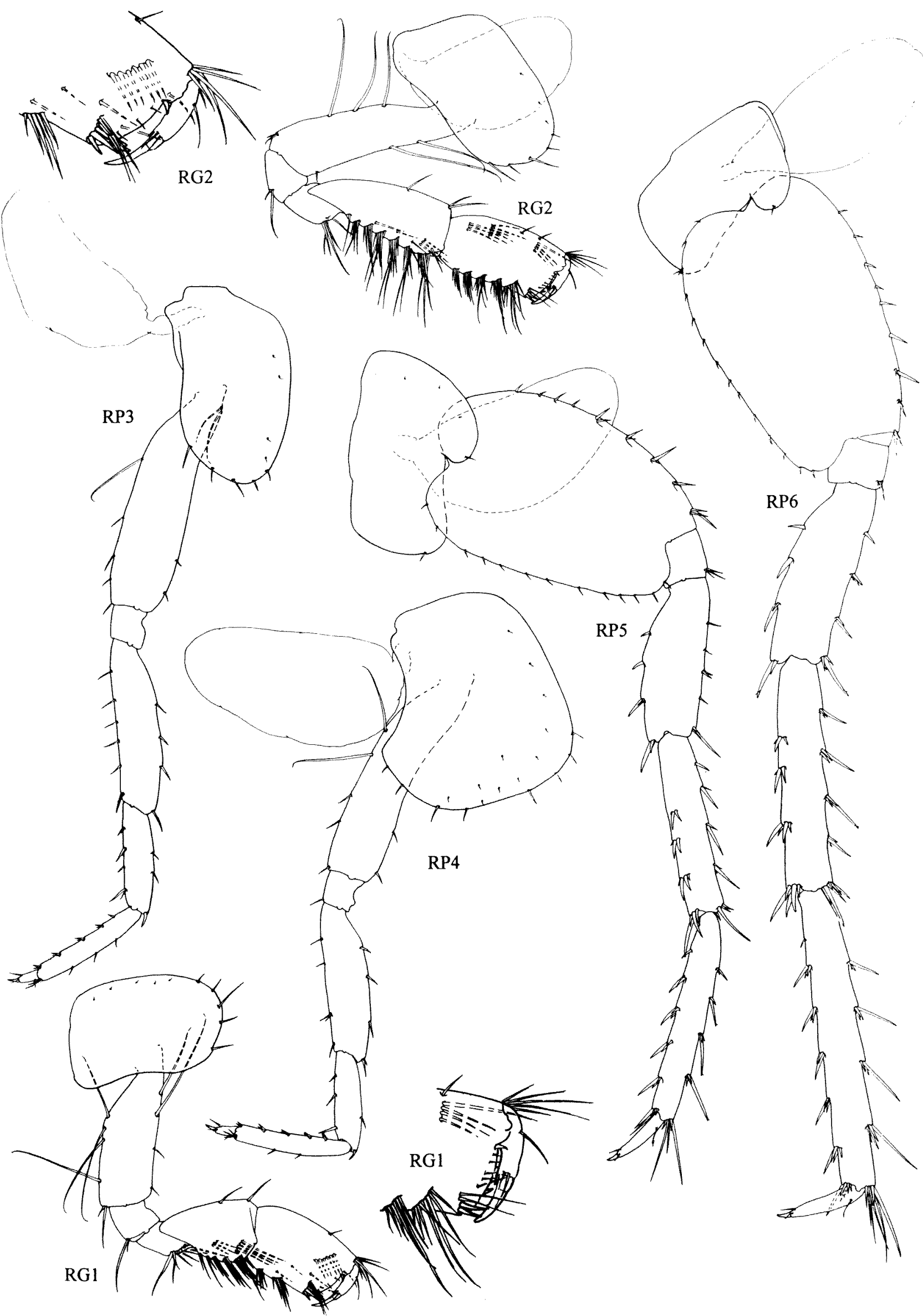

Figure 22 Chydaekata diagonalis sp. nov. holotype, male ' $a$ ' $6 \mathrm{~mm}$, gnathopods 1-2 and pereopods 3-6. 


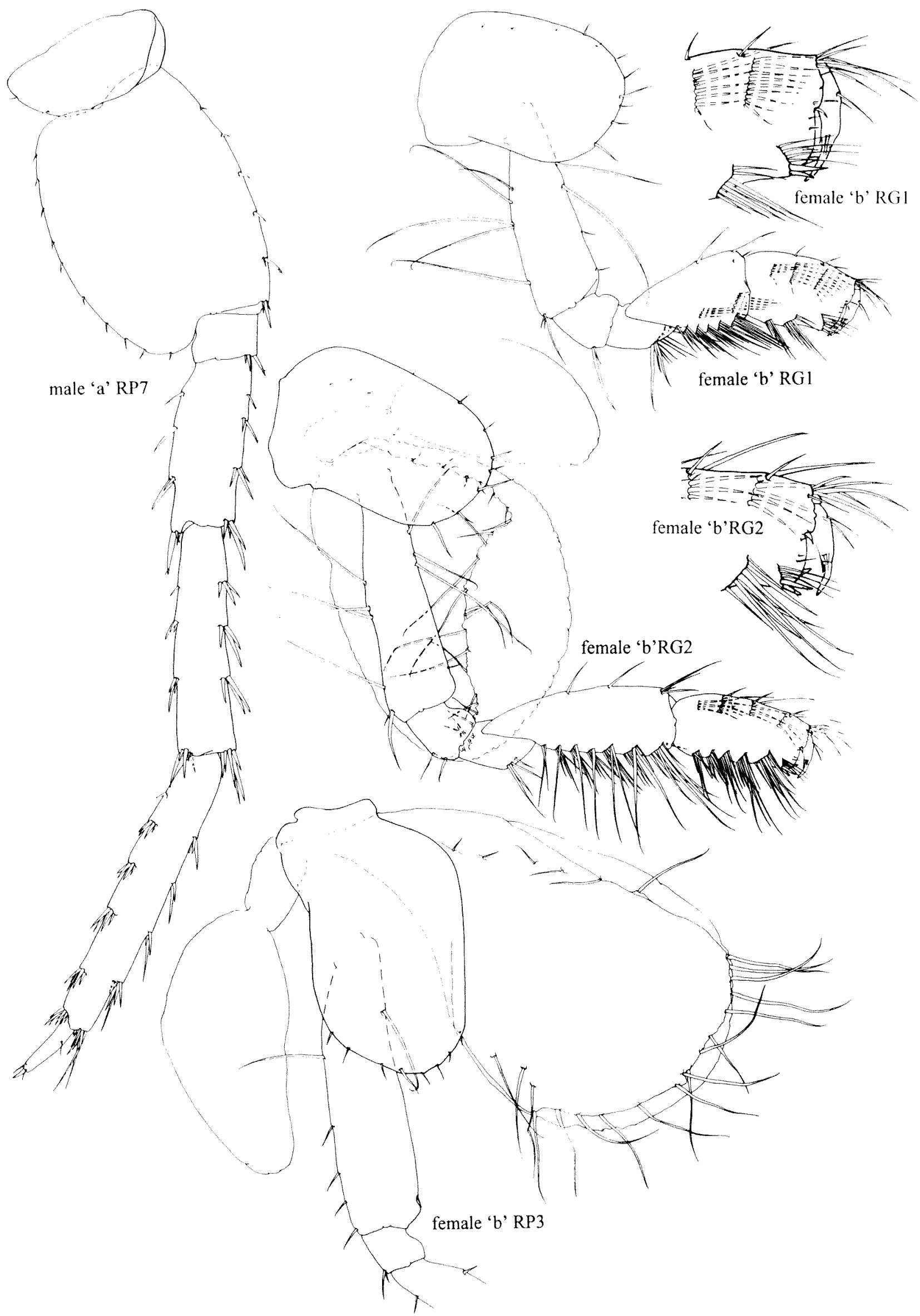

Figure 23 Chydaekata diagonalis sp. nov. holotype, male 'a' $6 \mathrm{~mm}$, pereopod 7 . Allotype female 'b' 8 mm, gnathopods 12 and coxa of pereopod 3. 


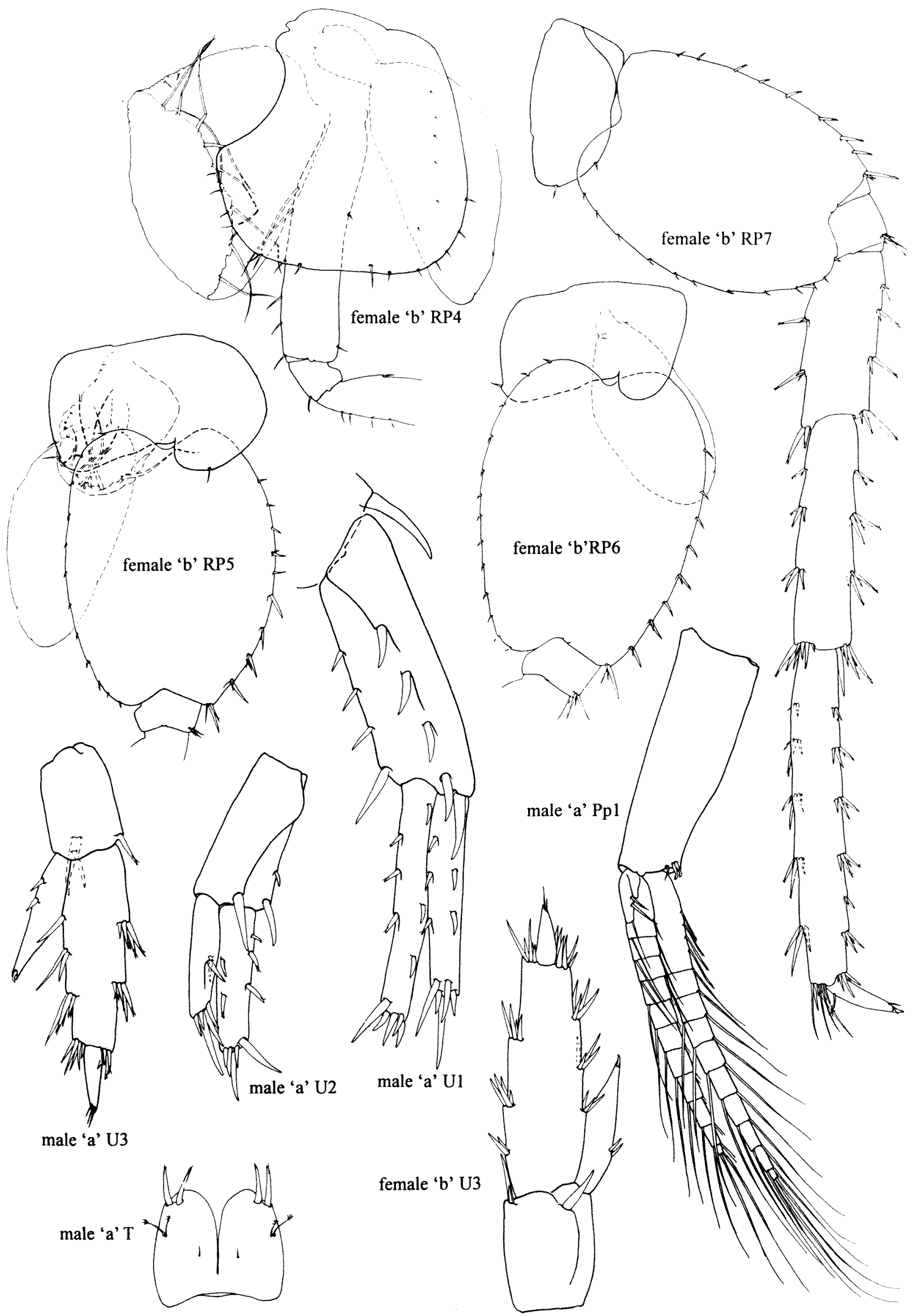

Figure 24 Chydaekata diagonalis sp. nov. holotype, male 'a' $6 \mathrm{~mm}$, pleopod 1, uropods $1-3$, telson. Allotype female ' $b$ ' 8 mm. coxae 4-6, pereopod 7 . 
uropod: outer ramus; proximal article bearing 3 (versus 2) translateral setal rows; distal article bearing 2 (versus 3 ) slender apical setae.

\section{Relationships}

Chydaekata diagonalis differs from others of the genus in: left mandible palp article 2 with a mediodistal row of 7 robust rastellate setae; right first maxilla right palp apex with 3 articulated tooth setae and 2 fused broad based tooth setae; first gnathopod propodus length less than $1.0 \times$ width pereopod 4 shorter than P3 pereopod 5 coxa bearing 2 setae on anterior lobe; epimera 1 posterior margin sinuous; epimera 2 with 6 robust setae on the anteroventral margin; third uropod outer ramus proximal article with 5 apicomedial robust setae.

\section{Etymology}

From the Latin 'diagonalus' (oblique), referring to the oblique palmar angle of the propodus of the first gnathopod.

\section{Chydaekata carscutica sp. nov.} Figures 25-28

\section{Material Examined}

Holotype

¿', 'a' $5 \mathrm{~mm}$, Newman bore field, WB23/4, Western Australia, Australia, $23^{\circ} 19^{\prime} \mathrm{S}, 117^{\circ} 51^{\prime} \mathrm{E}$, taken with trap, 24 July 1997, W.F. Humphreys and S.M. Eberhard, BES 4840 (WAM C24667).

\section{Allotype}

Australia: Western Australia: $q, b^{\prime} 7 \mathrm{~mm}$, same data as holotype (WAM C24668).

\section{Paratypes}

Australia: Western Australia: ca. 60 specimens, including $1 \delta$, ' $c$ ' $6 \mathrm{~mm}$, same data as holotype (WAM C24669).

\section{Diagnosis}

Second antenna: peduncle article 5 bearing 3 calceoli, flagellum 14 articulate, with calceoli on articles 1-8. Mandible: palp article 2 with a mediodistal row of 5 robust rastellate setae; article 3 with $13 \mathrm{D}$ and $4 \mathrm{E}$ setae apically. Left first maxilla: palp article 2 with 7 apical setae. Right first maxilla: palp apex with no articulated, and 4 fused broad based tooth setae. Maxilliped outer plate with a row of 8 slender naked, medial submarginal to disto-facial setae; a medial row of 8 submarginal to subapical robust, naked, tooth setae; 3 apicolateral setae. First gnathopod propodus: dactyl reaching to palmar corner, with two recumbent inner tooth spines. Second gnathopod carpus: with posterior setae ranked in 6 transverse bands. Telson: cleft $66 \%$, bearing 2 subapical robust setae.

\section{Description}

Holotype (male, 'a' $5 \mathrm{~mm}$ )

Body (Figure 25): urosomite 1 bearing 1 dorsolateral robust seta, urosomite 2 bearing 2 dorsolateral robust setae. First antenna (Figure 25): length $0.6 \times$ body, $1.6 \times$ second antenna; peduncle article 1 longest, with sparse setae; primary flagellum of 30 articles; accessory flagellum of 5 articles, reaching to article 7 of primary flagellum. Second antenna (Figure 25): length $0.4 \times$ body; peduncle length greater than flagellum, article 5 bearing 3 calceoli, article 4 subequal with article 5 , articles 3-5 with sparse setation; flagellum 14 articulate, with sparse setation, bearing calceoli on articles 1-8. Left mandible (Figure 25): palp article 2 with a medio-distal row of 5 robust rastellate setae, article 3 with $13 \mathrm{D}$ and $4 \mathrm{E}$ setae, facially setulose (pubescent); incisor with 5 teeth, lacinia mobilis with 4 teeth, and 4 plumose interraker setae; molar without pappose seta, with 3 penicillate hooked brushy basal setae, and no penicillate setules. Right mandible (Figure 25): palp article 2 with a mediodistal row of 5 robust rastellate setae, article 3 with $12 \mathrm{D}$ and $4 \mathrm{E}$ setae; incisor with 5 teeth, and 2 plumose interraker setae; molar, with 2 penicillate hooked brushy basal setae, and no penicillate setules. Left first maxilla (Figure 25): palp article 2 with 4 apical, and 1 subapical facial strong slender setae, with 1 apicomedial, 1 submarginal apicomedial setae; outer plate with 9 robust setae 9 denticulate, none naked; inner plate subtriangular, facially and medially setulose (pubescent). Right first maxilla (Figure 25): palp apex with no articulated and 4 fused broad based tooth setae, and 1 subterminal apicolateral facial seta. Second maxilla (Figure 25): outer plate length $3 \times$ width, bearing distal long, curved naked setae; apicomedial corner of inner plate with 2 weakly submarginal thick plumose/pappose setae. Maxilliped (Figure 25): inner plate length $2.7 \times$ width, extending to M0.7 of the outer plate, bearing small setules on the lateral margin and medioproximal face, no facial or medial pappose setae, with a row of 4 submarginal to subapical pappose setae, extending to a row of 4 similar subapical, and 1 apical setae, with 1 apicomedial, and 3 apical naked tooth setae; outer plate long, length $2.1 \times$ width, distally naked, with a row of 8 , slender naked, medial submarginal to distal facial setae, a medial row of 8 submarginal to subapical robust, naked, tooth setae, and 3 apicolateral setae 1 naked, and 2 pappose; palp second article weakly setose medially, third article sparsely setose laterally, weakly setose medially, with 3 facial, and 3 ventrofacial long strong setae basal to the dactyl, 
the apex moderately produced, setulate, with 3 long slender naked setae, and 1 dorsal accessory seta. First gnathopod (Figure 26): coxal plate with 3 anteroventral setae and 1 ventral seta; merus bearing posterior hump; carpus of moderate length, $1.4 \mathrm{x}$ width, subtriangular, posterior margin with setae ranked in 5 transverse bands; propodus ovate, small, length $1.7 \times$ width, posteroventral corner rounded, with 2 medial and 1 lateral robust setae, and 4 additional lateral elongate setae, palmar angle weakly oblique, smooth, dactyl reaching to palmar corner, with two recumbent inner tooth spines. Second gnathopod (Figure 26): slightly larger than first; coxal plate with 2 anteroventral and 2 ventral setae; carpus length $2.2 \mathrm{x}$ width, subtriangular, with posterior setae ranked in 6 transverse bands; propodus ovate, moderate size, length $1.6 \mathrm{x}$ width, with 1 medial robust seta, 2 lateral robust setae, and 5 additional lateral elongate setae, palmar angle transverse, smooth, dactyl reaching to palmar corner, with two recumbent inner tooth spines. Pereopods (Figure 26): first pereopod longer than the second gnathopod; coxa with 3 anterior setae, no long ventral setae, 1 short ventral seta, 1 seta at the posteroventral corner; carpus weakly setose posteriorly; pereopod 4 subequal in length with pereopod 3, coxa anteroventral margin with 3 setae, posteroventral margin with 4 setae, ventral margin with 2 setae, posterior margin moderately emarginate, carpus weakly setose posteriorly; coxa 5 bearing 1 seta on anterior and posterior lobes; basis of pereopod 5 with short slender posterior setae, bearing short robust anterior setae or bearing long robust anterior setae, moderately lobate posteroventrally; pereopod 6 coxa bearing no setae on anterior lobe, basis moderately expanded, bearing short and long robust anterior setae, moderately lobate posteroventrally; pereopod 7 coxa with 2 setae on the posterior lobe; basis bearing short and long robust anterior setae, moderately lobate posteroventrally; bases of periopods expanded unequally, basis of periopod 7 most expanded, basis of periopod 6 least expanded. Epimera: epimeron 1 with 1 slender seta on the posterior margin; posterior margin convex, posteroventral corner rounded; second epimeron with 2 robust setae on the anteroventral margin, posterior margin straight, posteroventral corner rounded; epimeron 3 with 3 robust setae on the anteroventral margin, without slender setae on ventral margin, posterior margin concave, posteroventral corner rounded, without spine or seta. Pleon: dorsolateral margin of pleonite 1 with 3 feeble setae, of pleonite 2 with 5 feeble setae, of pleonite 3 with 4 feeble setae, and no distolateral robust setae. Pleopods (Figure 28): first and second pleopods with 1 accessory retinacula, and third pleopod with no accessory retinacula. Urosomites: first urosomite bearing 1 distolateral slender and 1 distolateral robust setae; second urosomite with 1 distolateral slender seta, and 2 distolateral robust setae. First uropod (Figure 28): peduncle length $1.3 \mathrm{x}$ the length of the inner ramus with a strong row of 4 dorsolateral robust setae, and 3 dorsomedial robust setae; outer ramus with 2 dorsolateral robust setae, and 2 dorsomedial robust setae; inner ramus with 2 dorsolateral robust setae, 3 dorsomedial robust setae, and 5 apical robust setae. Second uropod: $0.6 \times$ length of uropod 1, peduncle about $1.2 \times$ length of inner ramus with 1 apicolateral, 1 dorsomedial, and 1 apicomedial robust setae; inner ramus with 1 dorsolateral, 1 dorsomedial, and 5 apical robust setae; outer ramus with 2 dorsolateral, 3 dorsomedial, and 5 apical robust setae. Third uropod (Figure 28): extending beyond uropods 1 and 2 in intact specimen, $0.7 \times$ length of uropod 1; peduncle length $0.4 \times$ outer ramus, shorter than, $0.9 \mathrm{x}$, urosomite three, with 1 apicolateral robust seta, and no apicolateral slender setae, 1 dorsomedial robust seta, and no dorsomedial slender setae, no apicomedial robust setae, and no apicomedial slender setae, and with 1 mediodistal robust seta; inner ramus length $0.5 \times$ outer ramus; outer ramus proximal article setae arranged laterally and medially in transverse bands or arranged medially singly with 3 lateral transverse bands of robust setae, 2 medial transverse bands of robust setae, 1 medial robust seta, 4 apicolateral robust setae, no apicolateral small setae, 4 apicomedial robust setae, 1 apicomedial small seta and, no apicomedial long slender setae; distal article short, with no apical robust setae, and 3 apical slender setae; inner ramus with 2 medial robust setae, no apical robust setae, and 1 apical slender seta. Telson (Figure 28): longer than, $1.1 \mathrm{x}$, urosomite 3 , cleft $66 \%$, as long as broad; apices rounded and laterally notched with 2 subapical robust setae and no subapical slender setae, with 1 apical penicillate seta and paired lateral penicillate setae at M0.7 from the telson base.

\section{Allotype (female, ' $b$ ' $7 \mathrm{~mm}$ )}

With the characteristics of the holotype, except: Body: length $7 \mathrm{~mm}$. First antenna: without aesthetascs or calceoli. Second antenna: without calceoli. First gnathopod (Figure 27): coxa bearing 2 additional anterior setae; carpus elongate, much longer than the male, bearing 7 (versus 2) posterior transverse setal bands; propodus less robust than the male, narrower, with 3 (versus 2) medio-facial setal bands, 3 (versus 2) lateral robust palmar corner setae and 5 (versus 4) elongate lateral accessory setae. Second gnathopod (Figure 27): coxa bearing 4 (versus 5) marginal setae, with huge round/ovate marginally setose and involute oostegite, length about $1.5 x$ coxal plate; carpus elongate, longer than the male, bearing 8 (versus 6) posterior transverse setal bands and additional medio-facial setae; propodus much narrower, longer and less robust than the male, 


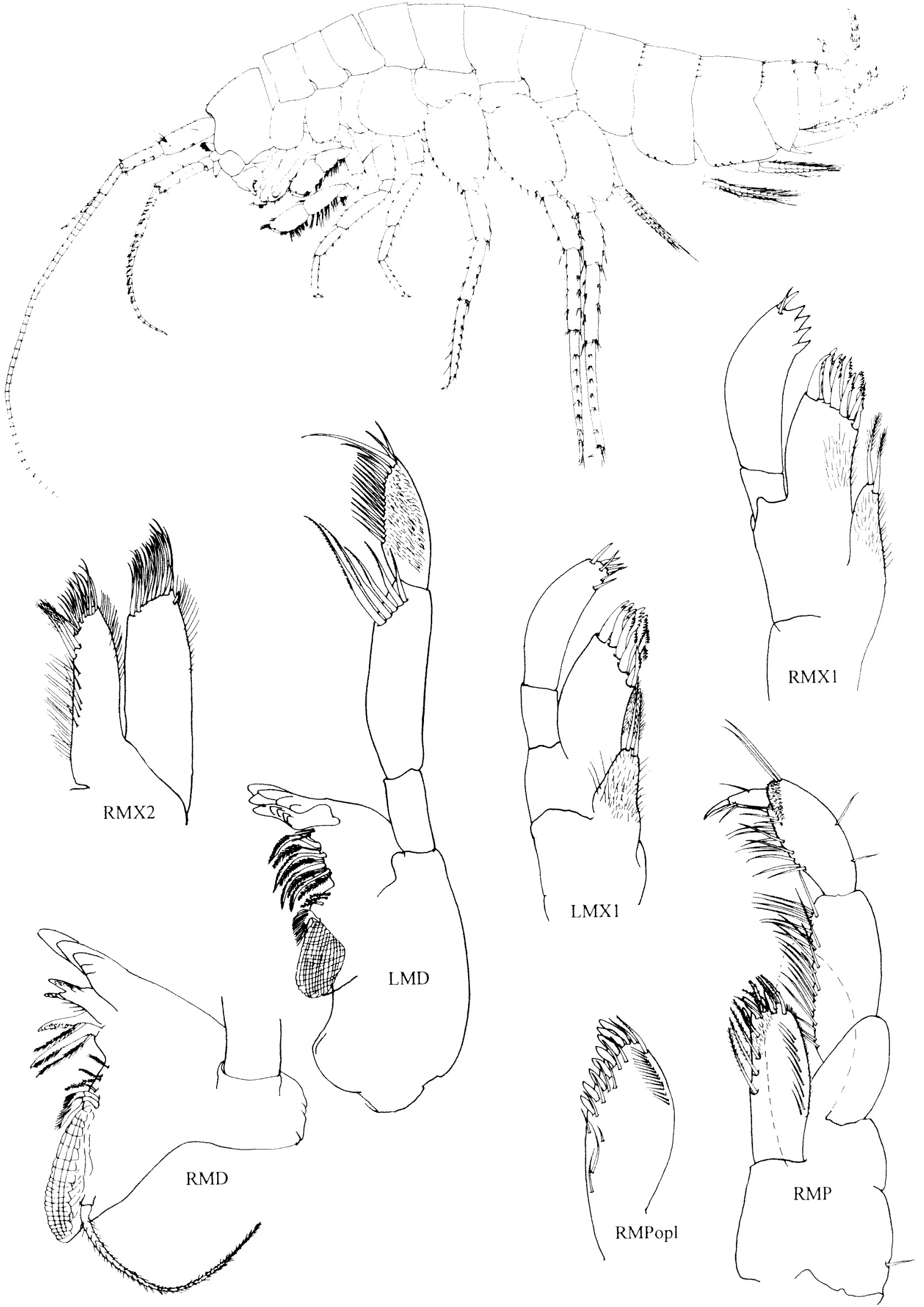

Figure 25 Chydaekata carscutica sp. nov. holotype, male 'a' $5 \mathrm{~mm}$ mouth parts. Male 'c' $6 \mathrm{~mm}$, whole animal. 


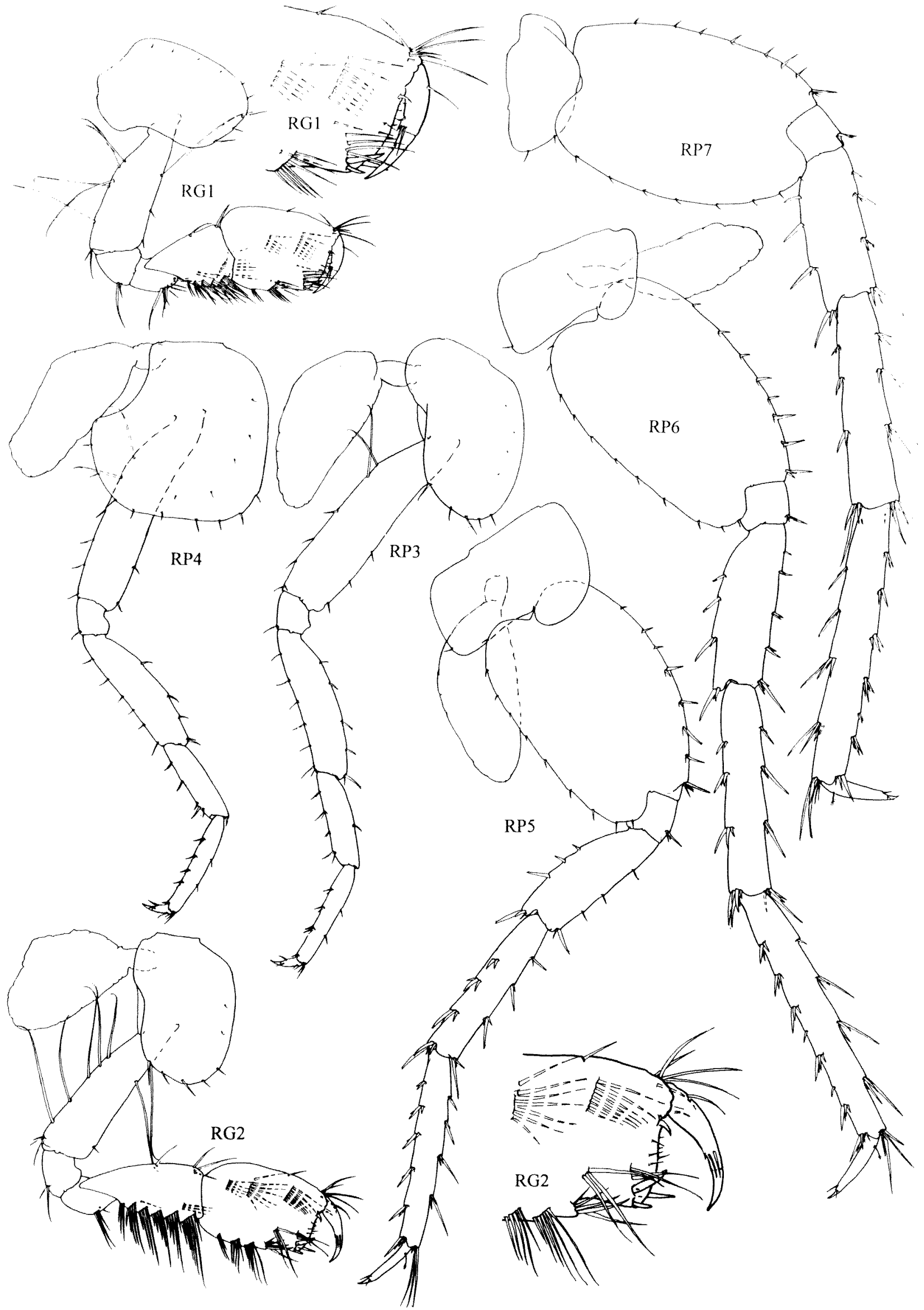

Figure 26 Chydaekata carscutica sp. nov. holotype, male ' $\mathrm{a}$ ' $5 \mathrm{~mm}$, gnathopods 1-2 and pereopods 3-7. 


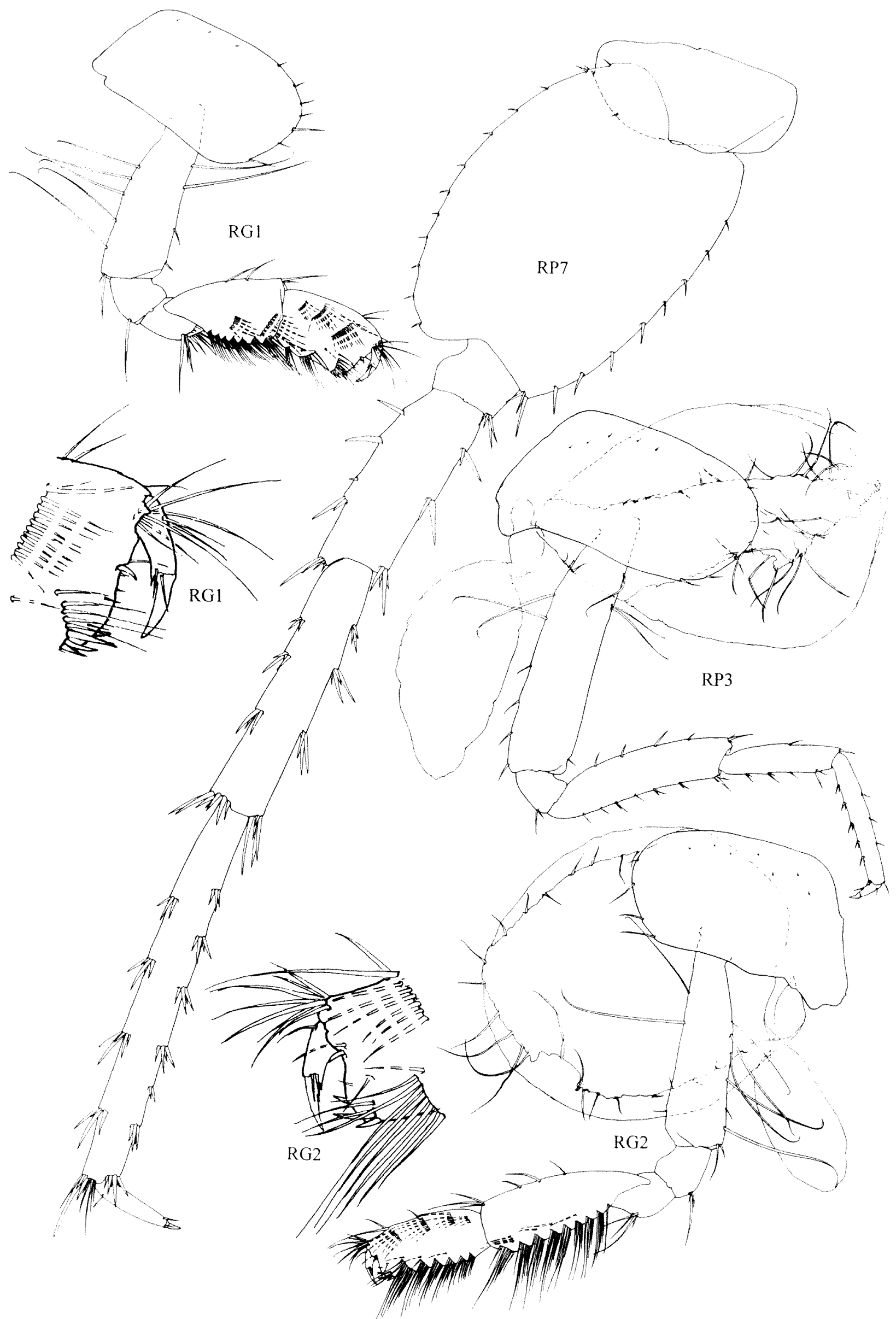

Figure 27 Chydackata carscutica sp. nov. allotype, female ' $b^{\prime} 7 \mathrm{~mm}$, gnathopods $1-2$ and pereopods 3 and 7 . 


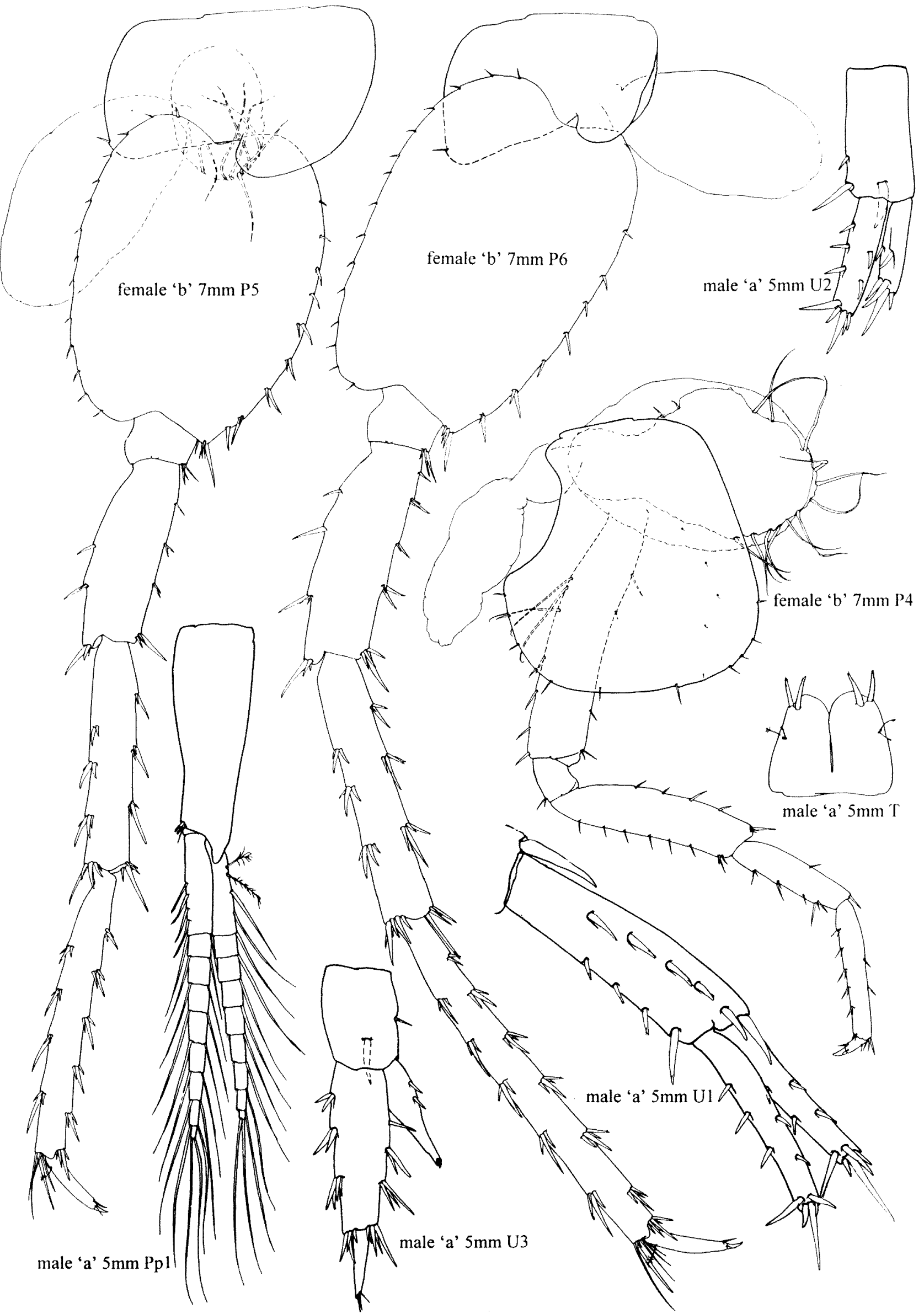

Figure 28 Chydaekata carscutica sp. nov. holotype, male 'a' $5 \mathrm{~mm}$, pleopod 1, uropods 1-3, telson. Allotype female 'b' 7 $\mathrm{mm}$, pereopods $4-6$. 
tapering apically, bearing 6 (versus 3) posterior translateral bands of setae and 4 (versus 3 ) mediofacial bands, palms and dactyl similar to the male. Pereopods (Figures. 27 and 28). Pereopod three: coxa longer than the male, with 7 (versus 5) marginal setae, bearing a huge, ovate, marginally setose, apically and posteriorly involute oostegite, length about $1.4 x$ coxal plate. Pereopod four: coxa bearing 11 marginal and submarginal setae (versus 9), and a large, ovate marginally setose and involute oostegite. Pereopod five: coxa bearing a moderate to small, marginally setose oostegite. Pereopods six and seven similar to the male.

\section{$\delta$ ('c' $6 \mathrm{~mm})$}

With the characters of the holotype except. Body: length $6 \mathrm{~mm}$. First antenna: flagellum of 41 articles, accessory flagellum of 6 articles. Second antenna: flagellum of 14 articles, calceoli present on articles 1-7. Pleon. Dorsolateral margin of pleonite 1 with 5 feeble setae and no robust setae, of pleonite 2 with 4 feeble setae, of pleonite 3 with 7 feeble setae. Urosome: first urosomite with 2 dorso-distal slender setae, 1 robust and 1 slender distolateral setae; second urosomite bearing 1 dorsodistal and 2 distolateral robust setae; third urosomite without setae. Uropods. First uropod; peduncle with 3 dorsolateral, 2 apicolateral, 3 dorsomedial and 1 apicomedial robust setae.

\section{Relationships}

Chydaekata carscutica differs from others of the genus in: second antenna flagellum 14 articulate; maxillipedal palp, second article weakly setose medially; second gnathopod propodus ovate; third uropod peduncle with 1 dorsomedial robust seta, outer ramus proximal article with 1 apicomedial small seta.

\section{Etymology}

From the Latin 'caritus' (lacking), and 'scutica' (whip), referring to the absence of a pappose seta on the molar of the left mandible.

\section{Chydaekata gyraspis sp. nov.} Figures 29-32

\section{Material Examined}

\section{Holotype}

8. 'a' $6 \mathrm{~mm}$, Newman bore field, K27 monitoring bore, Western Australia, Australia, $23^{\circ} 20^{\prime} \mathrm{S}, 117^{\circ} 51^{\prime} \mathrm{E}_{\prime \prime}$ taken with haul net, 23 July 1997, W.F. Humphreys and S.M. Eberhard, BES 4824 (WAM C24670).

\section{Allotype}

Australia: Western Australia: $q$, 'b' $8 \mathrm{~mm}$, same data as holotype (WAM C24671).
Paratypes

Australia: Western Australia: 11 specimens, same data as holotype (WAM C24672).

\section{Diagnosis}

Second antenna: peduncle article 5 bearing 2 calceoli, flagellum 12 articulate, with calceoli on articles $1-8$. Mandible: palp article 2 with a mediodistal row of 5 robust rastellate setae; article 3 with $12 \mathrm{D}$ and $4 \mathrm{E}$ setae apically. Left first maxilla: palp article 2 with 7 apical setae. Right first maxilla: palp apex with no articulated, and 4 fused broad based tooth setae. Maxilliped outer plate with a row of 8 slender naked, medial submarginal to disto-facial setae; a medial row of 9 submarginal to subapical robust, naked, tooth setae; 3 apicolateral setae. First gnathopod propodus: dactyl reaching to palmar corner, with a single recumbent inner tooth spine. Second gnathopod carpus: with posterior setae ranked in 6 transverse bands. Telson: cleft 75\%, bearing 2 subapical robust setae.

\section{Description}

\section{Holotype (male, ' $a$ ' $6 \mathrm{~mm}$ )}

Body (Figure 29): urosomite 1 bearing 1 dorsolateral robust seta; urosomite 2 bearing 2 dorsolateral robust setae. First antenna (Figure 29): length $0.6 \mathrm{x}$ body, $1.4 \mathrm{x}$ second antenna; peduncle article 1 longest, with sparse setae; primary flagellum of 31 articles; accessory flagellum of 5 articles, reaching to article 7 of primary flagellum. Second antenna (Figure 29): length $0.5 \times$ body; peduncle length less than flagellum, article 5 bearing 2 calceoli, article 4 subequal with article 5 , articles 3-5 with sparse setation; flagellum 12 articulate, with sparse setation, bearing calceoli on articles 1 to 8. Left mandible (Figure 29): palp article 2 with a medio-distal row of 5 robust rastellate setae, article 3 with $12 \mathrm{D}$ and $4 \mathrm{E}$ setae, facially strongly setulose (pubescent); incisor with 6 teeth, lacinia mobilis with 5 teeth, and 3 plumose interraker setae; molar bearing pappose seta, with 2 penicillate hooked brushy basal setae, and no penicillate setules. Right mandible (Figure 29): palp article 2 with a medio-distal row of 5 robust rastellate setae, article 3 with $12 \mathrm{D}$ and $3 \mathrm{E}$ setae; incisor with 6 teeth, and 2 plumose interraker setae; molar, with 4 penicillate hooked brushy basal setae, and no penicillate setules. Left first maxilla (Figure 29): palp article 2 with 3 apical, and 1 subapical facial strong slender setae, with 3 apicomedial, no submarginal apicomedial, and no ventrofacial apicomedial strong slender setae; outer plate with 10 robust setae, 10 denticulate, no naked; inner plate subtriangular, facially and medially setulose (pubescent). Right first maxilla (Figure 29): palp apex with no articulated, and 4 fused broad based tooth setae, and 1 subterminal apicolateral facial seta. 
Second maxilla (Figure 29): outer plate length $4.2 \times$ width, bearing distal long, curved rastellate setae or naked setae; apicomedial corner of inner plate with 2 weakly submarginal thick plumose/pappose setae. Maxilliped (Figure 29): inner plate length $2.4 x$ width, extending to M0.6 of the outer plate, bearing small setules on the lateral margin and medioproximal face, 1 facial pappose seta at M0. 9 of its length, 1 medial pappose seta, with a row of 3 , submarginal pappose setae, extending to a row of 4 similar subapical, and 2 apical setae, and 3 apical naked tooth setae; outer plate broad, length $1.7 \mathrm{x}$ width, distally setulose (pubescent), with a row of 8 , slender naked, medial submarginal to distal facial setae, a medial row of 9 submarginal to subapical robust, naked, tooth setae, and 3 apicolateral setae none naked, 3 pappose; palp, second article strongly setose medially; third article sparsely setose laterally, moderately setose medially, with 3 facial, and 2 ventrofacial long strong setae basal to the dactyl, the apex moderately produced, setulate, with 2 long slender naked setae, and 1 dorsal accessory seta. First gnathopod (Figure 30): coxal plate with 3 anteroventral setae, and 1 ventral seta; merus bearing posterior hump; carpus of moderate length, $1.3 \times$ width, subtriangular, posterior margin strongly setose, with setae ranked in 4 transverse bands; propodus subrectangular, moderate size, length $1.7 \times$ width, posteroventral corner subquadrate, with 2 lateral robust setae, and 4 additional lateral elongate setae, palmar angle transverse, smooth, dactyl reaching to palmar corner, with a single recumbent inner tooth spine. Second gnathopod (Figure 30): slightly larger than first; coxal plate with 3 anteroventral setae, and 2 ventral setae; carpus length $2.2 \times$ width, subtriangular, with setae ranked in 6 transverse bands; propodus subrectangular, moderate size, length $2.2 \times$ width, with 2 lateral robust setae, 1 medial robust seta and 2 additional lateral elongate setae, palmar angle transverse, smooth, dactyl reaching to palmar corner, with no recumbent inner tooth spine. Pereopods (Figures. 30-31): pereopod 1 subequal in length to the second gnathopod; coxa with 3 anterior setae, 2 long ventral setae, no short ventral setae, 1 seta at the posteroventral corner; carpus weakly setose posteriorly; pereopod 4 subequal in length with pereopod 3, coxa anteroventral and posteroventral margins with 4 setae, ventral margin with no setae, posterior margin strongly emarginate, carpus weakly setose posteriorly; pereopods $5-7$, coxa 5 bearing 1 seta on anterior and posterior lobes, basis of pereopod 5 with slender posterior setae, bearing short robust anterior setae or bearing long robust anterior setae, moderately lobate posteroventrally; pereopod 6 coxa bearing 1 seta on anterior lobe; basis moderately expanded, bearing short robust anterior setae or bearing long robust anterior setae, moderately lobate posteroventrally; pereopod 7 coxa with 2 setae on the posterior lobe, basis bearing short robust anterior setae or bearing long robust anterior setae, moderately lobate posteroventrally, bases of periopods equally expanded. Epimera: first epimeron with 1 slender seta on the posterior margin; posterior margin straight, posteroventral corner rounded; epimeron 2 with 2 robust setae on the anteroventral margin posterior margin straight, posteroventral corner rounded; epimeron 3 with 4 robust setae on the anteroventral margin, without slender setae on the ventral margin, posterior margin sinuous, posteroventral corner rounded, without spine or seta. Pleon: dorsolateral margin of pleonite 1 with 5 feeble setae; of pleonite 2 with 7 feeble setae; of pleonite 3 with 3 feeble setae and no distolateral robust setae. Pleopods (Figure 32): first pleopod and second pleopods each with 1 accessory retinacula, third pleopod with no accessory retinacula. Urosomites: urosomite 1 bearing 2 distolateral slender setae, and 1 distolateral robust setae; urosomite 2: with 1 distolateral slender seta, and 2 distolateral robust setae. First uropod (Figure 32): peduncle length $1.3 \times$ the length of the inner ramus, with a strong row of 4 dorsolateral robust setae and 3 dorsomedial robust setae; outer ramus with 2 dorsolateral robust setae, and 3 dorsomedial robust setae; inner ramus with 2 dorsolateral robust setae, 3 dorsomedial robust setae, and 5 apical robust setae. Second uropod (Figure 32): $0.5 \times$ length of uropod 1; peduncle about $1.3 \times$ length of inner ramus, with 1 apicolateral, 1 dorsomedial, and 1 apicomedial robust setae; inner ramus with 1 dorsolateral, 1 dorsomedial, and 5 apical robust setae; outer ramus with 1 dorsolateral, 2 dorsomedial, and 5 apical robust setae. Third uropod (Figure 32): extending beyond uropods 1 and 2 in intact specimen, $0.7 \times$ length of uropod 1; peduncle length $0.4 \times$ outer ramus, shorter than, $0.8 \times$ urosomite three, with 1 apicolateral robust seta, and no apicolateral slender setae, with no dorsomedial robust setae, and 1 dorsomedial slender seta, with 1 apicomedial robust seta, no apicomedial slender setae, and no mediodistal robust setae; inner ramus length $0.5 \times$ outer ramus; outer ramus proximal article setae arranged laterally and medially in transverse bands or arranged medially singly with, with 2 lateral transverse bands of robust setae, with 1 medial transverse band of robust setae, with no medial transverse bands of mixed robust and small setae, 1 medial robust seta, 4 apicolateral robust setae, no apicolateral small setae, 4 apicomedial robust setae, no apicomedial small setae, no apicomedial long slender setae; distal article short, with no apical robust setae, and 3 apical slender setae; inner ramus with 2 medial robust setae, no apical robust setae, and 1 apical slender seta. Telson (Figure 32): shorter than, $0.9 \mathrm{x}$, urosomite 3; cleft 


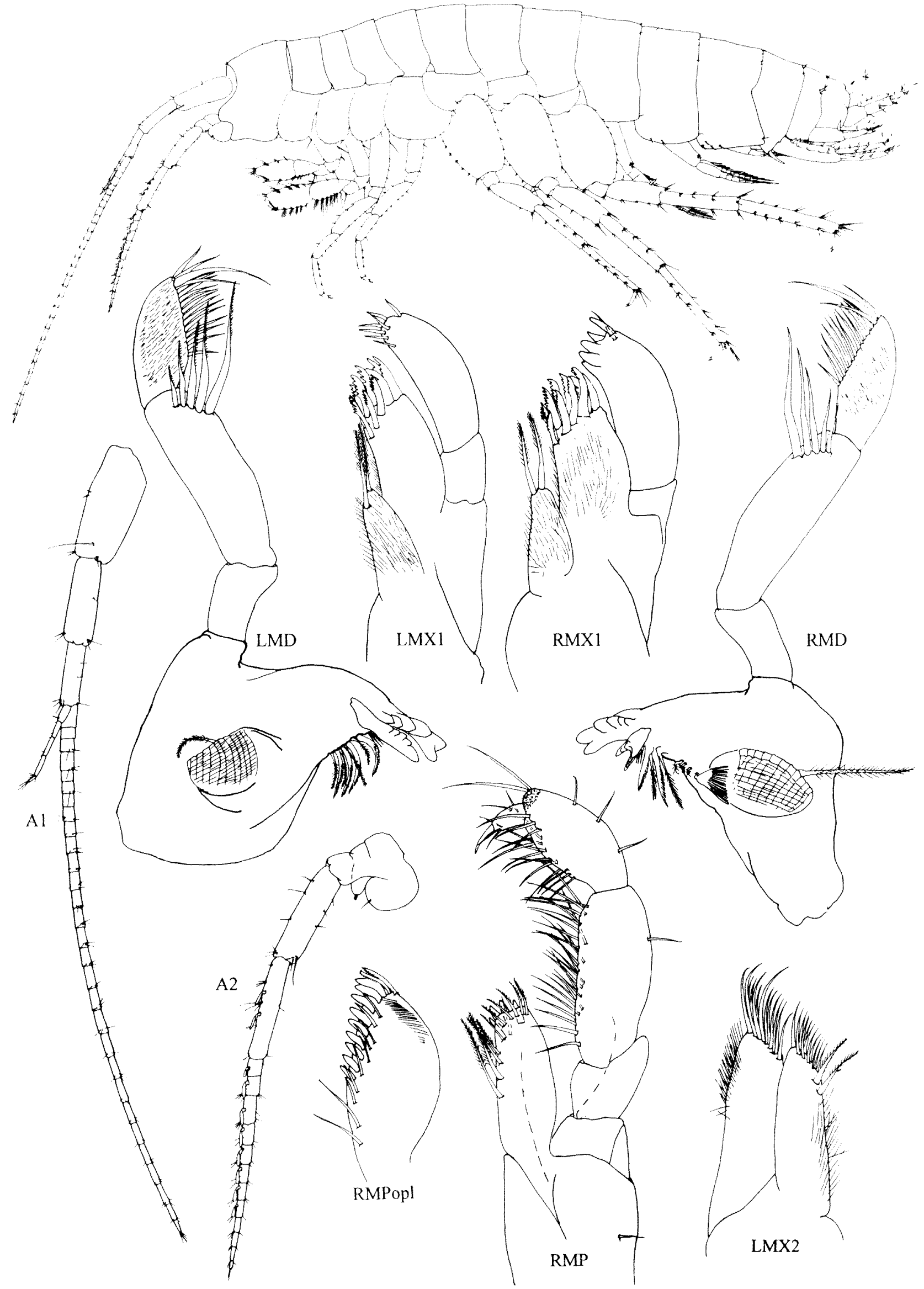

Figure 29 Chydaekata gyraspis sp. nov., holotype, male 'a' $6 \mathrm{~mm}$, whole animal, antenna 1 and mouthparts. 


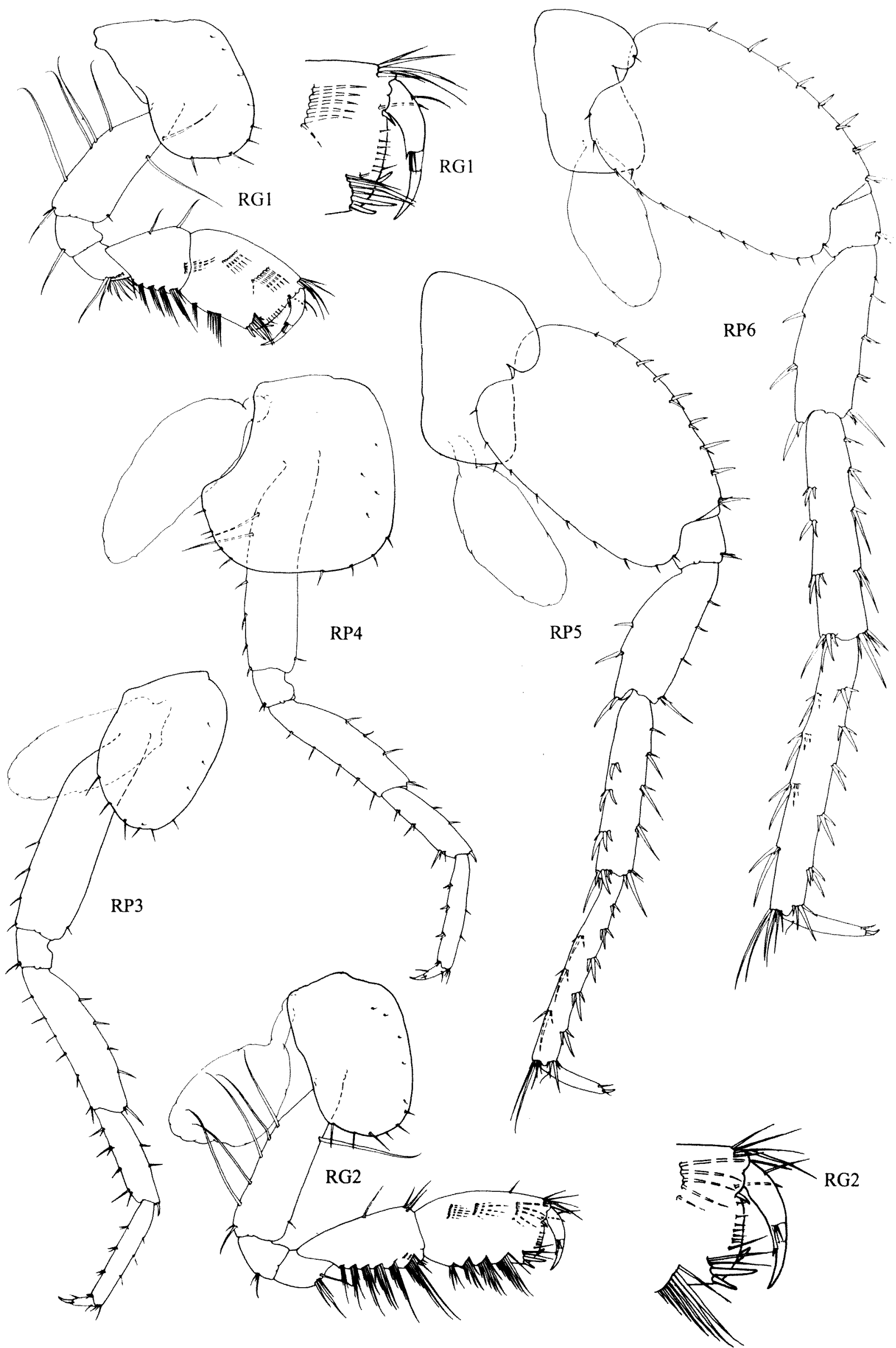

Figure 30 Chydaekata gyraspis sp. nov., holotype, male 'a' $6 \mathrm{~mm}$, gnathopods and pereopods. 


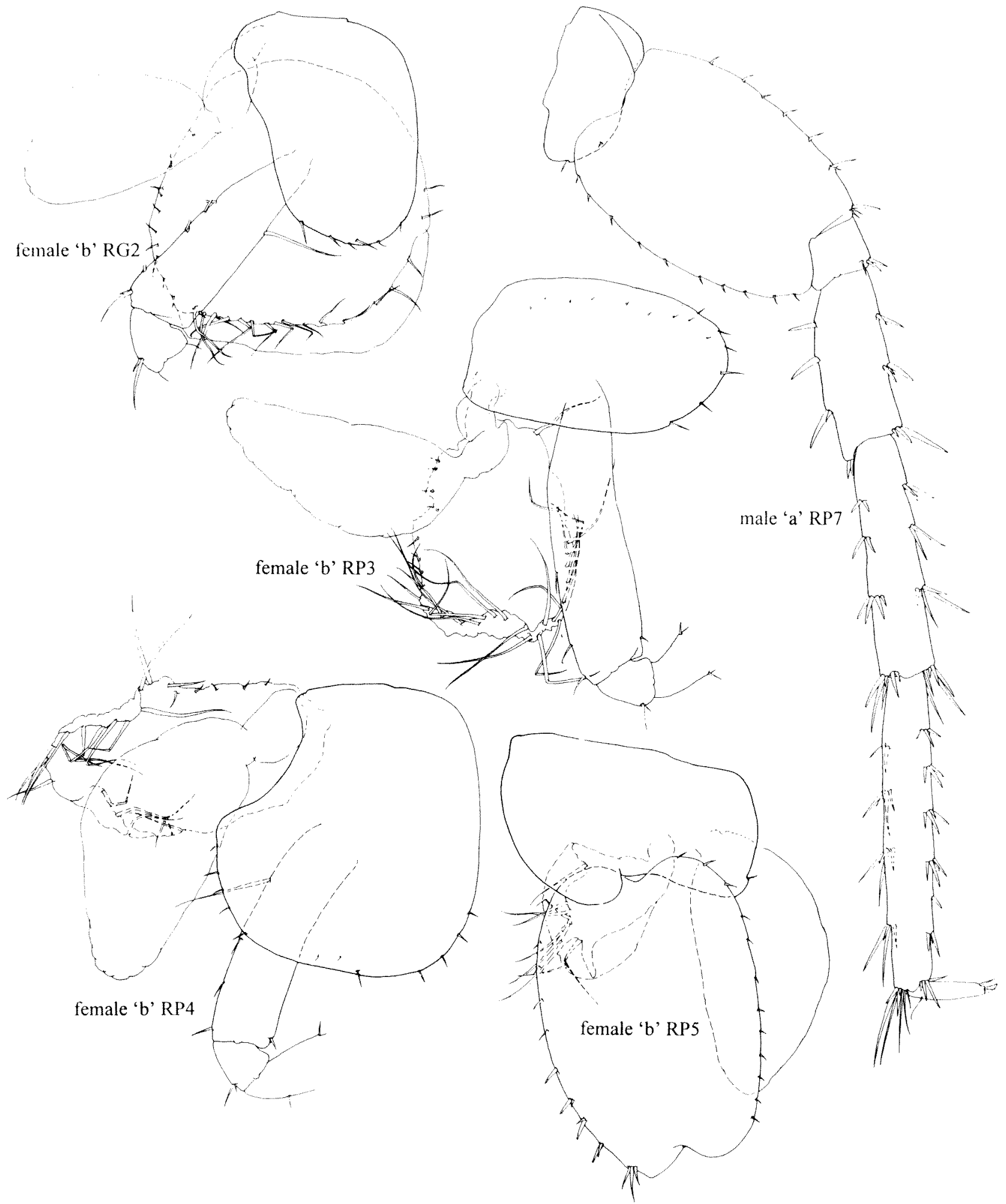

Figure 31 Chydaekata gyraspis sp. nov., holotype male 'a' $6 \mathrm{~mm}$, pereopod 7 . Allotype, female 'b' $8 \mathrm{~mm}$, coxae of gnathopod 2 and pereopods $3-5$.

$75 \%$; as long as broad; apices rounded and laterally notched; 2 subapical robust setae, and no subapical slender setae; with 1 apical penicillate seta; and paired lateral penicillate setae at M0. 7 from the telson base.

\section{Allotype (female, ' $b$ ' $8 \mathrm{~mm}$ )}

Similar to the holotype except in the following. Body: length $8 \mathrm{~mm}$. Second gnathopod (Figure 31); coxa bearing very large ovate, almost round, marginally setose and involute oostegite, length about 1.6x coxal 

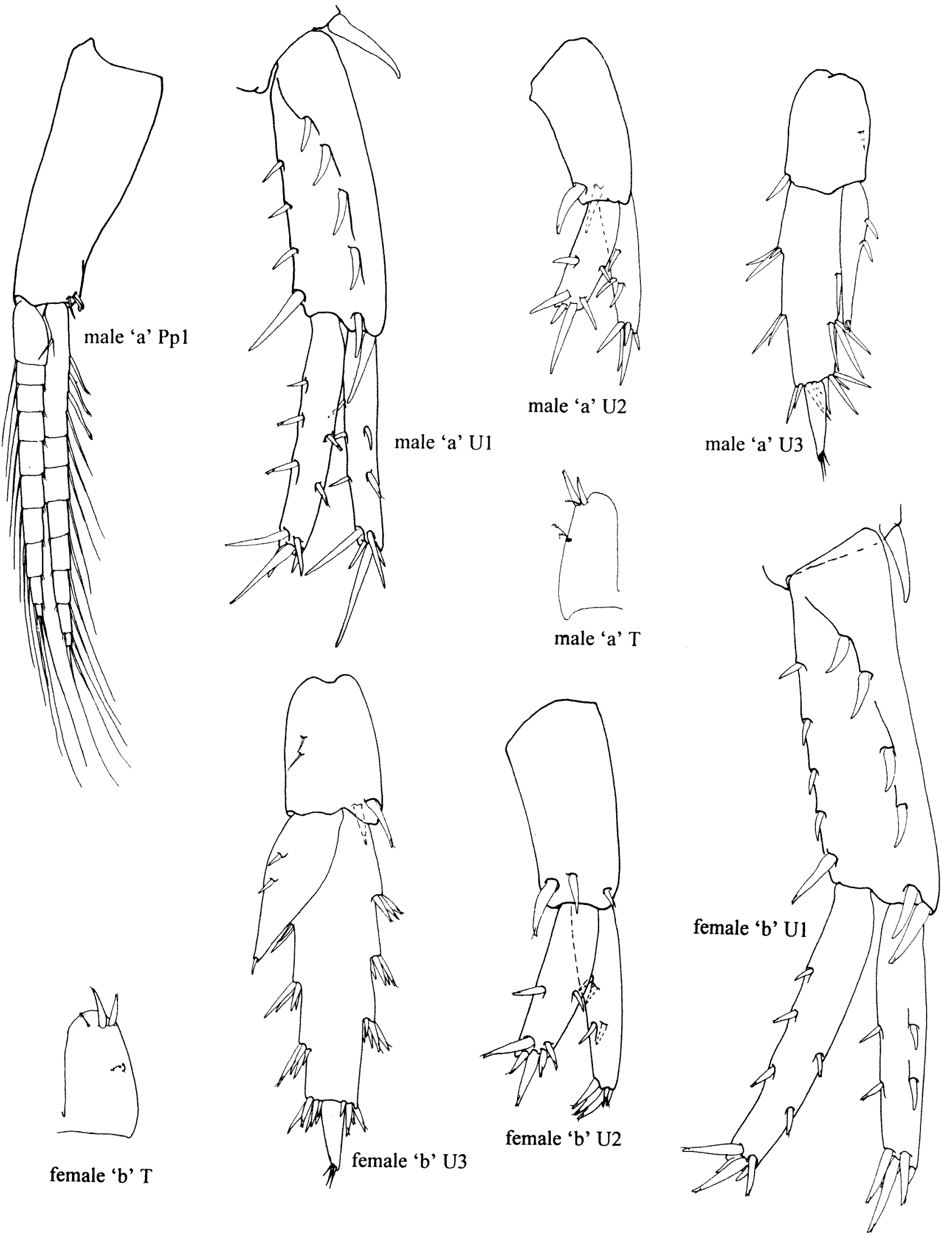

Figure 32 Chydaekata gyraspis sp. nov., holotype male 'a' $6 \mathrm{~mm}$, pleopod 1, uropods 1-3, telson. Allotype female 'b' 8 mm, uropods $1-3$, telson. 
plate. Pereopods (Figure 31): Third pereopod; coxa bearing large, irregular ovate, marginally setose, apically intumed oostegite, length about $1.0 \mathrm{x}$ coxal plate. Fourth pereopod; coxa strongly excavate, bearing 2 more marginal setae than the holotype; with a large, irregular paddle shaped, marginally setose oostegite; length about $0.9 x$ coxal plate. Fifth pereopod; coxa bearing moderate length irregularly shaped apically and posteriorly setose oostegite; length about $0.6 x$ coxal plate, about $0.5 x$ length of the oostegite of coxa 2. Uropods (Figure 32). First uropod: peduncle bearing 4 dorsomedial robust setae; outer ramus with 2 dorsomedial setae. Second uropod: peduncle bearing 1 dorso-distal robust seta; inner ramus bearing 2 dorsolateral setae; outer ramus with 5 apical robust setae. Third uropod; peduncle with 2 small setae dorsomedially and 2 apicolateral robust setae; inner ramus bearing 3 medial and 3 lateral transverse bands of robust setae.

\section{Relationships}

Chydaekata gyraspis differs from others of the genus in: second antenna flagellum 12 articulate; maxilliped inner plate length $2.0-2.4 \times$ width, with 1 medial pappose seta; first gnathopod: propodus posteroventral corner subquadrate, palmar angle transverse; pereopod 3 coxa bearing 2 long ventral setae; dorsolateral margin of pleonite 3 with 3 feeble setae.

\section{Etymology}

From the Greek 'gyros' (circle), and 'aspis' (shield), referring to the rounded posteroventral corner of the second epimeron.

\section{Chydaekata simulata sp. nov.}

Figures 33-36

\section{Material Examined}

\section{Holotype}

¿', ' $\mathrm{a}$ ' $5 \mathrm{~mm}$, Newman bore field, WP96, Western Australia, Australia, $23^{\circ} 20^{\prime} \mathrm{S}, 117^{\circ} 51^{\prime} \mathrm{E}$, taken with haul net, 23 July 1997, W.F. Humphreys and S.M. Eberhard, BES 4832 (WAM C24673).

\section{Allotype}

Australia: Western Australia: $q$, 'b' $6 \mathrm{~mm}$, same data as holotype (WAM C24674).

\section{Paratypes}

Australia: Western Australia: about 55 others in the type series including male $4.5 \mathrm{~mm}$, same data as holotype (WAM C24675).

\section{Diagnosis}

Second antenna: peduncle article 5 bearing 1 calceolus, flagellum 11 articulate, with calceoli on articles 1-7. Mandible: palp article 2 with a mediodistal row of 4 robust rastellate setae; article 3 with $9 \mathrm{D}$ and $3 \mathrm{E}$ setae apically. Left first maxilla: palp article 2 with 6 apical setae. Right first maxilla: palp apex with 1 articulated, and 4 fused broad based tooth setae. Maxilliped outer plate with a pair of slender naked, medial submarginal to disto-facial setae; a medial row of 7 submarginal to subapical robust, naked, tooth setae; 3 apicolateral setae. First gnathopod propodus: dactyl reaching to palmar corner, with a single recumbent inner tooth spine. Second gnathopod carpus: with posterior setae ranked in 5 transverse bands. Telson: cleft $83 \%$, bearing 2 subapical robust setae.

\section{Description}

Holotype (male, ' $a$ ' $5 \mathrm{~mm}$ )

Body (Figure 33): urosomites 1 and 2 without dorsolateral robust setae. First antenna (Figure 33): length $0.6 \mathrm{x}$ body, $1.6 \mathrm{x}$ second antenna; peduncle article 1 longest, with sparse setae; primary flagellum of 27 articles; accessory flagellum of 5 articles, reaching to article 5 of primary flagellum. Second antenna: length $0.4 \mathrm{x}$ body; peduncle length greater than flagellum, article 5 bearing 1 calceolus, article 4 subequal with article 5, articles 3-5 with sparse setation; flagellum 11 articulate, with sparse setation, bearing calceoli on articles $1-7$. Left mandible (Figure 33): palp article 2 with a mediodistal row of 4 robust rastellate setae, article 3 with $9 \mathrm{D}$ and $3 \mathrm{E}$ setae, facially setulose (pubescent); incisor with 5 teeth, lacinia mobilis with 4 teeth, and 4 plumose interraker setae; molar without pappose seta, with 2 penicillate hooked brushy basal setae, and no penicillate setules. Right mandible (Figure 33): palp article 2 with a medio-distal row of 4 robust rastellate setae, article 3 with $9 \mathrm{D}$ and 3 E setae; incisor with 4 teeth, and 2 plumose interraker setae; molar without penicillate hooked brushy basal setae, and few penicillate setules. Left first maxilla (Figure 33): palp article 2 with 4 apical and 1 subapical facial strong slender setae, and 1 submarginal apicomedial seta; outer plate with 9 robust setae -9 denticulate, none naked; inner plate subtriangular, facially and medially setulose (pubescent). Right first maxilla (Figure 33): palp apex with 1 articulated and 4 fused broad based tooth setae, and 1 subterminal apicolateral facial seta. Second maxilla (Figure 33): outer plate length $4.3 \mathrm{x}$ width, bearing distal long, curved naked setae; apicomedial corner of inner plate with 3 weakly submarginal thick plumose/pappose setae. Maxilliped (Figure 33): inner plate length $2.5 \mathrm{x}$ width, extending to M0.7 of the outer plate, bearing small setules on the lateral margin, no facial or medial pappose setae, with a row of 5 submarginal to subapical pappose setae, but not extending to a row of similar subapical or apical setae, with no 
apicomedial or mediodistal setae, and 3 apical naked tooth setae; outer plate broad, length $2.3 \mathrm{x}$ width, distally naked, with a row of 2 slender naked, submarginal setae, a medial row of 7 submarginal to subapical robust, naked, tooth setae, and 3 apicolateral setae -1 naked, and 2 pappose; palp second article strongly setose medially; third article sparsely setose laterally, moderately setose medially, with 3 facial, and 2 ventrofacial long strong setae basal to the dactyl, the apex moderately produced, setulate, with 2 long slender naked setae, and 1 dorsal accessory seta. First gnathopod (Figure 34): coxal plate with 3 anteroventral but no ventral setae; merus bearing posterior hump; carpus of moderate length, $1.5 \mathrm{x}$ width, subtriangular, posterior margin with setae ranked in 4 transverse bands; propodus subrectangular, small, length $1.7 \mathrm{x}$ width, posteroventral corner rounded, with 2 lateral and 1 medial robust setae, and 4 additional lateral elongate setae, palmar angle slightly oblique, smooth, dactyl reaching to palmar corner, with a single recumbent inner tooth spine. Second gnathopod (Figure 34): slightly larger than first; coxal plate with 3 anteroventral setae, and no ventral setae; carpus length $2.1 \mathrm{x}$ width, subtriangular, with posterior setae ranked in 5 transverse bands; propodus subrectangular, small, length $2 \times$ width, with 2 medial robust setae, 1 lateral robust seta, and 2 additional lateral elongate robust setae, palmar angle weakly oblique, smooth, dactyl reaching to palmar corner, with a single recumbent inner tooth spine. Pereopods (Figures. 34-35): pereopod 3 longer than the second gnathopod, coxa with 2 anterior setae, no long or short ventral setae, 1 seta at the posteroventral corner, carpus weakly setose posteriorly; pereopod 4 subequal in length with pereopod 3, coxa anteroventral margin with 2 setae, posteroventral margin with 3 setae, ventral margin with 1 seta, posterior margin moderately emarginate, carpus weakly setose posteriorly; coxa 5 bearing 1 seta on anterior lobe, and 1 seta on the posterior lobe; basis of periopod 5 with short slender posterior setae, bearing short robust and slender anterior setae, moderately lobate posteroventrally; pereopod 6 coxa bearing no setae on anterior lobe, basis moderately expanded, bearing short robust anterior setae, moderately lobate posteroventrally; pereopod 7 coxa with 1 seta on the posterior lobe; basis bearing short robust anterior setae, moderately lobate posteroventrally; bases of pereopods equally expanded. Epimera: first epimeron with 1 slender seta on the posterior margin, posterior margin straight, posteroventral corner rounded; epimeron 2 with 1 robust seta on the anteroventral margin; posterior margin straight, posteroventral corner rounded; epimeron 3 with 2 robust setae on the anteroventral margin, without slender setae on ventral margin, posterior margin straight, posteroventral corner rounded, without spine or seta. Pleon: dorsolateral margin of pleonite 1 with 1 feeble setae; of pleonites 2 and 3 with 2 feeble setae, with no distolateral robust setae on pleonite 3. Pleopods (Figure 36): first pleopod with 1 accessory retinacula, second and third pleopods with no accessory retinacula. Urosomites: urosomite 1 bearing 2 distolateral slender setae, and no distolateral robust seta; urosomite 2 with 1 distolateral slender setae, and 1 distolateral robust setae. First uropod (Figure 36): peduncle length $1.3 \mathrm{x}$ the length of the inner ramus, with a strong row of 3 dorsolateral robust setae, and 3 dorsomedial robust setae; outer ramus with 1 dorsolateral robust seta, and 2 dorsomedial robust setae; inner ramus with 1 dorsolateral robust seta, 2 dorsomedial robust setae, and 5 apical robust setae. Second uropod (Figure 36): $0.6 \times$ length of uropod 1, peduncle about $1.3 \times$ length of inner ramus, with 1 apicolateral, no dorsomedial, and 1 apicomedial robust setae; inner ramus with 1 dorsolateral, 1 dorsomedial, and 4 apical robust setae; outer ramus with 1 dorsolateral, 2 dorsomedial, and 4 apical robust setae. Third uropod (Figure 36): extending beyond uropods 1 and 2 in intact specimen, $0.7 x$ length of uropod 1 ; peduncle length $0.4 \times$ outer ramus, shorter than, $0.8 \mathrm{x}$, urosomite three, with 1 apicolateral robust seta and no apicolateral slender setae, no dorsomedial robust setae, no dorsomedial slender setae, with no apicomedial robust setae, no apicomedial slender setae, and with 1 mediodistal robust seta; inner ramus length $0.5 \times$ outer ramus; outer ramus proximal article setae arranged laterally and medially in transverse bands and medially singly with 2 lateral transverse bands of robust setae, with 1 medial transverse band of robust setae, 1 medial robust seta, 4 apicolateral robust setae, no apicolateral small setae, 4 apicomedial robust setae, no apicomedial small setae, no apicomedial long slender setae; distal article short, with no apical robust setae, and 2 apical slender setae; inner ramus with 2 medial robust setae, no apical robust setae, and 2 apical slender setae. Telson (Figure 36): shorter than, $0.9 x$, urosomite 3 , cleft $83 \%$, shorter than broad, length $0.9 \times$ breadth; apices rounded and laterally notched with 2 subapical robust setae, 1 apical penicillate seta, and paired lateral penicillate setae at M0.6 from the telson base.

\section{Allotype (female ' $b$ ' $6 \mathrm{~mm}$ )}

With the characteristics of the holotype except. Body: length $6 \mathrm{~mm}$. First antenna: without aesthetascs or calceoli. Second antenna. without calceoli. First gnathopod (Figure 35): carpus narrower, more elongate than male but nevertheless subtriangular, bearing 5 (versus 4) posterior translateral setal bands, and 2 (versus 1)mediofacial bands; propodus smaller, less robust than male, narrower and tapering apically though 


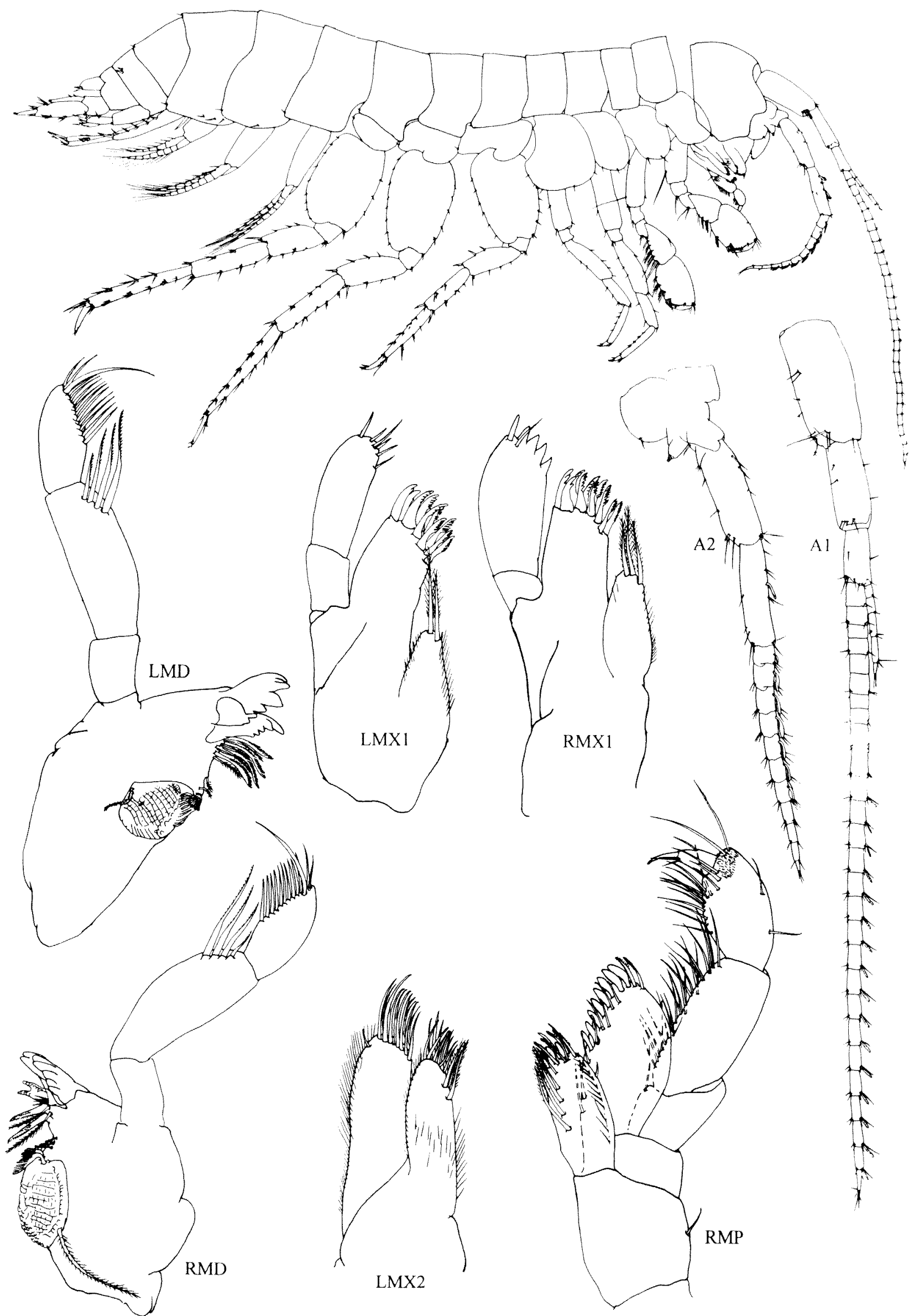

Figure 33 Chydaekata simulata sp. nov., holotype male 'a' $5 \mathrm{~mm}$, antennae and mouthparts. Male $4.5 \mathrm{~mm}$, whole
animal. 


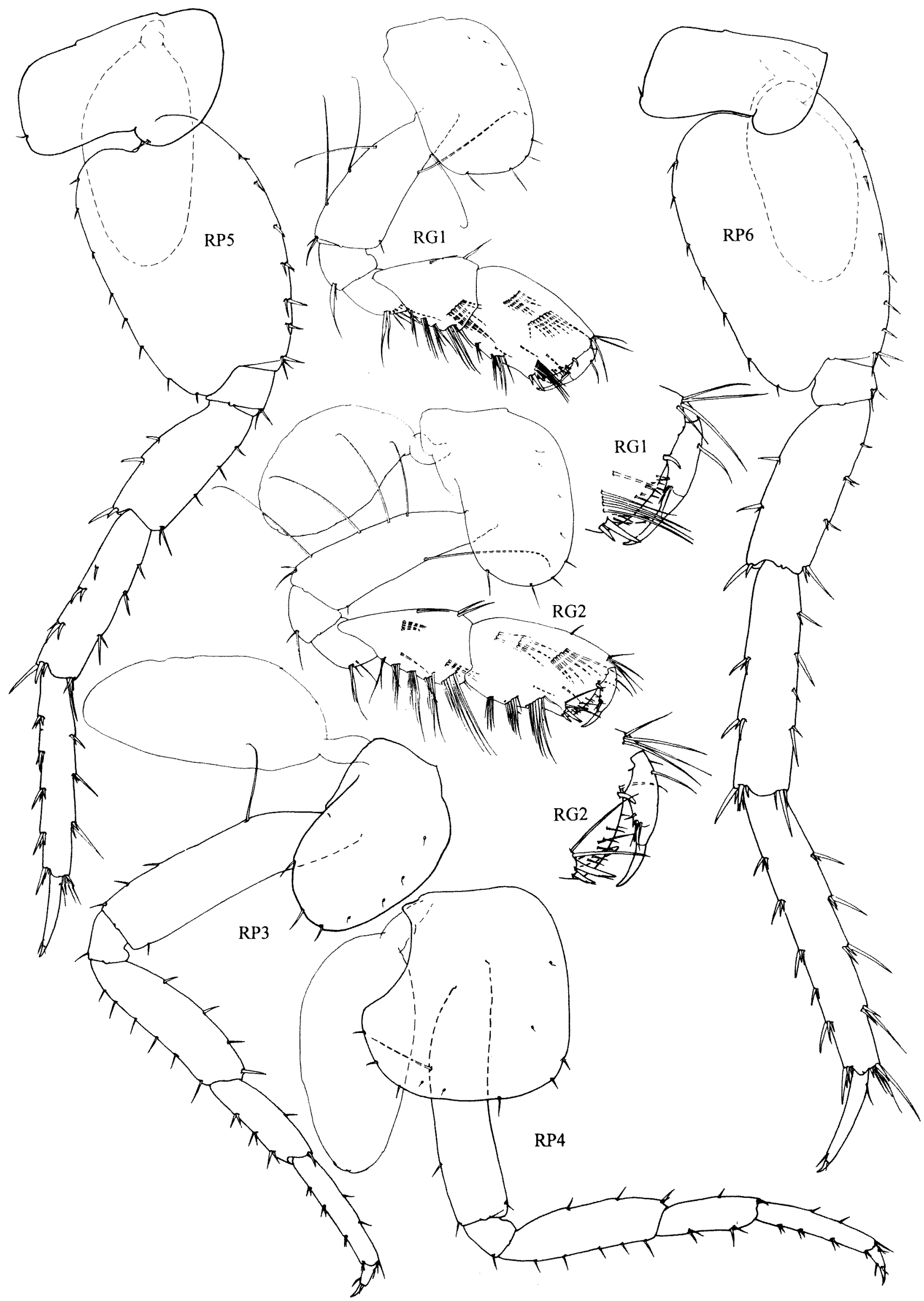

Figure 34 Chydaekata simulata sp. nov., holotype male 'a' $5 \mathrm{~mm}$, gnathopods 1-2 and pereopods 3-6. 


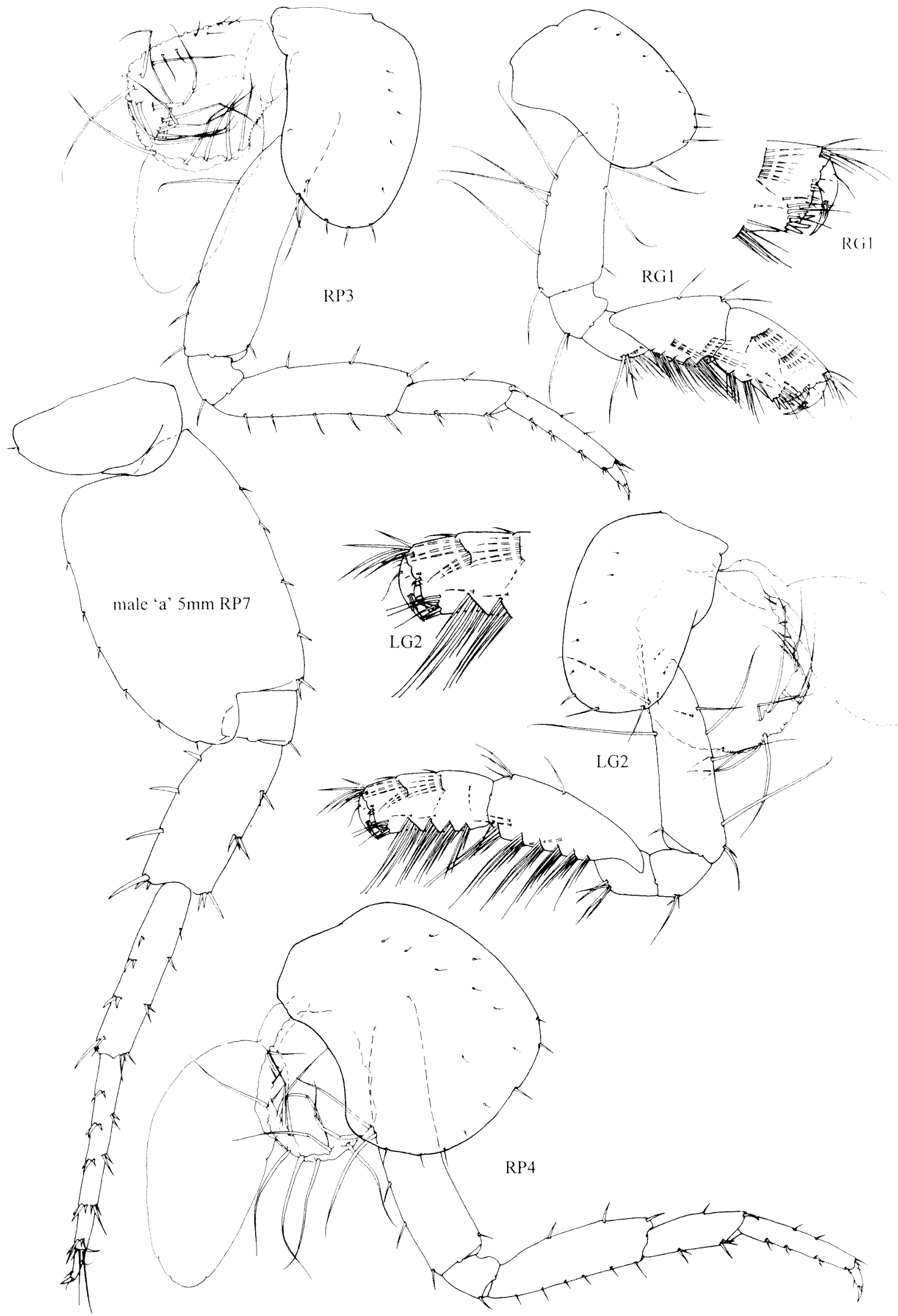

Figure 35 Chydaekata simulata sp. nov, allotype female 'b' $6 \mathrm{~mm}$, gnathopods 1-2, pereopods 3-4. Holotype male 'a' 5 $\operatorname{mm}$, pereopod 7 . 


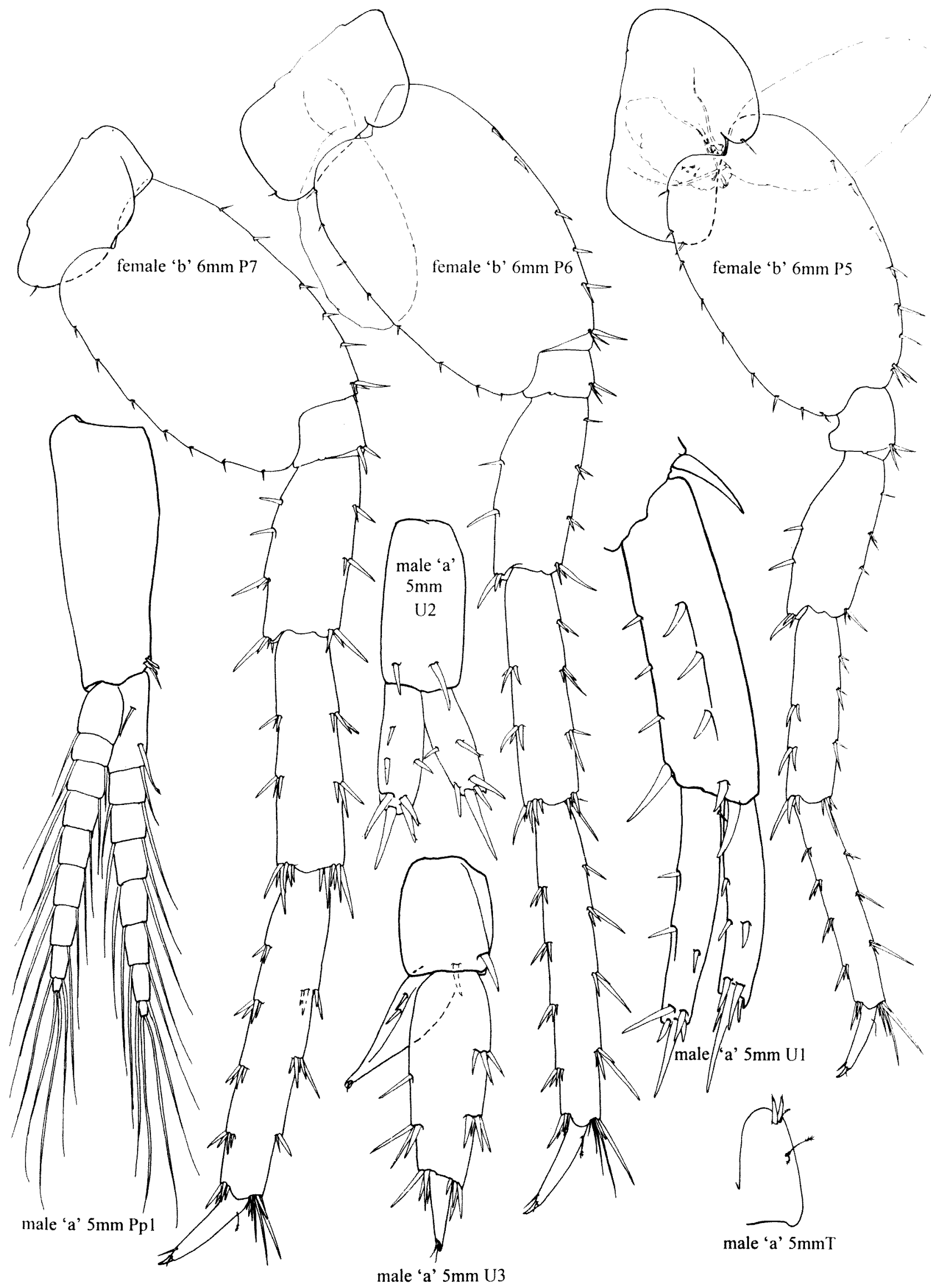

Figure 36 Chydaekata simulata sp. nov., holotype male 'a' $5 \mathrm{~mm}$, pleopod 1, uropods 1-3, telson. Allotype female 'b' 6 mm, pereopods $5-7$. 
similarly armed. Second gnathopod (Figure 35): coxa bearing fewer marginal setae, with large, round, posteriorly setose and involute, length about equal to coxal plate; carpus elongate and narrower than male, bearing 6 (versus 5) posterior translateral setal bands but 1 (versus 2) medio-facial band; propodus less robust than male, narrower, tapering apically, bearing 4 (versus 3 ) posterior translateral setal bands and 2 (versus 3) medio-facial bands; palm and dactyl similarly armed. Pereopods (Figures. 35 and 36). Third pereopod: coxa with an extra marginal seta, bearing a moderately large, paddle shaped, marginally setose and involute oostegite, length about $0.8 x$ coxal plate. Pereopod four: coxa similarly armed marginally, but bearing many facial setules, also with a moderately long, ovate, marginally setose and involute oostegite, length about $0.6 x$ coxal plate. Pereopod five: coxa bearing a small, ovate, apically setose oostegite, length about $0.6 x$ coxal plate, about $0.8 x$ oostegite of coxa 2. Pereopods six and seven: similar to male.

\section{Relationships}

Chydaekata simulata differs from others of the genus in: right first maxilla palp apex with 1 articulated tooth seta; second maxilla apicomedial corner of inner plate with 3 weakly submarginal thick plumose/pappose setae; maxilliped inner plate setae without a row of similar subapical setae, outer plate with a row of 2 slender naked submarginal setae; second pleopod with no accessory retinacula; second uropod outer ramus with 4 apical robust setae; third uropod inner ramus with 2 apical slender setae; telson cleft $83 \%$.

\section{Etymology}

From the Latin 'simulo' (imitate), referring to equal extensions of the propodal dactylus and palmar corner of the first gnathopod.

\section{Chydaekata tetraspis sp. nov.} Figures 37-40

\section{Material Examined}

\section{Holotype}

¿. 'a' $5.5 \mathrm{~mm}$, Ebathacalby Well, Fortescue Valley, Western Australia, Australia, $22^{\circ} 15^{\prime} \mathrm{S}, 118^{\circ} 45^{\prime} \mathrm{E}$, taken with haul net, 25 July 1997, W.F. Humphreys and S.M. Eberhard, BES 4847 (WAM C24676).

\section{Allotype}

Australia: Western Australia: $q$, 'b' $6.5 \mathrm{~mm}$, same data as holotype (WAM C24677).

\section{Diagnosis}

Second antenna: flagellum 13 articulate. Mandible: palp article 2 with a medio-distal row of
4 robust rastellate setae; article 3 with $10 \mathrm{D}$ and $4 \mathrm{E}$ setae apically. Left first maxilla: palp article 2 with 5 apical setae. Right first maxilla: palp apex with no articulated, and 4 fused broad based tooth setae. Maxilliped outer plate with a row of 8 slender naked, medial submarginal to disto-facial setae; a medial row of 4 submarginal to subapical robust, naked, tooth setae; 2 apicolateral setae. First gnathopod propodus: dactyl not reaching to palmar corner, with a single recumbent inner tooth spine. Second gnathopod carpus: with posterior setae ranked in 6 transverse bands. Telson: cleft $76 \%$, bearing 2 subapical robust setae.

\section{Description}

Holotype (male, 'a' $5.5 \mathrm{~mm}$ )

Body (Figure 37): urosomite 1 bearing 1 dorsolateral robust seta, urosomite 2 bearing 2 dorsolateral robust setae. First antenna (Figure 37): length $0.7 \times$ body, $2 \times$ second antenna; peduncle article 1 longest, with sparse setae; primary flagellum of 40 articles; accessory flagellum of 7 articles, reaching to article 10 of primary flagellum. Second antenna (Figure 37): length $0.3 \times$ body; peduncle length subequal to flagellum, article 4 longer than article 5, articles 3-5 with sparse setation; flagellum 17 articulate, with sparse setation. Left mandible (Figure 37): palp article 2 with a medio-distal row of 4 robust rastellate setae, article 3 with $10 \mathrm{D}$ and $4 \mathrm{E}$ setae, facially setulose (pubescent); incisor with 5 teeth, lacinia mobilis with 5 teeth, and 4 plumose interraker setae; molar bearing pappose seta, with 2 penicillate hooked brushy basal setae and no penicillate setules. Right mandible (Figure 37): palp article 2 with a mediodistal row of 3 robust rastellate setae, article 3 with $9 \mathrm{D}$ and $4 \mathrm{E}$ setae; incisor with 5 teeth and 2 plumose interraker setae; molar, with 3 penicillate hooked brushy basal setae, and no penicillate setules. Left first maxilla (Figure 37): palp article 2 with 3 apical and 1 subapical facial strong slender setae, with 1 apicomedial seta; outer plate with 10 robust setae - 10 denticulate, none naked; inner plate subtriangular, facially and medially setulose (pubescent). Right first maxilla (Figure 37): palp apex with no articulated and 4 fused broad based tooth setae, and 1 subterminal apicolateral facial seta. Second maxilla (Figure 37): outer plate length $2.4 \mathrm{x}$ width, bearing distal long, curved naked setae; apicomedial corner of inner plate with 1 weakly submarginal thick plumose/pappose seta. Maxilliped (Figure 37): inner plate length $4.2 \times$ width, extending to M0. 8 of the outer plate, bearing small setules on the lateral margin and medioproximal face, no facial pappose setae, no medial pappose setae, with a row of 3 submarginal pappose setae, extending to a row of 4 similar subapical, and 2 apical setae, with 1 apicomedial 
mediodistal, and 3 apical naked tooth setae; outer plate broad, length $1.7 \times$ width, distally setulose (pubescent), with a row of 4 , slender naked, medial submarginal to distal facial setae, a medial row of 8 submarginal to subapical robust, naked, tooth setae, and 2 apicolateral setae -1 naked, and 1 pappose; palp, second article strongly setose medially; third article sparsely setose laterally, strongly setose medially, with 3 facial, and no ventrofacial long strong setae basal to the dactyl, the apex moderately produced, setulate, with 2 long slender naked setae, and 1 dorsal accessory seta. First gnathopod (Figure 38 ): coxal plate with 4 anteroventral setae, and 3 ventral setae; merus without posterior hump; carpus long, $1.8 \times$ width, ovate, posterior margin with setae ranked in 5 transverse bands; propodus subrectangular, small, length $1.4 \mathrm{x}$ width, posteroventral corner rounded, with 2 lateral and 1 medial robust setae, and 3 additional lateral elongate setae, palmar angle weakly oblique, bearing fine marginal teeth, dactyl not reaching to palmar corner, with a single recumbent inner tooth spine. Second gnathopod (Figure 38): subequal in size with first gnathopod; coxal plate with 4 anteroventral setae, and 3 ventral setae; carpus length $3.6 \times$ width, subrectangular, with posterior setae ranked in 6 transverse bands; propodus subrectangular, small, length $2 \times$ width, with 2 lateral and 1 medial robust setae, and 2 additional lateral elongate setae, palmar angle transverse, smooth, dactyl reaching to palmar corner, with a single recumbent inner tooth spine. Pereopods (Figure 38): pereopod 3 longer than the second gnathopod; coxa with 3 anterior setae, no long ventral setae, 3 short ventral setae, 2 setae at the posteroventral corner; carpus weakly setose posteriorly; pereopod 4 subequal in length with pereopod 3; coxa anteroventral margin with 3 setae, posteroventral margin with 4 setae, ventral margin with 1 seta, posterior margin moderately emarginate; carpus moderately setose posteriorly; coxa 5 bearing 1 seta on anterior lobe, and 1 seta on the posterior lobe; basis of periopod 5 with short slender posterior setae, bearing short and long robust anterior setae, moderately lobate posteroventrally; pereopod 6 coxa bearing 1 seta on anterior lobe; basis moderately expanded, bearing short and long robust anterior setae, moderately lobate posteroventrally; pereopod 7 coxa with 4 setae on the posterior lobe; basis bearing short and long robust anterior setae, moderately lobate posteroventrally; bases of periopods equally expanded. Epimera: first epimeron with 1 slender seta on the posterior margin; posterior margin convex, posteroventral corner rounded; second epimeron with 3 robust setae on the anteroventral margin, posterior margin sinuous, posteroventral corner subquadrate; third epimeron with 4 robust setae on the anteroventral margin, without slender setae on ventral margin, posterior margin sinuous, posteroventral corner rounded, without spine or seta. Pleon: dorsolateral margin of pleonite 1 with 4 feeble setae, of pleonite 2 with 5 feeble setae and of pleonite 3 with 1 feeble seta, and no distolateral robust setae. Pleopods (Figure 40): first, second, and third pleopods with 1 accessory retinacula. Urosomites: first urosomite bearing no distolateral slender setae, and 2 distolateral robust setae; urosomite 2 with 1 distolateral slender seta and 2 distolateral robust setae. First uropod (Figure 40): peduncle length $1.2 \times$ the length of the inner ramus, with a strong row of 4 dorsolateral robust setae and 4 dorsomedial robust setae; outer ramus with 2 dorsolateral robust setae and 3 dorsomedial robust setae; inner ramus with 2 dorsolateral robust setae 3 dorsomedial robust setae and 5 apical robust setae. Second uropod (Figure 40): $0.6 \times$ length of uropod 1, peduncle about $0.9 \times$ length of inner ramus, with no apicolateral, no dorsomedial, and 2 apicomedial robust setae; inner ramus with 1 dorsolateral, 2 dorsomedial, and 5 apical robust setae; outer ramus with 1 dorsolateral, 3 dorsomedial, and 5 apical robust setae. Third uropod (Figure 40): extending beyond uropods 1 and 2 in intact specimen, $0.9 x$ length of uropod 1; peduncle length $0.3 \times$ outer ramus, subequal in length to urosomite 3 , with 2 apicolateral robust setae, and 2 apicolateral slender setae, with no dorsomedial robust setae, and no dorsomedial slender setae, with no apicomedial robust setae, and no apicomedial slender setae, and with 1 mediodistal robust seta; inner ramus length $0.5 \times$ outer ramus; outer ramus proximal article setae arranged laterally and medially in transverse bands, with 3 lateral transverse bands of robust setae, 3 medial transverse bands of robust setae, with no medial transverse bands of mixed robust and small setae, 4 apicolateral robust setae, 1 apicolateral small seta, 4 apicomedial robust setae, no apicomedial small setae, no apicomedial long slender setae, distal article short, with no apical robust setae, and 3 apical slender setae; inner ramus with 2 medial robust setae, 1 apical robust seta, and no apical slender setae. Telson (Figure 40): subequal in length to urosomite 3 ; cleft $76 \%$, shorter than broad, length $0.7 \times$ breadth; apices rounded, with 2 subapical robust setae and 1 subapical slender seta, with 1 apical penicillate setae; paired lateral penicillate setae at M0.5 from the telson base.

\section{Allotype (female, ' $b$ ' $6.5 \mathrm{~mm}$ )}

With the characteristics of the holotype except. Body: length $6.5 \mathrm{~mm}$. First antenna: flagellum of 47 (versus 42) articles, accessory flagellum of 9 (versus 7) articles; without aesthetascs or calceoli. Second antenna: flagellum of 21 (versus 17) articles; peduncle and flagellum without calceoli. First gnathopod (Figure 39): coxa bearing an additional marginal seta (9 versus 8 ); carpus of similar 


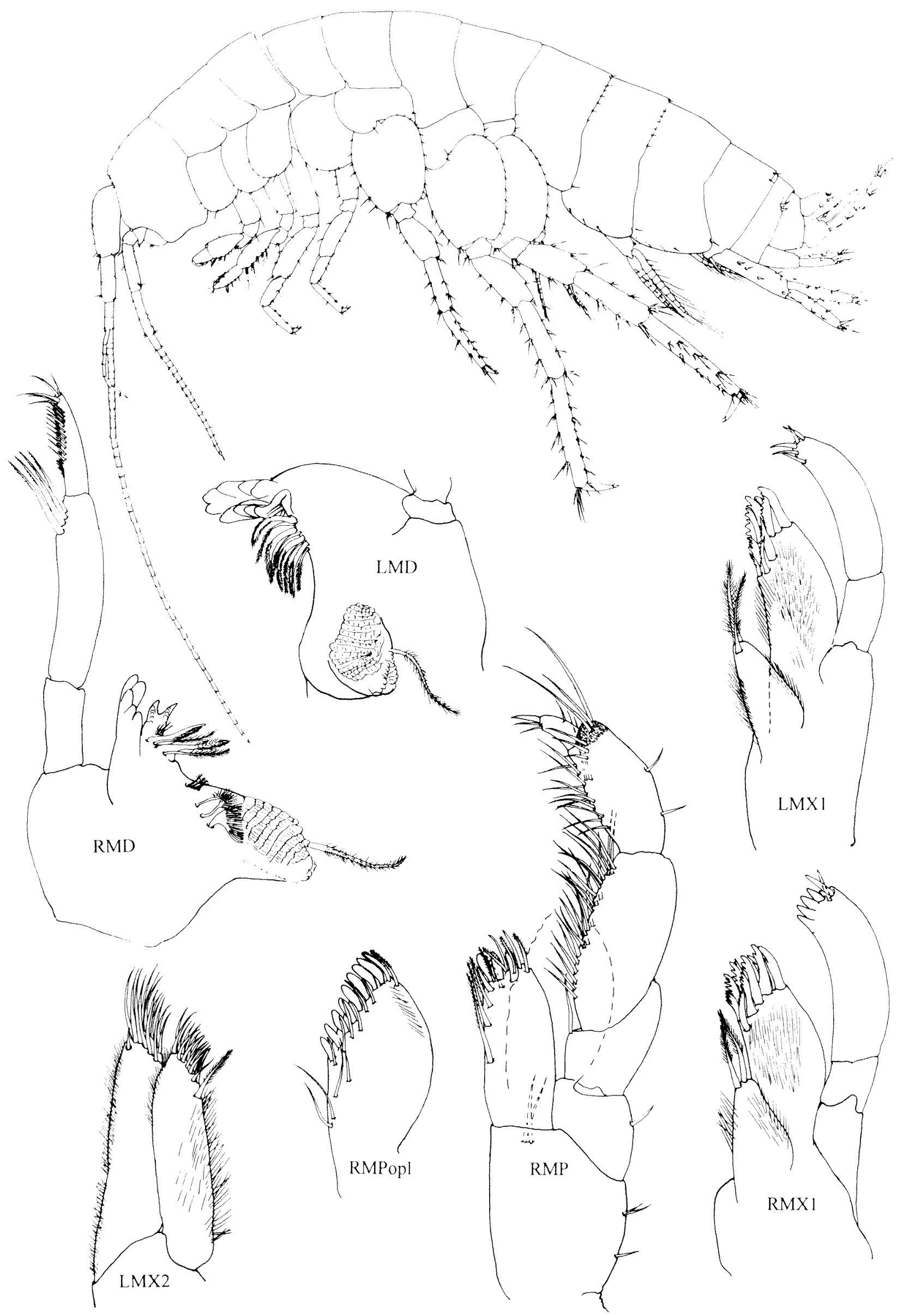

Figure 37 Chydaekata tetraspis sp. nov., holotype male 'a' $5.5 \mathrm{~mm}$, whole animal and mouthparts. 


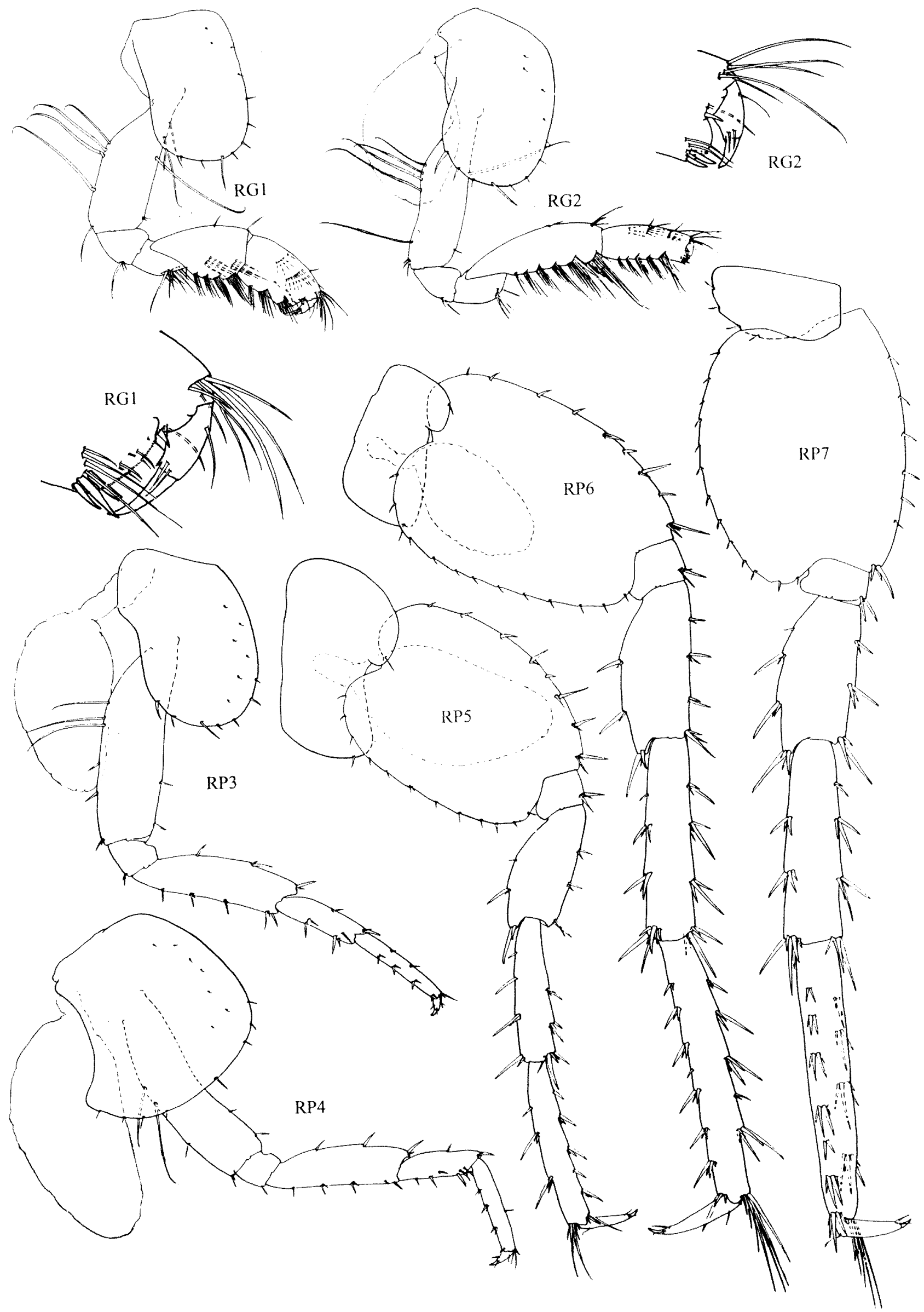

Figure 38 Chydaekata tetraspis sp. nov., holotype male 'a' $5.5 \mathrm{~mm}$, gnathopods and pereopods. 


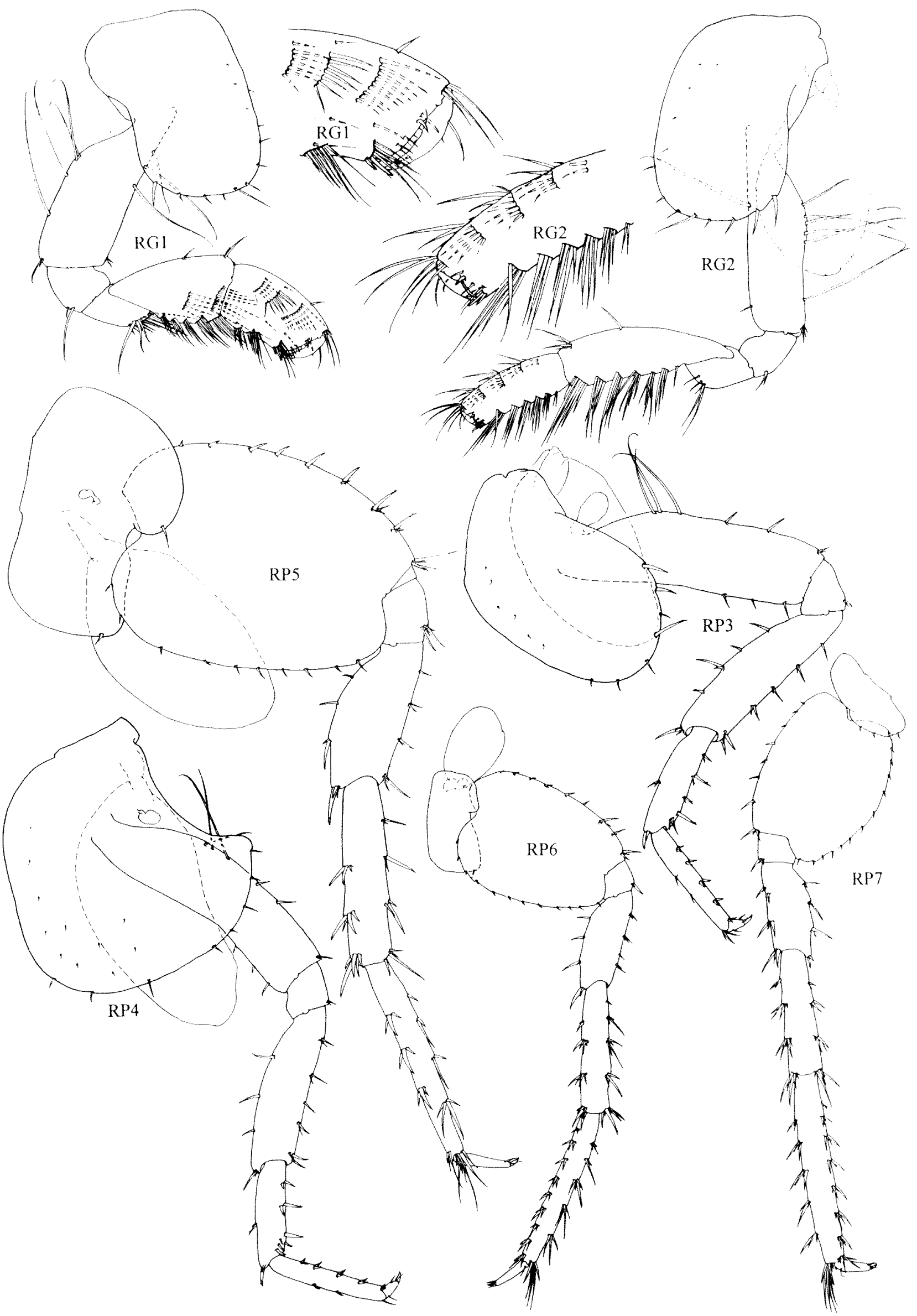

Figure 39 Chydaekata tetraspis sp. nov., allotype female ' $\mathrm{b}$ ' $6.5 \mathrm{~mm}$, gnathopods and pereopods (pereopods 6-7 shown half scale). 

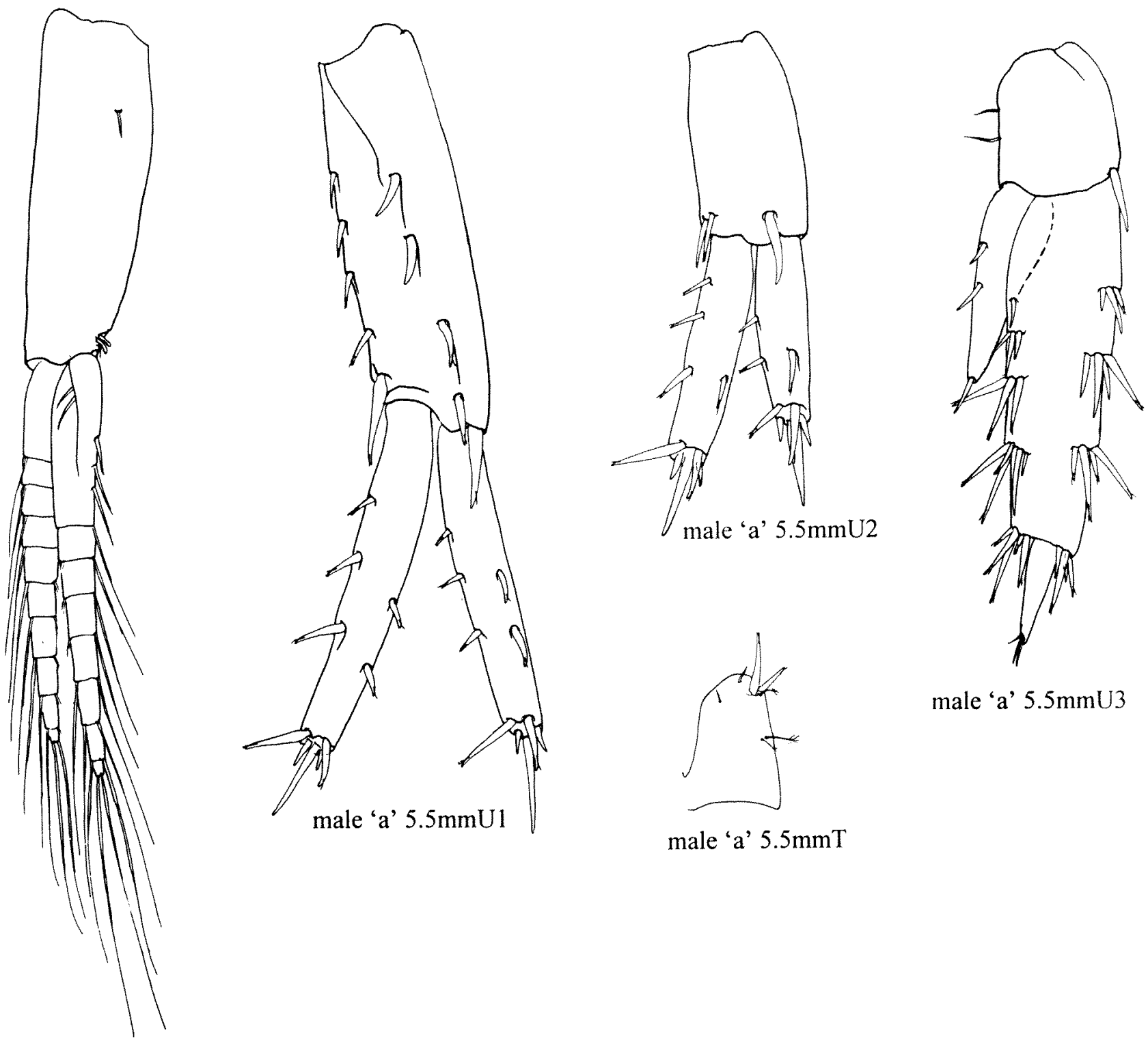

male 'a' $5.5 \mathrm{mmU} 3$

male 'a' $5.5 \mathrm{mmT}$

male 'a' $5.5 \mathrm{mmPp} 1$

Figure 40 Chydaekata tetraspis sp. nov., holotype male 'a' $5.5 \mathrm{~mm}$, pleopod 1, uropods 1-3, telson.

proportions to male, but bearing 5 (versus 4) posterior translateral setal bands; propodus shorter than male, tapering apically, bearing 3 (versus 2) medio-facial setal bands, otherwise similarly armed. Second gnathopod (Figure 39): coxa (bearing ovate oostegite), with 3 (versus 4) anterior setae; carpus longer and narrower than male, with 7 (versus 6) posterior translateral setal bands; propodus longer and narrower than in the male, bearing 6 (versus 7) posterior trans lateral setal bands and 4 (versus 3 ) medio-facial bands. Pereopods (Figure 39). Third pereopod: similar to male except for the presence on the coxa of a small ovate (immature) oostegite attached adjacent the basis. Fourth pereopod; coxa bearing a tiny ovate (immature) oostegite attached adjacent the basis. Fifth pereopod; similar to the male except for the presence on the coxa of a small bud possibly an immature oostegite near the attachment of the basis. Sixth pereopod: coxa without 1 ventro-marginal seta on the anterior lobe, otherwise similar to the male. Seventh pereopod: similar to the male. Uropods. First uropod: peduncle bearing 3 lateral and 2 apicolateral, 4 medial and 1 apicomedial robust setae; outer ramus 3 lateral, 5 medial and 5 apical robust setae; inner ramus bearing 3 lateral, 3 medial and 4 apical robust setae. Second uropod: peduncle bearing no lateral and 1 apicolateral, 1 medial and 2 apicomedial robust setae; outer ramus bearing 2 lateral, 2 medial and 5 apical robust setae; inner ramus bearing 2 lateral, 4 medial and 5 apical robust setae. Third uropod: peduncle bearing 1 apico-dorso-lateral, 2 apicoventro-lateral, 2 apico-ventral robust setae, and 1 slender dorsomedial seta; outer ramus, first article 
bearing 3 trans lateral bands and 4 distolateral, 4 transmedial bands and 5 distomedial bands of robust setae, the second article bearing 3 short, slender setae; inner ramus bearing 2 lateral robust and 1 apical slender setae. Telson: bearing a small apicolateral notch, with 1 left and 2 right robust setae and a single penicillate seta on both lobes; with paired penicillate setae submarginal at M0.6 and several dorsal setules on both lobes; cleft $80 \%$.

\section{Relationships}

Chydaekata tetraspis differs from others of the genus in: first antenna accessory flagellum of 7 articles reaching to article 10 of primary flagellum; second maxilla outer plate length less than $2.4 \times$ width, apicomedial corner of inner plate with 1 weakly submarginal thick plumose/ pappose seta; maxilliped inner plate length 3.6$4.5 \times$ width, outer plate with a row of 4 slender naked medial submarginal to disto facial setae, palp third article without ventrofacial setae basal to the dactyl; first gnathopod carpus ovate; second gnathopod propodus posteroventral corner lateral without medial robust setae; pereopod 3 coxa with 2 setae at the posteroventral corner; pereopod 7 coxa bearing 4 setae on the posterior lobe; epimera 2 posterior margin sinuous, posteroventral corner subquadrate; second uropod peduncle bearing 2 apicomedial robust setae; third uropod peduncle with 2 apicolateral robust setae, peduncle with 2 apicolateral slender setae, outer ramus proximal article with 1 apicolateral small seta; telson apices rounded each with 1 subapical slender seta.

\section{Etymology}

From the Greek 'tetra' (four) and 'aspis' (shield), referring to the sub-quadrate posteroventral corner of the second epimeron.

\section{Chydaekata ovatosetosa sp. nov.} Figures 41-44

\section{Material Examined}

\section{Holotype}

o, 'c' $6 \mathrm{~mm}$, Newman bore field, WI11, Western Australia, Australia, $23^{\circ} 20^{\prime} \mathrm{S}, 117^{\circ} 51^{\prime} \mathrm{E}$, taken with haul net, 22 July 1997, W.F. Humphreys and S.M. Eberhard, BES 4811 (WAM C24678).

\section{Allotype}

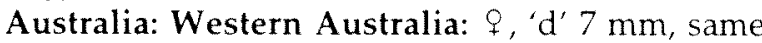
data as holotype (WAM C24679)

\section{Paratypes}

Australia: Western Australia: 1 9, 'a' $6 \mathrm{~mm}$, and about 50 others, same data as holotype (WAM C24680).

\section{Diagnosis}

Second antenna: peduncle article 5 bearing 1 calceolus, flagellum 9 articulate, with calceoli on articles 1-5. Mandible: palp article 2 with a mediodistal row of 3 robust rastellate setae; article 3 with $7 \mathrm{D}$ and $3 \mathrm{E}$ setae apically. Left first maxilla: palp article 2 with 6 apical setae. Right first maxilla: palp apex with no articulated, and 4 fused broad based tooth setae. Maxilliped outer plate with no medial submarginal to disto-facial setae; a medial row of 7 submarginal to subapical robust, naked, tooth setae; 2 apicolateral setae. First gnathopod propodus: dactyl reaching beyond the palmar corner, with a single recumbent inner tooth spine. Second gnathopod carpus: with posterior setae ranked in 4 transverse bands. Telson: cleft $68 \%$, bearing 2 subapical robust setae.

\section{Description}

\section{Holotype (male 'c' $6 \mathrm{~mm}$ )}

Body (Figure 41): urosomite 1 without dorsolateral robust setae, urosomite 2 bearing 1 dorsolateral robust seta. First antenna (Figure 41): length $0.6 \mathrm{x}$ body, $1.8 \times$ second antenna; peduncle article 1 longest, with sparse setae; primary flagellum of 25 articles; accessory flagellum of 4 articles, reaching to article 6 of primary flagellum. Second antenna (Figure 41): length $0.3 \times$ body; peduncle length greater than flagellum, article 5 bearing 1 calceolus, article 4 subequal with article 5, articles 3-5 with sparse setation; flagellum 9 articulate, with sparse setation, bearing calceoli on articles 1-5. Left mandible (Figure 41): palp article 2 with a mediodistal row of 3 robust rastellate setae, article 3 with $7 \mathrm{D}$ and $3 \mathrm{E}$ setae, facially setulose (pubescent); incisor with 6 teeth, lacinia mobilis with 5 teeth, and 2 plumose interraker setae; molar without pappose seta, without penicillate hooked brushy basal setae, and few penicillate setules. Right mandible (Figure 41): palp article 2 with a mediodistal row of 4 robust rastellate setae, article 3 with $7 \mathrm{D}$ and $3 \mathrm{E}$ setae; incisor with 5 teeth, and 2 plumose interraker setae; molar with 2 penicillate hooked brushy basal setae, and few penicillate setules. Left first maxilla (Figure 41): palp article 2 with 4 apical and 1 subapical facial strong slender setae, with 1 apicomedial, no submarginal apicomedial, and no ventrofacial apicomedial strong slender setae; outer plate with 10 robust setae, all denticulate, none naked; inner plate ovate, facially setulose (pubescent). Right first maxilla (Figure 41): palp apex with no articulated, 4 fused broad based tooth setae, and 1 subterminal apicolateral facial seta. Second maxilla (Figure 41): outer plate length $3 \times$ width, bearing distal long, curved naked setae; apicomedial corner of inner plate with 2 weakly submarginal thick plumose/ pappose setae. Maxilliped (Figure 41): inner plate 
length $2 \times$ width, extending to M0.6 of the outer plate, bearing small setules on the lateral margin, no facial pappose setae, no medial pappose setae, with a row of 3 submarginal pappose setae, extending to a row of 1 similar subapical, and 3 apical setae, with 3 apicomedial and 1 mediodistal naked tooth setae; outer plate long, length $2 \times$ width, distally naked, a medial row of 7 submarginal to subapical robust, naked, tooth setae, and 2 apicolateral setae - 1 naked, and 1 pappose; palp second article strongly setose medially, third article sparsely setose laterally, weakly setose medially, with no facial, and 2 ventrofacial long strong setae basal to the dactyl, the apex not produced, naked, with 2 long slender naked setae, and 1 dorsal accessory seta. First gnathopod (Figure 42): coxal plate with 2 anteroventral and no ventral setae; merus without posterior hump; carpus of moderate length, $1.3 \times$ width, subtriangular, posterior margin strongly setose, with setae ranked in 4 transverse bands; propodus subrectangular, small, length $1.7 \times$ width, posteroventral corner rounded, with 2 lateral and 1 medial robust setae, and 3 additional lateral elongate setae, palmar angle weakly oblique, smooth, dactyl reaching beyond palmar corner, with a single recumbent inner tooth spine. Second gnathopod (Figure 42): slightly larger than first; coxal plate with 3 anteroventral setae and no ventral setae; carpus length $2 \times$ width, subtriangular, with posterior setae ranked in 4 transverse bands; propodus subrectangular, small, length $2 \times$ width, with 2 medial robust setae, 1 lateral robust seta, and 2 additional lateral elongate setae, palmar angle transverse, smooth, dactyl reaching beyond palmar corner, with a single recumbent inner tooth spine. Pereopods (Figure 42): longer than the second gnathopod; coxa with 2 anterior setae, no long ventral setae, no short ventral setae, 1 seta at the posteroventral corner; carpus weakly setose posteriorly; pereopod 4 longer than pereopod 3, coxa anteroventral margin with 2 setae, posteroventral margin with 3 setae, ventral margin with 1 setae, posterior margin moderately emarginate, carpus weakly setose posteriorly; coxa 5 bearing 1 seta on anterior and posterior lobes, basis of pereopod 5 with short slender posterior setae, bearing short robust anterior setae or bearing short slender anterior setae, moderately lobate posteroventrally; pereopod 6 coxa bearing no setae on anterior lobe, basis moderately expanded, bearing short robust anterior setae, moderately lobate posteroventrally; pereopod 7 coxa with 1 seta on the posterior lobe; basis bearing short robust anterior setae, moderately lobate posteroventrally; bases of pereopods equally expanded. Epimera (Figure 44): first epimeron without slender setae on posterior margin; posterior margin straight, posteroventral corner subquadrate; second epimeron without robust setae on anteroventral margin; posterior margin straight, posteroventral corner rounded; third epimeron with 2 robust setae on the anteroventral margin, without slender setae on ventral margin, posterior margin convex, posteroventral corner rounded, without spine or seta. Pleon: dorsolateral margin of pleonite 1 and 2 with 1 feeble seta, of pleonite 3 with 2 feeble setae, and no distolateral robust setae. Pleopods: first pleopod with 1 accessory retinacula, second pleopod with 1 accessory retinacula, and third pleopod with no accessory retinacula. Urosomites: first urosomite bearing 2 distolateral slender setae and no distolateral robust setae; second urosomite with no distolateral slender setae and 1 distolateral robust seta. First uropod (Figure 44): peduncle length $1.3 \times$ the length of the inner ramus, with a strong row of 3 dorsolateral robust setae and 2 dorsomedial robust setae; outer ramus with 1 dorsolateral and 1 dorsomedial robust setae; inner ramus with 1 dorsolateral and 2 dorsomedial robust setae, and 5 apical robust setae. Second uropod (Figure 44): $0.6 \times$ length of uropod 1, peduncle about $1 \times$ length of inner ramus, with 1 apicolateral, no dorsomedial, and 1 apicomedial robust setae; inner ramus with no dorsolateral, 1 dorsomedial, and 5 apical robust setae; outer ramus with 1 dorsolateral, 2 dorsomedial, and 5 apical robust setae. Third uropod (Figure 44): extending beyond uropods 1 and 2 in intact specimen, $0.8 \times$ length of uropod 1; peduncle length $0.3 \times$ outer ramus, subequal in length to urosomite 3 , with 1 apicolateral robust seta and no apicolateral slender setae, no dorsomedial robust setae and no dorsomedial slender setae, with no apicomedial robust setae and 1 apicomedial slender seta, and with no mediodistal robust setae; inner ramus length $0.5 \times$ outer ramus; outer ramus proximal article setae arranged laterally and medially in transverse bands or arranged medially singly with 2 lateral transverse bands and 1 medial transverse band of robust setae, with no medial transverse bands of mixed robust and small setae, 1 medial robust seta, 4 apicolateral robust setae, no apicolateral small setae, 4 apicomedial robust setae, no apicomedial small or long slender setae; distal article short, with no apical robust setae and 3 apical slender setae; inner ramus with 1 medial robust seta, no apical robust setae, and 1 apical slender seta. Telson (Figure 44): subequal in length to urosomite 3 , cleft $68 \%$, shorter than broad, length $0.9 \times$ breadth; apices rounded and laterally notched with 2 subapical robust setae and no subapical slender setae, with 1 apical penicillate seta; and paired lateral penicillate setae at M0.6 from the telson base.

\section{Allotype (female 'd' $7 \mathrm{~mm}$ )}

With the characteristics of the holotype except. Body: length $7 \mathrm{~mm}$. First antenna: without 


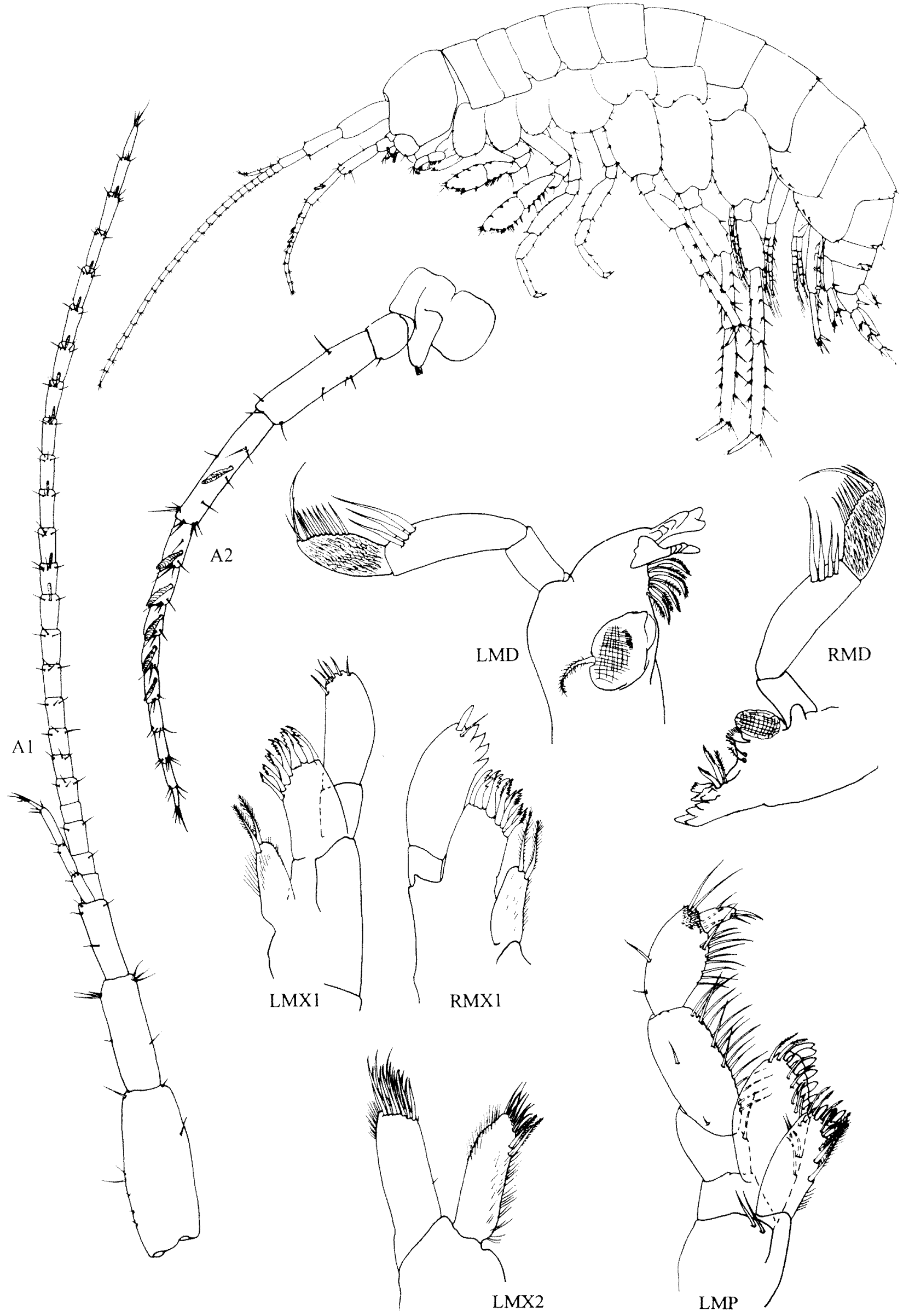

Figure 41 Chydaekata ovatosetosa sp. nov., holotype male 'c' $6 \mathrm{~mm}$, whole animal, antennae and mouthparts. 


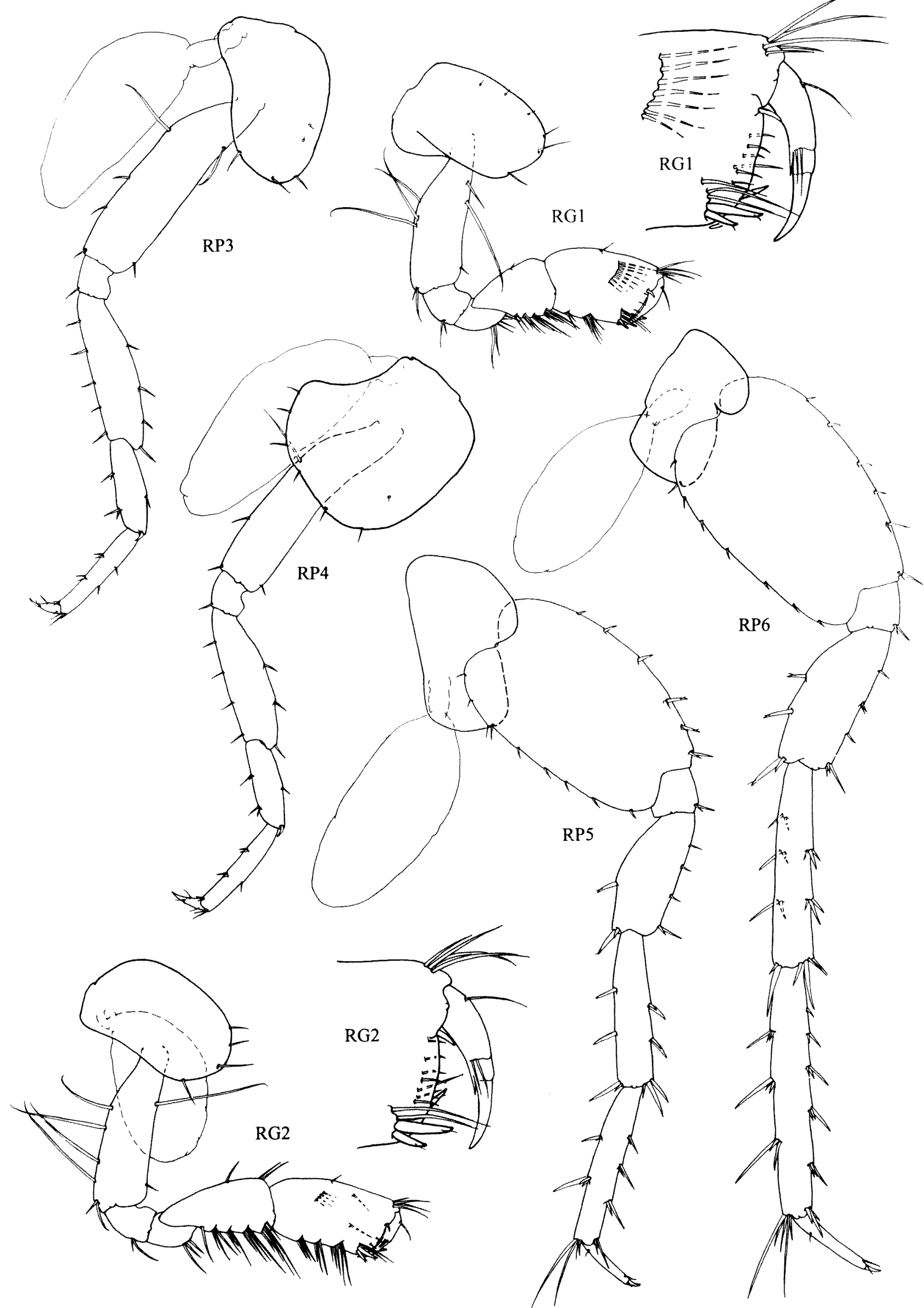

Figure 42 Chydaekata ovatosetosa sp. nov., holotype male ' $c$ ' $6 \mathrm{~mm}$, gnathopods $1-2$ and pereopods 3-6 


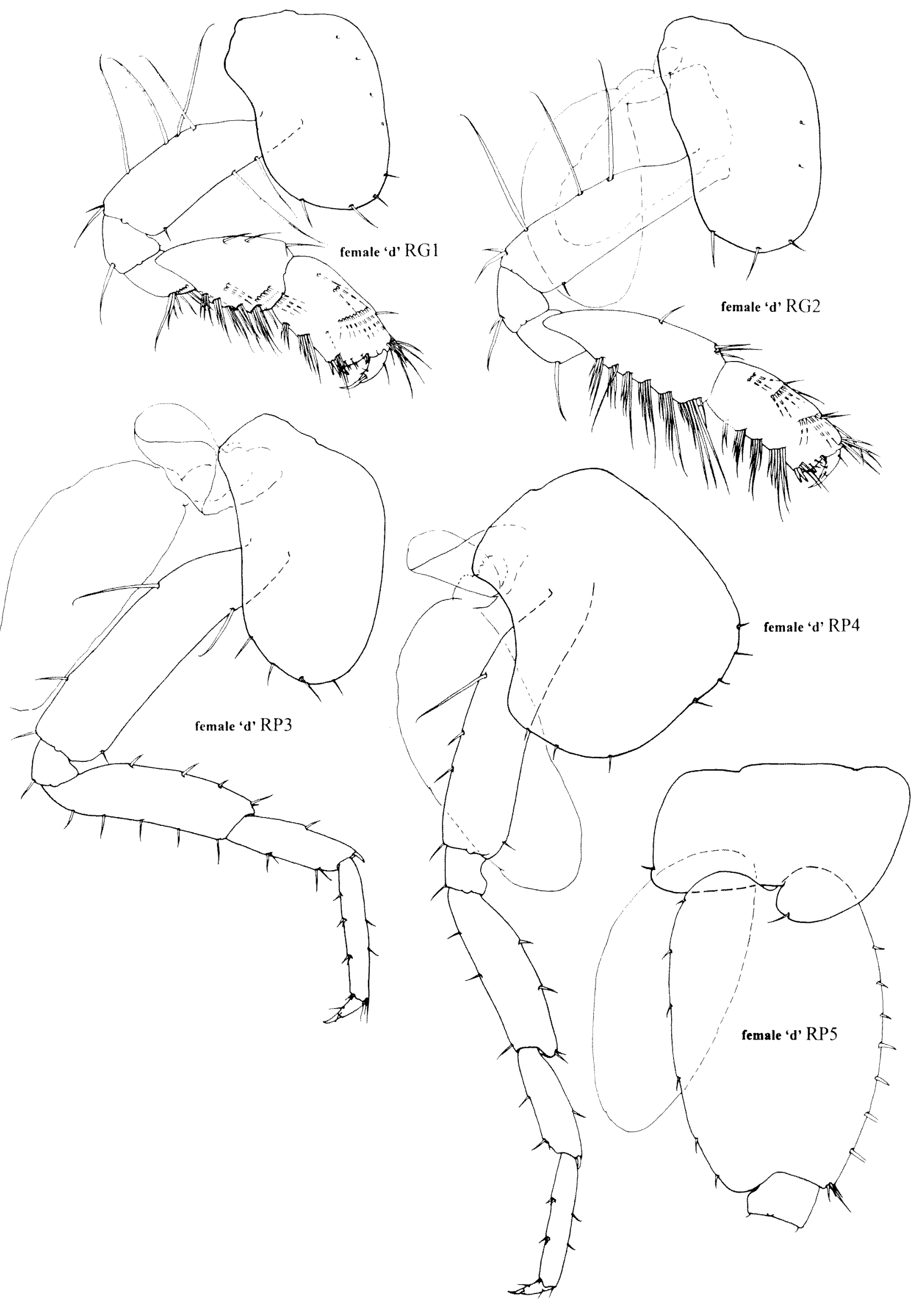

Figure 43 Chydackata ovatosetosa sp. nov, allotype female 'd' $7 \mathrm{~mm}$, gnathopods 1-2 and pereopods 3-5. 


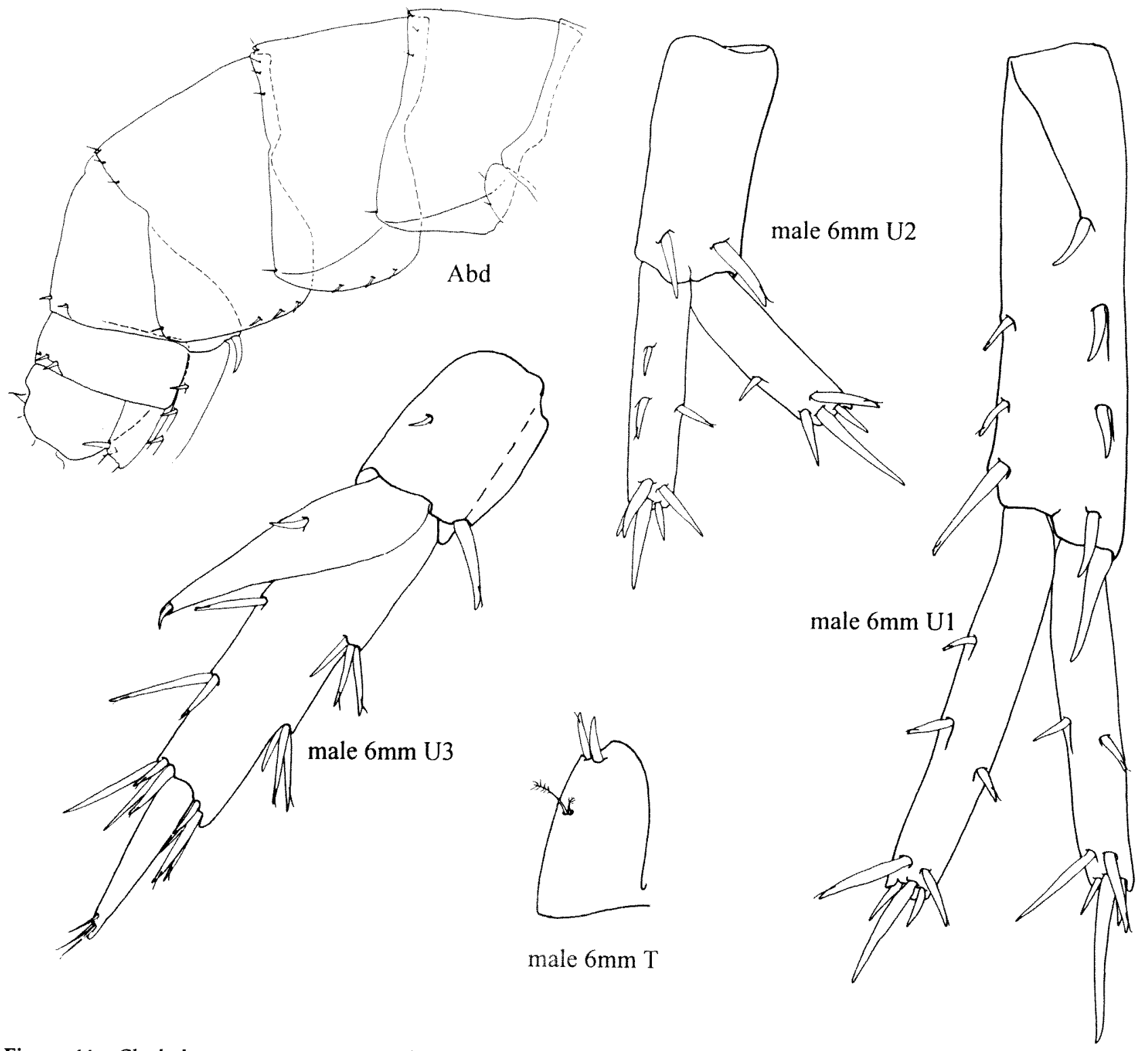

Figure 44 Chydaekata ovatosetosa sp. nov., holotype male 'c' $6 \mathrm{~mm}$, abdomen, uropods 1-3, telson.

aesthetascs or calceoli. Second antenna: without calceoli. First gnathopod (Figure 43): coxa bearing an additional anterior seta; carpus bearing 5 posterior transverse setal bands, and 2 medio-facial setal bands; propodus bearing 3 medio-facial setal bands. Second gnathopod (Figure 43): coxa with 1 fewer marginal setae; bearing large, naked, ovate oostegite, length about $1.0 x$ coxal plate; carpus longer than male, bearing 6 posterior transverse setal bands; propodus bearing 4 posterior transverse setal bands and 3 mediofacial bands. Pereopods (Figure 43). Third pereopod; coxa with 1 additional marginal seta; bearing moderate sized, naked, ovate oostegite, length about $0.7 x$ coxal plate. Fourth pereopod; coxa bearing additional marginal seta; with small to moderate sized ovate, naked oostegite, length about $0.5 x$ coxal plate. Fifth pereopod; bearing a ventro-marginal seta on the anterior lobe; without oostegite.

\section{Paratype (female $6 \mathrm{~mm}$ )}

With the characteristics of the holotype, except. Body: length $6 \mathrm{~mm}$. Pereopods. Pereopod 5 and pereopod 6 each bearing a ventral seta on the anterior lobe of the coxa; coxa 7 bearing an additional post-ventral seta.

\section{Relationships}

Chydaekata ovatosetosa differs from others of the genus in: second antenna: flagellum 9 articulate; left mandible: palp article 2 with a medio-distal row of 3 robust rastellate setae, article 3 with $7 \mathrm{D}$ setae; left first maxilla inner plate ovate, inner plate facially setose (pubescent); maxilliped inner plate setae extending to a row of 1 similar subapical setae, inner plate with 3 similar apical setae and 3 apicomedial naked tooth setae; outer plate without facial, submarginal or medial marginal setae; palp third article without facial long strong setae basal to 
the dactyl, facially naked; second gnathopod carpus with strong posterior rastellate setae ranked in 4 transverse bands; pereopod 4 longer than P3; epimera 1 with no slender setae on the posterior margin, posteroventral corner subquadrate; first uropod peduncle bearing 2 dorsomedial robust setae; first uropod peduncle bearing 1 apicomedial slender seta, inner ramus with 1 medial robust seta.

\section{Etymology}

From the Latin 'ovatus' (egg shaped), and 'setosus' (bristly), referring to the facially setose, ovate inner plate of the first maxilla.

\section{Chydaekata anophelma sp. nov.} Figures $45-47$

\section{Material Examined}

Holotype

ॐै' 'a' $5 \mathrm{~mm}$, Newman bore W129, Western Australia, Australia, $23^{\circ} 14^{\prime} \mathrm{S}, 119^{\circ} 53 \mathrm{E}, 12$ November 1998, S. Eberhard, BES 3539 (WAM C24681).

\section{Allotype}

Australia: Western Australia: $\&$, female 'b' 5 mm, same data as holotype (WAM C24682).

\section{Paratypes}

Australia: Western Australia: $1 \delta$, 'c' $6 \mathrm{~mm}$, and 57 other specimens, same data as holotype (WAM C24683).

\section{Diagnosis}

Second antenna: peduncle article 5 bearing 2 calceoli, flagellum 11 articulate, with calceoli on articles 1-7. Mandible: palp article 2 with a mediodistal row of 4 robust rastellate setae; article 3 with $10 \mathrm{D}$ and $4 \mathrm{E}$ setae apically. Left first maxilla: palp article 2 with 6 apical setae. Right first maxilla: palp apex with no articulated, and 3 fused broad based tooth setae. Maxilliped outer plate with a row of 9 slender naked, medial submarginal to disto-facial setae; a medial row of 8 submarginal to subapical robust, naked, tooth setae; 3 apicolateral setae. First gnathopod propodus: dactyl not reaching to palmar corner, with a single recumbent inner tooth spine. Second gnathopod carpus: with posterior setae ranked in 5 transverse bands. Telson: cleft $72 \%$, bearing 2 subapical robust setae.

\section{Description}

\section{Holotype (male ' $a$ ' $5 \mathrm{~mm}$ )}

Body (Figure 45): urosomite 1 bearing 1 dorsolateral robust setae; urosomite 2 bearing 2 dorsolateral robust setae. First antenna (Figure 45): length $0.6 \times$ body, $1.7 \times$ second antenna; peduncle article 1 longest, with sparse setae; primary flagellum of 27 articles; accessory flagellum of 5 articles, reaching to article 6 of primary flagellum. Second antenna (Figure 45): length $0.3 \times$ body; peduncle length greater than flagellum, article 5 bearing 2 calceoli, article 4 subequal with article 5 , articles $3-5$ with sparse setation; flagellum 11 articulate, with sparse setation, bearing calceoli on articles $1-7$. Left mandible (Figure 45): palp article 2 with a mediodistal row of 4 robust rastellate setae, article 3 with $10 \mathrm{D}$ and $4 \mathrm{E}$ setae, facially setulose (pubescent); incisor with 5 teeth, lacinia mobilis with 5 teeth, and 4 plumose interraker setae; molar without pappose seta, without penicillate hooked brushy basal setae, and few penicillate setules. Right mandible (Figure 45): palp article 2 with a medio-distal row of 4 robust rastellate setae, article 3 with $10 \mathrm{D}$ and $4 \mathrm{E}$ setae; incisor with 4 teeth, and 2 plumose interraker setae; molar without penicillate hooked brushy basal setae, and no penicillate setules. Left first maxilla (Figure 45): palp article 2 with 4 apical and 1 subapical facial strong slender setae, with 1 apicomedial seta; outer plate with 10 robust setae - 10 denticulate, none naked; inner plate subtriangular, facially and medially setulose (pubescent). Right first maxilla (Figure 45): with 5 fused broad based tooth setae, and 1 subterminal apicolateral facial seta. Second maxilla (Figure 45): outer plate length $3.6 \times$ width, bearing distal long, curved naked setae; apicomedial corner of inner plate with 2 weakly submarginal thick plumose/pappose setae. Maxilliped (Figure 45): inner plate length $3.3 \times$ width, extending to M0.7 of the outer plate, bearing small setules on the lateral margin and medioproximal face, no facial pappose setae, with a row of 5 submarginal to subapical pappose setae, extending to a row of 4 similar subapical, 1 mediodistal, and 3 apical naked tooth setae; outer plate broad, length $2.3 \times$ width, distally setulose (pubescent), with a row of 9 slender naked, medial submarginal to distal facial setae, a medial row of 8 submarginal to subapical robust, naked, tooth setae, and 3 apicolateral setae - none naked, 3 pappose; palp second article strongly setose medially; third article sparsely setose laterally, moderately setose medially, with 3 facial and 3 ventrofacial long strong setae basal to the dactyl, the apex moderately produced, setulate, with 2 long slender naked setae, and 1 dorsal accessory seta. First gnathopod (Figure 46): coxal plate with 3 anteroventral setae, and no ventral setae; merus bearing posterior hump; carpus of moderate length, $1.5 \mathrm{x}$ width, subtriangular, posterior margin with setae ranked in 4 transverse bands; propodus subrectangular, small, length $1.8 \mathrm{x}$ width, posteroventral corner rounded, with 2 lateral and 1 medial robust setae, and 2 additional lateral elongate setae, palmar angle slightly oblique, smooth, dactyl not reaching to palmar corner, with a single recumbent inner tooth spine. Second gnathopod (Figure 46): slightly larger than first; coxal plate with 
2 anteroventral setae and 1 ventral seta; carpus length $2.1 \times$ width, subtriangular, with setae ranked in 5 transverse bands; propodus subrectangular, moderate size, length $2 x$ width, with 2 lateral robust setae, 1 medial robust seta, and 1 additional lateral elongate seta, palmar angle transverse, smooth, dactyl reaching to palmar corner, with a single recumbent inner tooth spine. Pereopods (Figure 46): pereopod 3 longer than the second gnathopod; coxa with 1 anterior seta, 2 short ventral setae, 1 seta at the posteroventral corner; carpus weakly setose posteriorly; pereopod 4 subequal in length with pereopod 3, coxa anteroventral and posteroventral margins with 3 setae, ventral margin with no setae, posterior margin moderately emarginate, carpus weakly setose posteriorly; coxa 5 bearing no setae on anterior lobe, and 1 seta on the posterior lobe; basis of periopod 5 with short slender posterior setae, bearing short and long robust anterior setae, moderately lobate posteroventrally; pereopod 6 coxa bearing no setae on anterior lobe, basis moderately expanded, bearing short robust anterior setae, moderately lobate posteroventrally; pereopod 7 coxa with 2 setae on the posterior lobe; basis bearing short and long robust anterior setae, moderately lobate posteroventrally; bases of periopods equally expanded. Epimera: epimeron 1 with 1 slender seta on the posterior margin, posterior margin convex, posteroventral corner rounded; epimeron 2 with 2 robust setae on the anteroventral margin, posterior margin convex, posteroventral corner rounded; epimeron 3 with 3 robust setae on the anteroventral margin, without slender setae on ventral margin, posterior margin convex, posteroventral corner rounded, without spine or seta. Pleon: dorsolateral margin of pleonite 1 with 2 feeble setae, of pleonite 2 with 3 feeble setae, of pleonite 3 with 4 feeble setae and no distolateral robust setae. Pleopods (Figure 47): first pleopod with no accessory retinacula, second pleopod with 1 accessory retinacula, and third pleopod with no accessory retinacula. Urosomites: first urosomite bearing no distolateral slender setae, and 1 distolateral robust seta; urosomite 2 with no distolateral slender setae, and 2 distolateral robust setae. First uropod (Figure 47): peduncle length $1.2 \times$ the length of the inner ramus with a strong row of 3 dorsolateral robust setae, and 3 dorsomedial robust setae; outer ramus with 1 dorsolateral robust setae, and 2 dorsomedial robust setae; inner ramus with 1 dorsolateral robust seta, 3 dorsomedial robust setae, and 5 apical robust setae. Second uropod (Figure 47): $0.8 \times$ length of uropod 1, peduncle about $2 \times$ length of inner ramus; with 1 apicolateral, no dorsomedial, and 1 apicomedial robust setae; inner ramus with 1 dorsolateral, 1 dorsomedial, and 5 apical robust setae; outer ramus with 1 dorsolateral, 3 dorsomedial, and 5 apical robust setae. Third uropod (Figure 47): extending beyond uropods 1 and 2 in intact specimen, $0.8 \times$ length of uropod 1; peduncle length $0.6 \times$ outer ramus, subequal in length to urosomite 3 , with 1 apicolateral robust seta, and no apicolateral slender setae, with no dorsomedial robust setae, and no dorsomedial slender setae, no apicomedial robust setae, no apicomedial slender setae, and with 1 mediodistal robust seta; inner ramus length $0.6 \times$ outer ramus; outer ramus proximal article setae arranged laterally and medially in transverse bands and arranged medially singly with 3 lateral transverse bands of robust setae, 1 medial transverse band of robust setae, with no medial transverse bands of mixed robust and small setae, 1 medial robust seta, 3 apicolateral robust setae, no apicolateral small setae, 3 apicomedial robust setae, no apicomedial small setae, no apicomedial long slender setae; distal article short, with no apical robust setae, and 3 apical slender setae; inner ramus with 2 medial robust setae, no apical robust setae, and 1 apical slender seta. Telson (Figure 47): shorter than, $0.8 \mathrm{x}$, urosomite 3 ; cleft $72 \%$, as long as broad; apices rounded, with 2 subapical robust setae, and no subapical slender setae; apical penicillate setae absent, with paired lateral penicillate setae at M0.6 from the telson base.

\section{Allotype (female ' $b$ ' $5 \mathrm{~mm}$ )}

With the characteristics of the holotype except. Body: length $5 \mathrm{~mm}$. First antenna: without aesthetascs or calceoli. Second antenna: without calceoli. First gnathopod (Figure 47): smaller than the male; coxa bearing 4 (versus 5) marginal setae; carpus more elongate than the male, bearing 4 (versus 3) posterior translateral setal bands; propodus less robust than male, bearing 1 (versus 2) posteriro translateral setal bands and 2 (versus 3 ) medio-facial bands. Second gnathopod (Figure 47): coxa bearing 3 (versus 4) marginal setae, and (naked, ovate oostegite). Pereopods (Figure 47). Pereopod three: bearing 4 (versus 5) marginal setae and (naked, ovate oostegite). Pereopod four: bearing 6 (versus 5) marginal setae and a small, naked, ovate oostegite, length about $0.4 x$ coxal plate. Pereopod five: coxa bearing 1 ventromarginal seta (versus none) on the anterior lobe, and a small/moderate length naked, ovate oostegite, length about $0.5 x$ coxal plate. Pereopods six and seven: similar to the holotype.

\section{Paratype (male ' $\mathrm{c}$ ' $6 \mathrm{~mm}$ )}

With the characteristics of the holotype except. Body: length $6 \mathrm{~mm}$. First antenna: primary flagellum of 22articles, the accessory flagellum of 4 . Second antenna: flagellum of 9 articles, bearing prominent calceoli on articles 1, 3-6.

\section{Relationships}

Chydaekata anophelma differs from others of the 


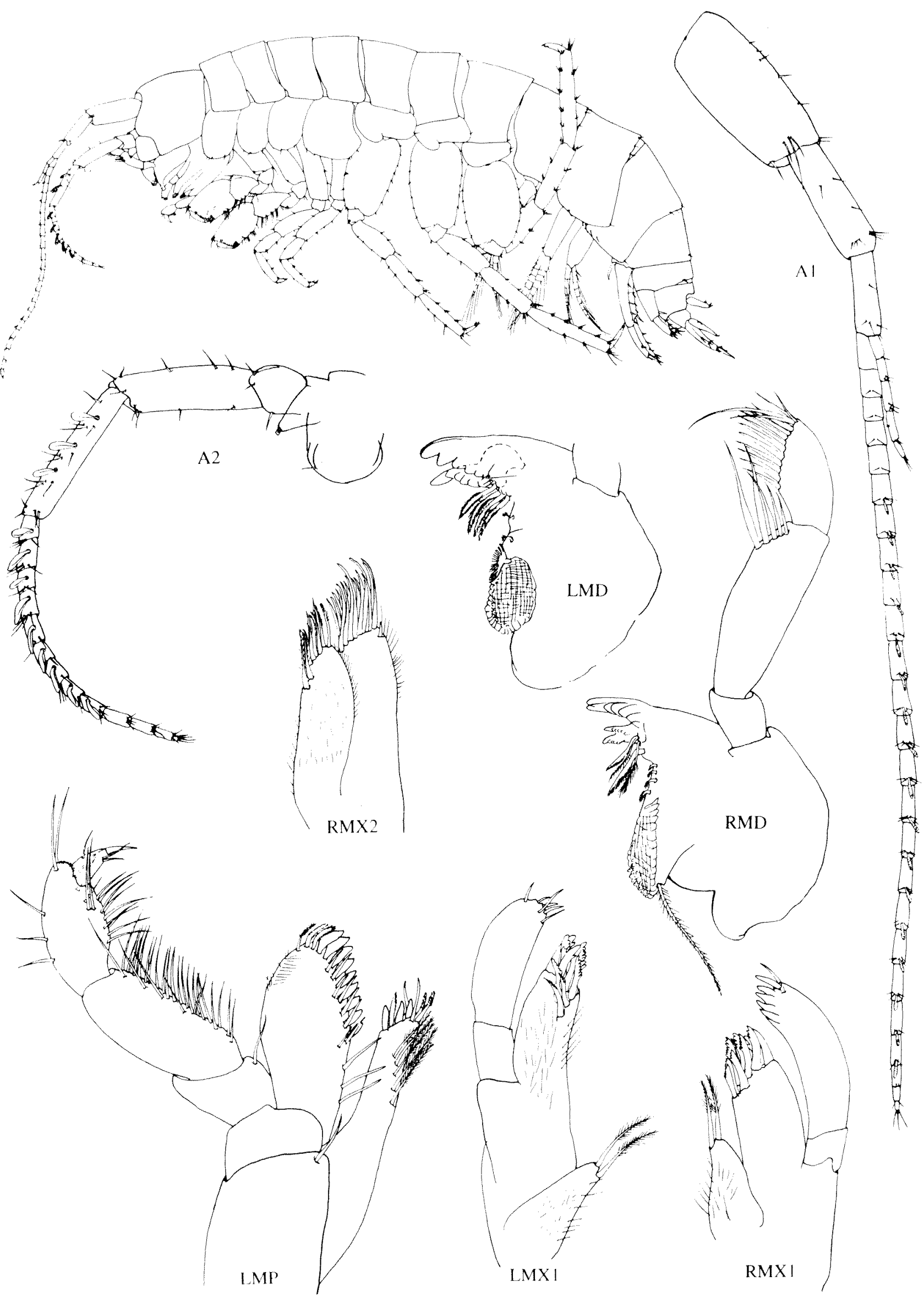

Figure 45 Chydaekata anophelma sp. nov, holotype male 'a' $5 \mathrm{~mm}$, whole animal, antennae and mouthparts. 


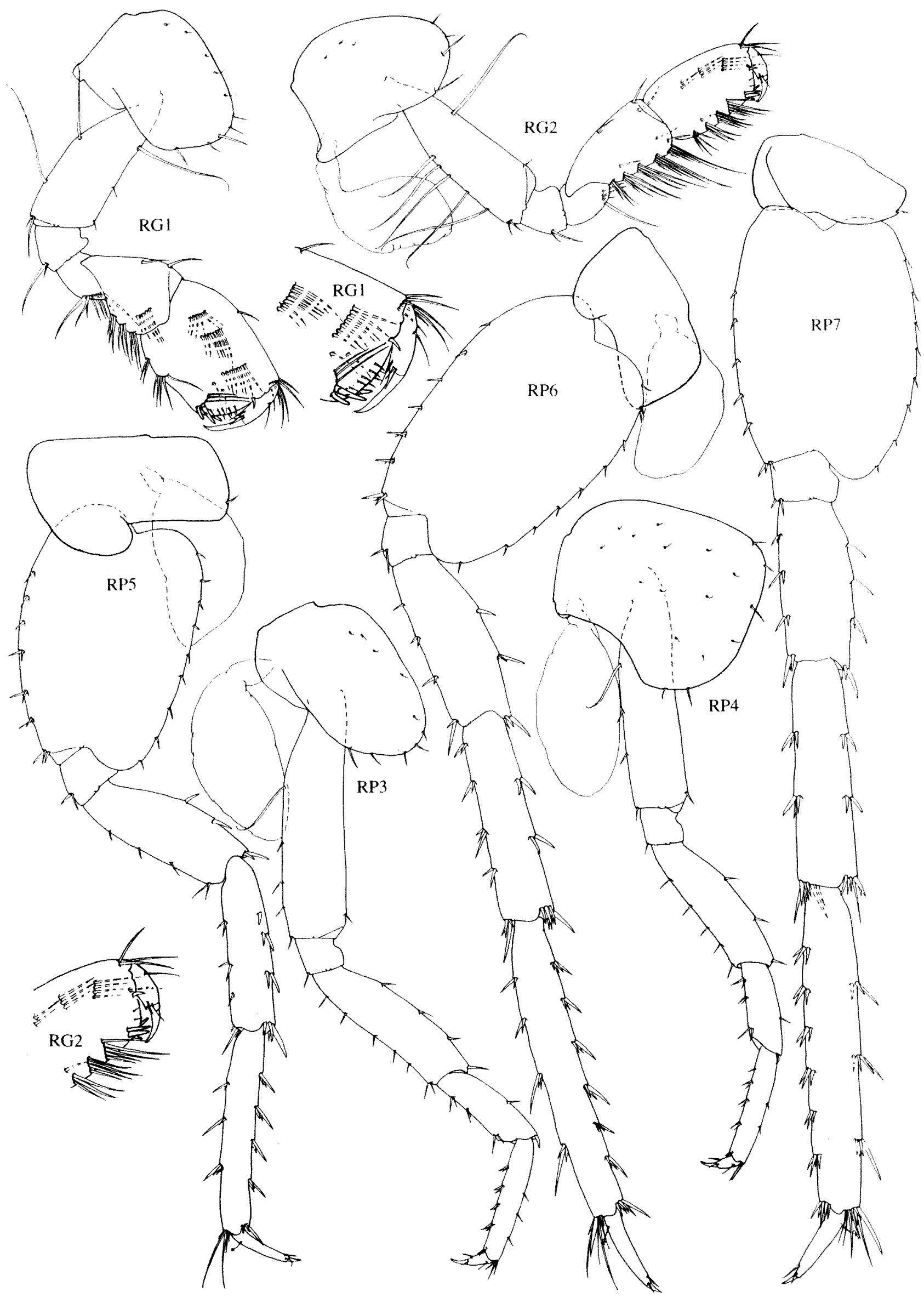

Figure 46 Chydaekata anophelma sp. nov., holotype male ' $a$ ' $5 \mathrm{~mm}$, gnathopods and pereopods. 

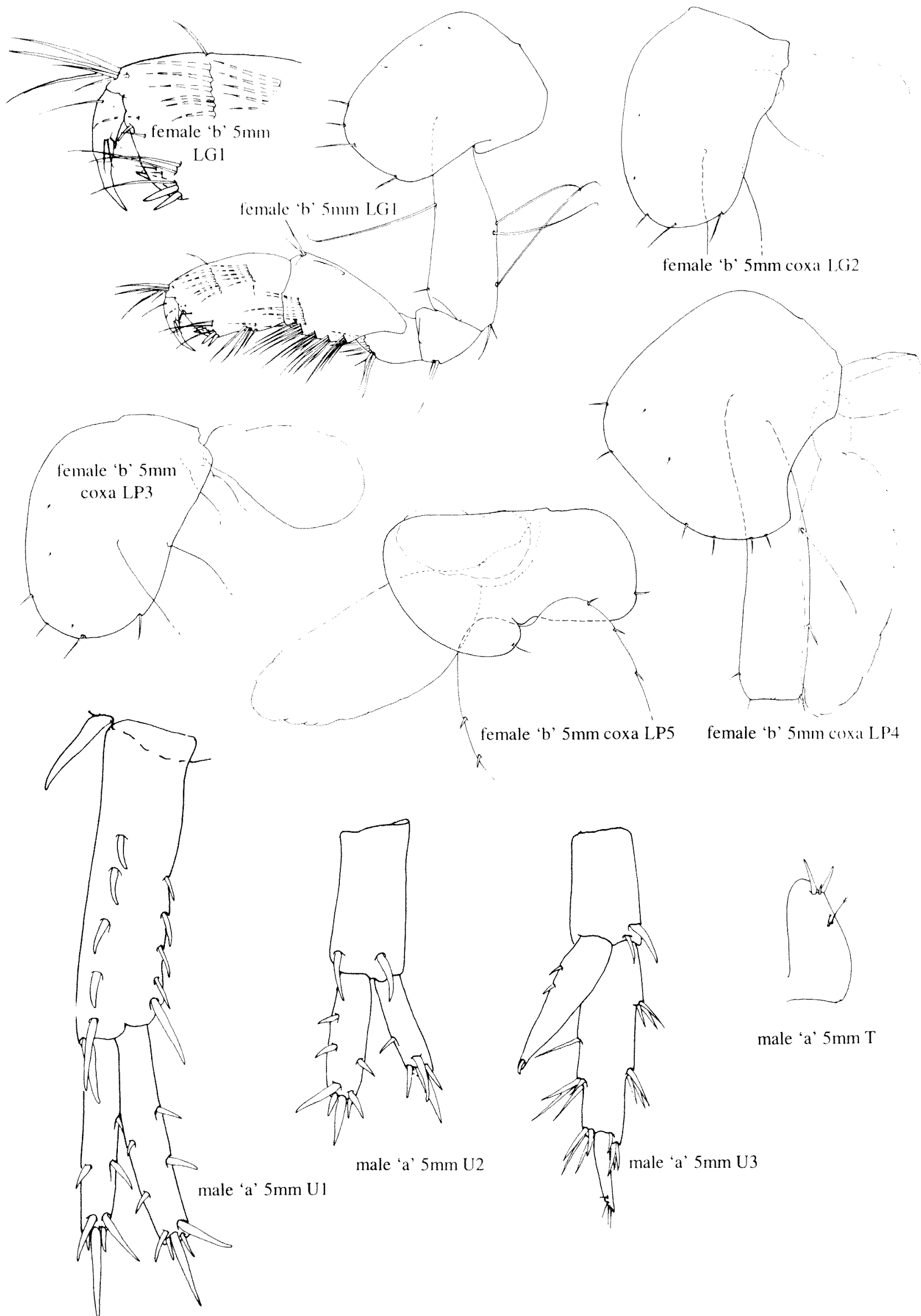

Figure 47 Chydaekata anophelma sp. nov., holotype male 'a' $5 \mathrm{~mm}$, uropods 1-3, telson. Allotype female 'b' $5 \mathrm{~mm}$, coxae 2-5. 
genus in: first gnathopod propodus posteroventral corner bearing 2 additional elongate setae on the lateral face; second gnathopod propodus posteroventral corner with 1 additional lateral elongate seta; pereopods 5 coxa bearing no setae on anterior lobe; epimera 2 posterior margin convex; first pleopod with no accessory retinacula; second uropod $0.7-1.0 \times$ length of uropod 1, peduncle length 1.4-2.5x length of inner ramus; third uropod outer ramus proximal article with 3 apicomedial robust setae.

\section{Etymology}

From the Greek 'an' (not), and 'ophelma' (broom), referring to the absence of brushy basal setae on the molar of the left mandible.

\section{Chydaekata scopula sp. nov.} Figures 48-51

\section{Material Examined}

\section{Holotype}

ठ', ' $a$ ' $5.5 \mathrm{~mm}$, Newman bore field, PZ13S, Western Australia, Australia, $23^{\circ} 19^{\prime} \mathrm{S}, 117^{\circ} 51^{\prime} \mathrm{E}$, taken with haul net, 24 July 1997, W.F. Humphreys and S.M. Eberhard, BES 4843 (WAM C24684).

\section{Allotype}

Australia: Western Australia: $q$, ' $b$ ' $6.5 \mathrm{~mm}$, same data as holotype (WAM C24685).

\section{Paratypes}

Australia: Western Australia: 7 specimens, same data as holotype (WAM C24686).

\section{Diagnosis}

Second antenna: peduncle article 5 bearing 2 calceoli, flagellum 13 articulate, with calceoli on articles 1-7. Mandible: palp article 2 with a mediodistal row of 4 robust rastellate setae; article 3 with $10 \mathrm{D}$ and $4 \mathrm{E}$ setae apically. Left first maxilla: palp article 2 with 6 apical setae. Right first maxilla: palp apex with no articulated, and 4 fused broad based tooth setae. Maxilliped outer plate with a row of 9 slender naked, medial submarginal to disto-facial setae; a medial row of 8 submarginal to subapical robust, naked, tooth setae; 2 apicolateral setae. First gnathopod propodus: dactyl reaching to palmar corner, with a single recumbent inner tooth spine. Second gnathopod carpus: with posterior setae ranked in 6 transverse bands. Telson: cleft $71 \%$, bearing 3 subapical robust setae.

\section{Description}

Holotype (male 'a' $5.5 \mathrm{~mm}$ )

Body (Figure 48): urosomites 1 and 2 bearing 2 dorsolateral robust setae. First antenna (Figure 48): length $0.5 \mathrm{x}$ body, $1.6 \mathrm{x}$ second antenna; peduncle article 1 longest, with sparse setae; primary flagellum of 31 articles; accessory flagellum of 5 articles, reaching to article 5 of primary flagellum. Second antenna (Figure 48): length $0.3 \times$ body; peduncle length greater than flagellum, article 5 bearing 2 calceoli, article 4 subequal with article 5 , articles 3-5 with sparse setation; flagellum 13 articulate, with sparse setation, bearing calceoli on articles $1-7$. Left mandible (Figure 48): palp article 2 with a medio-distal row of 4 robust rastellate setae, article 3 with $10 \mathrm{D}$ and $4 \mathrm{E}$ setae, facially setulose (pubescent); incisor with 5 teeth, lacinia mobilis with 5 teeth, and 4 plumose interraker setae; molar bearing pappose seta, with 1 penicillate hooked brushy basal seta. Right mandible (Figure 48): palp article 2 with a medio-distal row of 3 robust rastellate setae, article 3 with $9 \mathrm{D}$ and $4 \mathrm{E}$ setae; incisor with 5 teeth, and 2 plumose interraker setae; molar with 3 penicillate hooked brushy basal setae. Left first maxilla (Figure 48): palp article 2 with 4 apical, with 1 apicomedial, and 1 ventrofacial apicomedial strong slender setae; outer plate with 10 robust setae -10 denticulate, none naked; inner plate subtriangular, facially and medially setulose (pubescent). Right first maxilla (Figure 48): palp apex with no articulated and 4 fused broad based tooth setae, and 1 subterminal apicolateral facial seta. Second maxilla (Figure 48): outer plate length $3.9 \times$ width, bearing distal long, curved naked setae; apicomedial corner of inner plate with 2 weakly submarginal thick plumose/pappose setae. Maxilliped (Figure 48): inner plate length $3.3 \times$ width, extending to M0.7 of the outer plate, bearing small setules on the lateral margin and medioproximal face, with a row of 4 submarginal pappose setae, extending to a row of 5 similar subapical, and 2 apical setae, and 3 apical naked tooth setae; outer plate broad, length $1.8 \mathrm{x}$ width, distally setulose (pubescent), with a row of 9, slender naked, medial submarginal to distal facial setae, a medial row of 8 submarginal to subapical robust, naked, tooth setae, and 2 apicolateral setae none naked, 2 pappose; palp, second article moderately setose medially; third article sparsely setose laterally, moderately setose medially, with 3 facial, and 2 ventrofacial long strong setae basal to the dactyl, the apex moderately produced, setulate, with 2 long slender naked setae, and 1 dorsal accessory seta. First gnathopod (Figure 49): coxal plate with 3 anteroventral setae, and no ventral setae; merus without posterior hump; carpus of moderate length, $1.5 \mathrm{x}$ width, subtriangular, posterior margin, with setae ranked in 4 transverse bands; propodus subrectangular, moderate size, length $1.7 \mathrm{x}$ width, posteroventral corner rounded, with 2 lateral and 1 medial robust setae, and 3 additional lateral elongate setae, palmar angle 


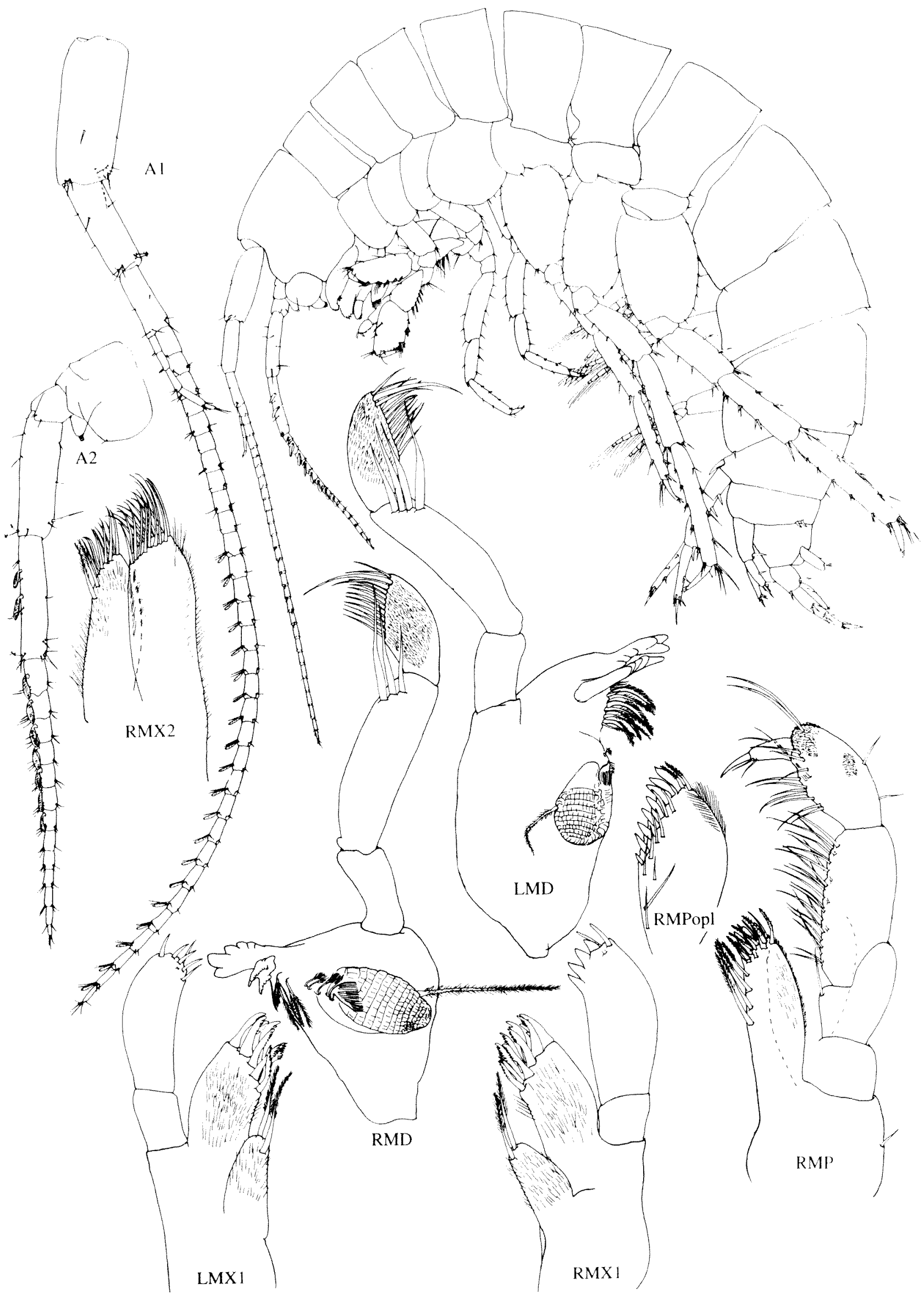

Figure 48 Chydaekata scopula sp. nov, holotype male 'a' $5.5 \mathrm{~mm}$, whole animal, antennae and mouthparts. 


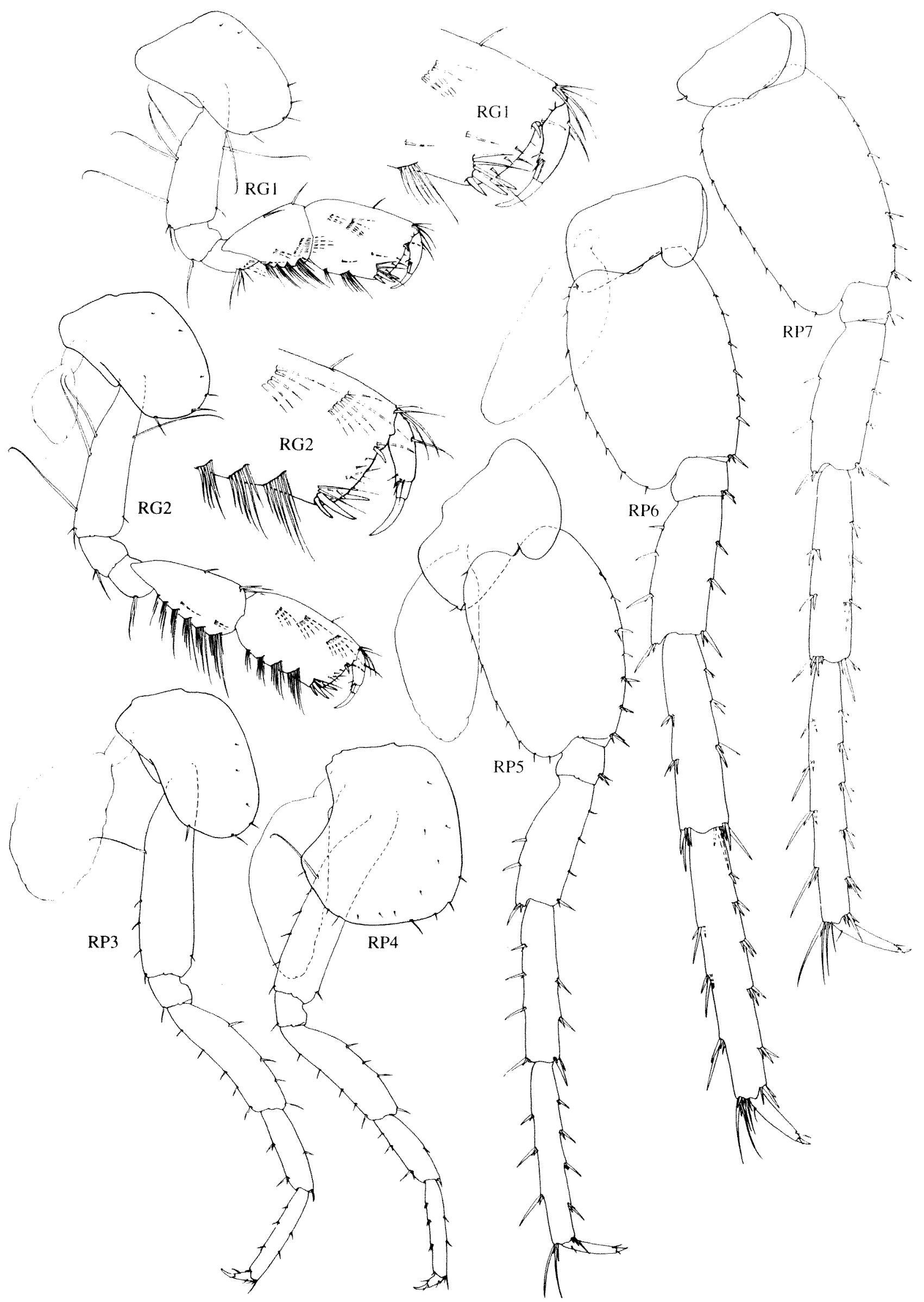

Figure 49 Chydaekata scopula sp. nov., holotype male 'a' $5.5 \mathrm{~mm}$, gnathopods and pereopods. 


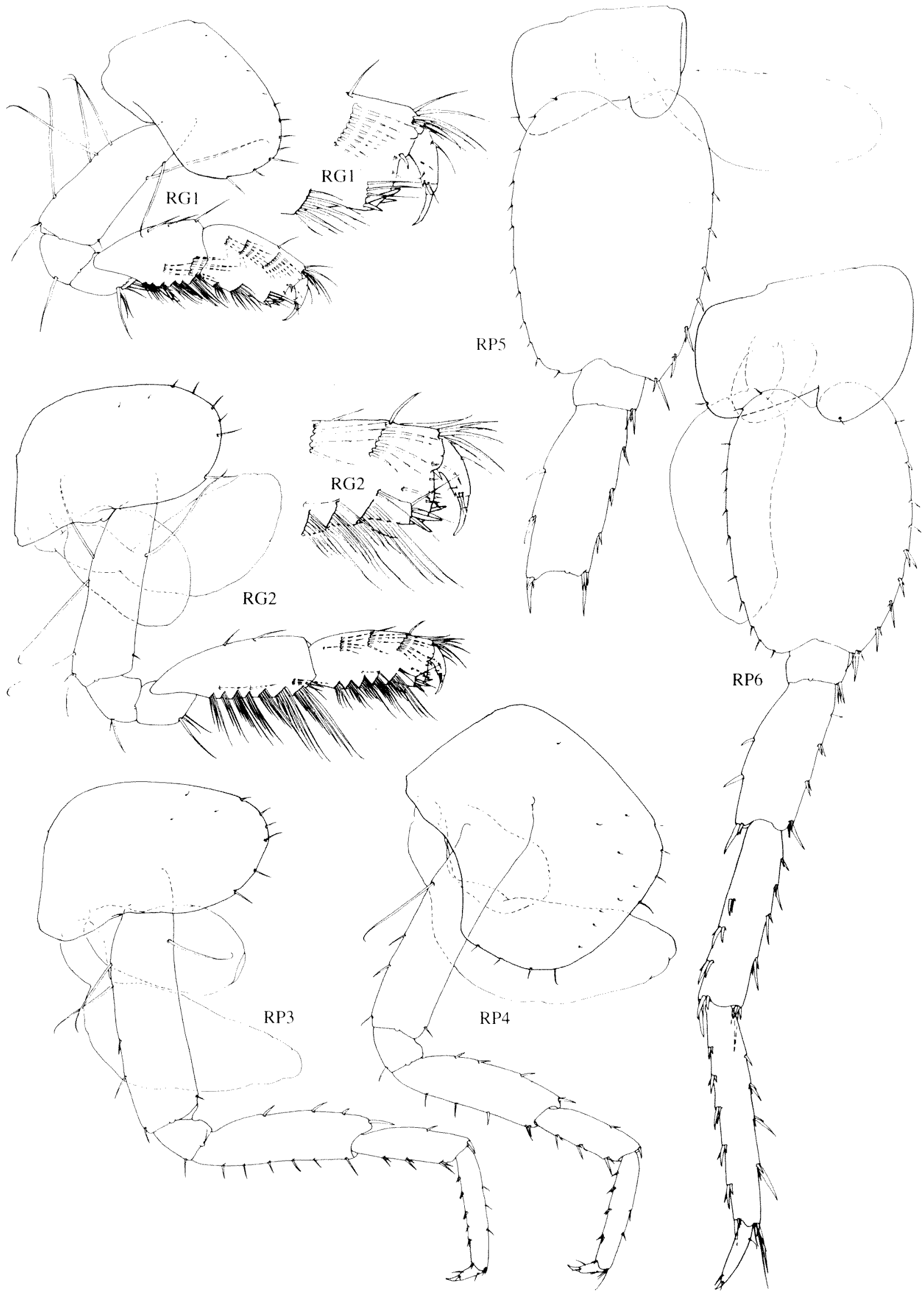

Figure 50 Chydaekata scopula sp. nov., allotype female ' $\mathrm{b}^{\prime} 6.5 \mathrm{~mm}$, gnathopods and pereopods $2-6$. 


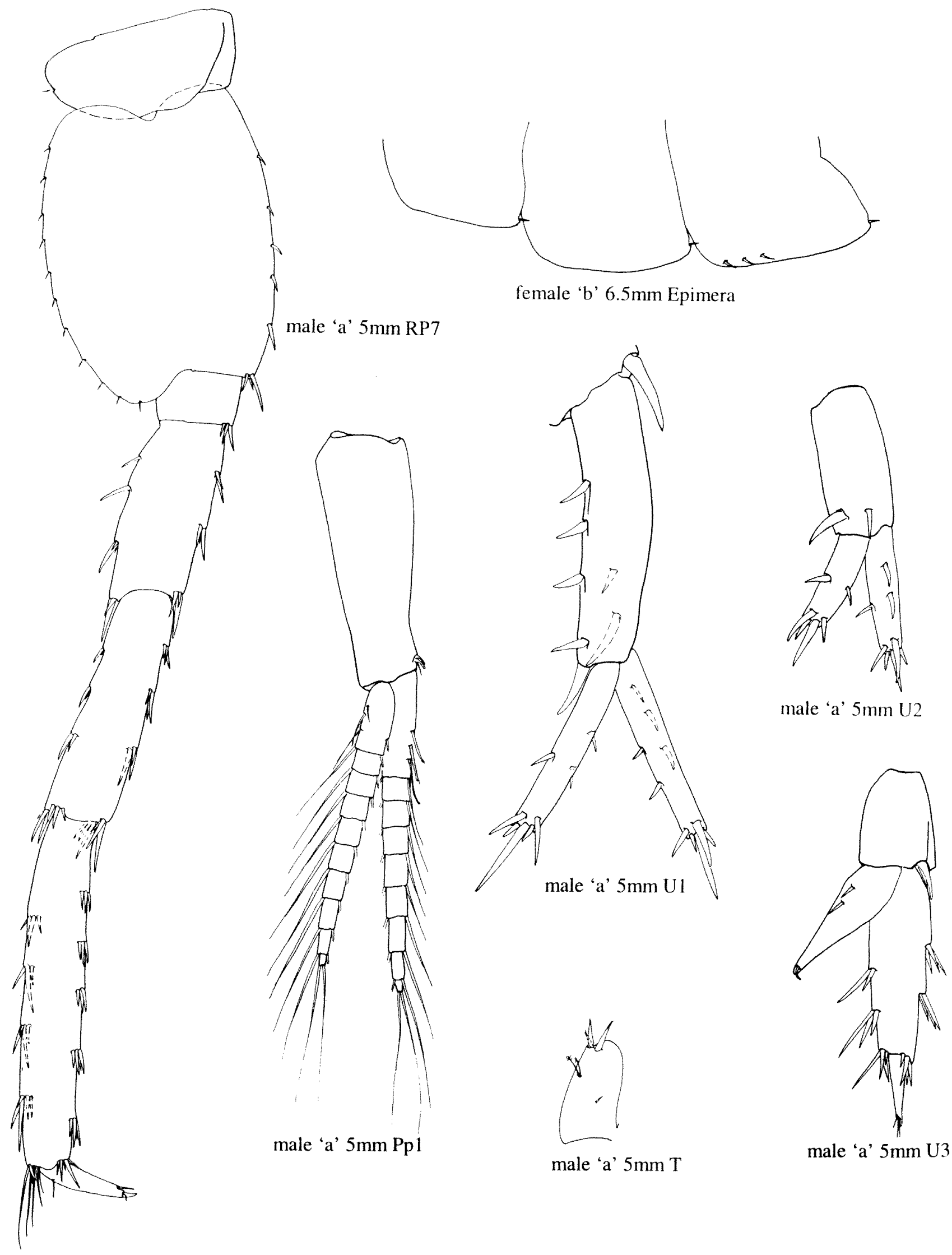

Figure 51 Chydaekata scopula sp. nov., holotype male 'a' $5.5 \mathrm{~mm}$, pleopod 1, uropods 1-3, telson. Allotype female 'b' 6.5 $\mathrm{mm}$, pereopod 7, epimera. 
slightly oblique, smooth, dactyl reaching to palmar corner, with a single recumbent inner tooth spine. Second gnathopod: slightly larger than first; coxal plate with 2 anteroventral setae, and no ventral setae; carpus length $2.2 \times$ width, subtriangular, with posterior setae ranked in 6 transverse bands; propodus subrectangular, moderate size, length 1.7 $x$ width, with 2 lateral and 1 medial robust setae, and 2 additional lateral elongate setae, palmar angle weakly oblique, smooth, dactyl reaching to palmar corner, with a single recumbent inner tooth spine. Pereopods (Figure 49): pereopod 3 longer than the second gnathopod, coxa with 1 anterior seta, 1 short ventral seta, and 1 seta at the posteroventral corner; carpus weakly setose posteriorly; pereopod 4 subequal in length with pereopod 3 , coxa anteroventral margin with 4 setae, posteroventral margin with 4 setae, ventral margin with no setae, posterior margin moderately emarginate, carpus weakly setose posteriorly; coxa 5 bearing 1 seta on anterior lobe, and 1 seta on the posterior lobe; basis with short slender posterior setae, bearing short and long robust anterior setae, moderately lobate posteroventrally; pereopod 6 coxa bearing no setae on anterior lobe; basis moderately expanded, bearing short and long robust anterior setae, moderately lobate posteroventrally; pereopod 7 coxa with 1 seta on the posterior lobe; basis bearing short and long robust anterior setae, moderately lobate posteroventrally; bases of periopods equally expanded. Epimera (Figure 51):first epimeron with 1 slender seta on the posterior margin, posterior margin straight, posteroventral corner rounded; second epimeron with 1 robust seta on the anteroventral margin, posterior margin straight, posteroventral corner rounded; third epimeron with 3 robust setae on the anteroventral margin, without slender setae on ventral margin; posterior margin convex, posteroventral corner rounded, with small spine. Pleon: dorsolateral margin of pleonite 1 with no feeble setae, of pleonite 2 with 2 feeble setae, of pleonite 3 with 1 feeble seta, and no distolateral robust setae. Pleopods (Figure 51): first and second pleopods with 1 accessory retinacula, and third pleopod with no accessory retinacula. Urosomites: first urosomite bearing 1 distolateral slender seta and 1 distolateral robust seta; urosomite 2 with no distolateral slender setae, and 3 distolateral robust setae. First uropod (Figure 51): peduncle length $1.4 \mathrm{x}$ the length of the inner ramus, with a strong row of 3 dorsolateral robust setae, and 3 dorsomedial robust setae; outer ramus with 1 dorsolateral robust seta, and 2 dorsomedial robust setae; inner ramus with 2 dorsolateral robust setae, 2 dorsomedial robust setae, and 5 apical robust setae. Second uropod (Figure 51): $0.6 \times$ length of uropod 1, peduncle about $1.2 \times$ length of inner ramus, with 1 apicolateral, no dorsomedial, and 1 apicomedial robust setae; inner ramus with 1 dorsolateral, 1 dorsomedial, and 5 apical robust setae; outer ramus with 1 dorsolateral, no dorsomedial, and 5 apical robust setae. Third uropod (Figure 51): extending beyond uropods 1 and 2 in intact specimen, $0.7 x$ length of uropod 1; peduncle length $0.4 \times$ outer ramus, shorter than, $0.8 \mathrm{x}$, urosomite three, with 1 apicolateral robust seta, and no apicolateral slender setae, with no dorsomedial robust setae, and no dorsomedial slender setae, with no apicomedial robust setae, and no apicomedial slender setae, and with no mediodistal robust setae; inner ramus length $0.5 \times$ outer ramus; outer ramus proximal article setae arranged laterally and medially in transverse bands, with 2 lateral transverse bands of robust setae, with 2 medial transverse bands of mixed robust and small setae, 4 apicolateral robust setae, no apicolateral small setae, 4 apicomedial robust setae, no apicomedial small setae, and no apicomedial long slender setae; distal article short, with no apical robust setae, and 3 apical slender setae; inner ramus with 2 medial robust setae, no apical robust setae, and 1 apical slender seta. Telson (Figure 51): shorter than, $0.7 x$, urosomite 3; cleft $71 \%$, shorter than broad, length $0.9 \times$ breadth; apices rounded and laterally notched, with 3 subapical robust setae and no subapical slender setae; apical penicillate setae absent, with paired lateral penicillate setae at M0.6 from the telson base.

\section{Allotype (female ' $b$ ' $6.5 \mathrm{~mm}$ )}

With the characteristics of the holotype except. Body: length $6.5 \mathrm{~mm}$. First antenna: without aesthetascs or calceoli. Second antenna: without calceoli. First gnathopod (Figure 50): coxa bearing 7 (versus 4) marginal setae; carpus longer than male, bearing 6 (versus 4) posterior translateral setal bands; propodus smaller and less robust than the male, tapering apically, bearing 3 (versus 2) mediofacial ranks of setae, palm and dactyl similar to male. Second gnathopod (Figure 50): coxa bearing 6 (versus 3) marginal setae and a large, ovate, margianally smooth and naked oostegite, length about $0.7 x$ coxal plate; carpus longer and narrower than the male, subrectangular rather than subtriangular, bearing 7 (versus 6) posterior translateral bands of setae as well as additional medial setae; propodus less robust than the male, longer and narrower, bearing 5 (versus 4) posterior translateral setal bands and additional medial setae, palm and dactyl similar. Pereopods (Figure 50). Pereopod three: coxa bearing 6 (versus 3) marginal setae, longer than the male, with a large, ovate, marginally smooth and naked oostegite, length about $0.7 x$ coxal plate. Pereopod four: coxa bearing small, paddle shaped, naked, round oostegite, length about $0.5 x$ coxal plate. Pereopod five: coxa bearing 1 (versus none) ventro-marginal seta on the anterior lobe, and a small round naked oostegite, length about $0.4 x$ coxal plate. Pereopods six and seven: similar to the Holotype. Epimera 
(Figure 51): second epimeron lacking marginal anteroventral seta.

\section{Relationships}

Chydaekata scopula differs from others of the genus in: left first maxilla palp article 2 with no subapical facial strong slender setae; epimera 2 posterior margin straight; second uropod outer ramus bearing no dorsomedial robust setae; third uropod outer ramus proximal article with no medial transverse bands of robust setae but 2 medial transverse bands of mixed robust and small setae.

\section{Etymology}

From the Latin 'scopa' (broom), referring to the presence of brushy basal setae on the molar of the left mandible.

\section{Chydaekata scuticara sp. nov.} Figures 52-55

\section{Material Examined}

Holotype

$\delta$, ' $\mathrm{a}$ ' $6.5 \mathrm{~mm}$, Newman bore W135, Western Australia, Australia, $23^{\circ} 17^{\prime} \mathrm{S}, 119^{\circ} 52^{\prime} \mathrm{E}, 20$ November 1998, S. Eberhard, BES 6379 (WAM C24687).

\section{Allotype}

Australia: Western Australia: $q$, ' b' $6 \mathrm{~mm}$, same data as holotype (WAM C24688).

\section{Paratypes}

Australia: Western Australia: $\delta, 6 \mathrm{~mm}$, and 33 other specimens, same data as holotype (WAM C24689).

\section{Diagnosis}

Second antenna: peduncle article 5 bearing 3 calceoli, flagellum 16 articulate, with calceoli on articles 1-10. Mandible: palp article 2 with a mediodistal row of 5 robust rastellate setae; article 3 with $14 \mathrm{D}$ and $4 \mathrm{E}$ setae apically. Left first maxilla: palp article 2 with 6 apical setae. Right first maxilla: palp apex with no articulated, and 4 fused broad based tooth setae. Maxilliped outer plate with a row of 9 slender naked, medial submarginal to disto-facial setae; a medial row of 8 submarginal to subapical robust, naked, tooth setae; 2 apicolateral setae. First gnathopod propodus: dactyl reaching to palmar corner, with a single recumbent inner tooth spine. Second gnathopod carpus: with posterior setae ranked in 6 transverse bands. Telson: cleft $80 \%$, bearing 3 subapical robust setae.

\section{Description}

Holotype (male ' $a$ ' $6.5 \mathrm{~mm}$ )

Body (Figure 52): urosomites 1 and 2 bearing 2 dorsolateral robust setae. First antenna (Figure 52): length $0.7 \times$ body, $1.8 \times$ second antenna; peduncle article 1 longest, with sparse setae; primary flagellum of 36 articles; accessory flagellum of 6 articles, reaching to article 7 of primary flagellum. Second antenna (Figure 52): length $0.4 \times$ body; peduncle length greater than flagellum, article 5 bearing 3 calceoli, article 4 shorter than article 5 , articles 3-5 with sparse setation; flagellum 16 articulate, with sparse setation, bearing calceoli on articles 1 - 10. Left mandible (Figure 52): palp article 2 with a medio-distal row of 5 robust rastellate setae, article 3 with $14 \mathrm{D}$ and $4 \mathrm{E}$ setae, facially setulose (pubescent); incisor with 5 teeth, lacinia mobilis with 5 teeth, and 4 plumose interraker setae; molar bearing pappose seta, with 3 penicillate hooked brushy basal setae, and no penicillate setules. Right mandible (Figure 52): palp article 2 with a medio-distal row of 5 robust rastellate setae, article 3 with $14 \mathrm{D}$ and $4 \mathrm{E}$ setae; incisor with 4 teeth, and 2 plumose interraker setae; molar without penicillate hooked brushy basal setae, and no penicillate setules. Left first maxilla (Figure 52): palp article 2 with 2 apical and 1 subapical facial strong slender setae, and 3 apicomedial setae; outer plate with 10 robust setae - 10 denticulate, none naked; inner plate subtriangular, facially and medially setulose (pubescent). Right first maxilla (Figure 52): palp apex with no articulated and 4 fused broad based tooth setae, and 1 subterminal apicolateral facial seta. Second maxilla (Figure 52): outer plate length $3.4 \times$ width, bearing distal long, curved naked setae; apicomedial corner of inner plate with 2 weakly submarginal thick plumose/ pappose setae. Maxilliped (Figure 52): inner plate length $2.6 \times$ width, extending to M0.7 of the outer plate, bearing small setules on the lateral margin and medioproximal face, no facial pappose setae, no medial pappose setae, with a row of 4 submarginal to subapical pappose setae, extending to a row of 5 similar subapical, and 2 apical setae, with 1 apicomedial and 3 apical naked tooth setae; outer plate broad, length $1.7 \times$ width, distally setulose (pubescent), with a row of 12 , slender naked, medial submarginal to distal facial setae, a medial row of 9 submarginal to subapical robust, naked, tooth setae, and 3 apicolateral setae - none naked, 3 pappose; palp, second article moderately setose medially; third article sparsely setose laterally, moderately setose medially, with 2 facial, and 3 ventrofacial long strong setae basal to the dactyl, the apex weakly produced, setulate, with 3 long slender naked setae, and 1 dorsal accessory seta. First gnathopod (Figure 53): coxal plate with 2 anteroventral setae, and 3 ventral setae; merus without posterior hump; carpus of moderate length, $1.3 \times$ width, subtriangular, posterior margin, with setae ranked in 6 transverse bands; propodus ovate, small, length $1.7 \times$ width, posteroventral corner 


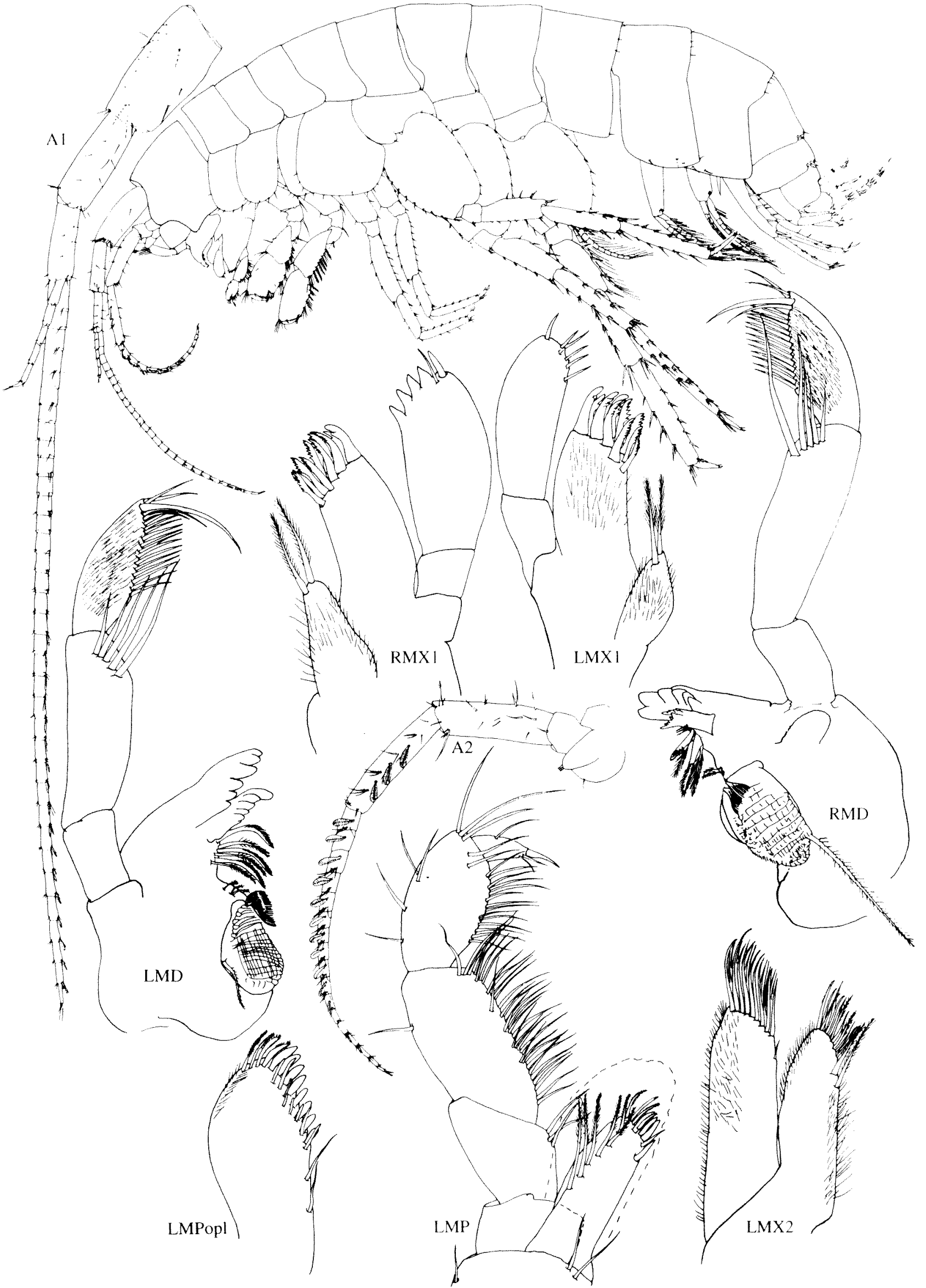

Figure 52 Chydaekata scuticara sp. nov., holotype male 'a' $6.5 \mathrm{~mm}$, whole animal, antennae and mouthparts. 


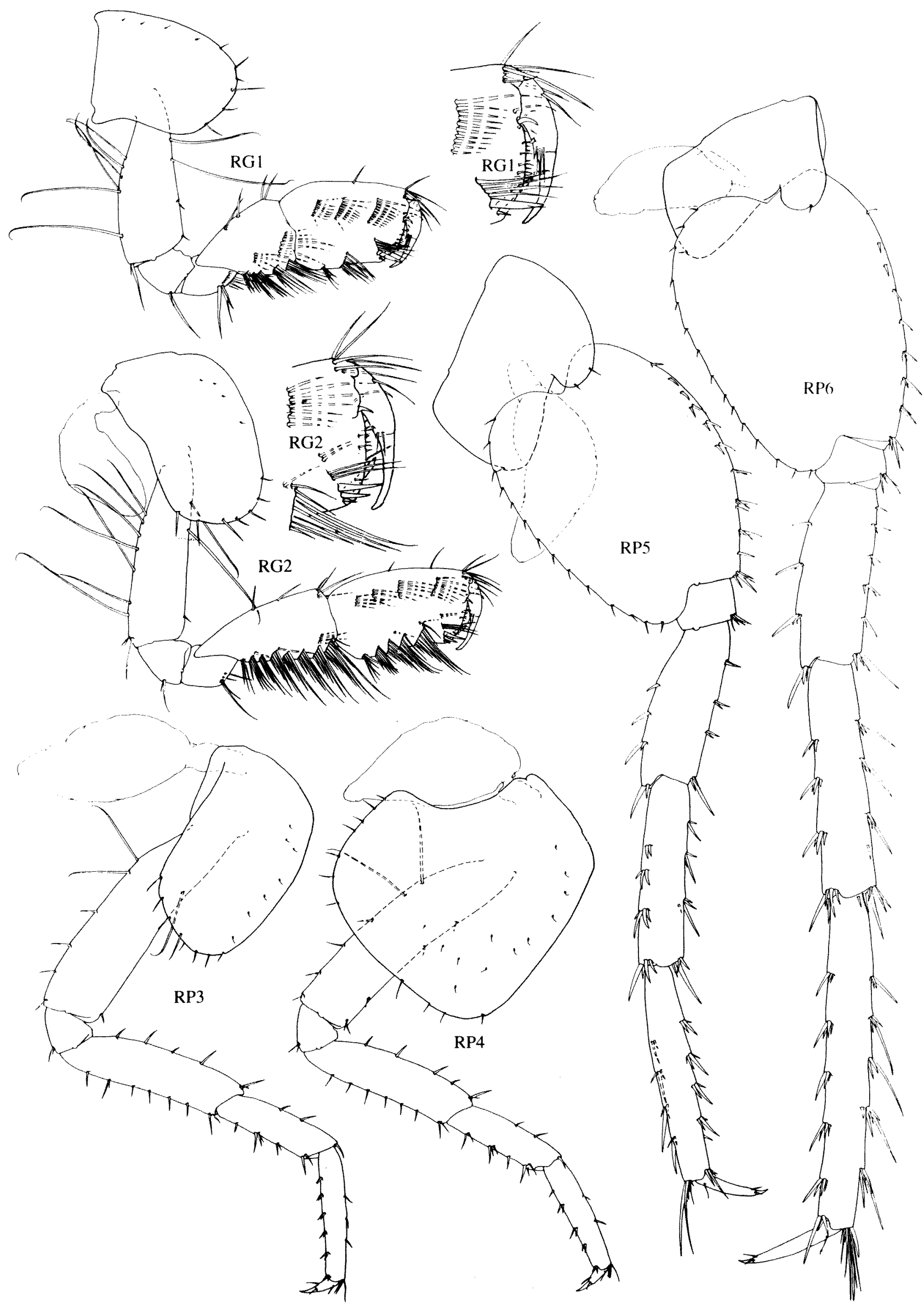

Figure 53 Chydaekata scuticara sp. nov., holotype male 'a' $6.5 \mathrm{~mm}$, gnathopods and pereopods 3-6. 


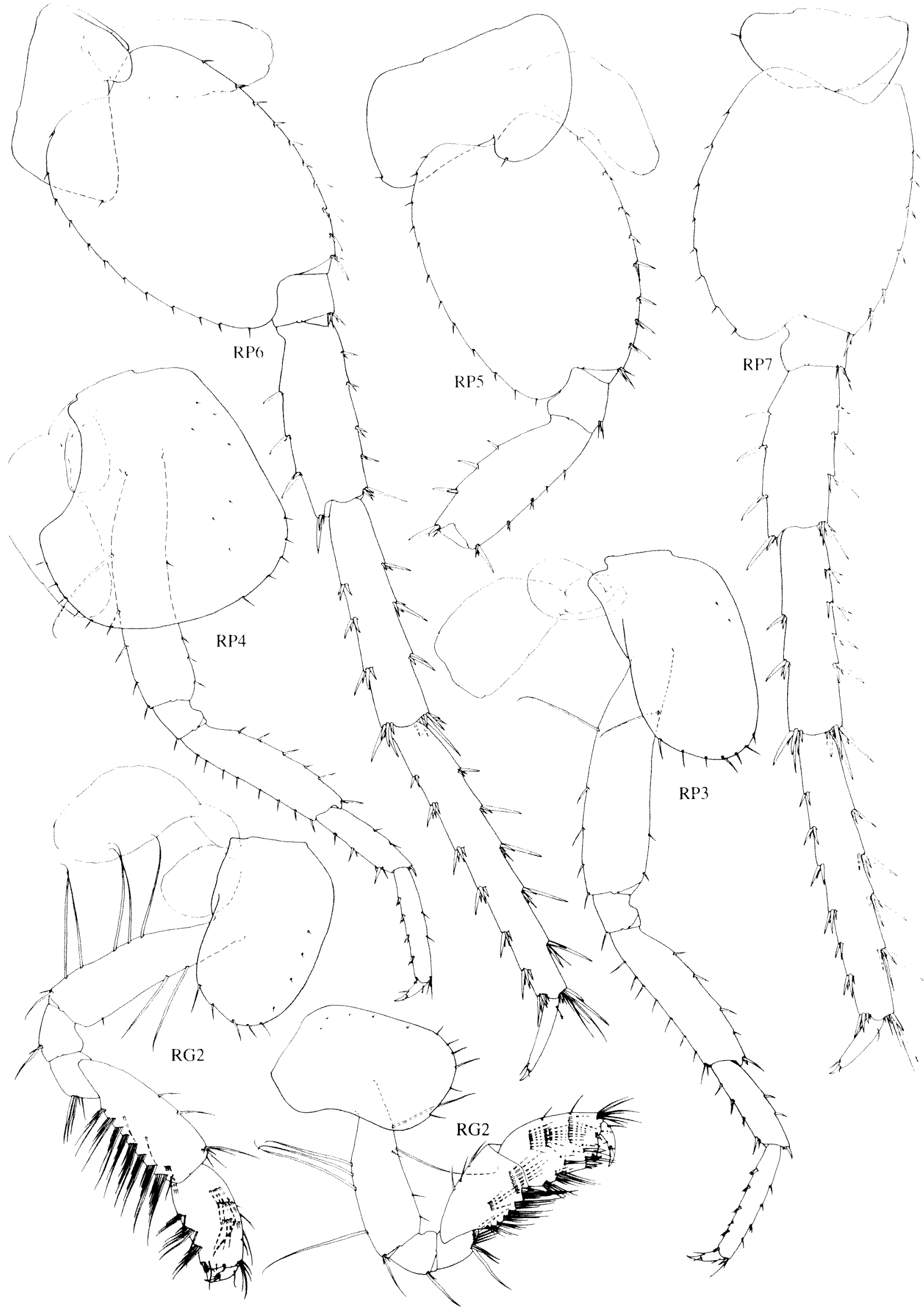

Figure 54 Chydaekata scuticara sp. nov., allotype female 'b' $6 \mathrm{~mm}$, gnathopods and pereopods. 


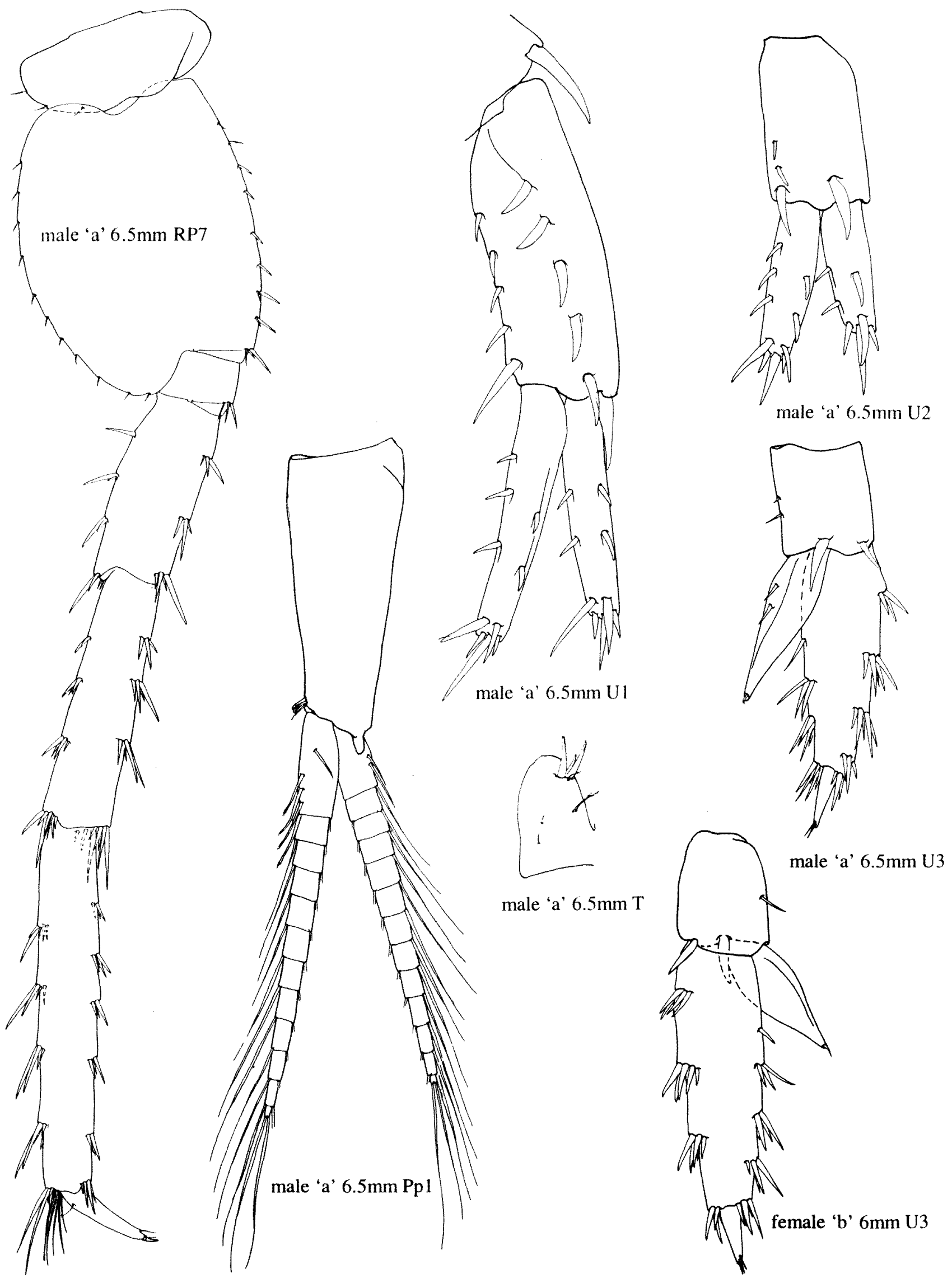

Figure 55 Chydaekata scuticara sp. nov., holotype male 'a' $6.5 \mathrm{~mm}$, pereopod 7, pleopod 1, uropods 1-3, telson. Allotype female ' $b$ ' $6 \mathrm{~mm}$, uropod 3 . 
rounded, with 1 long and one small lateral robust setae, and 4 additional lateral elongate setae, palmar angle weakly oblique, smooth, dactyl reaching to palmar corner, with a single recumbent inner tooth spine. Second gnathopod (Figure 53): slightly larger than first; coxal plate with 3 anteroventral setae, and 3 ventral setae; carpus length $2.1 \times$ width, subtriangular, with posterior setae ranked in 8 transverse bands; propodus subrectangular, small, length $1.9 \times$ width, with 3 lateral robust setae, 1 medial robust seta, and 2 additional lateral elongate setae, palmar angle transverse, smooth, dactyl reaching to palmar corner, with a single recumbent inner tooth spine. Pereopods (Figure 53, 55): pereopod 1 longer than the second gnathopod coxa with 1 anterior seta, no long ventral setae, 6 short ventral setae, 1 seta at the posteroventral corner carpus weakly setose posteriorly; pereopod 4 subequal in length with pereopod 3 coxa anteroventral margin with 4 setae, posteroventral margin with 7 setae, ventral margin with no setae, posterior margin moderately emarginate carpus weakly setose posteriorly; coxa 5 bearing 1 seta on anterior lobe, and 1 seta on the posterior lobe; basis of periopod 5 with short slender posterior setae, bearing short and long robust anterior setae, moderately lobate posteroventrally; pereopod 6 coxa bearing 1 seta on anterior lobe, basis moderately expanded, bearing short and long robust anterior setae, moderately lobate posteroventrally; pereopod 7 coxa with 2 setae on the posterior lobe basis bearing short and long robust anterior setae, moderately lobate posteroventrally; bases of periopods equally expanded. Epimera: first epimeron with 1 slender seta on the posterior margin, posterior margin convex, posteroventral corner rounded; epimeron 2 with 3 robust setae on the anteroventral margin, posterior margin straight, posteroventral corner rounded; epimeron 3 with 6 robust setae on the anteroventral margin, with 1 slender setae on the ventral margin, posterior margin concave, posteroventral corner rounded, without spine or seta. Pleon: dorsolateral margin of pleonite 1 with 4 feeble setae, of pleonite 2 with 7 feeble setae, of pleonite 3 with 6 feeble setae, and no distolateral robust setae. Pleopods (Figure 55): first, second and third pleopods with 1 accessory retinacula. Urosomites: urosomite 1 bearing 1 distolateral slender seta, and 2 distolateral robust setae; urosomite 2 with 1 distolateral slender setae, and 3 distolateral robust setae. First uropod (Figure 55): peduncle length $1.2 \times$ the length of the inner ramus; with a strong row of 4 dorsolateral robust setae, and 4 dorsomedial robust setae; outer ramus with 2 dorsolateral robust setae, and 2 dorsomedial robust setae; inner ramus with 2 dorsolateral robust setae, 3 dorsomedial robust setae, and 5 apical robust setae. Second uropod (Figure 55): $0.6 \times$ length of uropod 1, peduncle about $1.1 \times$ length of inner ramus; with 1 apicolateral, 1 dorsomedial, and 1 apicomedial robust setae; inner ramus with 1 dorsolateral, 2 dorsomedial, and 5 apical robust setae; outer ramus with 2 dorsolateral, 3 dorsomedial, and 5 apical robust setae. Third uropod (Figure 55): extending beyond uropods 1 and 2 in intact specimen, $0.7 \times$ length of uropod 1; peduncle length $0.4 \times$ outer ramus, shorter than, $0.9 \times$ urosomite three, with 1 apicolateral robust seta, and no apicolateral slender setae, with no dorsomedial robust setae, and 2 dorsomedial slender setae, with no apicomedial robust setae, and no apicomedial slender setae, and with no mediodistal robust setae; inner ramus length $0.6 \times$ outer ramus; outer ramus proximal article setae arranged laterally and medially in transverse bands or arranged medially singly with, with 4 lateral transverse bands of robust setae, with 2 medial transverse bands of robust setae, with no medial transverse bands of mixed robust and small setae, 1 medial robust seta, 3 apicolateral robust setae, no apicolateral small setae, 2 apicomedial robust setae, no apicomedial small setae, 3 apicomedial long slender setae; distal article short, with no apical robust setae, and 2 apical slender setae; inner ramus with 2 medial robust setae, no apical robust setae, and 1 apical slender setae. Telson (Figure 55): shorter than, $0.9 \mathrm{x}$, urosomite 3 ; cleft $80 \%$, shorter than broad, length $0.8 \times$ breadth; apices rounded and laterally notched with 3 subapical robust setae, and no subapical slender setae, with 1 apical penicillate seta and paired lateral penicillate setae at M0.5 from the telson base.

\section{Allotype (female ' $b$ ' $6 \mathrm{~mm}$ )}

With the characteristics of the holotype except. Body: length $6 \mathrm{~mm}$. First antenna: without aesthetascs or calceoli. Second antenna: without calceoli. First gnathopod (Figure 54): coxa longer than male but similarly armed; carpus longer, more slender than male but similarly subtriangular, bearing 7 (versus 5) posterior translateral setal bands; propodus less robust, narrower and apically tapering, bearing 3 (versus 2) lateral robust setae at the palmar corner. Second gnathopod (Figure 54): coxa bearing 5 (versus 7) marginal setae, with a small/moderate round naked oostegite, length about $0.5 x$ coxal plate; carpus longer and more slender than the male, but similarly armed; propodus less robust than the male, shorter and narrower, tapering apically, bearing 3 (versus 5) posterior translateral bands of setae and 3 (versus 4) medio-facial bands, palmar comer with 1 (versus 3) lateral robust seta, otherwise palm and dactyl similarly armed. Pereopods (Figure 54). Pereopod three: coxa with 7 (versus 8) marginal setae, bearing moderately small ovate, naked oostegite, length about $0.5 x$ coxal plate. Pereopod four: coxa with 6 (versus 7) posterior marginal setae and 5 Versus. 4) 
anterior marginal setae, bearing a small, ovate, naked oostegite, length about $0.4 x$ coxal plate. Pereopod five: coxa without oostegite, with 1 (versus 2) ventro-marginal seta. Pereopod six: coxa anterior lobe without a ventro-marginal seta (versus 1). Pereopod seven: coxa bearing 1 (versus 3 ) seta on the posterior lobe. Uropods (Figure 55). Third uropod: peduncle bearing 1 (versus 2 ) small medial seta; inner ramus small medial setae (versus 2); outer ramus proximal article with 3 (versus 4 ) translateral setal ranks and 4 (versus 3 ) transmedial setal ranks.

\section{Relationships}

Chydaekata scuticara differs from others of the genus in: second antenna peduncle article 4 shorter than article 5, flagellum 16 articulate, bearing calceoli on 10 articles; left mandible palp article 3 with $14 \mathrm{D}$ setae; left first maxilla palp article 2 with 2 apical strong slender setae; maxilliped outer plate with a row of 12 slender naked medial submarginal to disto facial setae; first gnathopod]: propodus post ventral corner with 1 lateral robust seta; second gnathopod carpus with strong post. rastellate setae ranked in 8 transverse bands; pereopod 3 coxa with 6 short ventral setae; epimera 3 with 1 slender seta present on ventral margin; dorsolateral margin of pleonite 3 with 6 feeble setae; third uropod outer ramus proximal article with 4 lateral transverse bands of robust setae, proximal article with 2 apicomedial robust setae.

\section{Etymology}

From the Latin 'scutica' (whip, lash), referring to the presence of a pappose seta on the molar of the left mandible.

\section{Chydaekata brachybasis sp. nov. Figures 56-58}

\section{Material Examined}

\section{Holotype}

$\delta$, 'a' $4 \mathrm{~mm}$, Newman bore W126, Western Australia, Australia, $23^{\circ} 15^{\prime} \mathrm{S}, 119^{\circ} 53^{\prime} \mathrm{E}, 12$ November 1998, S. Eberhard, BES 3575 (WAM C24690).

\section{Allotype}

Australia: Western Australia: $q$, ' b' $4 \mathrm{~mm}$, same data as holotype (WAM C24691).

\section{Paratypes}

Australia: Western Australia: $1 \delta, 5 \mathrm{~mm}$, and 5 other specimens, same data as holotype (WAM C24692).

\section{Diagnosis}

Second antenna: peduncle article 5 bearing 1 calceolus, flagellum 11 articulate, with calceoli on articles 1-5. Mandible: palp article 2 with a mediodistal row of 4 robust rastellate setae; article 3 with $8 \mathrm{D}$ and $4 \mathrm{E}$ setae apically. Left first maxilla: palp article 2 with 6 apical setae. Right first maxilla: palp apex with no articulated, and 3 fused broad based tooth setae. Maxilliped outer plate with a row of 5 slender naked, medial submarginal to disto-facial setae; a medial row of 9 submarginal to subapical robust, naked, tooth setae; 3 apicolateral setae. First gnathopod propodus: dactyl reaching beyond palmar corner, with a single recumbent inner tooth spine. Second gnathopod carpus: with posterior setae ranked in 5 transverse bands. Telson: cleft $74 \%$, bearing 2 subapical robust setae.

\section{Description}

\section{Holotype (male ' $a$ ' $4 \mathrm{~mm}$ )}

Body (Figure 56): urosomites 1 and 2 bearing 2 dorsolateral robust setae. First antenna (Figure 56): length $0.6 \times$ body, $1.5 \times$ second antenna; peduncle article 1 longest, with sparse setae; primary flagellum of 28 articles; accessory flagellum of 4 articles, reaching to article 6 of primary flagellum. Second antenna (Figure 56): length $0.4 \times$ body; peduncle length less than flagellum, article 5 bearing 1 calceoli, article 4 subequal with article 5, articles 3-5 with sparse setation; flagellum 11 articulate, with sparse setation, bearing calceoli on articles $1-5$. Left mandible (Figure 56): palp article 2 with a medio-distal row of 4 robust rastellate setae, article 3 with $8 \mathrm{D}$ and $4 \mathrm{E}$ setae, facially strongly setulose (pubescent); incisor with 6 teeth, lacinia mobilis with 5 teeth, and 4 plumose interraker setae; molar bearing pappose seta, without penicillate hooked brushy basal setae, and, few penicillate setules. Right mandible (Figure 56): palp article 2 with a medio-distal row of 4 robust rastellate setae, article 3 with $9 \mathrm{D}$ and $4 \mathrm{E}$ setae; incisor with 6 teeth, and 2 plumose interraker setae; molar without penicillate hooked brushy basal setae, and, few penicillate setules. Left first maxilla (Figure 56): palp article 2 with 4 apical and 1 subapical facial strong slender setae, with 1 apicomedial seta; outer plate with 10 robust setae -10 denticulate, none naked; inner plate subtriangular, facially and medially setulose (pubescent). Right first maxilla (Figure 56): palp apex with no articulated and 3 fused broad based tooth setae, and 1 subterminal apicolateral facial seta. Second maxilla (Figure 56): outer plate length $3.6 \times$ width, bearing distal long, curved naked setae; apicomedial corner of inner plate with 2 weakly submarginal thick plumose/pappose setae. Maxilliped (Figure 56): inner plate length $1.9 \mathrm{x}$ width, extending to M0. 8 of the outer plate, bearing small setules on the lateral margin and medioproximal face, no facial pappose setae, no medial pappose setae, with a row of 3 submarginal 


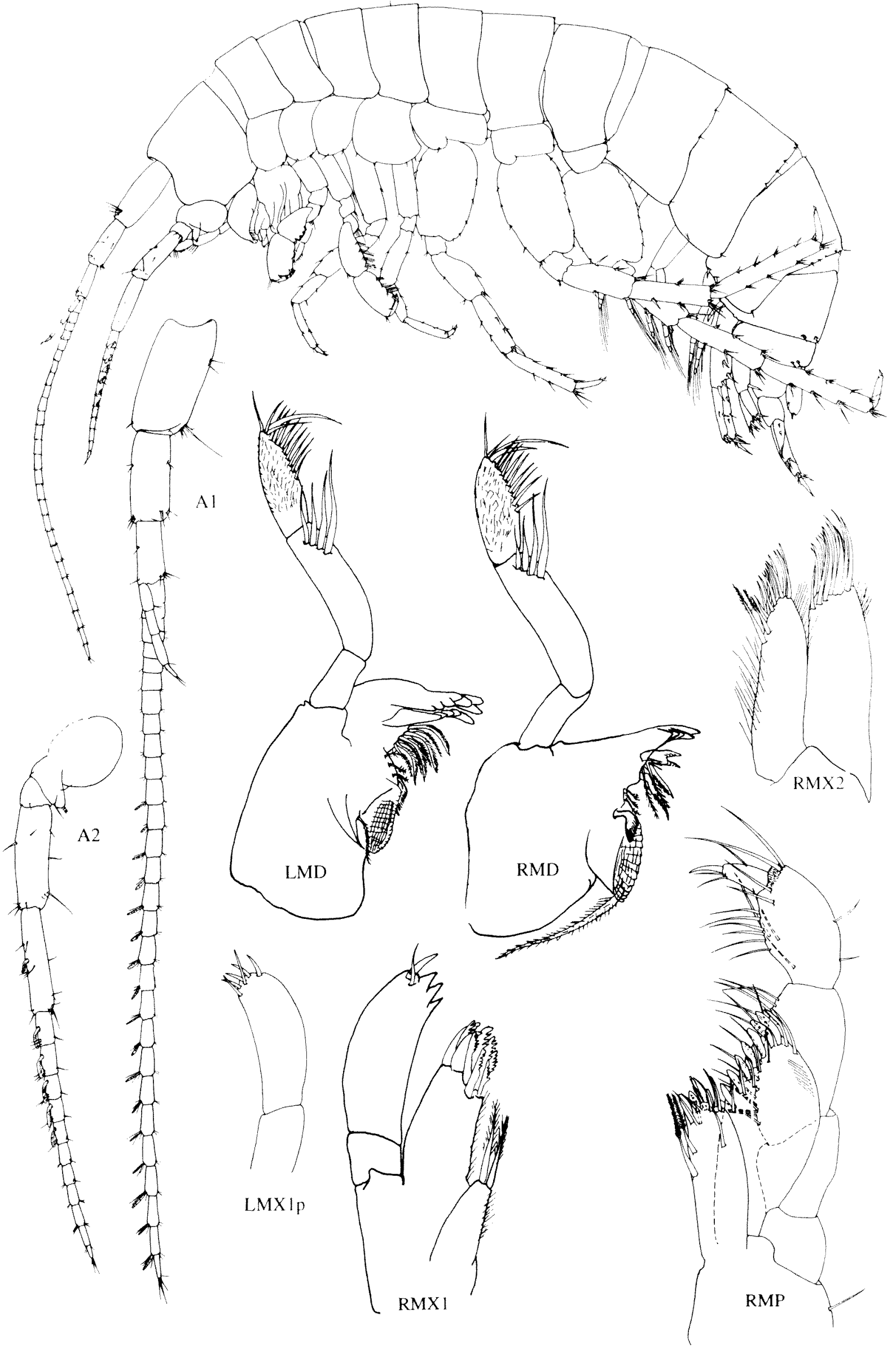

Figure 56 Chydaekata brachybasis sp. nov, holotype male 'a' $4 \mathrm{~mm}$, whole animal, antennae and mouthparts. 


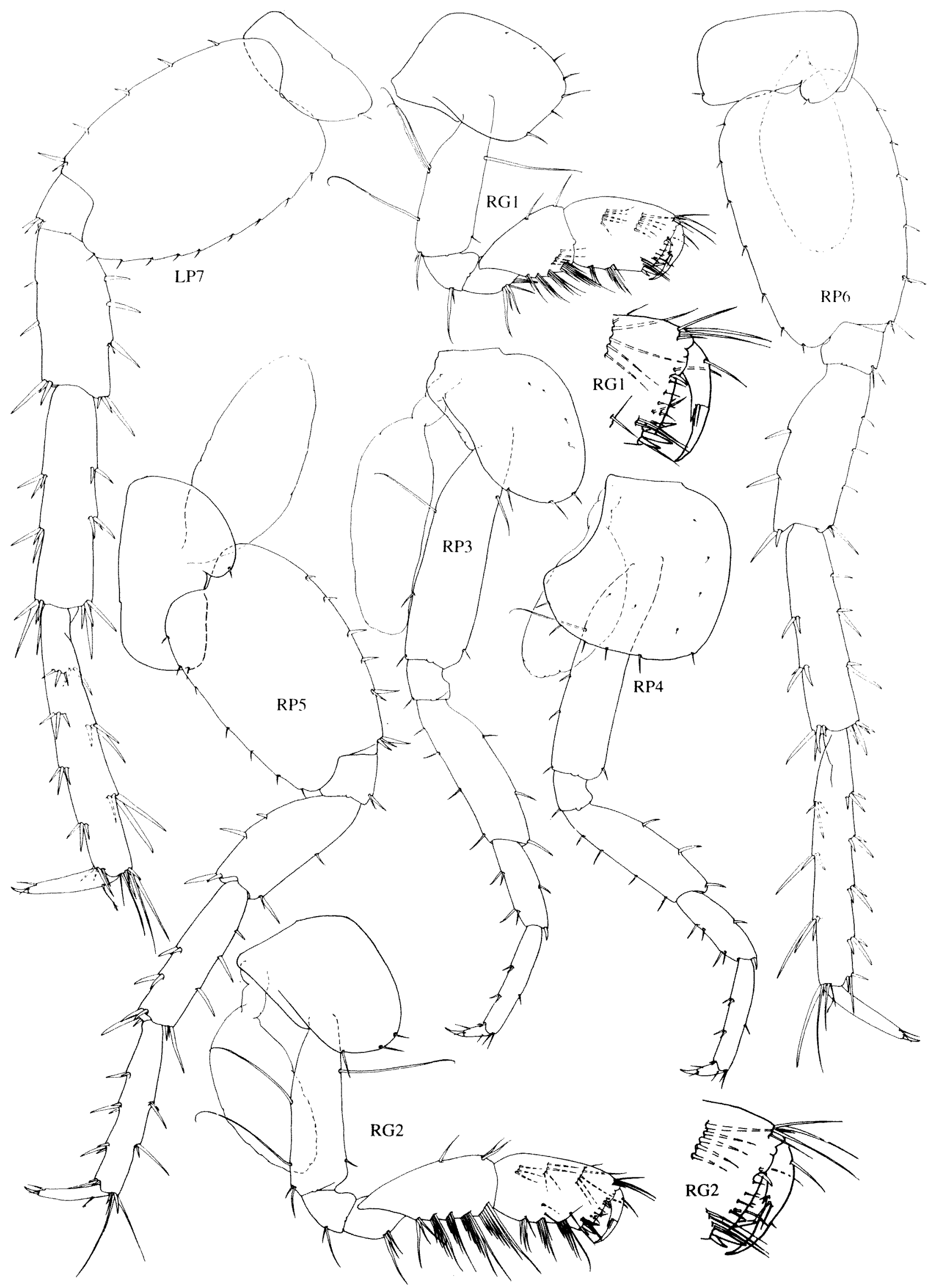

Figure 57 Chydaekata brachybasis sp. nov., holotype male 'a' $4 \mathrm{~mm}$, gnathopods and pereopods. 


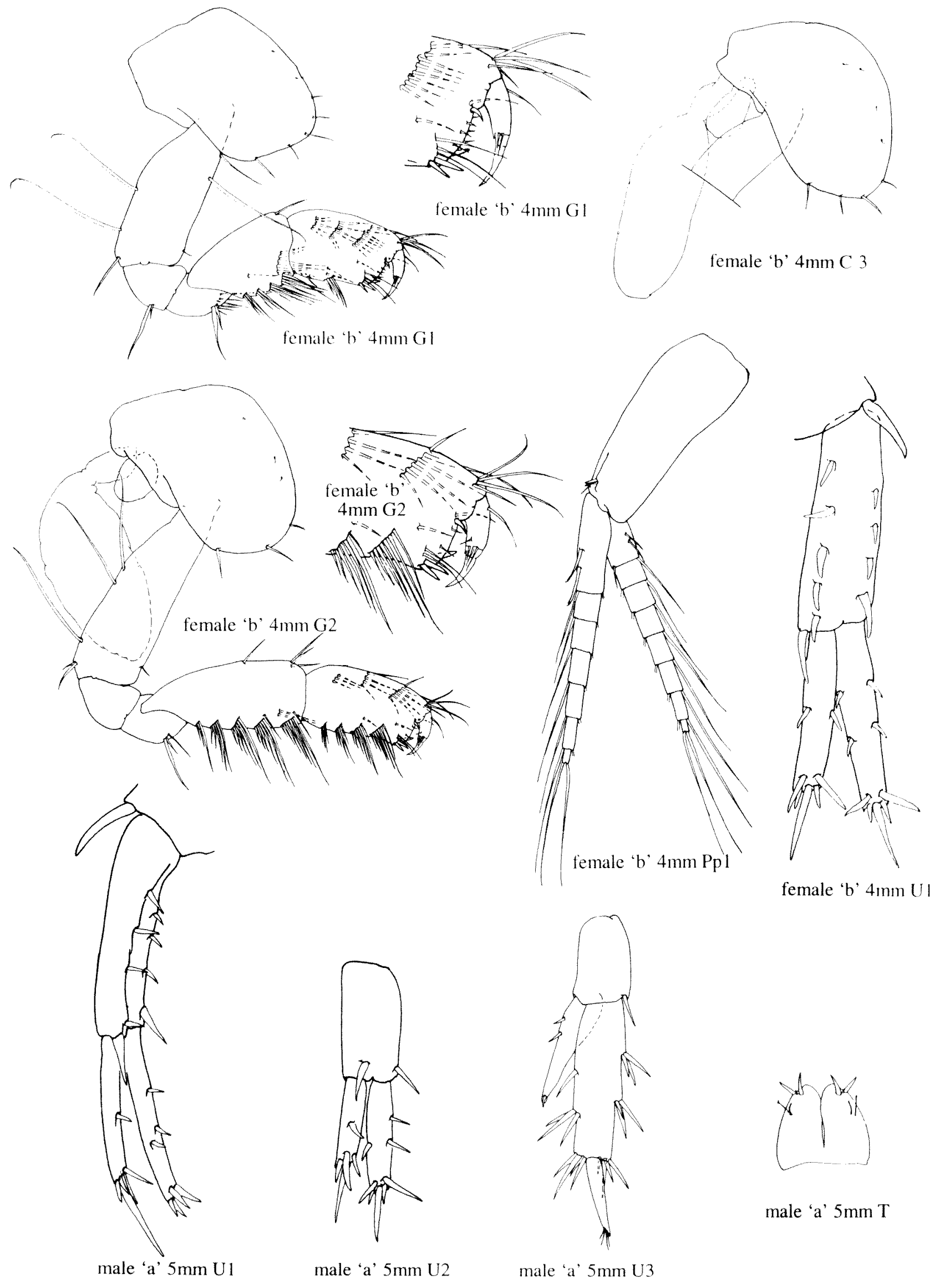

Figure 58 Chydaekata brachybasis sp. nov., holotype male 'a' $4 \mathrm{~mm}$, uropods 1-3, telson. Allotype female 'b' 4 mm, gnathopods 1-2, coxa 3, pleopod 1, uropod 1. 
to subapical pappose setae, extending to a row of 4 similar subapical, and 1 apical seta, with 1 apicomedial, 1 mediodistal, and 3 apical naked tooth setae; outer plate broad, length $2.7 \times$ width, distally setulose (pubescent), with a row of 9 , slender naked, medial submarginal to distal facial setae, a medial row of 5 submarginal to subapical robust, naked, tooth setae, and 3 apicolateral setae none naked, 3 pappose; palp, second article moderately setose medially; third article sparsely setose laterally, weakly setose medially, with 2 facial and 2 ventrofacial long strong setae basal to the dactyl, the apex moderately produced, setulate, with 2 long slender naked setae, and 1 dorsal accessory seta. First gnathopod (Figure 57): coxal plate with 3 anteroventral setae and no ventral setae; merus bearing posterior hump; carpus of moderate length, $1.5 \mathrm{x}$ width, subtriangular, posterior margin with setae ranked in 4 transverse bands; propodus ovate, small, length $1.6 \mathrm{x}$ width, posteroventral corner rounded, with 2 lateral and 1 medial robust setae, and 3 additional lateral elongate setae, palmar angle weakly oblique, smooth, dactyl reaching beyond palmar corner, with a single recumbent inner tooth spine. Second gnathopod (Figure 57): slightly larger than first; coxal plate with 2 anteroventral setae, and no ventral setae; carpus length $2.3 \times$ width, subrectangular, with posterior setae ranked in 5 transverse bands; propodus subrectangular, moderate size, length $2 x$ width, with 2 medial robust setae, 1 lateral robust seta, and 2 additional lateral elongate robust setae, palmar angle transverse, smooth, dactyl reaching beyond palmar corner, with a single recumbent inner tooth spine. Pereopods (Figure 57): pereopod 3 longer than the second gnathopod; coxa with 1 anterior seta, no long ventral setae, 1 short ventral seta, 1 seta at the posteroventral corner; carpus weakly setose posteriorly; pereopod 4 subequal in length with pereopod 3; coxa anteroventral margin with 1 seta, posteroventral margin with 2 setae, ventral margin with 2 setae, posterior margin moderately emarginate; carpus moderately setose posteriorly; coxa 5 bearing 1 seta on anterior lobe, and 1 seta on the posterior lobe; basis of periopod 5 with short slender posterior setae, bearing short and long robust anterior setae, moderately lobate posteroventrally; pereopod 6 coxa bearing 1 seta on anterior lobe; basis moderately expanded, bearing short and long robust anterior setae, moderately lobate posteroventrally; pereopod 7 coxa with 1 seta on the posterior lobe; basis bearing short and long robust anterior setae, moderately lobate posteroventrally; bases of periopods equally expanded. Epimera: first epimeron with 1 slender seta on the posterior margin, posterior margin straight, posteroventral corner rounded; epimeron 2 with 1 robust seta on the anteroventral margin, posterior margin straight, posteroventral corner rounded; epimeron 3 with 2 robust setae on the anteroventral margin, without slender setae on ventral margin, posterior margin straight, posteroventral corner rounded, without spine or seta. Pleon: dorsolateral margin of pleonite 1 with 3 feeble setae, of pleonite 2 with 3 feeble setae, of pleonite 3 with 1 feeble seta, and 1 distolateral robust seta. Pleopods (Figure 58): first and second pleopods with 1 accessory retinacula, and third pleopod with no accessory retinacula. Urosomites: first urosomite bearing 1 distolateral slender seta, and 2 distolateral robust setae; urosomite 2 : with no distolateral slender setae, and 2 distolateral robust setae. First uropod (Figure 58): peduncle length $1.2 \mathrm{x}$ the length of the inner ramus; with a strong row of 3 dorsolateral robust setae, and 3 dorsomedial robust setae; outer ramus with 1 dorsolateral robust seta, and 1 dorsomedial robust seta; inner ramus with 1 dorsolateral robust seta, 2 dorsomedial robust setae, and 5 apical robust setae. Second uropod (Figure 58): $0.6 \times$ length of uropod 1, peduncle about $1.1 \mathrm{x}$ length of inner ramus, with no apicolateral, no dorsomedial, and 1 apicomedial robust setae; inner ramus with no dorsolateral, 1 dorsomedial, and 5 apical robust setae; outer ramus with 1 dorsolateral, 2 dorsomedial, and 5 apical robust setae. Third uropod (Figure 58): extending beyond uropods 1 and 2 in intact specimen, $0.8 x$ length of uropod 1 ; peduncle length $0.4 \times$ outer ramus, subequal in length to urosomite 3 , with 1 apicolateral robust seta, and no apicolateral slender setae, with no dorsomedial robust setae, and 1 dorsomedial slender seta, with no apicomedial robust setae, and no apicomedial slender setae, and with no mediodistal robust setae; inner ramus length $0.5 \times$ outer ramus; outer ramus proximal article setae arranged laterally and medially in transverse bands or arranged medially singly with, with 2 lateral transverse bands of robust setae, with 1 medial transverse band of robust setae, with no medial transverse bands of mixed robust and small setae, 1 medial robust seta, 4 apicolateral robust setae, no apicolateral small setae, 4 apicomedial robust setae, no apicomedial small setae, no apicomedial long slender setae; distal article long, with no apical robust setae, and 4 apical slender setae; inner ramus with 2 medial robust setae, no apical robust setae, and 1 apical slender seta. Telson (Figure 58): shorter than, $0.5 \mathrm{x}$, urosomite 3; cleft $74 \%$, as long as broad; apices rounded and laterally notched, with 2 subapical robust setae, and no subapical slender setae; apical penicillate setae absent, with paired lateral penicillate setae at M0.7 from the telson base.

\section{Allotype (female ' $b$ ' $4 \mathrm{~mm}$ )}

With the characteristics of the holotype except. Body: length $4 \mathrm{~mm}$. First antenna: without aesthetascs or calceoli. Second antenna: without 
calceoli. First gnathopod (Figure 58): coxa as in the male; carpus broader and more ovate than male, bearing additional medio-facial setae; propodus with 1 (versus 2) posterior translateral setal bands and 3 (versus 2) medio-facial bands, more slender than the male, tapering apically, palm and dactyl similarly armed. Second gnathopod (Figure 58): coxa bearing a small, round, naked oostegite, length about $0.3 x$ coxal plate; carpus elongate, longer than male, but similarly armed; propodus less robust, narrower, longer than male, bearing 4 (versus 3 ) posterior translateral setal bands, and 3 mediofacial bands, palm and dactyl similarly armed. Pereopods (Figure 58). Pereopod three: coxa bearing 4 (versus 3) marginal setae, and a small, paddle shaped, naked oostegite, length about $0.4 x$ coxal plate. Pereopods four and five: coxa (bearing small naked ovate oostegite). Pereopods six and seven: similar to the Holotype. Uropods (Figure 58). Third uropod: peduncle bearing 4 (versus 3 ) dorsolateral robust setae; outer ramus with 1 (versus none) medial robust seta; inner ramus with 2 (versus 1) lateral robust setae.

\section{Relationships}

Chydaekata brachybasis differs from others of the genus in: left mandible palp article 3 with $8 \mathrm{D}$ setae; maxilliped outer plate length 2.6-3.0 $x$ width, bearing a medial row of 5 submarginal to subapical robust, naked, tooth setae; dorsolateral margin of pleonite 3 with 1 distolateral robust seta; third uropod outer ramus distal article with 4 apical slender setae.

\section{Etymology}

From the Greek 'braches' (short), and 'basis' (base), referring to the length of the peduncle of the second antenna, which is shorter than the flagellum.

\section{Molina gen. nov.}

\section{Type Species}

Molina pleobranchos sp. nov.

\section{Diagnosis}

Body: cuticle smooth; pereon and pleon sparsely setose dorsally; urosomite 3 without dorsolateral robust setae. Head: rostrum vestigial; eyes absent. First antenna: article 3 shortest; flagellum much longer than peduncle; bearing aesthetascs; articles uniform, and sparsely setulate. Second antenna: setate. Upper lip: apical margin evenly rounded; connection to epistome symmetrical. Left mandible: palp article 2 with no small outer or medial margin setae, bearing an oblique distofacial row of robust rastellate setae, article 3 much shorter than article 2 , bearing DE setae, mandible with 4 setose accessory blades; molar fully triturating. Right mandible: palp article 2 with no small outer or medial marginal setae, bearing an oblique distofacial row of robust rastellate setae, article 3 much shorter than article 2; lacinia mobilis bifid and denticulate; with 2 denticulate arms strongly extended; mandible bearing 2 setose accessory blades; molar bearing pappose seta, fully triturating. Left first maxilla: inner plate elongate, subtriangular to subrectangular, with 2 apicomedial plumose setae, outer plate with 10 robust denticulate apical setae, palp bearing 6 apical and 2 ventrofacial robust articulated setae. Right first maxilla: palp asymmetrical with left; article 2 with 1 apicolateral robust seta, 1 ventrofacial articulate robust seta and 4 apical setae fused to the article forming a row of broad teeth. Second maxilla: outer plate subtriangular, marginally setulose. Maxilliped: inner plate subrectangular; outer plate subovate; dactyl of palp third article bearing 2 accessory setae basal to the nail. First gnathopod: coxal plate subrectangular, with 1 posteroventral corner seta; merus with elongate scythe setae; carpus without posteroventral lobe or expansion; propodus posteroventral corner not lobate; bearing 4 lateral robust setae; palm convex; dactyl ; with accessory setules at the junction of the nail. Second gnathopod: coxal plate ovate, with 3 posteroventral corner setae, and large ovate gill; merus without posterior hump, with elongate scythe setae; carpus long, without posteroventral lobe or expansion, posterior margin strongly setose; propodus posteroventral corner subquadrate, not lobate, bearing 4 robust setae, palm convex, dactyl with accessory setules at the junction of the nail. Pereopods: dactyls of pereopods 5-7 multispinous; merus of pereopod 3 weakly setose posteriorly; pereopods 5-7 similar; basis of pereopod 5 moderately expanded; coxa 6 bearing 1 seta on the posterior lobe, basis of pereopod 6 bearing short slender posterior setae; pereopod 7 coxa bearing no setae on anterior lobe, article 2 moderately expanded, bearing short slender posterior setae. Gills: coxal gills present on coxae 2-7, gill of pereopod 6 not reduced; sternal gills present on sternites 2-7, of simple sausage form, attached to anterior of lateral edge of segments. Epimera: epimera 1: without anteroventral setae, without robust setae on anteroventral or posteroventral margin, without slender setae on ventral margin, posteroventral corner without spine or seta; epimera 2: without anteroventral setae, or robust setae on posteroventral margin, without slender setae on ventral margin, with 1 slender seta on the posterior margin, posteroventral corner without spine or seta; epimera 3: without anteroventral setae, or robust setae on posteroventral margin, or slender setae on posterior margin, posteroventral corner without spine or seta. Pleon: pleonite 2 with no distolateral robust setae; pleonite 3 without 
setae. Pleopods: peduncle of first pleopod with 2 retinacula and 2 additional setae disjunct from retinacula; peduncle of second pleopod with 2 retinacula and 1 additional seta disjunct from retinacula; peduncle of third pleopod with 2 retinacula and 1 additional setae disjunct from retinacula. Urosomites: first urosomite bearing long distoventral robust seta at the base of uropod 1; urosomite 3: bearing no distolateral slender or robust setae. Uropods: first uropod peduncle with no apicodistal robust setae; second uropod bearing 2 apicolateral and 1 apicomedial robust setae, the outer ramus shorter than inner, with 4 apical robust setae; second uropod peduncle with 4 dorsolateral robust setae, outer ramus shorter than inner; third uropod moderately long; peduncle with 1 dorsolateral robust seta, 1 dorsolateral and 1 mediodistal slender setae; inner ramus shorter than outer; outer ramus two articulate, proximal article without small setae, with lateral transverse bands of robust setae only, and with only robust apical setae; distal article of outer ramus narrow; sub triangular; without lateral or medial setae; and only small slender distal setae; inner ramus with 1 lateral robust seta, 2 medial robust setae and a single short slender apical seta. Telson: deeply cleft, lateral margins tapering, straight; single small slender dorsal setae present; without lateral setae; with single robust and short penicillate apical setae; bearing paired lateral penicillate setae.

\section{Relationships}

Molina has many similarities to Chydaekata, and thus differences from others of the family Paramelitidae. Nevertheless, Molina differs in significant ways from Chydaekata: calceoli are absent from the male antennae, gnathopodal propodi bear 4 or 5 robust posterior corner setae rather than 3 , dactyls of the pereopods are multispinous rather than simple, coxa 7 bears a gill and sternal gills are present on segments 2-7 compared with 6-7, a robust lateral seta is present on the inner ramus of the third uropod whereas Chydaekata has none, posterior marginal setae are present on the epimera, and dorsal setae are present on the telson.

The presence in Molina of a coxal gill on pereopod seven, and of sternal gills on sternites two to seven are characters borne in common with Austrogammarus, the most primitive of Australian paramelitids (Williams and Barnard, 1988). Notwithstanding, many differences clearly separate the two genera. Likewise, similarities are found with other genera: in common with Austrocrangonyx ventrodistal setae at the base of the first uropod are long and robust, coxae 1-3 do not bear posterior robust setae, and gills are present on coxae 2-7, the seventh being reduced; Hurleya also has only DE setae present on the mandibular palp, absence of medial setation on the maxillae, presence of two apicomedial plumose setae on the inner plate of the first maxilla, no oblique facial row of setae on the inner plate of the second maxilla, and slight apical extension of the third article of the maxillary palp; like Protocrangonyx the third article of the mandibular palp bears only DE setae, and, in common with Toulrabia, the inner plate of the second maxilla lacks an oblique facial row of setae; Toulrabia also bears only 2 apicomedial setae on the inner plate of the first maxilla; Chillagoe is similar to Molina in the presence of only DE setae on the mandibular palp, the inner plate of the first maxilla bearing only 2 apicomedial plumose setae, absence of an oblique facial setal row on the second maxilla, and simplicity of palmar setae; in common with Pilbarus the second article of the mandibular palp bears a distal oblique row of robust rastellate setae, maxillae are without medial setae, the inner ramus of the first maxilla bears two plumose apical setae and the inner plate of the second maxilla lacks an oblique facial row of setae and bears only two plumose apicodistal setae, the inner ramus of the third uropod is similarly elongate and the first article of the outer ramus bears transverse rows of robust setae without small slender setae and the second article is small; in common with Toulrabia coxae 2-7 bear gills and sternites 2-7 bear simple lateral gills.

However, these similarities are few compared with the differences between Molina and other genera of Paramelitidae. Most similarities are found with Chydaecata, but the presence of a seventh coxal gill, and of sternal gills on segments 2-7, the absence of calceoli in Molina, the greater number of corner setae on the gnathopodal propodi, the presence of lateral setae on the inner ramus of the third uropod and the presence of additional (multispinous) setae on the dactyls of pereopods 57 all indicate Molina a distinct genus.

\section{Distribution}

Millstream in the Pilbara region of north western Western Australia.

\section{Etymology}

The name of this genus is derived from the Latin 'molina' (mill). Therefore the word relates to the type locality - Millstream. The name is feminine.

\section{Molina pleobranchos sp. nov.} Figures 59-62

\section{Material Examined}

\section{Holotype}

9, 'a' $6.5 \mathrm{~mm}$, Millstream aquifer, P4, Western Australia, Australia, $21^{\circ} 35^{\prime} \mathrm{S}, 116^{\circ} 58^{\prime} \mathrm{E}$, taken with haul net in piezometer, 19 October 1996, BES 3994 (WAM C24693). 
Allotype

Australia: Western Australia: $\delta$, ' b' $6 \mathrm{~mm}$, same data as holotype (WAM C24694).

\section{Paratypes}

Australia: Western Australia: 1 o', 'c' $5.5 \mathrm{~mm}$, and 1 other specimen, same data as holotype (WAM C24695).

\section{Diagnosis}

With the characteristics of the genus.

\section{Description}

\section{Holotype (female 'a' $6.5 \mathrm{~mm}$ )}

Body (Figure 59): cuticle smooth; pereon and pleon sparsely setose dorsally; first urosomite bearing 1 dorsolateral robust seta; second urosomite bearing 3 dorsolateral robust setae; third urosomite without dorsolateral robust setae. Head: rostrum vestigial; eyes absent. First antenna (Figure 59): length $0.6 \times$ body, $1.8 \times$ second antenna, peduncle article 1 longest, article 3 shortest, with sparse setae; flagellum much longer then peduncle, of 33 articles, bearing aesthetascs; accessory flagellum of 6 articles, reaching to article 5 of primary flagellum, articles uniform, and sparsely setulate. Second antenna (Figure 59): length $0.3 \mathrm{x}$ body; peduncle length less than flagellum, peduncle article 5 without calceoli, article 4 longer than article 5 , articles 3-5 with sparse setation; flagellum 12 articulate or 16 articulate, with moderate setation, without calceoli. Upper lip: apical margin evenly rounded, connection to epistome symmetrical. Left mandible (Figure 59): palp article 2 with no small outer or medial marginal setae, with a medio-distal oblique facial row of 5 robust rastellate setae, article 3 much shorter than article 2 , with 12 D setae, and 4 E setae, facially strongly setulose (pubescent); incisor with 7 teeth, lacinia mobilis with 5 teeth, mandible with 4 setose accessory blades, and 4 plumose interraker setae; molar bearing pappose seta, with 5 penicillate hooked brushy basal setae, and, few penicillate setules, fully triturating. Right mandible (Figure 59): palp article 2 with no small outer or medial marginal setae, with a medio-distal row of 5 robust rastellate setae, article 3 much shorter than article 2 , with $11 \mathrm{D}$ setae, and $4 \mathrm{E}$ setae; incisor with 6 teeth, lacinia mobilis bifid and denticulate, with 2 denticles strongly extended, mandible with 2 setose accessory blades, and 2 plumose interraker setae; molar bearing pappose seta, with 3 penicillate hooked brushy basal setae, and, few penicillate setules, fully triturating. Left first maxilla (Figure 59): palp article 2 with 6 apical, and no subapical facial strong slender setae, with no apicomedial, with no submarginal apicomedial, with 2 ventrofacial apicomedial strong slender setae; outer plate with 10 robust setae, ( 10 denticulate, no naked ); inner plate subtriangular, with 2 apicomedial plumose setae, facially and medially setose (pubescent). Right first maxilla (Figure 59): right palp asymmetrical with left, apex with no articulated, and 4 fused broad based tooth setae, 1 apicolateral robust setae, and 1 subterminal apicolateral facial setae. Second maxilla (Figure 59): outer plate subrectangular, elongate, length $4 x$ width, bearing distal long, curved rastellate setae, marginally setulose; apicomedial corner of inner plate with 2 weakly submarginal thick plumose setae. Maxilliped (Figure 59): inner plate subrectangular, elongate, length $3.3 \times$ width, extending to M0.9 of the outer plate, bearing small setules on the lateral margin and medioproximal face, 1 facial pappose setae, at M0.8 of its length, 6 medial pappose setae, with a row of 5 , subapical pappose setae, with 1 apicomedial naked tooth setae, with 3 apical naked tooth setae; outer late subovate, broad, length $1.8 \times$ width, distally naked, with a row of 12 , slender naked, medial submarginal to disto facial setae, a medial row of 8 submarginal to subapical robust, naked, tooth setae, and 2 apicolateral setae, ( 1 naked, and 1 pappose ); palp, second article strongly setose medially; palp third article sparsely setose laterally, moderately setose medially, with no facial, and 3 ventrofacial long strong setae basal to the dactyl, the apex weakly produced, setulate, with 4 long slender naked setae, the dactyl bearing 2 accessory setae basal to the nail, and 1 dorsal accessory seta. First gnathopod (Figure 60): coxal plate subrectangular, with 5 anteroventral setae, with 1 posteroventral corner setae, and 1 ventral setae; merus bearing posterior hump, with elongate scythe setae; carpus moderate length, $2 x$ width, subtriangular, without posteroventral lobe or expansion, posterior margin, with setae ranked in 6 transverse bands; propodus subrectangular, small, length $1.8 \times$ width, posteroventral corner rounded, not lobate, with 2 medial robust setae, 3 lateral robust setae, and 4 additional lateral elongate robust setae, palmar angle weakly oblique, palm convex, bearing fine marginal teeth, dactyl reaching beyond palmar corner, with a single recumbent inner tooth spine, with accessory setules at the junction of the nail. Second gnathopod (Figure 60): slightly larger than first; coxal plate ovate, with 5 anteroventral setae, 2 posteroventral corner setae, and 1 ventral setae, and large ovate gill; merus bearing posterior hump, with elongate scythe setae; carpus long, $3 \times$ width, subrectangular, without posteroventral lobe or expansion, posterior margin, with setae ranked in 8 transverse bands; propodus trapezoidal, small, length $2.5 \mathrm{x}$ width, posteroventral corner rounded, not lobate, with 2 medial robust setae, 3 lateral robust setae, and 3 additional lateral elongate robust setae, palmar angle weakly oblique, palm convex, bearing fine marginal teeth, dactyl reaching 
to palmar corner, with a single recumbent inner tooth spine, with accessory setules at the junction of the nail. Pereopods (Figures. 60 and 61): dactyls of pereopods 5-7 multispinous, with 3,4 , and 5 setae; pereopod 3 longer than gnathopod 2, coxa 3 with no anterior setae, 3 long ventral setae, no short ventral setae, 3 setae at the posteroventral corner; merus weakly setose posteriorly; carpus weakly setose posteriorly; pereopod 4 subequal in length with P3, coxa 4 anteroventral margin with 2 setae, posteroventral margin with 5 setae, ventral margin with 2 setae, posterior margin moderately emarginate, carpus weakly setose posteriorly; pereopods 5-7 similar; coxa 5 bearing 1 setae on anterior lobe, and 1 setae on the posterior lobe; basis of pereopod 5 moderately expanded, bearing short slender posterior setae, bearing short robust anterior setae or bearing long robust anterior setae, moderately lobate posteroventrally; coxa 6 bearing no setae on anterior lobe, and 1 setae on the posterior lobe; basis of pereopod 6 moderately expanded, bearing short slender posterior setae, basis of pereopod 6 bearing short robust anterior setae or bearing long robust anterior setae, moderately lobate posteroventrally; coxa 7 bearing no setae on anterior lobe, and 1 setae on the posterior lobe; basis of pereopod 7 moderately expanded, bearing short slender posterior setae, bearing short robust anterior setae or bearing long robust anterior setae, moderately lobate posteroventrally. Bases of pereopods 5-7 equally expanded. Oostegites: oostegites present on coxae 25 , rudimentary. Gills (Figure 62): coxal gills present on coxae 2-7, gill of pereopod 6 not reduced, the seventh reduced; sternal gills present on sternites 2-7, of simple, sausage form, attached to anterior of lateral edge of segments. Epimera: First epimeron without anteroventral setae, without robust setae on anteroventral margin, without robust setae on posteroventral margin, without slender setae on ventral margin, with 1 slender setae on the posterior margin, posterior margin straight, posteroventral corner subquadrate, without spine or seta, Second epimeron with anteroventral setae, with 2 robust setae on the anteroventral margin, without robust setae on posteroventral margin, without slender setae on ventral margin, with 1 slender setae on the posterior margin, posterior margin straight, posteroventral corner acuminate, without spine or seta, Third epimeron without anteroventral setae, with 4 robust setae on the anteroventral margin, without robust setae on posteroventral margin, without slender setae on ventral margin, without slender setae on posterior margin, posterior margin straight, posteroventral corner acuminate, without spine or seta. Pleon: dorsolateral margin of pleonite 1 with 6 feeble setae, and no distolateral robust setae; of pleonite 2 with 6 feeble setae, and no distolateral robust setae; of pleonite 3 with 5 feeble setae, and no distolateral robust setae. Pleopods (Figure 62): peduncle of first pleopod with 2 retinacula, and 2 accessory retinacula, and no additional setae disjunct from retinacula; second pleopod with 2 retinacula, and 1 accessory retinacula, and no additional setae disjunct from retinacula; third pleopod with 2 retinacula, and 1 accessory retinacula, and no additional setae disjunct from retinacula. Urosome. First urosomite: bearing 2 distolateral slender setae, 1 distolateral robust setae, and a distoventral robust seta at the base of uropod 1. Second urosomite: bearing no distolateral slender setae, and 3 distolateral robust setae. Third urosomite: bearing no distolateral slender setae, and no distolateral robust setae. Uropods (Figure 62). First uropod: peduncle length $1.1 \times$ the length of the inner ramus, with a strong row of 4 dorsolateral robust setae, 2 apicolateral robust setae, 5 dorsomedial robust setae, and 1 apicomedial robust setae; outer ramus shorter than inner, with 3 dorsolateral robust setae, with 4 dorsomedial robust setae, and 4 apical robust setae; inner ramus with 3 dorsolateral robust setae, with 3 dorsomedial robust setae, and 5 apical robust setae. Second uropod: $0.6 \times$ length of uropod 1 ; peduncle about $1.2 \times$ length of inner ramus, with no dorsolateral robust setae, 1 apicolateral robust seta, 3 dorsomedial robust setae, 1 apicomedial robust setae; outer ramus shorter than inner; inner ramus with 2 dorsolateral robust setae, with 4 dorsomedial robust setae, and 5 apical robust setae; outer ramus with 1 dorsolateral robust setae, with 2 dorsomedial robust setae, and 4 apical robust setae. Third uropod: longer than U1-2 in intact specimen, long, $0.7 \times$ length of uropod 1 ; peduncle length $0.3 \times$ outer ramus, subequal in length to urosomite three, with no dorsolateral robust setae, no dorsolateral slender setae, with 1 apicolateral robust setae, no apicolateral slender setae, with no dorsomedial robust setae, no dorsomedial slender setae, with no apicomedial robust setae, no apicomedial slender setae, with 1 mediodistal robust setae, with no mediodistal slender setae; inner ramus shorter than outer ramus; length $0.6 \times$ outer ramus; outer ramus two articulate, proximal article setae arranged laterally and medially in transverse bands, with 4 lateral transverse bands of robust setae, with no lateral transverse bands of small setae, with no lateral transverse bands of mixed robust and small setae, with 5 medial transverse bands of robust setae, with no medial transverse bands of small setae, with no medial transverse bands of mixed robust and small setae, 3 apicolateral robust setae, no apicolateral small setae, no apicolateral long slender setae, 3 apicomedial robust setae, no apicomedial small setae, no apicomedial long slender setae; distal article short, narrow, sub triangular, with no lateral robust setae, with no lateral slender setae, with no medial robust setae, 


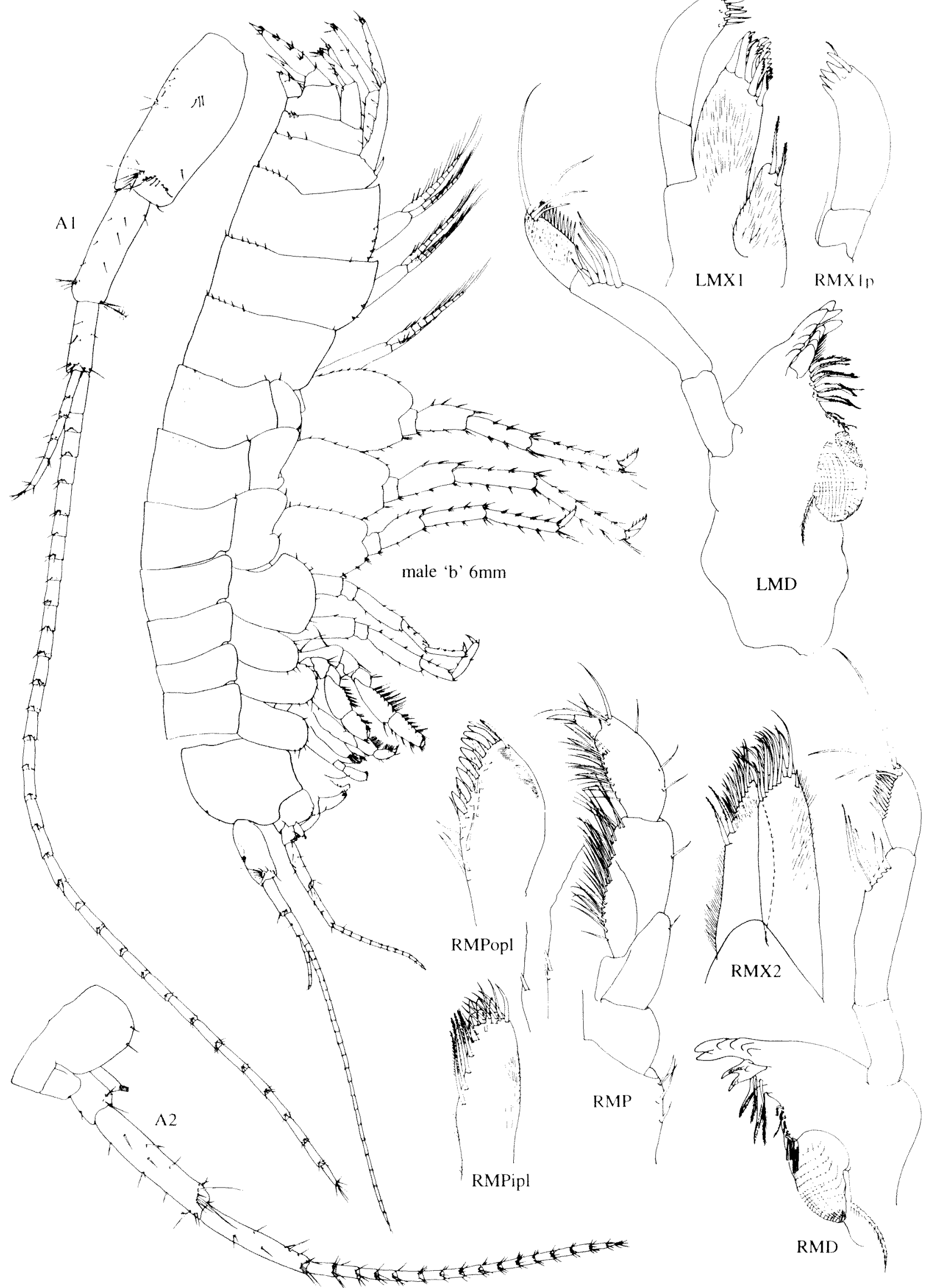

Figure 59 Molina pleobranchos sp. nov., holotype female 'a' $6.5 \mathrm{~mm}$, antennae and mouthparts. Allotype male 'b' $6 \mathrm{~mm}$, whole animal. 


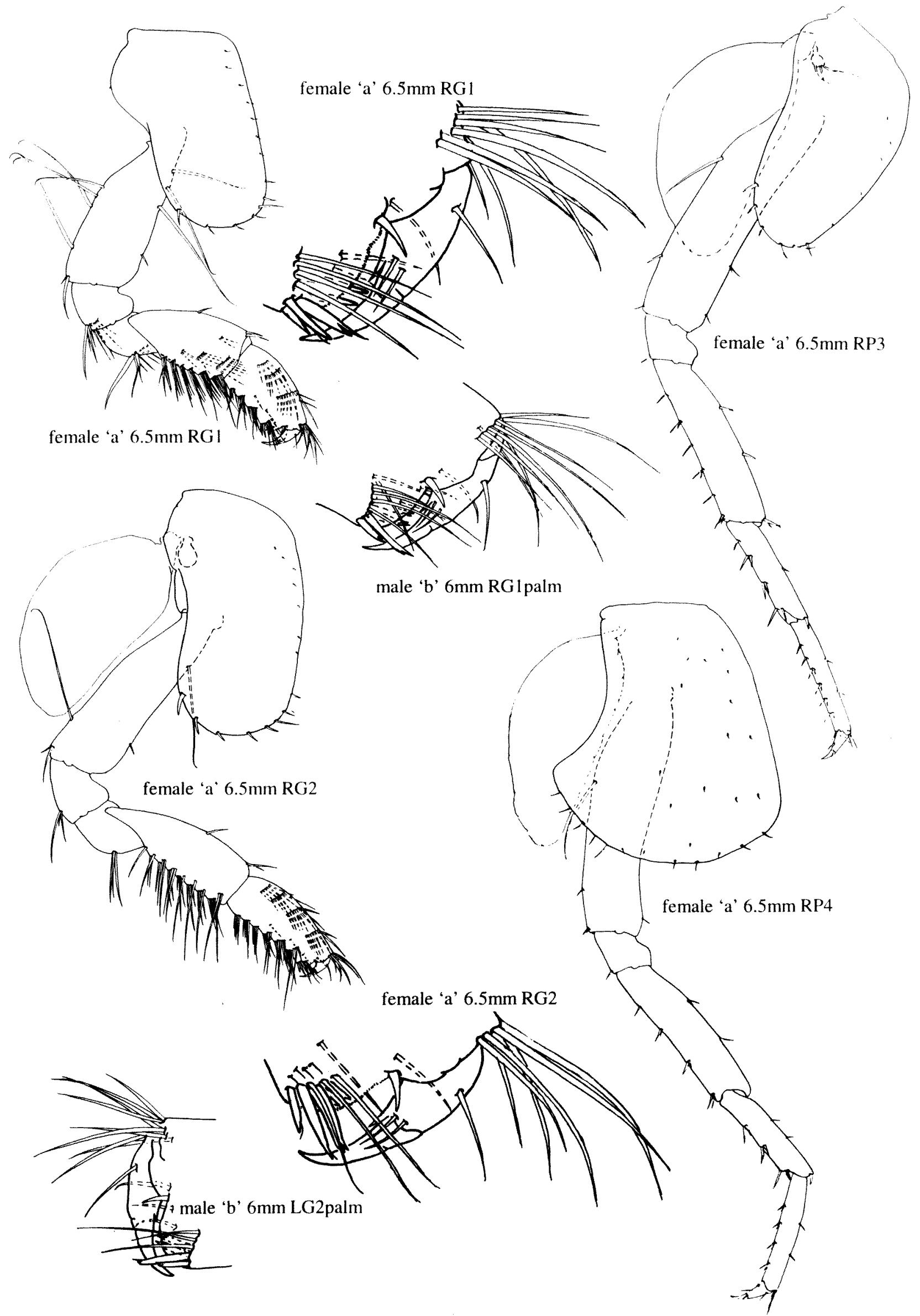

Figure 60 Molina pleobranchos sp. nov., holotype female 'a' $6.5 \mathrm{~mm}$, gnathopods $1-2$ and pereopods $3-4$. Allotype male 'b' $6 \mathrm{~mm}$, gnathopodal palms 1-2. 


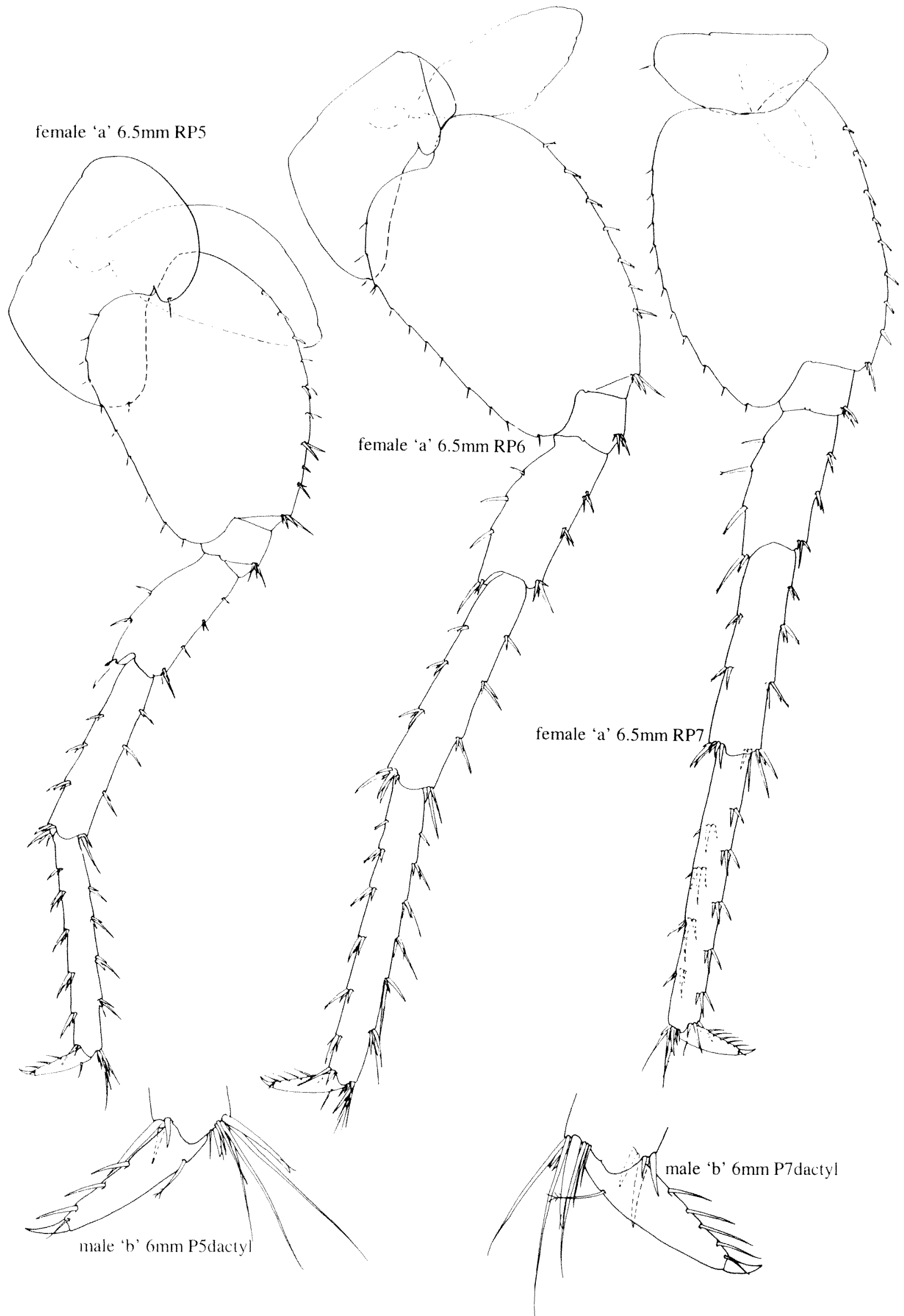

Figure 61 Molina pleobranchos sp. nov., holotype female 'a' $6.5 \mathrm{~mm}$, pereopods 5-7. Allotype male 'b' 6 mm, dactylus, pereopods 5 and 7 . 


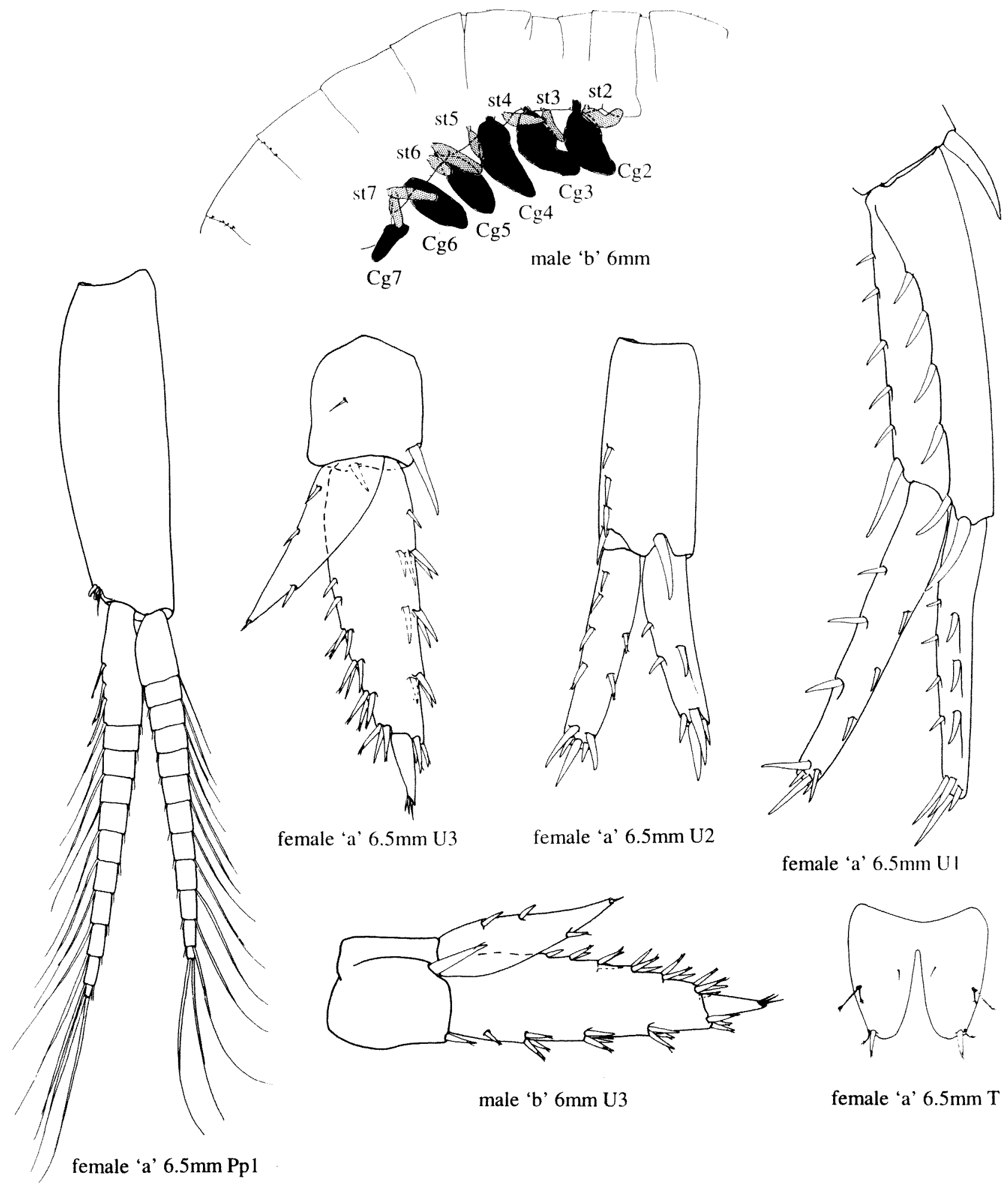

Figure 62 Molina pleobranchos sp. nov., holotype female 'a' $6.5 \mathrm{~mm}$, pleopod 1, uropods 1-3, telson. Allotype male 'b' 6 $\mathrm{mm}$, gills, uropod 3 .

with no medial slender setae, with no medial slender plumose setae, with no apical robust setae, with 3 apical slender setae, with no apical plumose setae; inner ramus with 1 lateral robust setae, with no lateral slender setae, with 2 medial robust setae, with no medial slender setae, with no medial plumose setae, with no apical robust setae, with 1 apical slender setae, with no apical plumose setae. Telson (Figure 62): subequal in length to urosomite three; deeply cleft, ( $80 \%)$, shorter than broad, length $0.9 \times$ breadth; lateral margins tapering, convex; apices rounded and laterally notched; with no dorsal robust setae, with 1 dorsal slender setae, with no lateral slender setae; with 1 apical robust 
setae, with no apical slender setae; with 1 apical penicillate setae, and paired lateral penicillate setae, at M0.7 from the telson base.

\section{Allotype (male ' $b$ ')}

Similar to the holotype except: Body: $6 \mathrm{~mm}$. First antenna: length $0.6 x$ body, flagellum of 34 articles, bearing aesthetascs on articles 9-33; accessory flagellum of 6 articles. Second antenna: without calceoli on peduncle or flagellum, flagellum of 17 articles. Mandibles: third article of mandibular palps bearing $13 \mathrm{D}$ and $4 \mathrm{E}$ setae only. First gnathopod: propodus bearing 2 lateral and 2 medial robust setae at the palmar corner, with 4 long accessory setae laterally. Second gnathopod: propodus bearing 2 lateral and 2 medial robust setae at palmar corner and 3 accessory setae laterally. Pereopods: dactyls of pereopods 5-7 multispinous, with 3,4 and 4 setae. Uropods. Third uropod peduncle bearing 1 small facial seta, 1 lateral and $1 \mathrm{mid}$ dorsal robust setae; inner ramus bearing 1 medial and 2 lateral setae and 1 small, single apical seta; lateral margin of the first article of the outer ramus bearing a single basolateral, 3 translateral bands, and 3 apicolateral robust setae, the medial margin bearing a single basomedial, 4 trans medial bands and 4 apicomedial robust setae; the second article of the outer ramus naked medially and laterally, bearing 3 slender apical and subapical setae.

\section{Paratype (male ' $c$ ')}

Juvenile. Similar to the allotype except: Body: 5.5 $\mathrm{mm}$. First antenna: $0.6 \mathrm{x}$ body, $1.8 \mathrm{x}$ antenna 2 , without aesthetascs, primary flagellum of 24 articles, accessory flagellum of 5 articles. Second antenna: flagellum of 12 articles; peduncle and flagellum without calceoli. Pereopods (Figure 61): dactyls of pereopods 5-7 multispinous with $3,4,3$ setae. Uropods (Figure 62): third uropod similar to female except peduncle without small facial seta; medial and lateral translateral bands of setae similar but bearing variable numbers of setae.

\section{Etymology}

From the Greek 'branchos' (gill), and 'pleos' (full), referring to the presence of a full complement of both coxal and sternal gills.

\section{ACKNOWLEDGEMENTS}

I am grateful to the Broken Hill Proprietary Company for supporting this work, to the Western Australian Museum for allowing examination of the specimens, and co-ordinating the research, particularly Dr W.F. Humphreys; to Mr Stefan Eberhard and Dr Humphreys who collected the specimens described here, and to Dr G.D.F. Wilson of the Australian Museum and another, anonymous, referee both of whom commented constructively on the manuscript.

\section{REFERENCES}

Barnard, J.L. and Barnard, C.M. (1983). Freshwater Amphipoda of the world, I. Evolutionary patterns. II. Handbook and Bibliography. Hatfield Associates, Mount Vernon, Virginia.

Bradbury, J.H. (1999). The systematics and distribution of Australian amphipods: a review. In F.R. Schram and J.C. von Vaupel Klein (eds), Crustaceans and the biodiversity crisis. Proceedings of the Fourth International Crustacean Congress, Amsterdam, Vol. 1: 533-540. Brill, Leiden.

Bradbury, J.H. and Williams, W.D. (1996). Freshwater amphipods from Barrow Island, Western Australia. Records of the Australian Museum 48: 33-74.

Bradbury, J.H. and Williams, W.D. (1997). The amphipod (Crustacea) stygofauna of Australia: description of new taxa (Melitidae, Neoniphargidae. Paramelitidae), and a synopsis of known species. Records of the Australian Museum 49: 249-341.

Bradbury, J.H. and Williams, W.D. (1999). Key to and checklist of the inland aquatic amphipods of Australia. Technical Reports of the Australian Musetm 14: $1-21$.

Camachoo, A.I.., Bello, E., Becerra, J.M. and Vaticon, N. (1992). A natural history of the subterranean environment and its associated fauna. In A.I. Camachoo (ed.), The natural history of biospeology: 171197. Monografias Museo Nacional de Ciencias Naturales. Consejo Superior de Investigaciones Cientificas, Madrid.

Dallwitz, M.J. (1980). A general system for coding taxonomic descriptions. Taxon 29: 41-6.

Dallwitz, M.J., Paine, T.A. and Zurcher, E.J. (1993). Users guide to the DELTA system: a General System for Processing Taxonomic Descriptions, $4^{\text {th }}$ edition, $136 \mathrm{pp}$. CSIRO Division of Entomology, Canberra.

Holsinger, J.R. (1994). Pattern and process in the biogeography of subterranean amphipods. Hydrobiologia 287: 131-145.

Humphreys, W.F. (1993a). Cave fauna in semi-arid tropical Western Australia: a diverse relict wet-forest litter fauna. Mémoires de Biospéologie 20: 105-110.

Humphreys, W.F. (1993b). Stygofauna in semi-arid tropical Western Australia: a Tethyan connection? Mémoires de Biospéologie 20: 111-116.

Humphreys, W.F. (ed.) (1993c). The biogeography of Cape Range, Western Australia. Records of the Western Australian Museum, Supplement 45: 1-248.

Humphreys, W.F. (1999). Relict stygofauna living in sea salt, karst and calcrete habitats in arid north western Australia contain many ancient lineages. In $\mathrm{W}$. Ponder and D. Lunney (eds), The other 99\%. The conservation and biodiversity of invertebrates: 219-227. Transactions of the Linnean Society of New South Wales, Mossman. 
Karaman, G.S. (1969). XXII Beitrag zur Kenntnis der Amphipoden. Über einige Formen des Genus Sarathrogammarus (Gammaridae) aus Afghanistan. Acta Musei Macedonici scientiarum Naturalium Skopje 11: 195-208.

Mann, A.W. and Horwitz, R.C. (1979). Groundwater calcrete deposits in Australia: some observations from Western Australia. Journal of the Geological Society of Australia 26: 293-303.

Watts, C.H.S. and Humphreys, W.F. (1999). Three new genera and five species of Dytiscidae (Coleoptera) from underground waters in Australia. Records of the South Australian Museum 32: 121-142.

Williams, W.D. and Barnard, J.L. (1988). The taxonomy of crangonyctoid Amphipoda (Crustacea) from Australian fresh waters: foundation studies. Records of the Australian Museum, Supplement 10: 1-180.

Manuscript received 16 February 2000; accepted 5 July 2000. 